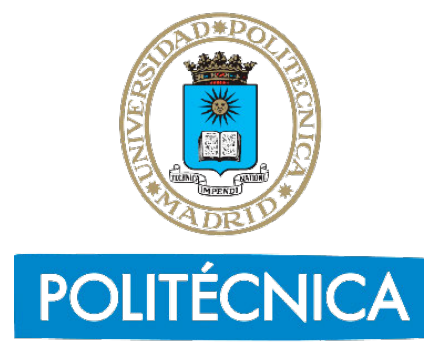

Universidad Politécnica de Madrid

Escuela Superior de Arquitectura (ETSAM)

\title{
La Ciudad Celular: Morfología y complejidad urbana de las plataformas digitales de servicios basados en la geolocalización en Madrid
}

TESIS DOCTORAL

Iñigo Lorente Riverola

Arquitecto, Máster en Planeamiento Urbano y Territorial 



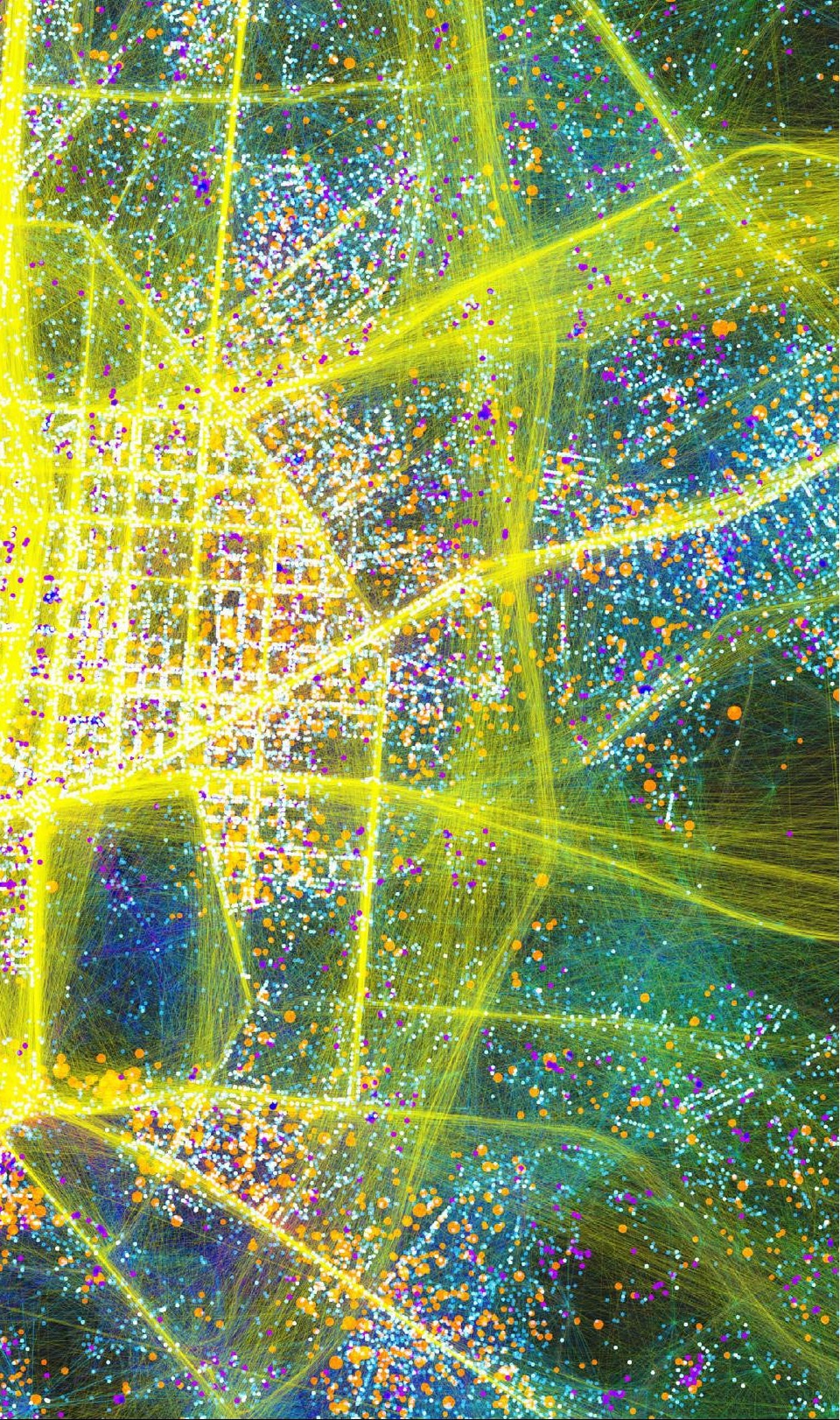

Departamento de Urbanística y Ordenación del Territorio (DUyOT).

Escuela Técnica Superior de Arquitectura (ETSAM)

\section{La Ciudad Celular: Morfología y complejidad urbana de las plataformas digitales de servicios basados en la geolocalización en Madrid}

TESIS DOCTORAL

Iñigo Lorente Riverola

Arquitecto, Máster en Planeamiento Urbano y Territorial

Director

Javier Ruiz Sánchez

Doctor Arquitecto

Departamento de Urbanística y Ordenación del Territorio. ESAM - UPM

Madrid, 2020 



\section{Resumen}

La popularización los servicios digitales basados en la geolocalización (LBS) tras el lanzamiento del smartphone en 2007, hace cada vez más necesaria la toma en consideración de la dimensión informacional de la ciudad en su planificación. Estas aplicaciones articulan el acceso y organización espacial a cada vez más actividades y servicios cotidianos -como descubrir lugares, la movilidad, el comercio, el hospedaje o las relaciones interpersonales-, lo cual contribuye a articular la 'Ciudad Celular'; donde las funciones y accesibilidad de los lugares materiales, está cada vez más condicionada por la formas y topologías digitales emergentes.

Esta tesis explora la integración de los LBS en la ciudad desde la óptica de la complejidad urbana, evaluando si la ciudad ve o no acrecentada su diversidad funcional accesible. Como hipótesis, se plantea que las tramas urbanas más complejas son aquellas más intensamente digitalizadas, resultando en una acumulación desigual de información, comunicaciones y por tanto complejidad urbana. Para testarla se ha contrastado la geografía de un conjunto de LBS -Facebook Places, Foursquare, AirBnB, MyTaxi, Grindr, Wallapop, Amazon Hub- con el plano social y material de Madrid; morfológica y topológicamente.

Los resultados ponen de relieve la naturaleza físico-digital de una ciudad contemporánea en la que las diferencias estructurales entre un centro urbano 'hiper digitalizado' y su periferia se traducen en un reparto desigual de desafíos y oportunidades, dependientes de la complejidad de la ciudad construida, y de la programación informática de cada servicio; determinante de los intercambios que favorece. Hechos que subrayan la importancia de una planificación sinérgica de la ciudad y las tecnologías emergentes, preservando y favoreciendo su diversidad funcional accesible, tanto física como digitalmente.

\section{Abstract}

The broad adoption of location-based services (LBS) running on smartphones since 2007 requires urban planning to better understand the informational dimension cities have. The number of activities and their traditionally associated places is becoming more uncertain as they become part of a geographic self-regulated cyberspace which imposes its own logics to urban visibility, mobility, commerce, accommodation or interpersonal relationships amidst other parts of everyday life; presenting the 'Cellular City' as a digitally-integrated whole.

This research explores the Cellular City from the perspective of urban complexity, assessing whether the physical city increases its accessible functional diversity under the action of LBS or not. The hypothesis to stress is that the more complex urban fabric is, the more intense the digitalization of its places will be, resulting in an uneven accumulation of information, communications and complexity. The geography of a representative selection of apps -Facebook Places, Foursquare, AirBnB, MyTaxi, Grindr, Wallapop, Amazon Hub- has been put into contrast with Madrid's physical morphology and topology to discuss that claim.

Results show the hybrid physical and digital nature of contemporary cities, upon which, for the studied case, structural imbalances between a hyper-digitalized center and its periphery produces an unequal distribution of challenges and opportunities related with the complexity of the underlying physical realm and the uncertainty in the communications the LBS may enact. Both facts call for developing synergic planning strategies of the city to preserve and foster its functional and communicative diversity, whether physical or digitally. 



\section{Agradecimientos}

A los mejores padres del mundo, Jose Antonio Lorente y Maria Jesús Riverola, porque sin su apoyo cuando lo he necesitado, ni este trabajo ni yo hubiéramos salido adelante. No escribo más, porque la "iFuerza!" y el amor de madre no se expresan con palabras.

A mi tío Roberto por dejarme jugar con su 'Macintosh Performa' cuando era pequeño, y a SSMM los Reyes Magos por alimentar mi afición por la informática. Admiración, agradecimiento y respeto a Ada Lovelace; inventora del software 100 años antes de que Alan Turing inventara la computación. También agradezco a toda la comunidad de desarrolladores informáticos de código libre y abierto su trabajo incansable por que la innovación esté al alcance de todos.

Al Ecce Homo de Borja y su peculiar forma de retratar las ideas de memoria y evolución que me llevaron a conocer a mi director, maestro y amigo Javier Ruiz; a quien no puedo dejar de agradecerle su constante apuesta por mí, y por darme el mejor consejo que un maestro puede dar a un aprendiz: "diviértete".

A Álvaro Ardura y todos mis compañeros y amigos de LoCUS, porque a pesar de que nos expresemos como un libro cerrado, sacamos adelante lo que nos echen.

A mis sufridores compañeros del Urban Analytics Lab (aka Gaza) del DUyOT Manuel Benito, Jose Carpio, Jose Manuel Gómez y Javier González por nuestra malquerida criatura "MinaCAT".

A Susana Eiroa, la primera ingeniera que en un proceso de selección no me puso un "pero" por ser arquitecto e incluirme en la familia de EIT Digital Madrid con Juan Manuel, Ahmad, Luis, Carmen, Raúl, Maxi, Joaquín, y los demás. A Susana Negrete, por dejarse la piel ayudándome a alcanzar uno de mis sueños académicos. Gracias a vosotras conocí a Carlo Ratti, y pude colaborar con el Senseable City Lab del MIT; uno de los grupos de investigación que más admiro. De los "senseables" agradezco especialmente a Irene de la Torre, Louis Charron y Fabio Duarte esas "dataviz meetings" los lunes a las 8 en las que tanto he aprendido, igual que a Snoweria, Lenna, Yuji Yoshimura, Ricardo Álvarez, César Hidalgo, y los demás genios que enriquecieron mi andadura por Boston. Por último, a Erin, Rachel e Irlande, por suministrarme estabilidad, emociones fuertes, y café por galones respectivamente. A Elena Contioso y Karolina por su ayuda en que de cierre a la etapa doctoral y mire con optimismo al futuro.

A Cristina, Oriol, María y Sugoi, por hacer de Howard Place mi hogar - y a Rabia por descontado.

A Yvon.

A Pablo, Almudena y Leticia por compartir 'friquismes' inquietudes conmigo, por tratarme tan bien en mis visitas levantinas, y por darme a conocer a Jesús, Damiano y al resto de SPINunit; con quienes colaborar y seguir aprendiendo siempre es un gran placer.

A todos los amigos que me hacéis sentir mucho mejor que afortunado, y habéis velado por mi estabilidad emocional todo este tiempo. A Dani, Gloria y Carlos, Ana GT, Miguel, Miriam y Alberto, Ana Ruiz, Alberto y Pablo, e Isaura porque el Furancho es ser feliz. A Toni, Dani We, Muzsi, Javito, Cyestera, Alberto Tete, Adri y DEH, porque sin gamberradas la vida sería más aburrida. A Dani Chia y Jose Banks, por dar color a Zaragoza.

A Clara, Raquel, Jon, y Aranzazu. A Iago, por iniciar una estirpe.

A quienes habéis velado por mi salud mejor que yo.

A quien lea con interés este trabajo.

A mi hermano menor Juan, que es todo lo que quiero ser de mayor.

A Madrid. 

La Ciudad Celular: Morfología y complejidad urbana de las plataformas digitales de servicios basados en la geolocalización en Madrid

\section{Contenidos}

Resumen
Abstract
Agradecimientos

\section{capítulo 1. New Babylon}

Introducción

1.1. La reprogramación digital del espacio urbano. Antecedentes y motivaciones 15

1.2. Introducción al concepto de "Ciudad Celular" 19

1.3. Justificación del tema 23

1.4. Preguntas de investigación e hipótesis 29

1.5. Objetos de estudio y apuntes metodológicos 31

1.6. Objetivos 33

1.7. Summary 35

\section{PARTE I. La Ciudad Celular}

_capítulo 2. La mediatización de los sistemas urbanos

Marco teórico

2.1. Tecnofetichismo y Urbanismo

2.1.1. La "Smart City"

2.2. Información y complejidad urbana

2.2.1. La parcela como unidad de información

2.2.2. La ciudad cognitiva

2.2.3. El espacio no parcelado, la red urbana física, y las redes digitales de comunicación

2.3. Los medios y la ciudad

2.3.1. La mediatización profunda

2.3.2. Sobre la autopoiesis y el propósito del medio

2.3.3. Los medios y el espacio social

2.4. Alteraciones digitales de la información en el sistema urbano. Los LBS y las plataformas 
2.4.1. Los LBS como sistema-entorno de la ciudad. Marco tecnológico 65

2.4.1.1. Arquitectura del sistema 66

2.4.2. La economía de las plataformas. Marco socioeconómico 69

2.4.2.1. De la plataforma industrial a la plataforma digital 69

$\begin{array}{ll}\text { 2.4.2.2. La plaza, la red, y el ecosistema } & 72\end{array}$

2.4.2.3. Economía ¿colaborativa? $\quad 74$

2.5. Fricciones entre el sistema urbano y su entorno tecnológico 78

2.6. Síntesis teórica $\quad 82$

\section{_capítulo 3. Describir la ciudad o transformar el sistema} Marco empírico

$\begin{array}{ll}\text { 3.1. Dos corrientes complementarias } & 87\end{array}$

3.2. Describir la ciudad 90

3.2.1. Localizar y describir lugares $\quad 91$

3.2.2. Comunidades y dinámicas 94

3.2.3. La crítica a la corriente descriptiva 96

3.3. Transformar el sistema 100

3.3.1. Reconexiones informacionales 101

$\begin{array}{ll}\text { 3.3.2. Cambios de uso y desafíos organizativos } & 105\end{array}$

\section{_capítulo 4. Diversidad y accesibilidad} Metodología

4.1. Terminología 113

4.2. Estructura de la exploración 116

$\begin{array}{ll}\text { 4.3. Oportunidad de Madrid } & 119\end{array}$

4.4. Construcción del modelo digital de Madrid para evaluar su complejidad urbana 128

4.4.1. Definición de contenidos y entornos 129

4.4.1.1. Dentro/fuera (Entorno I) 129

4.4.1.2. Externalidades sociotecnológicas (Entorno II) 130

4.4.1.3. Parcelas como subsistemas elementales (Entorno III) 130

4.4.1.4. La red urbana (Entorno IV) 131

4.5. Estimación de la complejidad urbana 132

4.5.1. Accesibilidad en la red urbana 133

4.5.2. Los índices de diversidad 140

4.5.3. Computación de los índices 143

4.6. Selección de plataformas $\quad 145$

4.6.1. Requisitos funcionales 145

4.6.2. Requisitos técnicos 147 
4.7. Descripción de LBS por tipo. Descarga de datos y construcción de mapas 147

4.7.1. Búsqueda de lugares: "el escaparate digital” 147

4.7.2. Movilidad con conductor: Hail-O/MyTaxi/Freenow 153

4.7.3. Redes geosociales: Grindr 154

4.7.4. Comercio C2C: Wallapop 156

4.7.5. Comercio B2C: Amazon Hub y Deliveroo 157

4.7.6. Alquiler vacacional: AirBnB 159

4.8. Análisis formal de los LBS 159

4.8.1. Análisis morfológico 160

4.8.2. Análisis topológico 165

4.9. Análisis complejo del sistema físico-digital 167

\section{PARTE II. Aspectos formales}

\section{_capítulo 5. Análisis morfológico}

$\begin{array}{ll}\text { Resultados I } & 171\end{array}$

$\begin{array}{ll}\text { 5.1. Digitalización selectiva de recursos } & 173\end{array}$

5.2. Huella de los LBS 174

5.2.1. Recomendación de lugares $\quad 174$

5.2.2. Transporte con conductor 188

5.2.3. Comercio B2C 191

5.2.4. Redes geosociales 195

5.2.5. Comercio C2C 198

$\begin{array}{ll}\text { 5.2.6. Alquiler vacacional } & 200\end{array}$

$\begin{array}{ll}\text { 5.3. Conclusiones parciales } & 205\end{array}$

5.4. El entorno socioespacial de los LBS 208

_capítulo 6. Análisis topológico

Resultados II

6.1. Redes celulares y redes urbanas 213

6.2. Topología de Madrid 215

6.3. Topologías digitales 219

6.3.1. De lo global a lo hiperlocal 219

6.3.2. Visibilidad digital, popularidad social, y centralidad urbana 223

6.3.3. Comunidad y proximidad 225

6.3.4. Jerarquizaciones de la red aleatoria 233

6.4. Urbanidad y celularidad 236 


\section{PARTE III. Desafíos estructurales}

_capítulo 7. Análisis complejo

Resultados III

7.1. Información accesible y complejidad urbana 243

7.2. La complejidad de Madrid 245

7.2.1. Resultados de los índices de complejidad urbana 245

7.3. Alteraciones de la complejidad urbana 249

7.3.1. Facebook. Diversificación general y enriquecimiento selectivo 249

7.3.2. Especialización hostelera, gentrificación, y regulación institucional de AirBnB

7.3.3. Grindr, Wallapop, y la importancia de los vínculos débiles 260

7.4. La incertidumbre como generadora de complejidad urbana. 267

_capítulo 8. La ciudad celular frente a la ciudad compleja

Discusión y conclusiones $\quad 273$

8.1. Discusión 273

8.1.1. Sobre las TIC y la complejidad urbana 273

8.1.2. Sobre el método 278

8.1.3. Sobre los resultados obtenidos 283

8.1.3.1. Información urbana e información digital 283

8.1.3.2. La celularidad frente a la urbanidad de las comunicaciones 286

8.1.3.3. Analizar la complejidad y sus alteraciones 290

8.2. Conclusiones 293

$\begin{array}{ll}\text { 8.3. Conclusions } & 305\end{array}$

Glosario $\quad 315$

PARTE IV. Anexos y referencias

$\begin{array}{ll}\text { Referencias bibliográficas } & 329\end{array}$

ANEXO I -Taxonomía de los LBS 349

ANEXO II - Arquitectura de los LBS 355

ANEXO III - Métodos de análisis urbano basado en big-data' procedente de plataformas digitales 359

ANEXO IV - Apuntes sobre topología de redes 369 
ANEXO V - MinaCAT. Software para la conversión de ficheros catastrales alfanuméricos (.CAT) en información tabular

ANEXO VI - KML2PG. Software de descarga, y almacenamiento de archivos KML de Catastro en bases de datos PostGIS 387

ANEXO VII - UCnet. Software para estimar la complejidad urbana391

ANEXO VIII - Mapa de edificabilidad por parcela. Elaboración propia. Fuente: Catastro (2018)

ANEXO IX - Mapa de usos y destinos del suelo en Madrid según el PGOUM-96 


\section{capítulo 1. \\ New Babylon \\ INTRODUCCIÓN}

«Al liberarnos de las constricciones del tiempo y del espacio alcanzaremos una nueva forma de urbanización. La movilidad como la incesante fluctuación de la población -la consecuencia inevitable de esta nueva libertad-redibujará las nociones de urbe y asentamiento. Sin un horario que respetar, ni un ámbito fijo, el ser

humano por necesidad se identificará con un estilo de vida nomádico, en un entorno artificial "construido" como un todo»

(Nieuwenhuis, 1974)

\subsection{La reprogramación digital del espacio urbano. Antecedentes y motivaciones}

Como la mayoría, esta tesis responde a una serie de inquietudes que pueden entenderse desde un retrato honesto, y en buena parte autobiográfico del autor; un arquitecto urbanista - hijo de arquitecto urbanista-, fascinado por las tecnologías digitales desde la infancia, que a lo largo de su vida ha visto cómo los datos digitales han ido adquiriendo cada vez más relevancia en la manera de experimentar y proyectar la ciudad.

Este trabajo versa sobre el proceso de acumulación de información sobre los lugares urbanos y sobre cómo el modo de producción y gestión de ésta se traduce en alteraciones puntuales de la actividad social que en conjunto pasan a formar parte de un sistema integrado de intercambios en el espacio. Se trata de un proceso que con el paso del tiempo ha ido adquiriendo una componente más social y autorregulado gracias a las tecnologías 
digitales, y en consecuencia, más difícil de acometer por parte de una disciplina urbanística centrada en acotar los abanicos de actividades que pueden desarrollarse en un lugar específico.

La toma de datos y decisiones sobre ciertos lugares podía materializarse en acciones sobre los mismos, así como una diferencia cognitiva entre quien posee un "plano llave" que retrata una estructura urbana en un momento dado, frente a quien habita el conjunto, $\mathrm{y}$ construye su propio mapa cognitivo, en base a los estímulos que recibe de su entorno. En poco más de una década, los usos de la edificación presentes y futuros han pasado de ser un aspecto básico de la planificación urbana, definidos por un compendio de documentos de difícil aprobación y por ello muy lenta actualización para ser un aspecto tan dinámico en la ciudad como una publicación en internet al alcance de cualquiera en cualquier momento y lugar.

Antes de 2008, conectarse a la red era un acto voluntario y premeditado atado a ordenadores de sobremesa y conexiones a domicilio. Internet era un escaparate global, donde ya se había construido un plano llave de las actividades urbanas planificadas accesible al público a través, entre otros, de Google Maps. La idea del escaparate no es banal, pues el flujo de información, al igual que en el planeamiento, era fundamentalmente vertical - de un ordenador remoto a un domicilio. Era fundamentalmente una red de consulta de información digitalizada, pero el aporte de información 'de abajo a arriba', estaba limitado a las redes sociales de reciente creación, y a la valoración puntual de ciertos servicios y lugares urbanos.

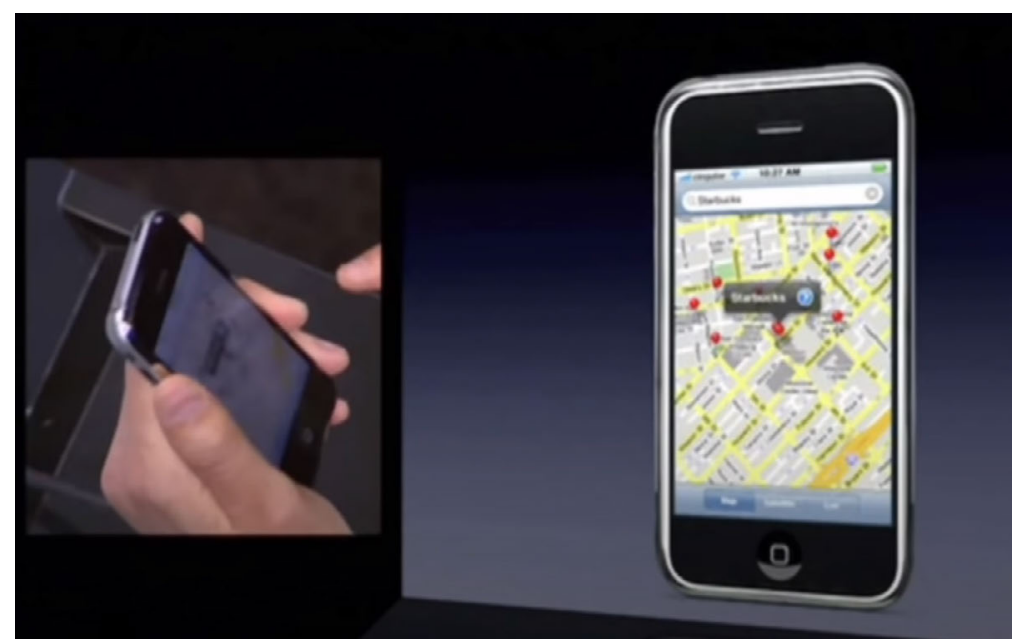

Figura 1. Presentación de los servicios basados en la geolocalización durante el lanzamiento del iPhone el 9 de enero de 2007. Conociendo la ubicación del usuario, el teléfono podría encontrar las cafeterías más cercanas, y comunicarse telefónicamente con el establecimiento para realizar un pedido o reserva Fuente: Youtube (2013) [enlace]

Puede afirmarse que el momento en el que todo cambió fue presentación del iPhone [VÉASE FIgURA 1] que Steve Jobs hizo en Cupertino (California). El "internet de segunda generación” permearía a públicos y ubicaciones mayores, no sólo gracias a las redes $3 \mathrm{G}$, sino también al GPS incorporado en el ordenador de bolsillo. Contra lo que se dio a entender en esa presentación, la "revolución" no consistiría en la manera de acceder a 
información sobre el entorno físico inmediato en todo momento y lugar, sino en inventar un dispositivo capaz de convertir a cualquier individuo en un potencial creador de información geográfica en torno a la que articular sus decisiones y comportamiento social. Además de saber cómo llegar a un sitio, guiado en todo momento por instrucciones en pantalla, una persona podría informar a otra de su ubicación, o a un sistema informático automatizado capaz de desplegar en la ciudad nuevos servicios adaptados a las necesidades inmediatas de cada cual.

En estos actos, la disciplina urbanística se hace mucho más compleja dado que el binomio lugar/actividad puede quedar supeditado a la voluntad de los usuarios de las aplicaciones móviles. ¿Puede un urbanismo basado en la certidumbre de que a cierta actividad le corresponde un conjunto estáticamente planificado de lugares considerados 'adecuados' responder al desafío sistémico que supone que ciertas actividades puedan desarrollarse en cualquier momento y lugar?

Defiendo que el smartphone podría es una herramienta de percepción e incluso de reprogramación de la información urbana. A los pocos años del lanzamiento del iPhone, se ha entretejido un ciberespacio que informa de mis preferencias y necesidades a mi entorno geográfico inmediato, articulando parte de mis interacciones con el mismo y las de mis vecinos. Bajar al supermercado es ahora una opción, pues la compra llega a mi casa en 2 horas tras confirmar un pedido; un vehículo puede venir a recogerme a pesar de que la calle donde vivo sea estrecha y poco transitada para el tráfico rodado; un vecino al que nunca había visto está interesado en una silla de oficina que no utilizo en casa; la tienda de discos de coleccionista o el estanco a la vuelta de la esquina es parte no de una, sino de tres cadenas logísticas globales que transportan cualquier compra que haga mientras trabajo; la mitad del edificio de enfrente; tan residencial como en el que vivo según el plan urbanístico, se ha convertido en una hospedería; a 200 metros de donde me encuentro 20 personas buscan sexo rápido -algunas incluso montando una fiesta en casa-, 3 venden drogas a domicilio, y el resto busca darse a conocer; o que lo que una "app" me anuncia como un restaurante hindú con entrega a domicilio, es en realidad una cocina dentro de un local comercial con poca actividad aparente al verlo a pie de calle.

Sin el smartphone, seguiría pensando en los usos del suelo como la información que otro urbanista plasmó en un mapa; que la vivienda no es un espacio de pública concurrencia, un hostal, una empresa global, o parte de un mercadillo de segunda mano, que la compra de productos de primera necesidad se realizaría en un comercio de proximidad y no en una nave industrial a kilómetros de mi casa, o que mis compras ocasionales no las recibiría en ese comercio cercano, dado que su letrero no hace honor a su capacidad logística adquirida. El smartphone ha democratizado la información geográfica, y con ello la capacidad individual de toma de decisiones sobre el uso del espacio.

Pero este proceso de desarrollo tecnológico, también se ha consolidado un nuevo modo de producción estrechamente ligado a una industria tecnológica que tras la crisis económica del 2008 podría haberse beneficiado de un trasvase de grandes capitales antes 
destinados al desarrollo de la ciudad en su plano material (Srnicek, 2017). La creación del smartphone aceleró en gran medida una nueva economía - por algunos denominada colaborativa, y por otros como 'capitalismo de las plataformas digitales'-, que Bill Gates pareció vaticinar en los años 90 como un "capitalismo sin fricciones" (Schröter, 2016), en el que la actividad económica podría realizarse entre grandes masas de individuos $-\mathrm{y}$ ahora también, lugares- interconectados bajo las premisas de pequeñas empresas de software monofuncional (o 'startups'), que han visto en la hiperconectividad geográfica digital, y en la dinamización de la actividad social urbana preexistente un filón empresarial.

Esta tesis va dirigida a aquellos que, como yo, se plantean formas por las que el urbanismo pueda comprender adaptarse y responder ante la incertidumbre actual de que la tecnología contribuya a tomar nuevas decisiones, aparentemente desreguladas e imprevisibles, sobre "qué se puede hacer y dónde". Supone una exploración inicial del ciberespacio social que, más que haberse superpuesto a la ciudad, se ha integrado en ella profundamente alterando a escala hiperlocal ('aquí y ahora'), el abanico de lugares y actividades accesibles para cada ciudadano, las actividades preexistentes con las que convivir, y aquellas que sustituir.

Si la ciudad y las plataformas digitales se consideran sistemas complejos autorregulados de personas y lugares en constante interacción, ambas cuentan con una estructura formal relativamente estable, sea o no material, ambas tienen una topología o lógica por la cual sus lugares tienden a visibilizarse, comunicarse o disgregarse, y lo que es más importante puesto que ambos son sistemas en constante interacción, las alteraciones de estado de cualquiera de ellos, inducirán nuevos procesos de desarrollo en el otro. En este sentido, la cuestión no es cómo una ciudad se digitaliza, o cómo es el mapa urbano de la información digital, sino cómo la digitalización en forma de servicios basados en la geolocalización transforma la vida cotidiana del individuo, y en su escalamiento global, altera el funcionamiento de los conjuntos urbanos, suponiendo nuevos desafíos y oportunidades para el urbanismo.

De esta idea nace el concepto que me permito acuñar de "Ciudad Celular", que resuena con el organicismo celular de los sistemas vivos; complejos por naturaleza, y con las tecnologías móviles homónimas. Una ciudad cuyos espacios, redes de comunicación, patrones estructurales, y aspectos normativos tienen una doble componente, material e informacional/tecnológica, en adelante indisolubles, que deben explorarse de manera unificada para identificar los patrones de desarrollo urbano en un momento histórico de "no-expansión" de la ciudad construida.

Se trata de una motivación sin duda ambiciosa, dado que pone el foco en una tecnología que se desarrolla a una velocidad vertiginosa, cuyo plano de operación es intangible. No por ello su conocimiento es menos necesario. 


\subsection{Introducción al concepto de "Ciudad Celular"}

La premisa fundamental de este trabajo es poner de relieve la importancia las tecnologías de la información (TIC) y las infraestructuras y sistemas de telecomunicación en el funcionamiento de la ciudad contemporánea. Cada vez más intercambios de información a través de redes telemáticas propician un abanico mayor de actividades más allá de la simple comunicación entre conocidos. Sobre este tipo de intercambios, sostengo que el urbanismo debería adquirir una mayor consciencia y comprensión en su naturaleza.

Pero el objeto de interés de esta tesis no son las TIC como tales dada su enorme variedad y rápida evolución sino la ciudad, y algunas formas por las que en su desarrollo, la prestación de determinados servicios, incluyendo la propia percepción del entorno urbano se está digitalizando, y están naciendo nuevas redes comunicativas complementarias a las redes materiales que integran la ciudad. En el desarrollo de estas tecnologías y como se ha presentado en el apartado anterior, la invención del smartphone y el desarrollo de redes de transmisión de datos cada vez más rápidas y omnipresentes ha permitido el desarrollo de un modelo de negocio basado en ambas tecnologías que permite a cualquier usuario digitalizar un recurso en el espacio geográfico, y en base a esta ubicación geográfica y otros parámetros perceptivos, visibilizarlo y hacerlo accesible en un ciberespacio que ha evolucionado de las arquitecturas de redes, cables, servidores informáticos y demás estrategias jerárquicas de provisión de servicios, ha alcanzado a toda la población en cualquier momento y lugar.

La tesis estudia los servicios digitales basados en la geolocalización (LBS) ${ }^{1}$, también conocidos como servicios "hiperlocales", que utilizan la ubicación geográfica para informar de que en un lugar se presta o se requiere de un servicio, y en base a esta ubicación de la oferta y la demanda, utilizar la tecnología como un canal directo autorregulatorio entre dicho par. Este modelo, conocido como "plataforma" contrasta con la especialización espacial que suele requerir una organización empresarial de carácter jerárquico, para constituir un mero intermediario tecnológico entre partes interesadas en realizar un intercambio allá donde se encuentren.

No se trata de un modelo que haya surgido con los smartphones. Pues determinados autores han llegado a caracterizar la plataforma como una trasposición tecnológica de la idea de la plaza-mercado (Karhu, Pajulahti y Syd, 2018). También existían plataformas digitales antes de inventarse el smartphone, como podía ser eBay o cualquier página dedicada al sector inmobiliario. Sin embargo, con la popularización de este dispositivo, la creación y gestión de información geográfica en forma de pares de coordenadas GPS ha llegado al público general, y dicho modelo se ha geolocalizado e integrado más profundamente en el espacio social de las ciudades, utilizando cierta noción de proximidad a la hora de priorizar las comunicaciones más inmediatas espacial y

\footnotetext{
${ }^{1}$ En el contexto de esta investigación, se ha optado por este término como una traducción del término anglosajón 'Location Based Services' (LBS). También se les denominará indistintamente como Servicios Geolocalizados, o servicios hiperlocales (del inglés "Hyperlocal Services").
} 
temporalmente, computadas sobre una base de información que se superpone a la ciudad, y se autorregula en función de las necesidades de cada par de personas equipadas con un teléfono móvil.

Aunque el término aluda al uso de redes celulares donde cualquier comunicación en cualquier momento y lugar es posible mediante las TIC, la idea de "Ciudad Celular", no debe confundirse con "la ciudad de los móviles", o "la ciudad de las TIC", en la medida que se rechaza frontalmente cualquier determinismo tecnológico, o si se quiere, fetichismo 'tecnoutópico' en torno a ellas.

Aunque la influencia de las TIC en la evolución de las ciudades sea un tema que ha concitado cierto interés desde la construcción de Internet en los años 90 del siglo XX desde la consolidación de una sociedad-red (Castells, 1996b), donde las ciudades globales (Sassen, 2005) constituyen grandes nodos de acumulación de capital e información-, su influencia sobre las ciudades a escala local como paradigma presente, aunque no se haya negado, no ha mostrado patrones materiales de transformación unívocos o claramente identificables (Graham, 1997; Graham y Marvin, 2001; Yousefi y Dadashpoor, 2019).

Sin embargo, el desarrollo de las tecnologías de la información es cada vez más rápido y perenne, y como se planteaba en el apartado anterior, cada vez más lugares, habitantes, y recursos en las ciudades forman parte de redes geográficas intangibles, de intercambio de información representativas de un complejo proceso de desarrollo sociotécnico global cuyo impacto en los sistemas urbanos se desconoce. La naturaleza de estas redes de comunicación, tan integrados en la vida cotidiana de la ciudadanía, ha favorecido su banalización como parte de la realidad cotidiana, y por tanto cierto desinterés en el ámbito de los estudios urbanos.

En línea con Graham y Marvin (2001), sostengo que los procesos de desarrollo tecnológico no deberían conceptualizarse desde el determinismo que supondría atribuir a una tecnología un cambio lineal en la estructura urbana o la forma de hacer ciudad como la industrialización al 'zonning' o la motorización al 'sprawl'. ¿Cuál sería en ese caso "la ciudad de internet"?, o de manera todavía más abstracta y seguramente absurda ¿la ciudad de las "nuevas" tecnologías? Pero por otra parte, lo cierto es que las innovaciones tecnológicas inducen ciertas transformaciones en la percepción del espacio y sus usos vinculados en relación a cómo funciona cierta tecnología en cuestión. Es decir, la tecnología, y más las TIC, pueden producir cambios puntuales sobre la distribución de ciertas actividades cotidianas en el espacio, cambios que en ningún caso deberían observarse desde una perspectiva lineal, sino desde una perspectiva sistémica. Nadie va a utilizar el teléfono de la misma manera ni en la misma cantidad, ni va a instalar ni utilizar la misma parte de todo un ecosistema de aplicaciones disponibles. Tampoco es predecible con quién o qué ni para qué va a comunicarse ni dónde se encuentra ubicado el par comunicativo. Al igual que idear "Futurama" como la ciudad del motor fue una utopía 
simplista sobre el uso de una tecnología en la planificación de la ciudad; el tecnofetichismo con las "nuevas" 2 tecnologías implica los mismos riesgos.

En cierto modo, la ciudad puede conceptualizarse como si de una tecnología o una plataforma se tratase "un constructo organizado para que un conjunto elevado de personas pueda desarrollar su vida en un ámbito espacial accesible”. Tal definición implica un grado de incertidumbre o indeterminismo similar al de las tecnologías de la información, dado que las necesidades humanas son diversas y aunque sigan ciertos patrones, no son unívocos. No solo es dormir, comer, y trabajar, sino también divertirse, socializar, y satisfacer un abanico indeterminado de alternativas. Lo mismo sucede con las TIC, ayudan a satisfacer un abanico cada vez más amplio de necesidades mediante soluciones muy variadas; por lo que su impacto sobre la ciudad será indeterminado por necesidad, y tratar de profetizar sobre "la ciudad de las TIC" seguramente sea más una tarea, más que científica, de ciencia ficción.

Habida cuenta del indeterminismo que entraña la tecnología y el objeto urbano, la "Ciudad Celular" puede definirse como parte de la etapa de desarrollo sociotécnico y espacial presente. Una ciudad con un plano material, que ha evolucionado a lo largo de la historia como un sistema autopoiético (Maturana y Varela, 1973) adaptándose a las circunstancias del entorno -físico, económico, social, y tecnológico-, cuya configuración espacial y funcional facilita un conjunto de interacciones individuales diverso y en gran medida indeterminado. No por ello este sistema deja de responder al propósito de habitar. En él, las redes celulares en apariencia han aumentado la incertidumbre espacial y comunicativa entre los elementos del sistema, pudiéndose, en teoría, desplegar servicios vinculando información digital a los lugares y habitantes del sistema.

En este sentido, la idea de ciudad celular entraña un doble indeterminismo. Primero, que la ciudad no es un "conjunto de edificios con funciones estáticamente programadas" por acción del urbanismo, sino un sistema informacional complejo sobre el que se articula la actividad cotidiana individual y colectiva. Es decir, la actividad que en ella se produce tiene ciertos grados de libertad que motivan las sucesivas transformaciones espaciales y funcionales a nivel microscópico, y de la agrupación y autoorganización resulta un producto que es más que la suma de sus partes. Análogamente, que las TIC no son "un conjunto de aplicaciones y dispositivos monofuncionales" que produzcan interacciones unívocas, sino un conjunto de capacitadores para la organización de la actividad cotidiana individual y colectiva.

\footnotetext{
${ }^{2}$ Ada Lovelace (matemática y escritora), hija de Lord Byron inventó el "software" en 1840, 100 años antes de que se inventara el ordenador. El que las bases de la informática se sentaran hace más de un siglo y medio hace cuestionarse su "novedad". Su idea de software no sólo se basaba en realizar operaciones matemáticas complejas, sino que también planteó el mundo de posibilidades que el invento favorecería. En sus palabras "la máquina analítica podría operar más allá de los números [...] componiendo elaboradas piezas musicales por extensas o complejas que sean”.
} 
Por ello la ciudad celular representa un sistema doblemente complejo, de espacios accesibles adaptados a las necesidades individuales que se intercomunican físicamente por múltiples redes -que condicionan su accesibilidad- en cuya evolución se ha superpuesto una red comunicativa celular que, a través de dispositivos informáticos, tiene la capacidad de representar, alterar el uso y ámbito comunicativo de cualquiera de sus espacios.

Aunque estas ideas sobre la autorregulación e indeterminismo sistémico de las ciudades ya se hayan explorado de manera empírica mediante nociones como la entropía, la topología, o los autómatas celulares para comprender la organización material de las ciudades (Hillier, 1996; Portugali, 2000; Ruiz-Sánchez, 2001a; Batty, 2005; Aquilué Junyent, 2017), lo cierto es que las redes de telecomunicaciones y la diversidad funcional que pueden introducir no se ha explorado a nivel urbano detalladamente. Era difícil estimar los orígenes y destinos de las telecomunicaciones en la ciudad, también era difícil estimar o sistematizar el propósito de las mismas a nivel desagregado. Pero el desarrollo de los smartphones y la sistematicidad de los LBS permiten, si acaso, explorar la geografía y la topología de una pequeña parte de estas nuevas redes, intangibles, pero necesariamente geográficas.

Si los LBS se articulan a modo de plataforma, es decir, respondiendo a un propósito determinado, necesariamente tendrán un comportamiento sistémico en la medida que el servicio es más que la suma de sus partes. Por ejemplo, un comerciante que quiera informar de la existencia de su negocio puede sumarse a una plataforma digital para visibilizarlo, y un usuario deseando encontrar un comercio puede o no recurrir a esta tecnología. Para satisfacer la función de encontrar cualquier establecimiento -propósito superior a la suma de pequeñas partes aportando información de manera automática-, el LBS deberá adaptarse a la incertidumbre implícita en las necesidades y localizaciones de los usuarios a quienes sirve.

Pero estos servicios digitales, como muestra el apartado anterior, no solo tienen la capacidad de distribuir la información sobre servicios urbanos preexistentes, sino también de informar teóricamente, de la ubicación de cualquier cosa en el entorno de sus usuarios. Por ello están consolidando nuevas distribuciones espaciales indeterminadas de actividades en la ciudad, pudiendo incluso alterar las actividades alguna vez planificadas. También están creando nuevos protocolos y redes comunicativas ad-hoc entre proveedores y usuarios para acceder a estos servicios, con una huella espacial urbana compuesta por ubicaciones indeterminadas. En ello se basan nuevas estrategias económicas de acumulación de capital y nuevas formas de creación de capital humano en la escala urbana local, ámbitos que atañen a un planeamiento urbanístico con una fuerte inercia física por encima del carácter sistémico de las ciudad (Batty, 2013).

Sabiéndose las áreas funcionales sobre las que los LBS están implementándose, abarcando la movilidad, la compraventa de artículos, el alojamiento turístico, o los contactos interpersonales, estas aplicaciones están teniendo un impacto relevante en la vida urbana y el desarrollo de las ciudades, suponiendo desafíos sustanciales en su planificación. 
Mientras que las ciudades consolidadas poseen estructuras funcionales únicas, fruto de su carácter evolutivo complejo, y su planificación urbanística determina marcos de certidumbre en su distribución espacial de actividades, el diseño de los LBS responde a criterios de escalabilidad global para favorecer su disrupción competitiva en el mercado y su rápido crecimiento económico, pudiendo alterar el funcionamiento de la ciudad alterando el uso y accesibilidad de sus espacios. El interés de esta tesis es el estudio de los nuevos espacios comunicativos que los LBS están consolidando en la ciudad y, ligado a éstos, qué dinámicas de ocupación espacial y estructuras comunicativas están produciendo, que cambios se están dando en los usos del espacio físico y qué estrategias institucionales se plantean para controlar o favorecer su despliegue.

En definitiva, y planteado el concepto de ciudad celular como la superposición de nuevos sistemas digitales de información geográfica orientados despliegue de actividades indeterminadas sobre espacios indeterminados, creando redes comunicativas indeterminadas, esta investigación explora su inserción en la ciudad construida, analizando la huella espacial, y estructuras funcionales de ambos sistemas en constante interacción. Los desafíos y oportunidades derivados de ello son la principal motivación de esta investigación, que aporta una exploración crítica del espacio físicodigital urbano, y sus dinámicas ante la consolidación de nuevos entornos comunicativos cada vez más complejo los cuales, de un modo u otro, atañen a la planificación de la ciudad actual y futura.

\subsection{Justificación del tema}

En la medida que el urbanismo es la proyección de futuros deseables sobre el uso del espacio por la sociedad responde a las necesidades y aspiraciones de ésta en base a los recursos y medios de los que dispone en cada momento histórico. Entre los paradigmas más recientes, destaca el de la 'smart city' (ciudad inteligente) como aquella en la que las TIC juegan un papel fundamental en el uso y distribución de actividades en el espacio y la optimización del metabolismo urbano. Más allá de la crítica terminológica, del uso del paradigma tecnológico como algo innovador, o de la fuerte intervención que están jugando los mayores agentes económicos globales en la promoción de una visión tecnocrática e ideológicamente neutral de la ciudad inteligente, el desarrollo de la tecnología digital a partir de la crisis financiera del año 2008 bajo el modelo de la plataforma como epítome de un 'capitalismo sin fricciones', lo cierto es que las TIC están interviniendo en cada vez más interacciones sociales y produciendo de manera autorregulada ciertas transformaciones sobre el uso, la ubicación y el entorno comunicativo de cada vez más lugares urbanos. Sin embargo, el alcance geográfico y espacial de estos cambios está pasando relativamente inadvertido por la inmaterialidad, privacidad y relativa aleatoriedad de las telecomunicaciones.

El germen de este paradigma puede situarse en la consolidación global de la 'sociedad red' (Castells, 1996b) y el desarrollo de la economía de Internet durante los años 90 del siglo 
XX, no alcanzaría su nivel de desarrollo conceptual hasta la crisis financiera del año 2008 . Entre las consecuencias de esta crisis se encuentra el desarrollo del 'capitalismo de las plataformas' (Srnicek, 2017) acelerado por el trasvase de capital financiero al sector tecnológico. Un aspecto característico de este modelo económico es la acumulación de información e infraestructuras para su gestión y transmisión, y una externalización de activos y riesgos - incluyendo tanto bienes de producción como mano de obra.

Es interesante reseñar cómo evolucionó el interés científico acerca de los términos presentados - servicios contextuales, servicios geolocalizados (LBS) y servicios de localización. A partir de la democratización del GPS y la ubicuidad de internet en los dispositivos móviles vía GPRS, el interés científico de los servicios contextuales y los servicios geolocalizados creció en paralelo hasta el año 2007. El 29 de junio de 2007, Steve Jobs, consejero delegado de la compañía Apple, presentó el iPhone revolucionando el mercado de los smartphones y la computación ubicua.

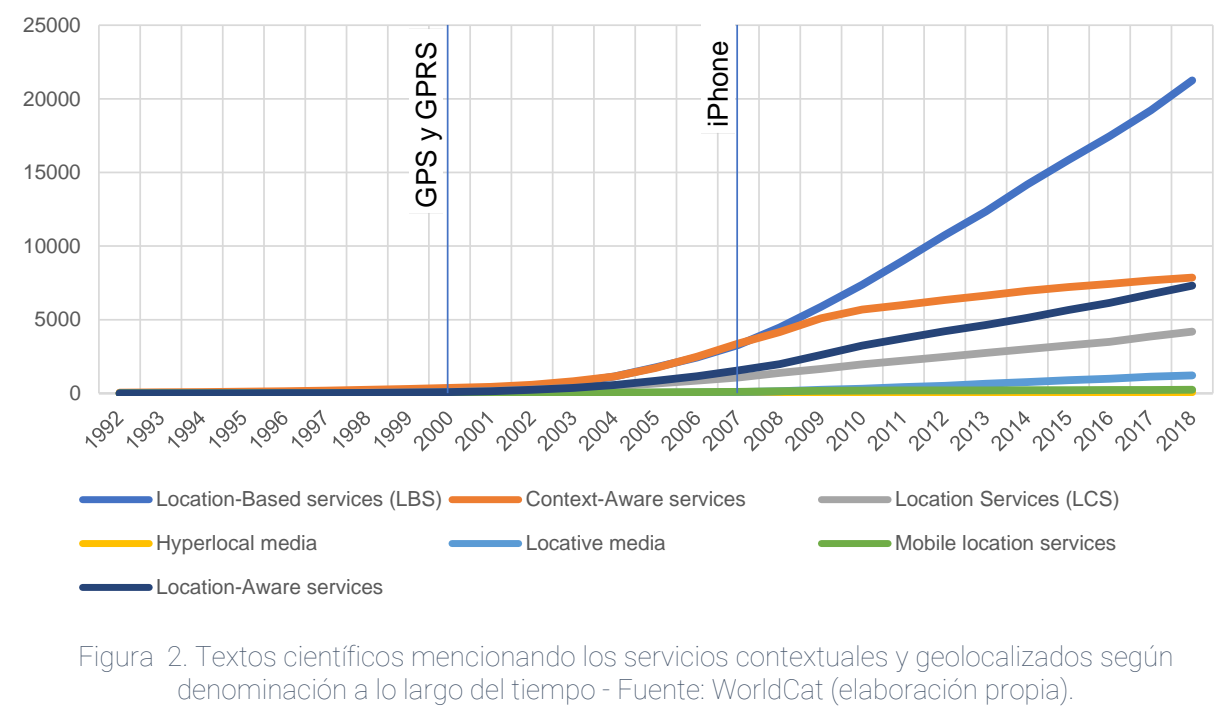

Hasta entonces, los dispositivos móviles con conectividad a internet contaban con una audiencia que se limitaba a los entornos empresariales a través de PDAs y las populares BlackBerry - teléfonos equipados con un teclado alfanumérico físico conectados a internet por GPRS. El iPhone atrajo la mirada de las masas entre otros factores a una interfaz de usuario sencilla totalmente táctil en un teléfono con capacidades de comunicación por internet además de la navegación, la posibilidad de crear un ecosistema de desarrollo de aplicaciones al servicio de una audiencia no empresarial, que junto con la incorporación de cámaras y sensores de movimiento y geolocalización, permitirían en los años siguientes el desarrollo de los LBS (Laugesen y Yuan, 2010; West y Mace, 2010; Eadicicco, 2017) -no obstante, la incorporación del GPS en una computadora de bolsillo solo ocupó 5 de los 90 minutos que duró la presentación del producto. El lanzamiento de este producto disparó la venta de smartphones a nivel global y atrajo el interés de los desarrolladores informáticos, e investigadores de otras disciplinas sobre los servicios basados en la geolocalización [VÉASE FIGURA 2] y sus potenciales aplicaciones más allá del 
ámbito empresarial y turístico. Esto aclararía las características de diseño, campos posibles de aplicación de un LBS, y las formas que tiene de comercializarse.

Los LBS son el epítome de este modelo económico. Contando con una mínima infraestructura propia ${ }^{3}$, el producto ofertado consiste en una aplicación digital que comunica participantes en una transacción y no los bienes materiales que forman parte de la misma. Bien sea en forma de red social; monetizada mediante publicidad personalizada a las condiciones socioespaciales del usuario (el producto es el usuario y el cliente el anunciante), o en forma de servicios de alojamiento o movilidad entre otros, el modelo económico en las escalas locales se basa en los intercambios de información sobre elementos tangibles en su contexto social y espacial específico.

Esta importancia del contexto urbano motiva la presente investigación, no tanto desde el campo de desarrollo de la smart city, las tecnologías específicas o modelos de gobernanza que en ellas podrían implementarse, sino desde el de la capacidad de adaptación de la ciudad existente; consolidada desde estructuras funcionales tangibles, ahora mediadas por infraestructuras tecnológicas que están transformando la manera en la que las actividades urbanas se organizan, hacen visibles y accesibles (Couldry y Hepp, 2016). En otras palabras, tecnologías ya implantadas que han complejizado el sistema comunicativo urbano, diversificando sus usos del espacio y cambiado sus parte de sus condiciones de visibilidad y accesibilidad ante los paradigmas de un modelo de acumulación capitalista emergente.

Aunque radicalmente opuesto en sus premisas, cabe traer a colación la utopía urbana de "Nueva Babilonia” [VÉASE FIgURA 3] planteada por Constant Nieuwenhuis (1974), obra culmen de la bienal situacionista en respuesta al racionalismo imperante de la Carta de Atenas. Este proyecto, plantea la superposición de una superestructura espacial carente de jerarquías funcionales y divisiones espaciales estáticas que se superpondría a las ciudades y se extendería a lo largo del planeta constituyendo un espacio desregulado que, inicialmente se retroalimentaría de la población y actividades de la ciudad construida, para finalmente constituir el hábitat de un 'homo-ludens' liberado de las ataduras espaciotemporales de la vida urbana (Nieuwenhuis, 1974; Sadler, 1998). En otras palabras, el proyecto perseguía la creación de una infraestructura que dotara a la ciudad de mayor complejidad y capacidad de autoorganización social frente a la estaticidad de su espacio construido.

La popularización de los servicios geolocalizados, ligeramente posterior al año 2007 en que puede datarse la democratización del smartphone como bien de consumo tras el lanzamiento del iPhone, radica en el aprovechamiento del GPS, la portabilidad del 'hardware' y la conectividad ubicua a internet. Estas tres componentes han dotado al 'ciberespacio' de una componente geográfica ligada a aquellos elementos físicos que

\footnotetext{
${ }^{3}$ Los LBS suelen utilizar redes de telecomunicaciones propiedad de las operadoras telefónicas, y servidores informáticos propiedad de gigantes tecnológicos como Microsoft, Google, y Amazon, y pequeños equipos de trabajo integrados por profesionales altamente cualificados
} 
representa - como sucedió en primera instancia con las plataformas de mapas y lugares (como 'Google’ y 'Bing Maps', 'Facebook Places', o 'Foursquare City Guide'), y más adelante en la constelación de ubicaciones temporales que comunican las plataformas indicadas anteriormente.

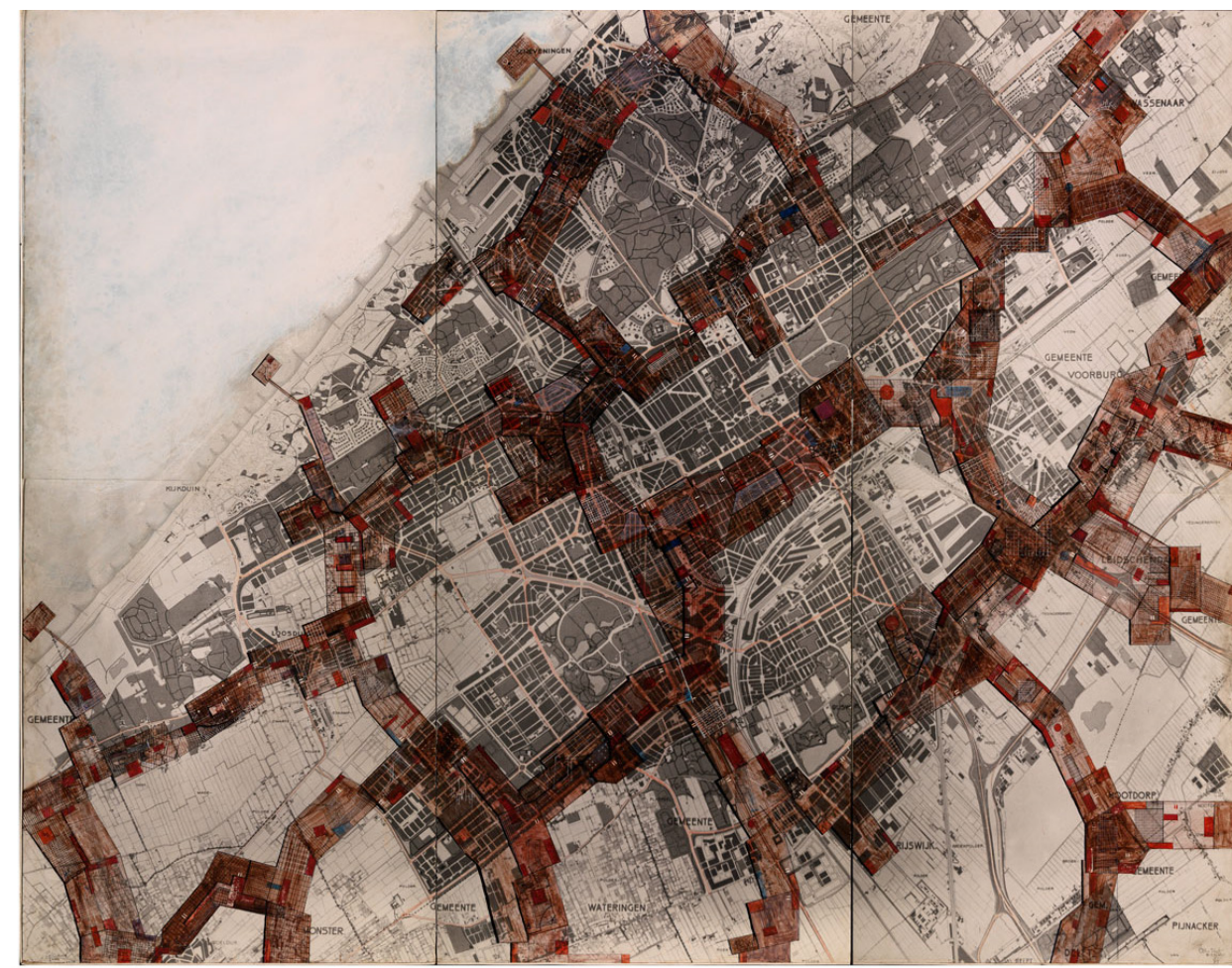

\section{CONSTANT}

New Babylon - Den Haag, 1964

[Nueva Babilonia - La Haya] - [New Babylon - The Hague]

Acuarela sobre papel sobre contrachapado

$220 \times 279,9 \mathrm{~cm}$

Gemeentemuseum Den Haag

Figura 3. Mapa de Nueva Babilonia sobre la Haya. Esta utopía plantea la construcción de un espacio omnipresente, indeterminado funcionalmente, y carente de jerarquías que se superpondría a las ciudades para dinamizar su funcionamiento a futuro. Sobre este espacio abstracto, cualquier persona en todo momento y lugar podría comunicarse con su entorno librándose de las determinaciones que la ciudad impone. Fuente: Constant (1974)

Es precisamente al alcanzar esta segunda etapa de desarrollo de los servicios geolocalizados en la que se produce una ruptura con la certidumbre urbanística establecida, pues rompe con la asociación clásica entre espacio y programa tan loada por el urbanismo racionalista como denostada por el situacionismo. Los usos del espacio prescritos por el planeamiento se ven desafiados ante unas plataformas digitales que capacitan a una actividad a desarrollarse en prácticamente cualquier momento y lugar al hacerla visible digitalmente. Las plataformas digitales de movilidad privada subvierten la necesidad de acudir a paradas fijas de taxi o bicicletas, o de acudir a una calle transitada para maximizar las probabilidades de encontrar un vehículo en menor tiempo. Las plataformas de compraventa de artículos de segunda mano subvierten la eventualidad y fijación espacial del mercadillo, y lo dotan de una proximidad extrema y de la certidumbre de encontrar lo que uno busca. Las plataformas de citas conocer gente cercana sea cual fuere el momento, lugar y propósito del encuentro. Y las plataformas de alquiler de corta duración subvierten el uso de la vivienda como alojamiento permanente o de larga 
duración. Cualquiera de estas subversiones no queda exenta de polémica, pues producido el escalamiento o 'efecto de red ${ }^{4}$ de la plataforma, extiende en el espacio urbano los desafíos derivados de su crecimiento y las oportunidades de planificar la ciudad aprovechando las potencialidades de la tecnología emergente para alcanzar un futuro deseable.

Sirva por tanto el paralelismo entre Nueva Babilonia y los servicios geolocalizados para ilustrar la relevancia del tema tratado en esta investigación. Ante un urbanismo fuertemente enfocado al desarrollo del espacio urbano físico, y dotado de herramientas de zonificación y delimitación estática de usos en el plano físico (Batty, 2013), la aparición de una tecnología capaz de diluir las barreras y condiciones de accesibilidad y uso prestablecidos supone la creación de una nueva hiperestructura urbana (invisible en el caso que nos ocupa) que superpone sus dinámicas funcionales al sistema de usos, comunicación e intercambios del que se nutre: la ciudad.

Inteligente o no, se persigue ahondar en una visión de la ciudad como un sistema comunicativo complejo constituido por las simbiosis emergentes entre sus planos físico y digital. Esto es pertinente tanto para la teoría como la praxis del urbanismo dadas las carencias que muestran algunas aproximaciones a la materia. De una mano, existen visiones mecanicistas sobre las plataformas digitales y la ciudad que reducen la comprensión de las primeras a su funcionalidad intrínseca. Ello induce a plantear la plataforma digital como un ente carente de escala y estructura urbana local; lo cual sería razonable en las plataformas de internet cuyos espacios de acumulación y redes logísticas, siendo perfectamente tangibles, exceden la escala netamente urbana ${ }^{5}$. Sin embargo, al dotar a la información en las plataformas de servicios locales y redes sociales de ubicación geográfica se incide en el espacio urbano y sus dinámicas en la medida que las condiciones regulatorias de las plataformas digitales rigen parte de los usos del espacio urbano. De otra mano, proliferan las visiones reduccionistas de la ciudad a través de su representación digital obviando la especificidad de un servicio que únicamente reflejará aquellos elementos urbanos tangibles necesarios para su funcionamiento. Por tanto, el análisis de los servicios geolocalizados debe realizarse desde su relación bilateral con la ciudad en la que se utilizan sin preponderar la estructura funcional y normativa de una parte sobre la otra.

En suma, la exploración de la 'ciudad celular' de la que consta este trabajo persigue explorar el espacio urbano actual como un lugar de convergencia entre dos sistemas comunicativos complejos cuyas dinámicas determinan buena parte de la vida urbana contemporánea [VÉASE FIgURA 4]. Para ello, este trabajo consta de un estudio de determinadas plataformas digitales en su contexto histórico y económico, comprendiendo sus

\footnotetext{
${ }^{4}$ Aunque se explicará en mayor profundidad en el siguiente capítulo, el efecto de red consiste en crear una atracción simbiótica entre varios tipos de participante hacia una plataforma. Por ejemplo: Propietarios de viviendas y turistas en las plataformas de alquiler de corta duración.

${ }^{5}$ Por ejemplo, los almacenes, rutas aéreas, y centros de datos de Amazon (AWS o Amazon Web Services), desde los que se da servicio a un $42 \%$ de los servicios en la nube externalizados del mundo y casi un 50\% del comercio electrónico en los Estados Unidos (Weise, 2017; Lunden, 2018).
} 
protocolos de funcionamiento y comunicación determinantes a la hora de generar sus propias geografías a escala urbana, las cuales se estudian en relación con la geografía urbana física de Madrid como caso de estudio que permite comprender los conflictos, transformaciones sociales y normativas que producen, además de las oportunidades que presentan ante la necesidad de una planificación sensible a la complejidad intrínseca del objeto urbano.
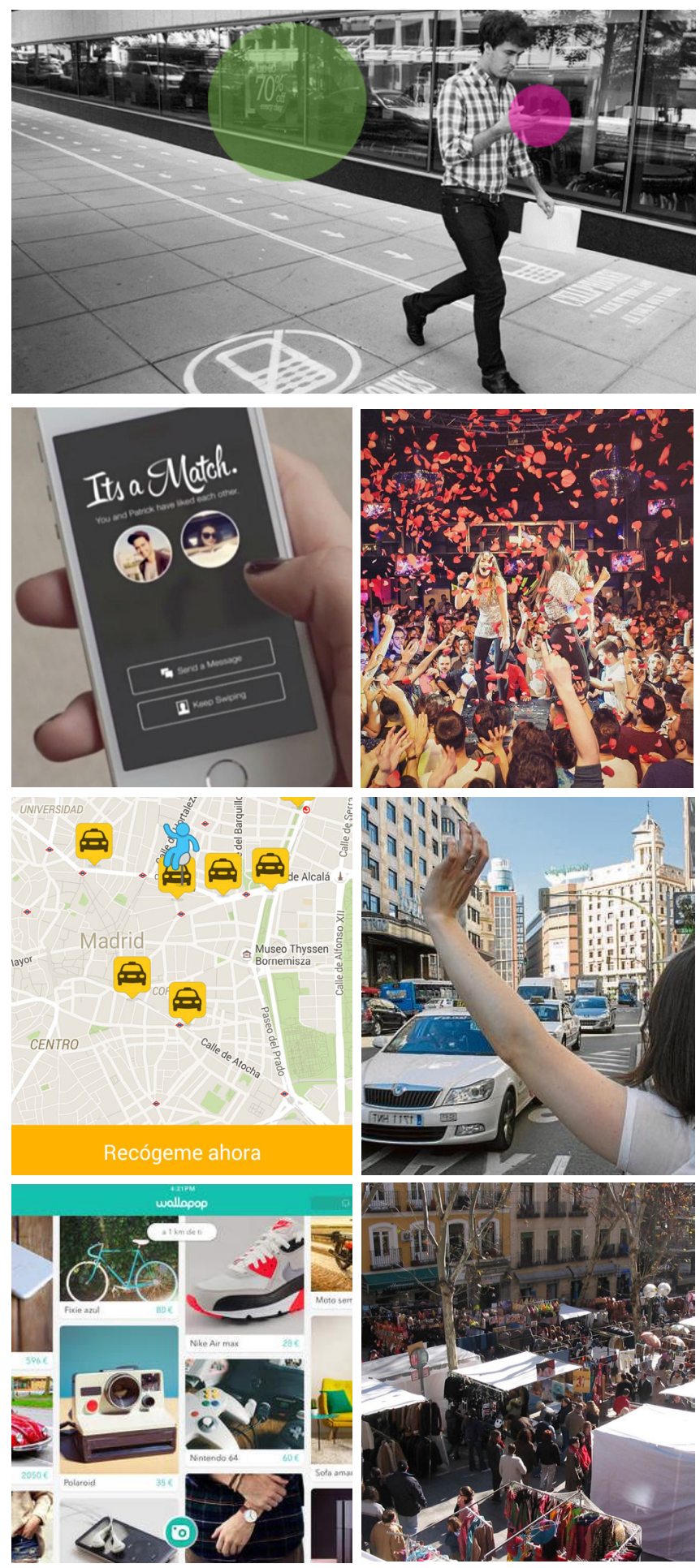

Figura 4. Estímulos visuales de las actividades urbanas y espacios digitales. Las aplicaciones móviles como espacios virtuales de flirteo, paradas de taxi y mercadillos. 


\subsection{Preguntas de investigación e hipótesis}

Si bien el desarrollo de los servicios geolocalizados es relativamente reciente, su acelerada adopción masiva, y sus 'efectos colaterales' en la ciudad motivan el interés del tema a tratar en esta investigación.

El objeto de interés va un paso más allá de estudiar las plataformas digitales como soluciones aisladas a problemas concretos, sino que comprendiendo las características funcionales de la tecnología que las soporta y el papel de la información geográfica que ponen en valor, se trata de explorar su sistematicidad como estrategia de colonización y reprogramación del espacio urbano.

Se sostiene que, a través de los LBS, se está creando sobre la ciudad un ciberespacio geográfico en torno a los recursos susceptibles de un aprovechamiento lucrativo. Bajo esta premisa, la práctica totalidad del espacio urbano podría contar con una representación virtual, y nuevas condiciones de accesibilidad adquirida, y unas lógicas de aprovechamiento capitalista de la información que sostienen parte del crecimiento de la economía de las plataformas digitales.

Esta realidad plantea numerosas cuestiones que estructuran los bloques de interés de esta tesis: la representación digital del espacio físico, las nuevas condiciones de accesibilidad informacional, y el acoplamiento de estructuras funcionales.

En primer lugar, es necesario conocer la espacialidad de la información geolocalizada autoproducida por la población urbana. ¿Qué lugares están ganando una mayor representación digital? ¿qué características tienen? ¿surgen patrones identificables de digitalización del espacio urbano? Resulta importante estudiar estas cuestiones para descubrir si las plataformas muestran cierta predilección por representar ciertas zonas de la ciudad frente a otras, y con ello induciendo nuevas dinámicas de diferenciación y/o exclusión comunicativa. Asimismo, es necesario discernir qué atributos es capaz de aportar una plataforma digital a un lugar determinado, y así identificar la capacidad transformadora de la actividad urbana de las plataformas digitales, es decir, ¿qué nuevos atributos y funciones aportan las plataformas digitales sobre el espacio urbano físico más allá de su mera representación?

En segundo lugar, en la medida que cada plataforma cuenta con un objetivo determinado, se dota de mecanismos condicionantes de las comunicaciones posibles y más probables que producen, resultando en una topología de red alternativa o no a la urbana. De esta cuestión pueden desentrañarse las nuevas condiciones de accesibilidad informacional del espacio urbano físico.

Por último, y en tanto que la parte representada digitalmente del espacio físico puede dotarse de nuevos atributos y entornos comunicativos, se abren cuestiones sobre el entrelazamiento de estructuras funcionales entre las ciudades y los servicios 
geolocalizados. ¿Cuál era el abanico de funciones accesibles de la ciudad antes y después del surgimiento de los LBS?

Se trata por tanto de preguntas que conciernen a la morfología de la ciudad -entendida desde el binomio forma-función de sus espacios habitados y su representación digital-, de su topología -las similitudes y decalajes entre la red viaria y las redes digitales-, y desde la complejidad sistémica - evaluando si la ciudad resultante de las anteriores superposiciones amplía o reduce el rango de funciones accesibles.

Aunque estas cuestiones tienen un marcado carácter exploratorio, se ha marcado la siguiente hipótesis transversal a las cuestiones planteadas:

Ante la falta de normas específicas que determinen la implantación de un servicio digital en un lugar o zona, la digitalización de lugares urbanos por medio de los LBS se realizará preferentemente sobre las zonas de la ciudad de mayor complejidad, es decir, aquellos lugares cuyo entorno tenga una mayor accesibilidad material y una mayor diversidad funcional. Los desafíos estructurales de esta interacción se traducen en una pérdida o ganancia de diversidad funcional o accesibilidad en el sistema urbano, inducida por el entorno digital.

Esta hipótesis confronta una dos premisas ideológicas de las que se ha servido la industria tecnológica para el desarrollo de soluciones: la neutralidad y la indeterminación espacial. Como se verá en el desarrollo de este trabajo, las soluciones tecnológicas nunca son ideológicamente neutras. La mera selección de características observables de la ciudad que queda recogida en los atributos de la base de datos que soporta cada servicio, así como los protocolos de acceso y filtrado de la información para hacerla aprehensible por sus usuarios. Asimismo, la ubicación de la información representa una realidad tangible del espacio urbano, que está determinada por sus entornos espaciales sociales y económicos. Por ello, la creación de un nuevo plano comunicativo en la ciudad introducirá en el espacio urbano existente nuevas tensiones y dinámicas. 


\subsection{Objetos de estudio y apuntes metodológicos}

Para explorar el espacio social que los LBS como un ejemplo presente de "mediatización" del espacio social urbano bajo el modelo de organización autorregulatorio de la plataforma digital, se ha seleccionado la ciudad de Madrid y un conjunto de servicios digitales basados en la geolocalización que se popularizaron en el contexto histórico y económico posterior a la crisis financiera del año 2008. Esta exploración se ha realizado utilizando los marcos conceptuales de la teoría de sistemas y la teoría de la información, campos que permiten comprender la organización de la ciudad y sus redes desde el indeterminismo necesario para afrontar la incertidumbre que introduce un conjunto dinámico incierto, poco regulado desde la escala de gobernanza local. Se espera que la comprensión de los aspectos formales y estructurales de este nuevo espacio físico y digital urbano permita trazar determinadas ideas fuerzas en la elaboración de estrategias de planificación urbanística sensibles al marco sociotécnico presente.

Se ha optado por el estudio de una única ciudad y múltiples aplicaciones digitales de distinta índole para poner el foco en las distintas dinámicas espaciales, económicas y comunicativas que cada plataforma establece, y que éstas resulten comparables entre sí. En paralelo, se ha estudiado la estructura funcional de la ciudad para comprender las características del entorno material de las nuevas redes digitales.

Madrid supone un caso de estudio relevante dada la evolución histórica de su forma y resultante complejidad de tejidos urbanos que comprende, así como su posicionamiento en la economía global. Debido a su prolongado crecimiento a lo largo de la historia, cuya expansión abarca desde mediados del siglo XVI, la estructura funcional de Madrid integra tejidos morfológica, funcional y socialmente diversos que permiten evaluar la materialización de diferentes geografías de la información que entretejen su centro, ensanche decimonónico y periferias modernas. Además, es la tercera ciudad más grande de Europa en población, y la primera de los países mediterráneos del sur del continente. La fuerte dependencia y especialización de la economía española en el sector de la construcción y la financiación inmobiliaria, ahondó en los efectos de la crisis financiera del año 2008 facilitando las posteriores transformaciones del mercado de trabajo e inmobiliario que siguen teniendo lugar en la ciudad. Ello unido a su interés turístico a escala global, su centralidad en las redes supramunicipales de transporte y comunicaciones, y por tanto su centralidad logística, han hecho de esta ciudad un objetivo estratégico para el despliegue de las nuevas redes económicas y espaciales desarrolladas tras la crisis global. Asimismo, la falta de un marco de planeamiento general que contemplara el surgimiento de los LBS ha propiciado la aprobación reactiva de nuevas normativas desde el planeamiento municipal para la mitigación de los impactos de algunas plataformas en la ciudad. Todos estos factores quedan reflejados en la sección de metodología. 
Se han seleccionado servicios digitales que cumplan con las siguientes condiciones.

1. Que sean accesibles en todo momento y lugar a través de un dispositivo móvil.

2. Que su modelo económico sea la plataforma en lugar de una prestación tradicional de servicios por medio de una aplicación digital.

3. Que la información accesible desde sus aplicaciones esté geolocalizada, dotándole de una correspondencia espacial con lugares urbanos específicos.

4. Que su escala de adopción haya sea global probando un efecto de red efectivo en su estrategia económica expansionista.

5. Que alteren la percepción del espacio urbano, visibilizando recursos inaccesibles de otro modo, o bien alterando la accesibilidad de los recursos mediante parámetros dictados por la plataforma exclusivamente.

De la amplia selección de aplicaciones disponibles en las 'app stores' (tiendas de aplicaciones), se han seleccionado las siguientes para comprender su sistematicidad desligada de su propósito específico:

- Representación y promoción de la actividad urbana existente: Foursquare y Facebook Places.

- Redes sociales basadas en la geolocalización: Grindr.

- Transporte con conductor: Hail-O (posteriormente fusionado con Mytaxi y posteriormente en FreeNow) haciendo mención a sus alternativas en la modalidad de VTC: Uber y Cabify.

- Comercio B2C ('business-to-consumer) y logística: Amazon Hub.

- Comercio C2C ('consumer-to-consumer): Wallapop.

- Inmobiliario/hostelero: AirBnB (alquiler de corta duración).

Sobre esta selección de plataformas, se ha realizado un análisis empírico en tres etapas basado en grandes cantidades de datos ("big-data" 6 ) ubicados en Madrid; acumulados por las instituciones públicas o bien por las plataformas digitales.

La primera fase de análisis morfológico se basa en la estructura de la propiedad de Madrid reflejada en el Catastro y su propia morfología, atendiendo a los usos y superficies de todos los bienes inmuebles -y por tanto de la forma del espacio no parcelado que soporta la estructura topológica de la red urbana. Sobre esta fuente de información se exploran las plataformas, que representan en cierta medida la percepción social de la información urbana, y qué zonas de Madrid aglutinan una mayor cantidad de información digital.

La segunda fase consiste en un análisis topológico de la red urbana y las redes digitales. $\mathrm{Si}$ la ciudad mantiene su integridad a través de la red viaria, dicha red evidencia una jerarquía de lugares y ciertas leyes de probabilidad de interacción entre un lugar y otro dadas sus características funcionales y de su entorno. Por otra parte, los lugares urbanos digitales

\footnotetext{
${ }^{6}$ El anglicismo 'big-data', traducible al español como datos masivos, hace referencia a las tecnologías y campo del conocimiento diferenciados que se encargan de la gestión y análisis de grandes cantidades y tipos de datos digitales de manera coste efectiva. No se trata por tanto de una diferenciación exclusivamente relativa al tamaño o cantidad, sino a los recursos utilizados para lidiar con ello.
} 
forman parte de redes alternativas que los hacen más o menos visibles con independencia o no de la jerarquía urbana.

El carácter sistémico de la ciudad hace que no pueda aislarse su morfología de la topología como aspectos independientes. Ambas configuran la noción de complejidad urbana como la diversidad funcional accesible. Utilizando técnicas cuantitativas, se ha realizado un análisis complejo, evaluando las zonas de la ciudad que amplían o reducen sus capacidades comunicativas o de diversificación de su actividad utilizando las redes digitales.

\subsection{Objetivos}

En suma, la tesis persigue como objetivo la generación de conocimiento sobre los siguientes aspectos de la ciudad contemporánea:

- Estudiar el funcionamiento de la ciudad como un sistema comunicativo complejo en el que ha emergido un nuevo entorno comunicativo digital que forma parte de la realidad cotidiana y agrega nuevas incertidumbres en lo que respecta a la adecuada asignación de funciones al espacio construido.

- Generar metodologías de análisis del espacio urbano digital: La complejidad implícita del espacio urbano digitalmente integrado (Ratti y Claudel, 2016)(grandes cantidades de datos, alta volatilidad en el tiempo y superposición de funciones) es multiescalar y difícil de comprender con las herramientas de las que se ha dotado el planeamiento tradicional: el mapa estático del espacio físico y sus funciones.

- Explorar ciertas implicaciones socioespaciales de este tipo de tecnología comprendidos en su contexto económico de desarrollo. En otras palabras, desentrañar las características de la economía urbana que comporta el capitalismo de las plataformas y sus productos, a saber:

o Nuevas estrategias de visibilización y aprovechamiento lucrativo del espacio.

o Nuevas estructuras de red intercomunicando lugares urbanos.

o Afectaciones en el balance de actividades de la ciudad.

- Poner en valor la dimensión informacional y sistémica en una disciplina urbanística con una fuerte inercia materialista, como vía para comprender un entorno social y tecnológico dinámico, y cada vez más dominado por la industria tecnológica.

- En suma, la búsqueda de simbiosis entre un sistema digital de reprogramación de la actividad urbana y los objetivos tradicionales del planeamiento urbanístico: la mejora de las condiciones de vida del conjunto de la población aprovechando el carácter integrador de las infraestructuras tecnológicas manteniendo la diversidad e identidad de la ciudad. 


\subsection{Summary}

This research reflects on how urban planning can deal with the present situation in which a growing number of services, whose linkage to certain places was previously modeled by spatial planning, are now being dynamically de-located and relocated by means location-based services (LBS). Cities are immersed in a 'geographic cyberspace' that complements the information that individuals can perceive from their environment, alters the social and spatial reach of individual and collective communications, and produces new activity patterns, opportunities and frictions in the social space.

The idea of a "Cellular City" raises from the urban-technological entanglement presented above. A city whose physical spaces, communication networks, structural patterns, and planning regulations are becoming increasingly dependent on the digital representations of those places, dynamically structured communicative networks, and norms dictated by a technological industry whose 'apps' feed the present "platform capitalism" (Srnicek, 2017) in an era of non-physical growth of the consolidated city.

'Apps' installed on GPS-equipped ubiquitously connected smartphones have become a key technology of the digitalization of individual and social everyday activity, consolidating a social space more mediatized than ever (Couldry y Hepp, 2016). These apps produce a plethora of informational hyperlocal (here and now) transformations of the places they operate at; dictating, at least temporarily, what can be done at them. This is challenging the role of physical planning and the certainties it attempts to establish, particularly in the urban areas where LBS are used more intensively. There are many examples of such transformations, like homes becoming flea markets (through $\mathrm{C} 2 \mathrm{C}$ ecommerce), places to date people (Grindr), or amateur hostels (AirBnB) - potentially inducing a new wave of transnational gentrification (Sigler y Wachsmuth, 2016; Aalbers, 2019). Apart from housing, retailer can now become last-mile logistic operators (Amazon Hub), or dark-kitchens (Deliveroo), and some secondary streets may now accommodate spontaneous stops for taxis and personal renting vehicles, added to an increased homedelivery traffic (Weltevreden, 2008).

Although the cellular city is the present rather than the future, its "digitally integrated urban space" (Ratti y Claudel, 2016) has not been sufficiently explored in a systematic way. The structural dynamics of urban digitalization and its enabling technologies, in the way they transform the urban economy and lifestyles are still being grasped through isolated case-studies rather than as an integrated sociotechnical system.

Both the city and LBS can be conceptualized as mutually-dependent systems, whose functional structure emerges from self-organization of the exchanges of matter energy and information carried out by their living agents, including the planners of material space (Ruiz-Sánchez, 2001; Portugali, 2011; Batty, 2013; Ruiz-Sánchez et al., 2014) and the computer programmers of its digital counterpart (Mitchell, 2003; Kitchin y Dodge, 2011). A quadruple friction between these agents and programmers may appear. The city conceived by urban planners and programmers and the one perceived by the population 
through a material or digital environment that conditions the possible and probable interactions legitimated by both kinds of planning agents can collide.

Taking the undesired frictions that platform capitalism produces into account, it is worth to question to what extent such digital integration can be considered synergetic. In this sense, systemic complexity, understood as the diversity of a system's accessible states (Wagensberg, 1985), transposed to cities as the variety of individual activities urban fabrics enable (Alexander, 1964; Aquilué Junyent, 2017) may help to clarify this question. LBS can complement the already existing activities in the city and its communicative channels introducing both functional diversity and accessibility, yet, they can also replace existing activities and concentrate communications in certain zones given their selfregulated nature.

Such dichotomy can only be understood through the systemic lens, analyzing the processes of digital data accumulation and related activities over the physical urban space, and the new invisible yet spatial communicative networks that suffuse the material city. Based on a comprehensive urban model made of empirical, institutionally and platform source data, this thesis explores the morphology and complexity of the Cellular City, exploring its formal and functional structures, and the emerging structural challenges urban digitalization presents. By raising awareness on the systemic non-material organization of contemporary urban life, strategies that use technology for the common good can be introduced in the planning practice, in order to preserve and enhance urban complexity. 


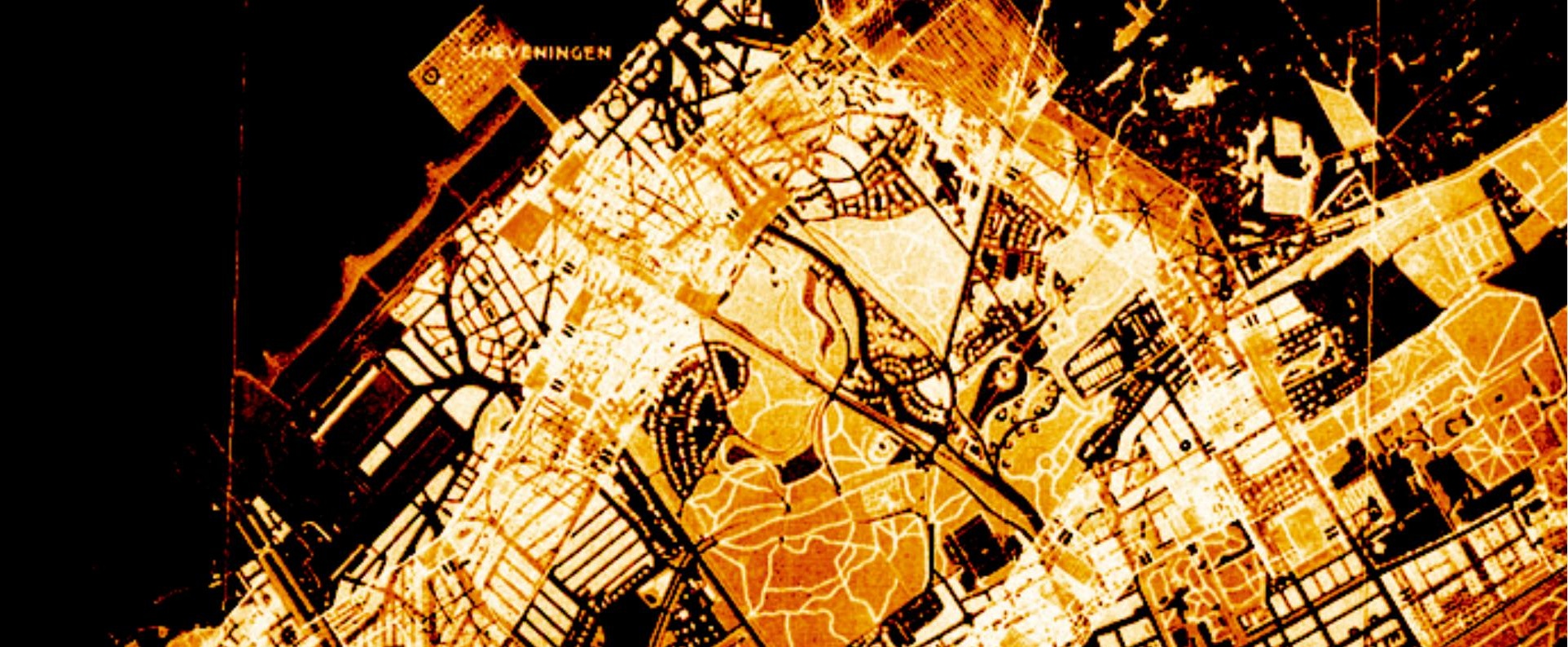

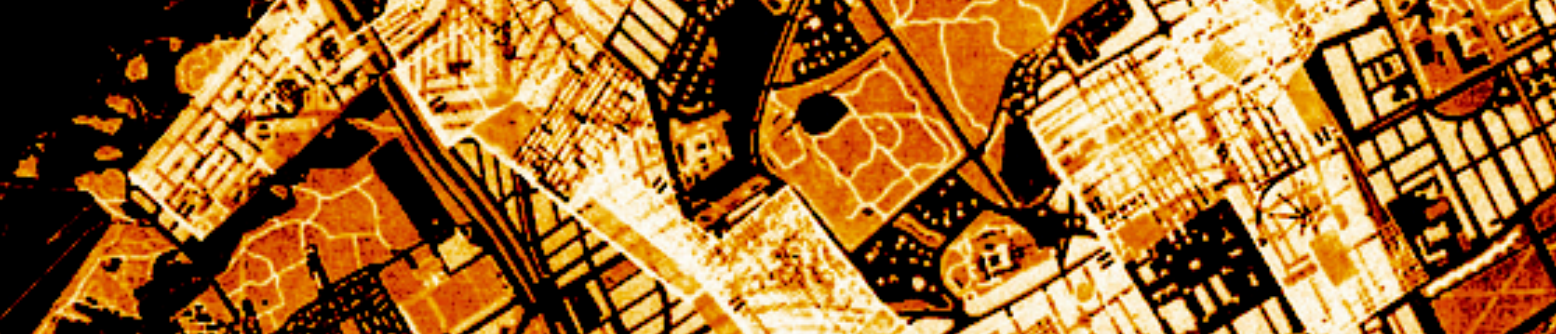
(2) - I. 1 i - . . . . . .

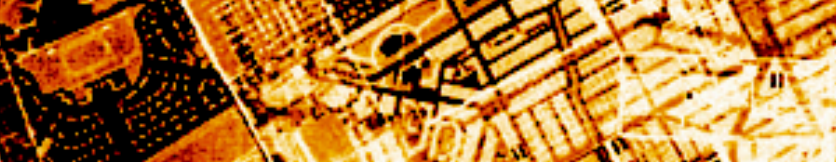

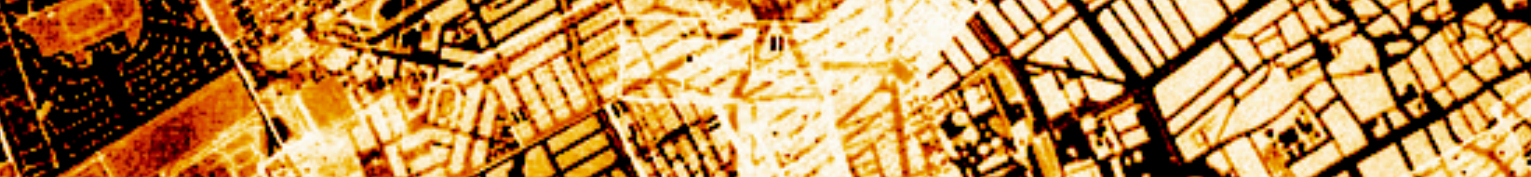



Si se tienen en cuenta las cinco categorias fundamentales del conocimiento según Ranganathan (1931) - personalidad, materia, energía, espacio y tiempo-podemos observar que, para todas salvo el espacio, se han establecido artefactos digitales de distribución masiva. Los servicios geolocalizados pueden ser el campo del que emerja tal artefacto»

(Raper etal., 2007)

\section{Resumen del capítulo}

La literatura muestra que los LBS han alcanzado notables grados de madurez tecnológica, variedad funcional, y adopción masiva. Sin embargo, las implicaciones sociales de estos sistemas, que incluyen la alteración de la complejidad urbana en su forma innovadora de organizar la actividad en el espacio no se han analizado en suficiente profundidad (Raper et al., 2007).

Los LBS operan en el dominio informacional de los sistemas urbanos, estableciendo sistemas autoorganizados de usuarios y lugares urbanos interconectados. Su arquitectura informática está diseñada a tal efecto, localizando en el espacio la oferta y demanda del servicio que regulan, construyendo un entorno ilocal mercantilista en la ciudad.

El auge de la economía de las plataformas digitales encuentra en la ciudad la densidad y diversidad de usuarios suficiente para operar. El valor de la plataforma digital radica en su complejidad sistémica, atraer el máximo número de usuarios ofertantes y demandantes 
de un recurso (efecto de red) para maximizar su aprovechamiento comercial (Sundararajan, 2016; Srnicek, 2017). Los LBS se convierten en una interfaz de usuario de bolsillo de este Sistema de Información Geográfica, cuya información pasa a formar parte del mapa cognitivo de los ciudadanos (Portugali, 2006) mediando sus acciones. Al mismo tiempo, la información proporcionada por los usuarios de los servicios puede utilizarse por terceras partes externas a la plataforma (recursos de borde), entre los que pueden incluirse planificadores que buscan analizar el sistema urbano desde estas fuentes de información geográfica contribuida por la sociedad (Martí, Serrano-Estrada y NolascoCirugeda, 2019).

\section{Chapter's summary}

The literature shows that LBS have acquired a high level of technological maturity, functional variety, and massive adoption. However, their social implications, that include the alteration of urban complexity due to their innovative way of deploying activities in space have not been studied profoundly enough (Raper et al., 2007).

From a conceptual standpoint, LBS operate in the informational realm of urban systems, by establishing parallel self-organized systems of interconnected users and urban places. Their computer architecture responds to the need of geolocating the supply and demand of a service, consolidating nonlocal virtual urban markets.

The rise of platform economy has found in cities the optimal density and variety to operate. Rather than commercializing products, the value of digital platforms lies in their systemic complexity, attracting as many interdependent users and resources as possible (network effects) to maximize their commercial usage (Sundararajan, 2016; Srnicek, 2017). As Geographic Information Systems, LBS become the user interfaces of the platform economy, integrating digital geospatial information in the citizen's cognitive maps (Portugali, 2006) mediating their actions. At the same time, digital platforms have certain degree of openness in a way that third parties may reutilize the information they gather (boundary resources), including planners who want to explore the city through volunteered geographic information (Martí, Serrano-Estrada y Nolasco-Cirugeda, 2019). 


\subsection{Tecnofetichismo y Urbanismo}

Desde la llegada de Internet, la literatura académica sobre los estudios urbanos se ha planteado los efectos formales del despliegue digital sobre las ciudades. Es necesario en este contexto establecer una distinción de escala global y local para enmarcar la cuestión de las transformaciones que se han tratado de contextualizar. A nivel global, se ha asumido que el desarrollo de una economía capitalista volátil, fluida y rápidamente cambiante en torno a las telecomunicaciones ha centrado el interés en las ciudades como nodos centrales de las nuevas redes económicas-informacionales (Castells, 1995, 1996b; Sassen, 1999, 2005) por las que las TIC - entre otras tecnologías de la comunicaciónmaterializan las compresiones espaciotemporales que permiten la aceleración de los ciclos de producción (Harvey, 1989). Bajo estas circunstancias, mucho de lo que experimentamos y caracterizamos como local, resulta ser un microentorno de alcance global. Dicho de otro modo, a través de "circuitos invisibles" la ciudad es el sujeto en el que se localizan los procesos organizativos globales (Sassen, 2010).

En lo que refiere a la escala urbana, es relevante la relación entre tecnología y ciudad explorada por Melvin Webber (1964) en un esfuerzo por comprender la naturaleza de la vida urbana. El autor introdujo la idea de 'comunidad sin proximidad' aludiendo a la importancia creciente de las redes de transporte y la importancia de planificar la ciudad atendiendo a la accesibilidad en la misma. La ciudad se presenta como una convergencia de "comunidades de interés" de escalas variadas desde lo local hasta lo global sin límites definidos y con una tendencia al crecimiento en la medida que las comunicaciones mejoraban. Si bien el desarrollo del transporte ha contribuido al crecimiento y a la dispersión urbana, el desarrollo de las telecomunicaciones ha atraído un debate sobre sus efectos sobre la estructura urbana.

A pesar del consenso sobre la ciudad global y la explosión urbana presentes, y la evidente presencia de las TIC en la reorganización de la actividad productiva, los efectos de estas últimas han estado debatidos desde posiciones dicotómicas -maximalismo frente a minimalismo (Kellerman, 1984), concentración frente a dispersión (Audirac y Fitzgerald, 2003; Dadashpoor y Yousefi, 2018), evolución frente a revolución (Audirac, 2005), lugares frente a flujos (Castells, 1996b)... También han primado las revisiones sobre la ciudad y las TIC relativamente generalistas; que consideran las TIC como una única tecnología con el único propósito de la comunicación remota; sin contemplar que a medida que ha avanzado su desarrollo, han variado significativamente en formatos, propósitos, y alcance socioespacial.

Las aproximaciones de índole dicotómica han tendido a basarse en la premisa de que el despliegue de las TIC, por el hecho de posibilitar comunicaciones remotas en tiempo real -lo que se denominó 'efecto túnel' (Graham, 1998) o la muerte de la distancia (Cairncross y Cohen, 1997)—, conducirían hacia una concentración o bien hacia la dispersión de la forma urbana en su conjunto (Salomon, 1996) basada en los modos por los que las telecomunicaciones reestructuraría espacialmente las actividades cotidianas. Estas aproximaciones se pueden clasificar según reconozcan o no que las TIC influyen sobre la 
estructura espacial urbana ${ }^{7}$, y dentro de las que reconocen la influencia, si producen efectos de concentración o dispersión urbana, o efectos duales -concentración y dispersión simultáneas.

La revisión literaria elaborada por Dadashpoor y Yousefi (2018) muestra una gran diversidad de conclusiones alcanzadas entre 1990 y 2017. La gran mayoría de académicos mantenían un consenso en torno a que las TIC han afectado a la estructura espacial urbana (91\% de los estudios). Sin embargo, demuestra un debate en torno a la tesis de la descentralización ${ }^{8}$ ( $42 \%$ de los estudios analizados) y los efectos duales de centralización y descentralización simultánea (33\%) -marginalizando las tesis sobre la concentración ${ }^{9}$ de actividades (16\%).

A pesar del interés de este metaanálisis, se evidencia un problema transversal a la literatura sobre la ciudad y las tecnologías de la comunicación; considerar a estas últimas como un ente homogéneo cuya consecuencia es favorecer, o en su defecto mitigar la necesidad de producir encuentros cara a cara, y con ellos dependencias sobre el transporte y la concentración y dispersión de actividades urbanas. Si algo muestran las TIC, es precisamente su adaptabilidad al entorno cualquiera que sea su forma, y la posibilidad que brinda la informática de programarse en torno a propósitos diversos que pueden requerir de proximidad espacial, o no, lo cual justifica la infertilidad de cualquier aproximación dicotómica a la ciudad y la tecnología, o cualquier aproximación determinista y tecnofetichista que estudie la "tecnología" como un fin en sí mismo y no como parte del entorno complejo de los sistemas urbanos (Graham, 1997, 1998; Graham y Marvin, 2001).

Asimismo, el nacimiento de los LBS ha implicado la importancia de la geolocalización, y con ella el binomio forma-información perceptible-acción comunicativa como componente fundamental de los sistemas urbanos complejos (Ruiz-Sánchez, 2001b; Portugali, 2011b; Aquilué Junyent, 2017). Los LBS constituyen una tecnología catalizadora de los actos comunicativos en los sistemas urbanos en la escala local. Ello implica que, por lo menos una rama de las TIC utilizada por la totalidad de la población mundial que posea un smartphone, está orientada a favorecer intercambios de materia-

\footnotetext{
${ }^{7}$ El patrón de distribución espacial de las actividades urbanas, agrupaciones de edificios, usos del suelo y redes. Es decir, es el modo por el que los elementos urbanos se ubican unos junto a otros. (Dadashpoor y Yousefi, 2018)

${ }^{8}$ La corriente de la descentralización argumenta en línea con la muerte de la distancia y la descentralización de las actividades a través de las redes globales de comunicación basada en cuatro principios: sustitución de las necesidades de transporte; desmaterialización de los soportes físicos; acceso ubicuo a las telecomunicaciones; y la creación de áreas periféricas de actividad urbana (Salomon, 1996).

${ }^{9}$ La idea de la centralización urbana (Gaspar \& Glaeser, 1996; Glaeser, 2011; Panayides \& Kern, 2005) se basa en que las TIC favorecen la creación de encuentros cara a cara, lo cual implica un crecimiento de los lugares centrales en las ciudades debido a que cuentan con una mayor aglomeración de infraestructuras.
} 
energía radicados en la apertura de nuevas redes geográficas intangibles por las que la información del sistema urbano fluye.

En un segundo metaanálisis elaborado por los mismos autores (2019) se concluye en torno a esta hipótesis de la complejidad. Ello implica asimilar la diversidad de propósitos, y con ello aspectos de la vida cotidiana en los que pueden mediar las TIC. Pueden introducir nuevas actividades (como las indicadas en el anterior ejemplo), y reprogramar la mayoría de las existentes en una revolución digital de la geografía existente (Ash, Kitchin y Leszczynski, 2018) - a lo cual contribuyen los LBS. Quiere decir, que el espacio urbano se encuentra parcialmente representado, y ese 'ciberespacio', como se ha apuntado anteriormente, es una representación de la información de la ciudad que representando lo existente, permite proyectar nuevas actividades, decisiones de localización, redes de comunicación y flujos.

Todo ello es susceptible de afectar a la estructura espacial urbana (Audirac y Fitzgerald, 2003; Sassen, 2010; Harvey, 2012). Sin embargo, esta combinación compleja de espacio físico y virtual, al no operar de manera unívoca, hace que los efectos de las TIC sobre el espacio urbano en la escala local no describan un patrón fácil de definir, ni sobre el que teorizar. A pesar de que las TIC hayan conquistado la variable espacial.

En base a esta literatura, se puede afirmar que, si las exploraciones sobre las transformaciones de la forma urbana por las TIC se han demostrado infructuosas, es precisamente por la incomprensión de su diversidad y su complejidad. Por otra parte, las numerosas fricciones surgidas entre una planificación urbana 'de lo tangible' (Batty, 2013) y las redes emergentes requieren de un retorno a la ciudad de modo tal que ésta "no siga considerándose un sujeto pasivo de las telecomunicaciones; tal y como se ha considerado en numerosas revisiones sobre el cambio tecnológico [...] sino hacia una planificación urbana acorde a la complejidad de estos procesos de cambio [...], los cuales aparte de las referencias hacia la globalización o a la reestructuración económica, han encontrado un espacio marginal para el debate (Graham, 1997, p. 117).

Esta situación de relativa marginalidad de las tecnologías digitales en el planeamiento no despuntó hasta la aparición del concepto de 'smart city' años después de comenzar la consolidación de las tecnologías sobre las que en buena parte se basa; y como se verá, sin haberse explorado de manera empírica la cuestión del espacio geográfico y social de los servicios informáticos basados en la geolocalización, perenne en su desarrollo.

\subsubsection{La "Smart City"}

Tiempo después de las primeras proclamas de un urbanismo y una ciudad transformada formalmente por acción de las tecnologías digitales surgió la corriente sobre las 'smart cities' (o ciudades inteligentes). Sus definiciones son muy variadas dada la tremenda ambigüedad del concepto, sin embargo, se observa la adopción de una idea a lo largo de la corta historia de este término: el uso de la tecnología para alcanzar objetivos de planeamiento. Las definiciones iniciales de los años 2000 sobre las 'digital cities' como 
entornos virtuales para la provisión de servicios urbanos públicos o privados adoptaron las ideas de sostenibilidad basada en la optimización algorítmica unida a la adaptación al usuario que proporcionaba la tecnología. Si el iPhone sirvió para acuñar el concepto de smartphone, la utopía del 'Smart Planet' de IBM, junto con la Agenda 2020 europea impulsaron el desarrollo de este término (Cocchia, 2014). Sin embargo, la smart city es un concepto tremendamente elástico, cuyas definiciones varían enormemente en función de la institución que las proporciona. Puede decirse que, teniendo en común la tecnología digital como mecanismo vertebrador, las premisas atribuidas a esa 'smart city' son muy diversas. Entre otras, atañen a la sostenibilidad medioambiental, la economía y la economía digital, la movilidad, la participación ciudadana en los procesos de gobernanza, y los modos de vida de la ciudadanía (Fernandez-Anez, 2016).

Tomando la diversidad de ejes estratégicos atribuidos a la smart city según los organismos que la definen, Fernández Áñez (2016), ha proporcionado una definición de consenso para comprender este concepto: «una Smart City es un sistema que potencia el capital social y humano interactuando sabiamente con los recursos naturales y económicos mediante soluciones y procesos de innovación basados en la tecnología para abordar los problemas urbanos y alcanzar de manera eficiente un desarrollo sostenible y con calidad de vida, sobre la base de acuerdos multilaterales coordinados a nivel municipal».

La anterior definición muestra elementos característicos que diferencian la smart city de las ciudades digitales. En primer lugar, fundamentalmente reconoce el carácter sistémico de la ciudad (Portugali, 2000; Batty, 2013; Ruiz-Sánchez etal., 2014; Fernández-Güell etal., 2016). También pone a la administración pública $-\mathrm{y}$ el planeamiento urbanístico municipal como una de sus herramientas- como agente coordinador de acuerdos multilaterales entre entidades públicas y privadas para alcanzar los objetivos de sostenibilidad. Por último, reconoce el papel de la tecnología digital para alcanzar estos objetivos.

Ahora bien, la ciudad se ha desarrollado de manera acorde a la tecnología disponible en cada momento histórico, y el éxito de su planificación y su supervivencia en el tiempo ha dependido en gran manera de comprender su carácter sistémico y cómo la tecnología afecta a la configuración socioespacial de dichos sistemas sociotécnicos (Alexander, 1964). Si la tecnología del momento es la digital, ees entonces la 'smart city' un objeto distinto de una ciudad contemporánea? Más que eso, se puede considerar como un paradigma de planificación. Cabe plantear el debate en torno de si 'la tecnología' es un hecho diferencial. Si ésta toma formas tan diversas, debe evitar utilizarse como un término comodín al igual que 'las TIC' en el punto anterior. Entonces, ¿a qué tecnología se refiere la smart city?

En base a este marco teórico, sostengo que, si la 'smart city' tuviera un significado que diferencie el concepto de paradigmas anteriores de planificación, se refiere a las tecnologías de soporte a los servicios geolocalizados -o dependientes del contexto-, que se popularizaron tras la democratización del smartphone (Cocchia, 2014), la organización de la innovación y la producción de una economía de la información en torno a la 
plataforma tecnológica como modo de organización (Gawer, 2010; Anttiroiko, 2016) en un contexto social de mediatización profunda del espacio social (Couldry y McCarthy, 2004b; Couldry y Hepp, 2016). Por ello, a pesar del enfoque aparentemente tecnocéntrico de esta tesis, se busca el encaje sistémico de la tecnología como parte del entorno del sistema urbano, y no como un elemento propio de la ciudad que transforme su forma o su manera de funcionar de manera radical. Bajo esta premisa, las TIC constituyen un entorno de 'sensores y actuadores' (Mitchell, 2003; Ratti, 2011; Ratti y Claudel, 2016) semiautomáticos en torno a propósitos definidos (Latour, 2004), los cuales pueden (o no) aproximarse a los objetivos del planeamiento vigente.

Frente a una smart city naif en cuanto a tecnologías específicas, la ciudad sensorizada ('senseable city') (Ratti y Claudel, 2016) representa un sistema urbano claramente diferenciable. Este objeto urbano se caracteriza por la infiltración de toda suerte de sensores digitales dentro de objetos cotidianos capaces de actuar en función del contexto y por ello desplegar servicios de una forma innovadora - no por ello exenta de polémica o debate al igual que todos los discursos tecnocentristas acerca de las smart city (Clark y Shelton, 2016). La monitorización de recursos geolocalizados y su contexto crea una representación digital de la ciudad que hace posible incrementar los canales de accesibilidad a estos recursos complementarios al espacio físico urbano. La ciudad sensorizada se articula a través de un espacio físico-digital en ningún momento neutro sino moldeado de acorde a los propósitos de cada aplicación digital (Duarte y Firmino, 2009). Un planeamiento 'inteligente' será capaz de articular estos propósitos para lo cual necesita una comprensión profunda de las implicaciones socioespaciales de las tecnologías presentes.

Esto vuelve a incidir en la necesidad de crear lecturas del espacio social producido por los servicios geolocalizados, dado que son tecnologías extendidas globalmente capaces de rearticular la provisión de servicios urbanos, de las cuales todavía se desconocen las maneras por las que estas se despliegan en la ciudad física. Es un paso necesario que contribuye a alcanzar los ideales de sostenibilidad, desarrollo económico, y justicia social del urbanismo. Si todavía no hemos estudiado en profundidad el despliegue espacial y relacional de las plataformas digitales, ¿cómo vamos a incorporar estas herramientas en el planeamiento? Además, si las plataformas digitales más popularmente utilizadas están controladas por organismos privados ¿cómo vamos a hacer partícipes a las administraciones públicas del debate sobre la ciudad y la tecnología digital?

Por ello, sin menoscabo de la validez de los propósitos y los medios que la literatura sobre "smart cities" presenta, propongo un distanciamiento con respecto a este término para centrar la investigación en los sistemas sociotécnicos presentes, infiltrados en los espacios y vidas cotidianas urbanas, y que por tanto tienen la capacidad de rearticular el espacio social a través de entornos comunicativos virtuales complejos. 


\subsection{Información y complejidad urbana}

Más allá de la definición geométrica y funcional determinista del espacio urbano, la ciudad puede comprenderse como un organismo que evoluciona de manera incierta con respecto a lo concebido y lo previsible por sus planificadores.

La ciudad es un sistema complejo, en el que se producen múltiples procesos de diferenciación; iniciándose con una diferenciación material con respecto del entorno territorial, una diferenciación social derivada de la densificación de población en dicho ámbito donde sus espacios pueden a su vez diferenciare, entre otros procesos, por la división del trabajo y la necesidad de un asentamiento permanente; hechos que resultan en la creación de un hábitat urbano cuya morfología espacial tiende a la permanencia histórica (Bairoch, 1990; Ruiz-Sánchez, 2001b; Ruiz-Sánchez etal., 2014).

Se trata de un sistema abierto que tiende a la organización intercambiando materia, energía e información con sus múltiples entornos reorganizándose constantemente, pero manteniendo su identidad y en gran medida su organización; pues en estos intercambios se refuerza la complementariedad de los elementos que interactúan en ella. En cierto modo, esta definición de la ciudad se acerca a la definición de ecosistema o sistema ecológico de Ramón Margalef como "relación multivariada entre organismos y medio ambiente en un espacio determinado, buscando conseguir una constancia con el medio ambiente" (Margalef, 1980).

La ciudad se construye a sí misma por acumulación de actos comunicativos entre los sujetos que la habitan —esta afectación mutua entre sujetos interdependientes procede de la definición de comunicación de Wiener y de la idea cibernética de la observación. De esta complementariedad se construye una densa malla de relaciones de codependencia que resuena con la definición básica de sistema de Von Bertalanffy como conjunto de partes en mutua interrelación con propiedades investigables y descriptibles-; una estructura relacional funcional que mantiene cohesionado el conjunto de elementos con sus entornos de manera estable y organizada; según Ruiz-Sánchez (Ruiz-Sánchez, 2001b; Ruiz-Sánchez etal., 2014) de cuatro tipos:

1. Exterior físico del sistema. El mundo físico fuera de los límites de la ciudad.

2. Sistemas que interactúan con el urbano: legal, político, económico, social, tecnológico, etc...

3. Las parcelas como sistemas elementales interiores al sistema urbano, habida cuenta de su posibilidad de transformación por acción de sistemas humanos.

4. Estructura de comunicaciones interior al sistema.

Cualquier cambio observable en el entorno conduce a un cambio en la organización del sistema, al alterar las acciones racionales que pueden establecerse en torno a cualquier elemento del sistema. Ello implica la autorregulación (Maturana y Varela, 1973) y el carácter informacional (Shannon, Weaver y Vajda, 1950; Margalef, 1980) del sistema urbano. Según Ramón Margalef, la información y la forma se definen como el modo en 
que la energía y la materia se combinan y se expanden por el espacio formando patrones reconocibles (Alexander, 1977; Haken y Portugali, 1995). La forma deriva así de la acumulación de información transmisible y observable de cualquiera de los entornos urbanos, definiendo un estado del sistema, pero no su funcionamiento ni futuro evolutivo, el cual depende de la percepción del mismo.

Aunque en los sistemas urbanos la existencia de canales físicos indica la transmisión de materia y energía, ambas, por la definición anterior tiene una componente informacional. La accesibilidad mutua y la mutua observación no es una condición para que se produzca un intercambio. Cualquier punto de nuestro espacio físico está relacionado con el resto, en el sentido de que es posible la comunicación. No obstante, las comunicaciones no siempre se dan, sino que aparecen relaciones más regulares entre algunos elementos basadas en la idea de accesibilidad y el interés mutuo de los agentes de que un intercambio se produzca. En este interés mutuo efectivamente interviene el azar, pues es imposible predecir el comportamiento de los individuos que habitan el sistema, el entorno, o el comportamiento de los entornos del sistema. Ello implica que en funcionamiento de la ciudad interviene el azar relacionado con la información transmitida en el sistema, produciendo intercambios que podrían ser predecibles por la estructura formal del sistema, pero también por la percepción del mismo por parte de los agentes que lo habitan.

Pero a pesar de ese azar comunicativo y diversidad funcional, la ciudad tiene una organización, y esa organización condiciona de manera teórica el número máximo de estados que puede alcanzar el sistema urbano. En este punto, conviene acotar la definición de estado como una combinación estable de comunicaciones entre elementos con sus funciones definidas.

Ante la imposibilidad de determinar con exactitud los intercambios y transformaciones individuales que vayan a producirse o se estén produciendo, se recurre a la idea de entropía del sistema; en física entendida como el nivel de "desorganización" de sus elementos. Concepto que se aprovechó en la teoría de la información para caracterizar la cantidad de información contenida en un mensaje (Shannon, Weaver y Vajda, 1950) o incertidumbre a la hora de predecir la combinación exacta de elementos que lo componen. En línea con la entropía de Shannon, numerosos autores del ámbito del urbanismo utilizan el índice de entropía o diversidad de Shannon como un indicador de complejidad urbana. Pero hablar de complejidad urbana no se traduce por tanto en hablar de diversidad o variedad de los elementos aislados del sistema. La propia definición de sistema implica una interrelación entre los elementos que lo componen, y dicha interrelación, como se ha dicho anteriormente implica una ley de proximidad y accesibilidad que define las interacciones más probables entre elementos. Asimismo, existen usos mayoritarios y minoritarios, actividades fragmentadas en más unidades y actividades concentradas; es decir, existe un orden estructural. El desorden y la entropía, no pueden ser indicadores de complejidad en un sistema organizado como el urbano, y 
como tal, la ciudad no puede modelizarse como un problema de 'complejidad desorganizada' (Weaver, 1991) como si de un Arca de Noé se tratara [VÉASE Figura 5].

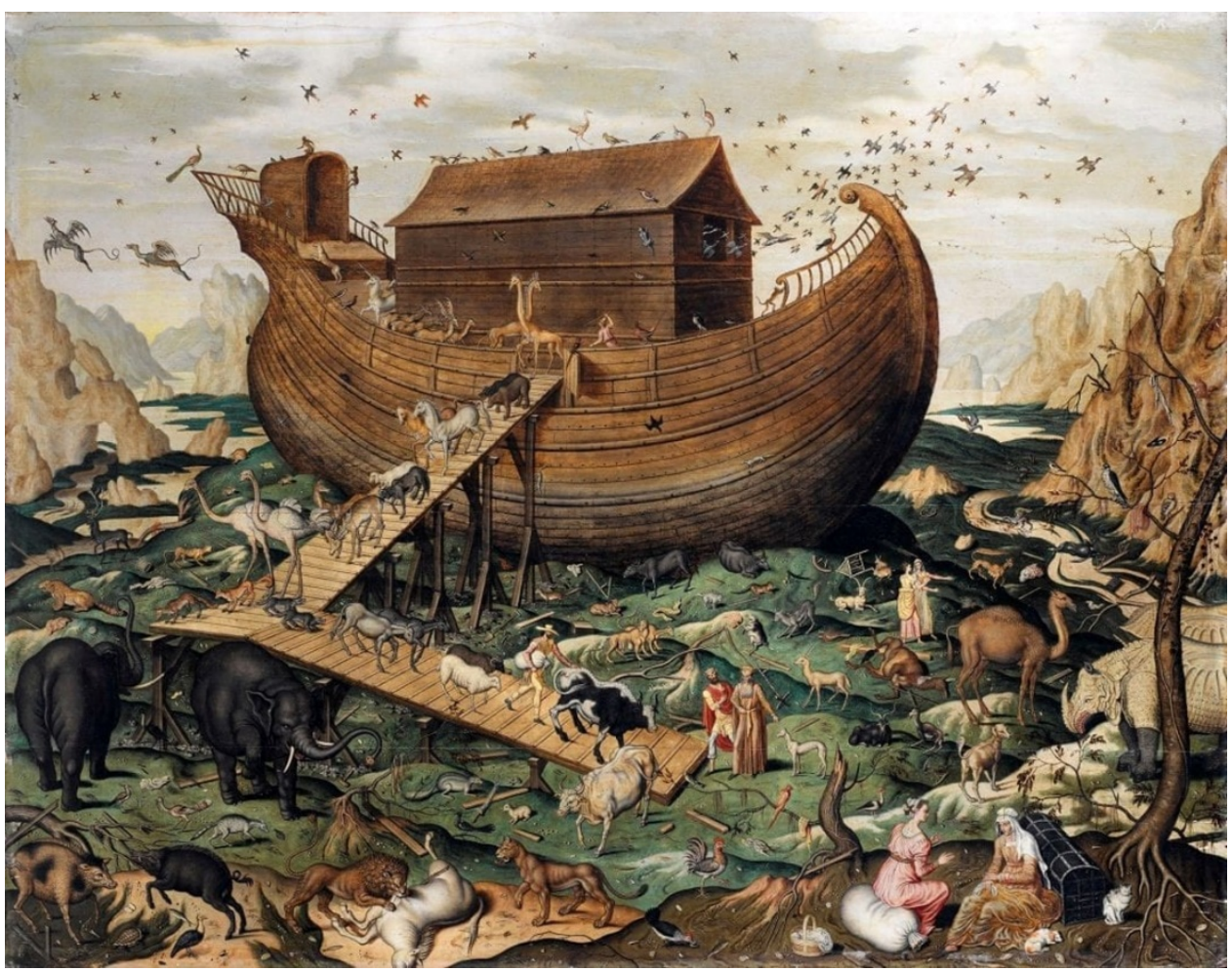

Figura 5. El Arca de Noé sobre el monte Ararat. Simon de Myle (1570). El Arca de Noé representa ur problema de máxima entropía de Shannon, y un ejemplo de complejidad mal entendida. Al haber muchas especies, y el mismo número de especímenes de cada cual, se trata de una distribución con una gran incertidumbre estadística. En una selección aleatoria, es poco predecible conocer de antemano qué animal podría salir seleccionado. Sin embargo, en los ecosistemas naturales no se producen distribuciones de especímenes y especies aleatorias, sino que existe un orden, muchos especímenes de especies pequeñas y pocos grandes.

En esta línea, otros autores definen la complejidad de un sistema como la "cantidad de información necesaria describirlo" (Bar-yam, 2019), hecho que resuena más con los problemas de complejidad organizada que Weaver (ibid. 1991, p. 69) describió como "un conjunto acotable de factores relacionados de manera orgánica". Sin embargo, en una ciudad puede haber problemas de redundancia de la información necesaria para describirla, y la redundancia en la información puede ser un sinónimo de no interacción, dado que no se va a establecer una observación de diferencias. Por ejemplo, en una ciudad dormitorio construida con los mismos tipos edificatorios y ningún espacio para la interacción social.

Otra definición de complejidad relacionada con la teoría de la información es la complejidad algorítmica de Kolmogorov (Grunwald y Vitanyi, 2017), consistente en que un sistema es más complejo en la medida que el algoritmo para reproducirlo es más largo. En el caso de una ciudad, cuanto más regulares fueran sus patrones formales y funcionales, menos complejo sería su orden a pesar de que su tamaño fuera grande - hecho que requeriría de una gran cantidad de información para describirla. 
Por último, y quizás la mejor definición de complejidad sistémica es la proporcionada por Wagensberg (1985), que entiende la complejidad como un problema de diversidad de estados accesibles, permitiendo evaluar sus combinaciones de comunicaciones presentes en base a las múltiples opciones de reconexión internas. La complejidad urbana se presenta como una "incertidumbre probable" (Aquilué Junyent, 2017, p. 87) definible para la ciudad como la variedad de actividades en un ámbito espacial accesible.

Para Margalef, la complejidad urbana se define como el conjunto de variables discretas con contenido significativo de información, de su abundancia, de sus interacciones, y de cómo se integran en el espacio y el tiempo, concluyendo, que un sistema con muchas especies y por tanto más organización tiene un número mayor de circuitos para regular y estabilizar la función global del sistema; hecho relacionado con su resiliencia o capacidad de adaptarse a los cambios de sus entornos.

Surge un desafío teórico y empírico a la hora de seleccionar esas variables discretas con contenido significativo de información para medir su abundancia e interacciones posibles integradas en el espacio. Máxime cuando, como se desarrolla en este capítulo, la información fluye por canales inespaciales que han adquirido gracias a las TIC un carácter geográfico que integra y altera la información espacial de la ciudad.

Este apartado presenta primero una perspectiva sistémica en el urbanismo para acotar el concepto de información acerca de los elementos del sistema urbano -información definida por la variedad morfotipológica en el espacio parcelado, jerarquizada por la red urbana conformada por el vacío entre parcelas. A continuación introduce el problema de la cognición de la información del sistema que por el principio de observación altera el comportamiento de la ciudad y de sus agentes, haciendo de ésta, según Portugali (2006) un sistema cognitivo doblemente complejo.

\subsubsection{La parcela como unidad de información}

Existen cuatro elementos a tener en cuenta en la definición de un sistema: su propósito, sus elementos y sus funciones propias, y las relaciones entre los elementos. Como se ha introducido, la función del sistema urbano es el de proporcionar las herramientas necesarias para que sus habitantes desarrollen su actividad cotidiana. Para lo cual, se inserta en el medio físico - primera diferenciación sistema-entorno- con unas parcelas -segunda definición de entorno- que son colonizadas con edificaciones cuya forma permite el desarrollo de una serie de funciones propias. Estas parcelas se encuentran interconectadas por el espacio no parcelado, que constituye una red más o menos jerárquica de canales físicos por los que se realizan los intercambios de materia y energía con el entorno.

Se habla de un sistema doblemente complejo en la medida que la ciudad evoluciona en tamaño y número de funciones contenidas en su interior a lo largo de la historia, estableciendo conexiones con más elementos de su entorno, y en su interior, el entorno parcelado también crece en variedad funcional y diversidad tipológica, produciéndose un 
proceso de acumulación de información de la ciudad sobre su entorno, y de los elementos de la ciudad en sí mismos. Tanto la ciudad, como los elementos que la componen son sistemas complejos (Portugali, 2006).

La constante adaptación de la ciudad a su entorno produce una acumulación de información que hace que el sistema absorba mejor la incertidumbre del entorno. Con el tiempo, las parcelas y los edificios se subdividen y crecen en variedad. A nivel intraurbano, la parcela define una estructura de la propiedad y la información asociada a ella y a nivel general, la forma de la ciudad se deriva de las relaciones entre parcela y edificación; ámbito de acción del planeamiento. La estructura de la propiedad que se distribuye a través de las parcelas acumula la información que determina gran parte de las posibilidades de transformación del sistema urbano. Esto supone que la distribución de las parcelas y su información urbanística define su función y las relaciones que entre ellas se establecen (Ruiz-Sánchez, 2001b; Aquilué Junyent, 2017).

Esta distribución de información en el espacio, por tratarse de un sistema abierto, no implica una inmutabilidad sino una capacidad de adaptación a las circunstancias del entorno. En la medida que la diversidad funcional, y por tanto la información del sistema es mayor, la ciudad puede absorber una mayor cantidad de alteraciones del entorno externas sin producirse alteraciones significativas en su forma/información.

De este modo se produce un acoplamiento sinérgico entre el sistema y su entorno acumulando transformaciones automáticas o autopoiéticas (Maturana y Varela, 1973) que permiten adaptarse ambos a las circunstancias y necesidades que el otro le impone.

El espacio no parcelado constituye canales físicos por los que la observación de diferencias puede producirse. Una calle se convierte en un canal por el que la materia y la energía fluye, y la información contenida en las parcelas se hace accesible para cualquier observador situado en ella, y en base a ella se motivan las decisiones individuales sobre las posibles actividades y alteraciones en el estado del sistema. Este hecho agrega un nivel de complejidad a la ciudad superior como sistema cognitivo.

\subsubsection{La ciudad cognitiva}

Se ha expuesto la manera por la que el sistema urbano posee un orden generativo basado en su autorregulación. El orden en las ciudades tiene un carácter generativo, lo cual se basado en la percepción, comportamiento y acción de los ciudadanos -y los planificadores- sobre de un contexto, a su vez complejo en el que los procesos naturales, sociales, económicos y políticos tienen lugar (Wirth, 1938; Portugali, 2000, 2006).

Los ciudadanos perciben la información sobre su entorno construido, mientras que los planificadores de la ciudad utilizan herramientas para la planificación y proyección de estados accesibles del sistema a futuro. Quiere decir, que la información percibida por los agentes que habitan el sistema condiciona sus actividades y según su poder de decisión sobre la propiedad inducen transformaciones más o menos significativas de la información contenida en el sistema - desde un propietario que altera un comercio según 
su proyección de lo que el entorno social puede demandar, un propietario de una vivienda que cierra el balcón para ganar metros cuadrados introduciendo una singularidad en una fachada perceptible por el resto de agentes, etc...

Igualmente, el conjunto de alteraciones informacionales producidas desde abajo es más o menos perceptible por quien tiene la responsabilidad de planificar la ciudad y seleccionar el marco de transformaciones legítimas que en la ciudad puedan llegar a darse. Como sistema sociocultural y técnico, las ciudades se encuentran entre la planificación y la autoorganización. Si bien la planificación ex-novo, vertical, y sin asumir la complejidad del sistema ha producido asentamientos con escasa capacidad evolutiva (Alexander, 1964).

Partiendo de la teoría de agentes libres en un espacio celular ${ }^{10}$ (Haken y Portugali, 1995), Juval Portugali (Portugali, 1997) presenta la dificultad de modelizar los sistemas humanos en base a la noción de las propiedades emergentes de los sistemas naturales. Este principio de la emergencia natural se basa a que en base a principios de interacción sencilla entre agentes independientes, emergen sistemas complejos que describen patrones organizativos orgánicos (Simon, 1969).

Pero los sistemas humanos no son naturales y la emergencia (de abajo a arriba) de patrones no se basa en interacciones simples. La complejidad de los sistemas urbanos se inscribe en la complejidad de su entorno y la de sus agentes humanos (Goodchild, 2007) -organismos complejos-, cuya percepción del entorno les conduce a generar mapas cognitivos propios. Estos mapas cognitivos pueden encontrarse en una situación de contraposición o concordancia con los mapas cognitivos impuestos por otros agentes del sistema, lo cual forma una red compleja de maneras de aprehender un objeto complejo como las ciudades.

El proceso evolutivo de las ciudades por tanto quedará determinado por la doble interacción, entre los individuos y a su vez entre sus representaciones cognitivas particulares del espacio social. "Comienza con los agentes que llegan a una ciudad con una imagen preconcebida de ésta (o mapa cognitivo). Con esta imagen en mente, observan la información externa que les proporciona el contexto urbano. La interacción entre estas formas internas y externas de información da lugar a el mapa específico, según el cual el agente toma decisiones de localización y acciones determinadas en la ciudad. Esta última acción implica algunos cambios, tanto en la ciudad como en la información que proporciona al siguiente agente y así sucesivamente en un proceso sinérgico (Hardey, 2007) de causalidad circular" (Portugali, 2006, p. 17).

\footnotetext{
${ }^{10}$ En topología, se entiende como espacio celular aquel en que existen vecindarios colindantes no superpuestos denominados células. Por ejemplo, el espacio por el que se distribuye la señal de los teléfonos móviles. Las comunicaciones entre cualquier teléfono dentro del espacio celular de las antenas son equiprobables.
} 
Es importante entonces reseñar el principio de competición y hegemonía entre órdenes sistémicos. La aparición de nuevos parámetros de interacción -proporcionados natural o artificialmente- externos: por cambios en el entorno del sistema urbano, como puede ser la adopción de una nueva tecnología-, puede determinar el comportamiento individual de los agentes, emergiendo nuevos órdenes en la ciudad que determinarán el comportamiento futuro de los agentes, y subyugando los principios organizativos previos como consecuencia.

Todo ello supone en su conjunto, que la complejidad urbana, entendida como el abanico de estados accesibles del sistema esté condicionada a la comunicabilidad con la información perceptible, natural o artificialmente, del rango de funciones contenidas en los tipos edificatorios y la manera por la que se comunican.

El tipo edificatorio, correspondiente a la unión formal y funcional del binomio parcela edificio (Ruiz-Sánchez, 2001b) contiene información no perceptible, no comunicable, y por tanto condicionadora de las acciones que puedan realizarse en la ciudad en función del medio por el que se percibe. El ejemplo de la batalla de Mogadiscio (Aquilué-Junyent y Ruiz-Sánchez, 2013) revela una asimetría con respecto a la información perceptible del entorno y las acciones derivadas sobre la ciudad. En este caso, la ciudad albergaba en su interior una diversidad de lugares invisible a nivel cenital, es decir, una diversidad de canales comunicativos superior a la aparente [VÉASE FIGURA 6].
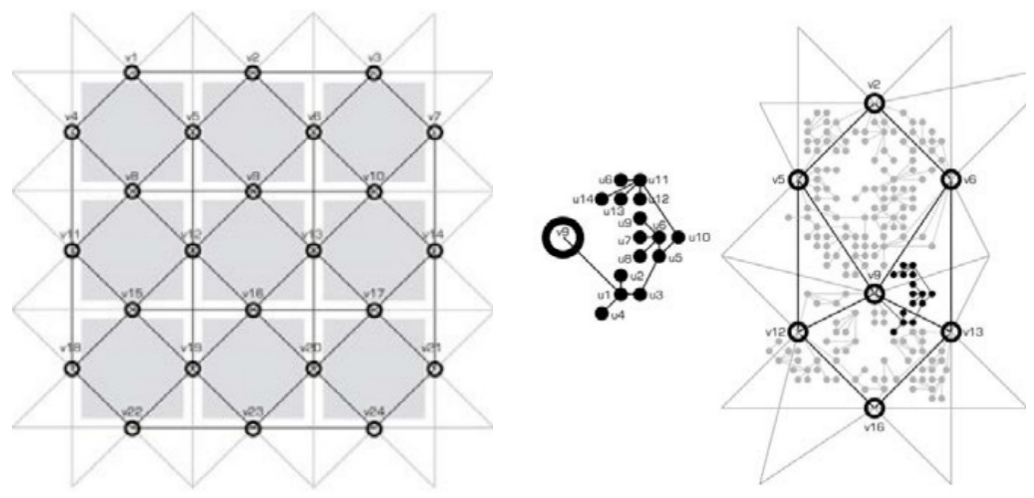

Figura 6. Información visible desde arriba (izda.) versus información accesible a pie de calle (dcha.). La ciudad de Mogadisco tiene una trama viaria ortogonal si se observa desde el aire. A nivel peatonal, la trama ortogonal contiene en su interior una red de comunicaciones oculta que da acceso a la diversidad funcional real del sistema urbano, gracias a la cual se resistió al primer ataque del ejército americano. Fuente: (Aquilué-Junyent y Ruiz-Sánchez, 2013)

Este ejemplo pone de manifiesto la importancia de controlar la información que contiene el tejido edificado y los canales por la que esta se hace accesible. Ahora bien, ¿cuál es el papel de los canales artificiales de transmisión de información sobre la ciudad a la hora de alterar los comportamientos de los habitantes y alterar el abanico de estados accesibles del sistema?

Según Portugali (2011b, pp. 361-362), la información en la ciudad es un fenómeno interrepresentativo en el que una vez se produce una representación de algo se convierte en dominio público construyendo la memoria colectiva del lugar. Una memoria que 
puede construirse y sostenerse mediante artefactos externos, entendibles como "medios" en la definición de McLuhan (1964): "cualquier tecnología que media en nuestra comunicación afectando nuestra percepción y comprensión del mundo que nos rodea” desde los propios edificios, los libros, planes y mapas, y por supuesto, las Tecnologías de la Información y la Comunicación (TIC).

\subsubsection{El espacio no parcelado, la red urbana física, $y$ las redes digitales de comunicación}

Meier (1963) caracterizó las ciudades como entornos bombardeados por mensajes — que alteran el comportamiento de los agentes internos del sistema cualquiera que sea su nivel de percepción del mismo. Entendiendo las parcelas como unidad de información en las ciudades, el espacio, se ha planteado el espacio no parcelado como el tejido conectivo entre dichas unidades de información. Jane Jacobs (1961), argumentó que la ubicación de las cosas constituye la base sobre la que se construyen las redes de relaciones interpersonales - por ende, los intercambios- en las ciudades. Kevin Lynch (1998) identificaba los elementos tangibles que integraban la imagen de la ciudad. Jean Gehl (1987) caracteriza la red urbana de espacios públicos como un conjunto de espacios interconectados entre edificios.

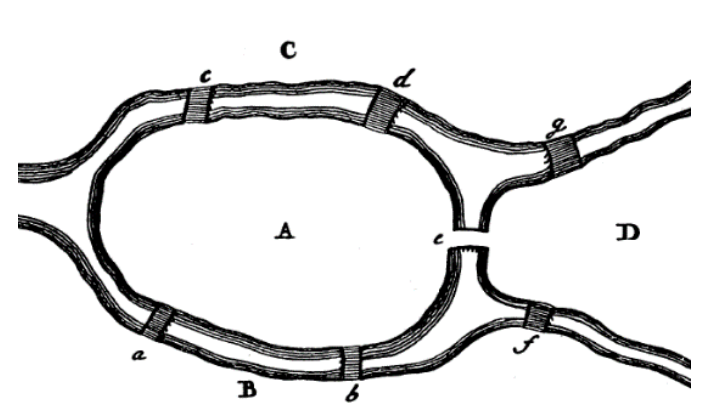

Figura 8. Diagrama de los puentes de Königsberg. Fuente: (Euler, 1736)

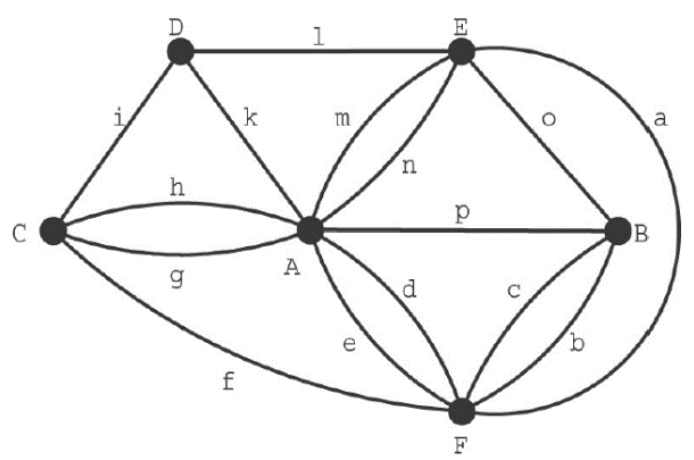

Figura 8. Representación topológica del grafo de los puentes de Königsberg. Fuente: (Hopkins y Wilson, 2004)
Este espacio no parcelado constituye un ámbito perceptivo a la hora de organizar el acceso a parte de la información en la ciudad. La red que constituye condiciona las probabilidades de que se establezcan comunicaciones y relaciones de observación de diferencias y comunicación entre elementos del sistema.

Para el análisis de redes, el urbanismo se ha nutrido de herramientas procedentes de la topología, como la rama de la matemática que estudia las relaciones de continuidad y conectividad entre elementos que componen un sistema.

En el siglo XVIII, Euler fue el primero en aproximarse a la descripción de la estructura de una ciudad a través de las conexiones entre sus componentes. Su obra 'Solutio problematis ad geometriam situs pertinentis' (1736) (en español: solución a los problemas adicionales a la geometría del lugar) caracteriza la estructura urbana de Königsberg (actual Kaliningrado) mediante las posibilidades de comunicación entre las márgenes del río Pregolia determinadas por los puentes que las comunicaban. Este trabajo fue la obra fundacional de la teoría de grafos; la rama de la matemática que estudia las propiedades 
topológicas de las redes. Representables tanto por su geometría cartesiana [VÉASE FIGURA 8], como por su representación topológica en forma de nodos y vértices ${ }^{11}$ [VÉASE FIGURA 8].

La teoría de grafos para entender las redes de comunicaciones urbanas no llegaría a los estudios urbanos hasta bien alcanzado el siglo XX. Cristopher Alexander (Alexander, 1964) presta especial atención a la red urbana de comunicaciones física [VÉASE FIGURA 9]. Esta red puede estudiarse desde su configuración topológica, como herramienta descriptiva y analítica clave para comprender la estructura urbana como un sistema de actividades interconectadas de manera más o menos compleja —-defendiendo las ventajas de la complejidad desde la perspectiva de la evolucionabilidad urbana.
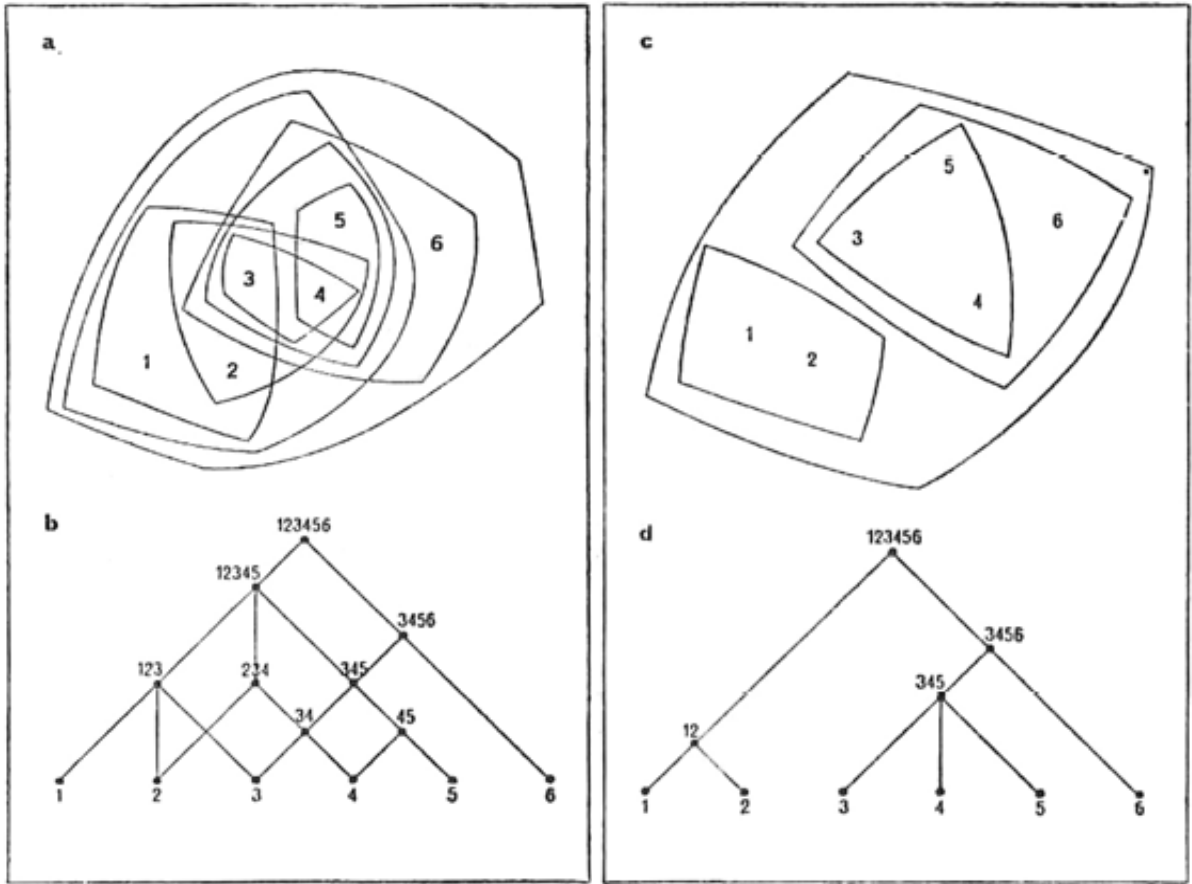

Figura 9. La estructura de semitrama (figuras a y b) frente al árbol (figuras c y d). En una semitrama, el número de interconexiones entre conjuntos de actividades en la semitrama es mucho mayor que en una estructura en árbol. Fuente: (Alexander, 1964)

Salingaros (1998) ahondó en las ideas de Gehl y Alexander ahondando en las ventajas y limitaciones de la representación por grafos de lo que denominó 'red urbana' ('urban web'), sugiriendo soluciones para organizar la complejidad de los grafos complejos defendidos por Alexander.

En este sentido, la complejidad urbana puede entenderse no sólo como una diversidad funcional sino como las relaciones de conectividad que se establecen entre las funciones de la ciudad. La topología de las redes urbanas describe ciertos patrones de las redes complejas libres de escala (Albert y Barabási, 2002) - la existencia de mundos pequeños, o una alta interconectividad entre lugares, la existencia de comunidades, o la desigualdad

\footnotetext{
${ }^{11}$ La primera representación por nodos y vértices de un grafo no la realizó Euler, sino Walter W. R. Ball en 1892; un siglo y medio más tarde (Hopkins y Wilson, 2004).
} 
Sin embargo, no es el sentido de la vista el único que determina esa cognición, ni el espacio urbano un constructo únicamente material; máxime cuando los servicios geolocalizados agregan una capa de información que hace la ciudad perceptible por interfaces muy diferentes al espacio físico-geométrico, constituyendo redes de lugares alternativas, y cada vez más utilizadas a las propias calles.

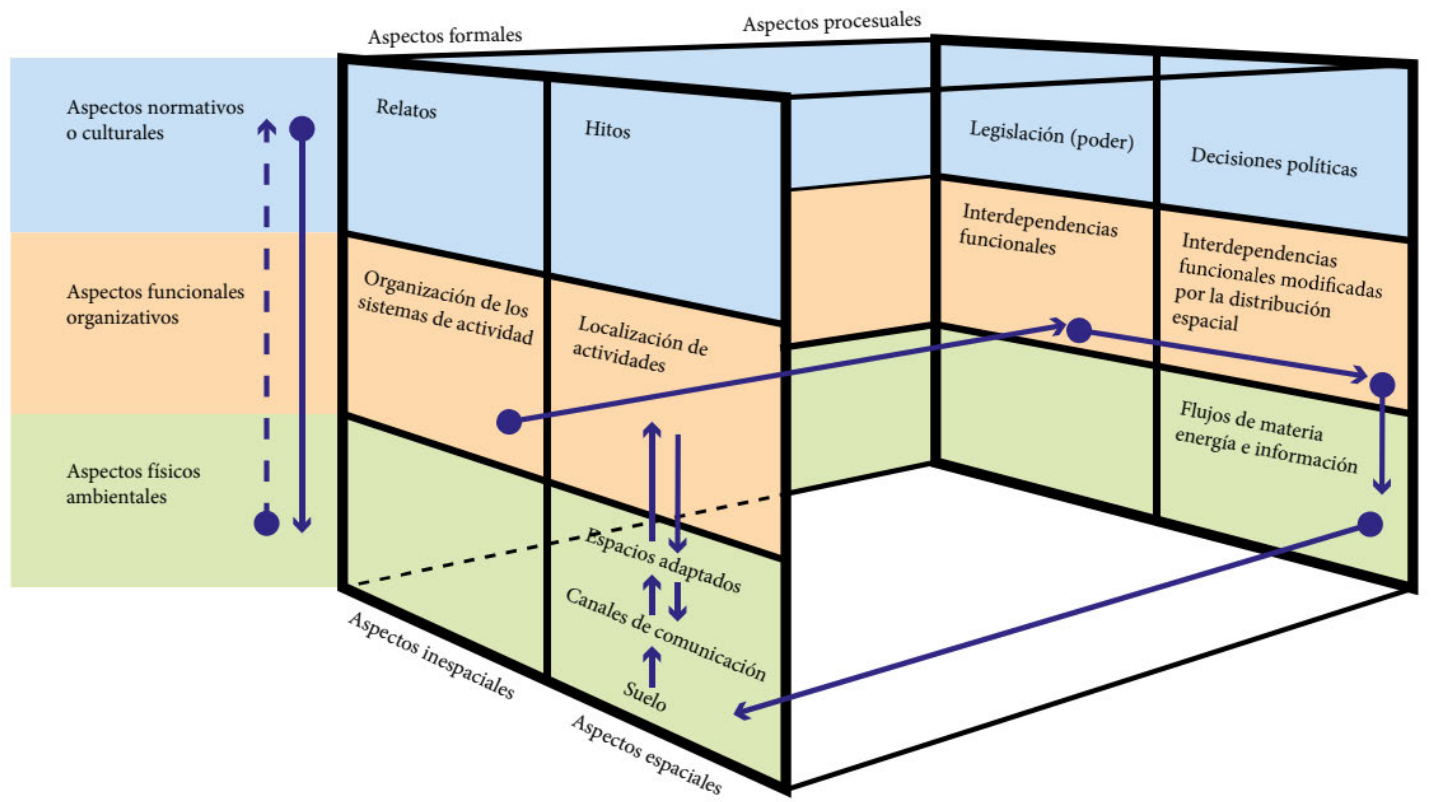

Melvin Webber (Webber, 1964) ya introdujo la idea de 'comunidad sin proximidad'. La existencia de medios de transporte y comunicación tiene el potencial de favorecer unos flujos en el sistema frente a otros. Dos lugares lejanos podrían ser accesibles si el medio que los comunica es más rápido o barato. En consecuencia, tanto la construcción de un sistema urbano en un espacio euclídeo retroalimenta y se retroalimenta de los procesos en el plano topológico subyacente. El autor afirmaba que "los vínculos entre establecimientos forman la malla inespacial de interdependencias funcionales, y definen el modo como estas interdependencias son luego modificadas por las distribuciones espaciales”. Partiendo de esa base, un sistema urbano es una tricotomía de tres dimensiones: física, funcional y normativa cuyas formalizaciones; tanto espaciales como inespaciales, se interrelacionan con procesos subyacentes. En un plano físico espacial, la disponibilidad de superficies de suelo adaptadas a usos determinados e interconectadas mediante canales de comunicación afectaría a la organización de actividades en la ciudad y subsistemas urbanos de actividad caracterizados por interdependencias funcionales tanto lógicas como por aquellas propiciadas por la proximidad o lejanía en el espacio [VÉASE FIGURA 11]. De estas interdependencias emergen patrones en los flujos de materia-energíainformación en la ciudad que retroalimenta la elección de suelos para construir lugares adaptados. 
En la sonada crítica al Space Syntax de Carlo Ratti titulada "sugerencias para el desarrollo del Space Syntax" (traducido del inglés "Suggestions for Developments in Space Syntax") (2005) - resultado de múltiples réplicas en revistas académicas entre el italiano y Hillier. El objetivo del artículo es sugerir cómo las nuevas herramientas podrían continuar en el presente ayudar a responder la pregunta fundacional que el Space Syntax ayudó a resolver en décadas pasadas: “¿cuál es la influencia de la configuración urbana en 'la lógica social del espacio?" (ibid. 2005, p. 83). Por una parte, se identifican inconsistencias en la transformación de geometría a topología de red, y otra relativa a la tridimensionalidad del suelo. Ambas podrían resolverse reajustando el modo por el que el software analiza la geometría del espacio físico. Pero por otra la crítica identifica una limitación de base de este método: la materialidad del espacio y sus interconexiones ante el desarrollo de las TIC - sobre todo tras la llegada de los LBS. La digitalización está produciendo que los objetos y personas interconectados por medios digitales produzca una capa de información digital que se entremezcla con el espacio urbano físico [VÉASE FIGURA 12] para servir a sus habitantes, pero conocer las implicaciones de este fenómeno en lo social, lo espacial y lo económico en gran medida se desconoce, aunque su potencial e impactos disruptivos se hacen progresivamente más evidentes.

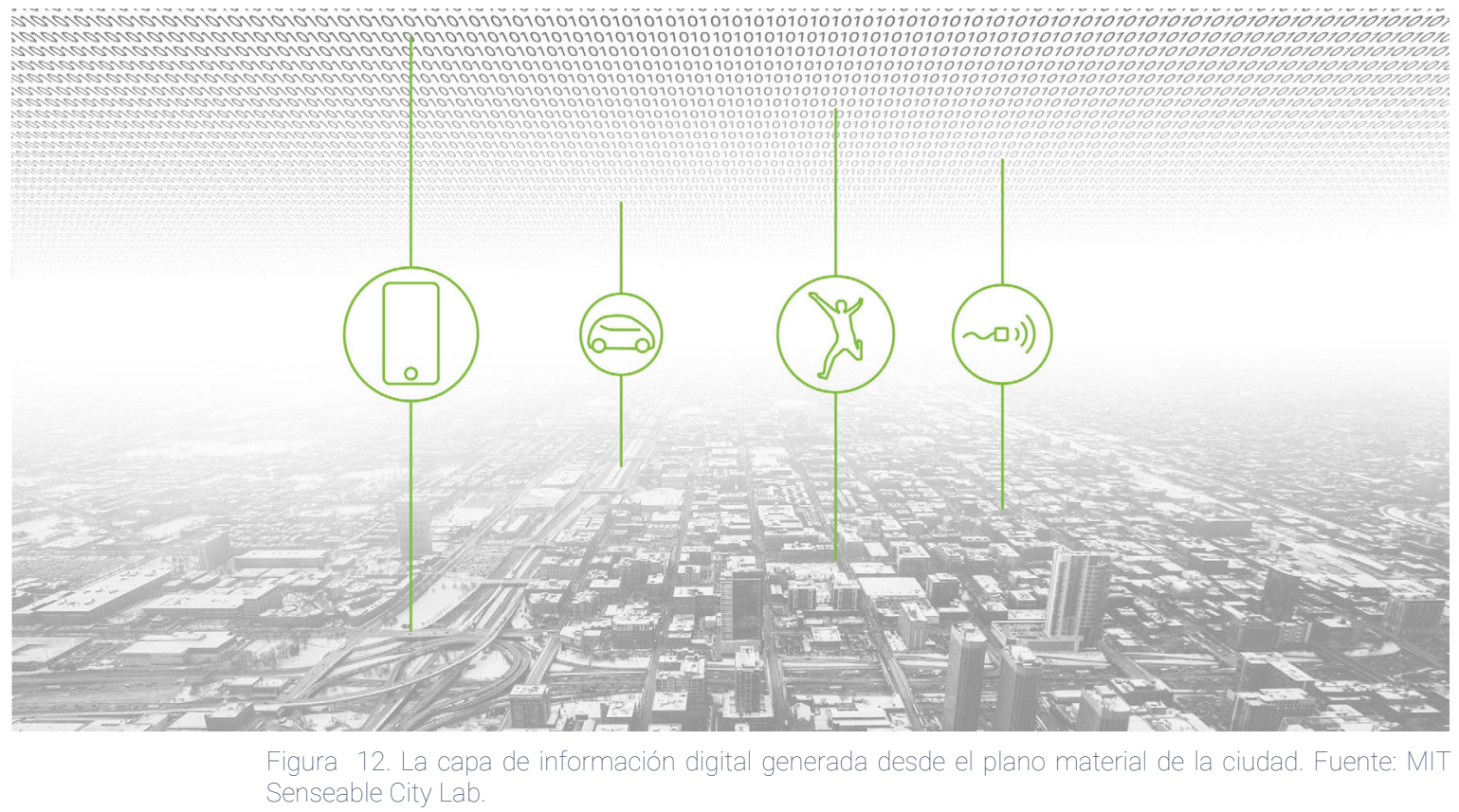

\subsection{Los medios y la ciudad}

Es evidente que las TIC modifican los dominios de acción del individuo, alterando su capacidad perceptiva, estableciendo nuevos espacios de comunicación y socialización. Lo social se ha venido estructurando por las relaciones de poder que consolidaron una 'economía política del cuerpo' consolidada en determinados arreglos espaciales y sistemas de vigilancia y disciplina (Foucault, 1975; Lorente-Riverola, 2015b) capaces de sostener la productividad en la sociedad.

Si la frase de Winston Churchill «modelamos nuestros edificios, por lo que nuestros edificios nos modelan» (1943) ilustraba la lógica social disciplinaria de lo construido, la 
difusión de información disociada de su materialidad impregnó buena parte de la teoría social de los años 60 en adelante.

La tradición de comprender la formación de lo social como un producto de la realidad cognitiva producida por los encuentros cara a cara en el entorno físico (Durkheim etal., 1938) se fue complementando por una sociología de las comunicaciones mediatizadas. Mc Luhan (1964) adaptaría la cita de Churchill «modelamos nuestras herramientas, luego nuestras herramientas nos modelan», mostrando la hegemonía de los medios, ahora convertidos en 'el mensaje' ${ }^{13}$ que rearticula la sociedad modificando sus espacios y procesos de socialización. También acuñó la idea de 'aldea global' en la que los medios afectan a la organización cognitiva y a la organización social. Esta obra resultó influyente de los teóricos de la 'sociedad de la información' (Machlup, Masuda, Tourain, Bell, Porat...) en la que los servicios del conocimiento constituirían el eje central de una economía basada en la información. Esa idea de la sociedad de la información se rearticuló hacia una sociedad del conocimiento; un conocimiento telemático de lo que sucede en el mundo para optimizar su funcionamiento.

En esta línea, surgió la idea de 'ciberespacio' fruto de Neuromancer (Gibson, 1984), una de las obras culmen de la literatura cyberpunk que retrata un mundo virtual, mediatizado por computadoras, que refleja aquello que sucede en el mundo físico. Ante los nuevos paradigmas en un contexto global de transformación de las estructuras industriales y las relaciones sociales, apoyadas en el despliegue y privatización de internet, numerosos autores entre los que destaca Manuel Castells rearticularon la teoría social en torno a la producción y difusión de información que al utilizarse como organizador de la producción y las relaciones sociales adquiere la entidad de recurso económico (Castells, 1996b, 1996a).

La idea de la información y las telecomunicaciones como entes indivisibles del social tomó fuerza durante las teorías de la ciudad informacional, la sociedad del conocimiento, la sociedad red (Castells, 1996b) de la que emana una economía informacional global capaz de transformar la estructura de las organizaciones y actividades físicas a través de la 'topología'14 de la propia red. Esta estructura determina las relaciones de conocimiento, producción y consumo y poder en base a los propósitos para los que se haya proyectado, siendo más flexible y adaptativa a los cambios en el entorno que nunca, y ofreciendo nuevas oportunidades de democracia y participación. Apunta Castells, que 'la red' impone su propia lógica de inclusión, hegemonía y exclusión a los nodos que la conforman.

Internet no se puede entender como un medio cerrado y neutro o carente de jerarquías de poder, sino como un conjunto de infraestructuras y protocolos de comunicación entre

\footnotetext{
13 "El medio es el mensaje" (McLuhan, 1964), ilustra la transformación social propiciada por los medios de comunicación. Significa que las características del medio, y no sólo el mensaje transmitido, constituyen un motor de cambio en las relaciones sociales en la medida que la existencia de un medio condiciona la transmisibilidad de un mensaje y su contenido.

${ }^{14}$ Se entiende como topología de red a la estructura de las conexiones entre los nodos que integran la red.
} 
máquinas (hardware) cuyas funciones son programables (software). Lo que inicialmente se conocía como la World Wide Web, que en su primera versión suponía una comunicación unilateral entre emisor y receptor, permitió por acumulación de funciones la comunicación bilateral entre la audiencia y el emisor (Web 2.0). Tanto esta como todas las innovaciones que consolidaron el compendio de medios que integra internet (páginas web, redes sociales, plataformas, dispositivos conectados...) requieren de una enorme participación multilateral de la sociedad para funcionar y generar valor a partir de éstas.

Siendo cierto que constituye una nueva infraestructura comunicativa mucho más flexible y dotada de oportunidades, sería inadecuado pensar que induce a la homogeneización de los espacios sociales en el mundo, sino más bien a su diferenciación (Brenner, 2019). Internet, como sistema de comunicación sigue poseyendo una infraestructura física para su funcionamiento, y lógicas que rigen las transacciones que orquesta. Las comunicaciones en esta red; si bien se han desligado de numerosas barreras espaciotemporales y políticas, responden a propósitos e intereses determinados, y como tal, se estructuran con arreglo normas.

En línea con McLuhan, y en busca de una aproximación epistemológica más reciente adecuada al grado actual de mediatización, Couldry y Hepp (2016) sostienen que hemos llegado a un punto en que la teoría social debe restructurarse para comprender el rol que juegan los medios contemporáneos en la construcción de 'lo social'. Entienden lo social como un fenómeno comunicativo materializado en objetos, relaciones, infraestructuras y plataformas que hacen posible la comunicación y la reproducción social (Luhmann, 1984; de Greiff, Honneth y Wright, 1997). Lo innovador de su visión es el reconocimiento de un carácter dual de los medios: como una infraestructura versátil articuladora de un complejo abanico de intercambios, y como marco normativo que responde a un propósito. Asimismo, presentan un espacio social mediatizado ${ }^{15}$ como un híbrido físicodigital producido por la digitalización omnipresente de la actividad social.

\subsubsection{La mediatización profunda}

La idea de mediatización profunda o total (Manheim, 1979; Jansson, 2013; Couldry y Hepp, 2016) alude a las formas por las que los medios retroalimentan la transformación y estabilización del orden social. Si todo lo que construye la realidad cotidiana forma parte de procesos comunicativos tecnológicos desde que cuenta con una representación digital propia, el acceso tanto al medio como a aquello que representa queda imbricado en las relaciones de poder que el medio le otorga. Esta mediatización puede considerarse total en el momento que las relaciones de poder establecidas por el medio afectan a más partes de las que comunica el medio directamente. En otras palabras, la mediatización es "el modo por el que otros procesos sociales en una amplia variedad de dominios y niveles se hacen inseparables y dependientes de procesos tecnológicos y recursos de comunicación" (Jansson, 2013).

\footnotetext{
${ }^{15}$ Del inglés 'Mediaspace’o el 'espacio de los medios' (Couldry y McCarthy, 2004a)
} 
Es imprescindible resaltar este aspecto de 'colateralidad' inherente a la idea de mediatización profunda en relación con la arquitectura de sistemas de los LBS y las plataformas digitales. Si un medio digital está transformando, aunque sea momentáneamente el uso de un bien, las personas que también interactúan con dicho bien también pueden verse afectadas por esa transformación, a pesar de no estar utilizando el medio indicado.

Sirva como ejemplo un apartamento anunciado en cualquier plataforma digital de alojamiento turístico. La plataforma otorga al arrendador la capacidad de comunicarse con una comunidad global de viajeros, que otorga nuevas expectativas de rentabilidad a un apartamento. Ello no solo altera la cadena de valor del bien físico - de su alquiler prolongado a una rotación rápida de visitantes-, las relaciones sociales prestablecidas entre casero e inquilino a reemplazar por visitantes, o entre el apartamento y sus vecinos-, sino que los efectos de red implícitos en la arquitectura de la plataforma producen un escalamiento desregulado - a falta de regulación externa. Este escalamiento acelerado por el medio de comunicación produce cambios en el espacio social local, puesto que no se trata de un caso aislado, incrementando las expectativas de cobijar a un nuevo colectivo en un espacio - los turistas en viviendas-, afectando a la composición de determinados barrios cuyo espacio residencial está parcialmente mediatizado por una plataforma emergente. Nadie, ni los propietarios, ni los antiguos inquilinos, ni los vecinos, comerciantes cercanos, ni siquiera la administración local escapa a la configuración social consolidada por la plataforma, sean usuarios o no de ésta.

La mediatización ilustra la restructuración de los sistemas sociales en el contexto tecnológico digital global. Aunque los medios de comunicación no ocuparon un papel relevante en la sociología de sistemas de Niklas Luhmann (1984), pues quedarían enmarcados dentro de los mecanismos de observación del sistema-entorno. Posteriormente, admitió su relevancia en los sistemas sociales a comienzos del siglo XXI (Luhmann y Cross, 2000), como un subsistema autorreferencial dentro de los sistemas sociales; que acumulan y producen información, y desinformación de su entorno según su propia configuración. En otras palabras, enmarca los medios como parte de los códigos técnicos que articulan las operaciones que perpetúan los sistemas sociales.

Si bien esta visión sistémica es parcialmente admisible en la medida que reconoce la importancia estructural de los vínculos comunicativos para la transmisión de observaciones.

\subsubsection{Sobre la autopoiesis y el propósito del medio}

Existe por tanto una dualidad en la comprensión de la sociedad contemporánea que debe tenerse en cuenta, la dualidad 'actante' ${ }^{16}$-red (Latour, 2005) - constituyendo sistemas autorregulados (Maturana y Varela, 1973; Varela, Maturana y Uribe, 1974) cuyo orden

\footnotetext{
${ }^{16}$ Latour utiliza el término 'actante' en lugar de actor (por su identificación con los seres humanos), para reconocer la autonomía de acción de determinados objetos en las redes humano-tecnológicas actuales.
} 
emana de los vínculos orgánicos entre actantes, actores sociales y sus redes- y lo social como un lugar cuyo orden enmarca los campos de acción individuales se encuentran constantemente desafiados los costes, tensiones y contradicciones evidenciados en una realidad cuyas representaciones se han construido y redefinido (Elias, 1939, 1978).

La idea de figuración acuñada por Elias trata de compatibilizar la autorregulación de las redes de interdependencia basadas en la observación, y la comunicación enmarcada en los acuerdos sociales que orientan los propósitos de una acción social.

La ‘figuración' refiere a aquellas redes de actores que orientan su acción hacia un propósito común, de cuyo propósito emanan las relaciones de poder que rigen tal acción (Elias, 1978). Estos dos elementos, red de actores y relaciones de poder u orientaciones de las acciones no son excluyentes, pues los roles emanantes de las relaciones de poder dotan a la red de un significado determinado que permite identificarla como un elemento relativamente autónomo.

En el marco sociológico de esta tesis, una plataforma digital, y por consiguiente aquellos servicios geolocalizados basados en este modelo, se entienden como figuraciones. La plataforma, materializada en el LBS constituye un medio que reúne dos o más partes interesadas en llevar a cabo intercambios autopoiéticos bajo una serie de propósitos compartidos materializados en reglas que acotan el ámbito de acción de los participantes, sus roles, e interacciones legítimas.

Estas nuevas figuraciones, constituyen un sistema comunicativo cuyas dinámicas de comunicación se diferencian de las anteriores, incluso de las plataformas no basadas en la geolocalización [VÉASE TABLA 1]. Si las plataformas utilizan su arquitectura cliente-servidor, existe un interlocutor informático en el proceso comunicativo que en base al propósito de la plataforma acota los fragmentos de información que reciben los participantes (Hepp y Hasebrink, 2014). Este interlocutor se sirve de un conjunto de parámetros definidos para filtrar el contenido que el usuario recibirá, generando una 'situación sintética' (o contexto) de los 'medios orientados' (o plataformas) (Knorr Cetina, 2014). Por tanto, las posibilidades de comunicación de un participante (humano) estarán condicionadas por la arquitectura del medio resultante de las decisiones de diseño tomadas durante su creación (Couldry y Hepp, 2016).

En el momento que la información contextual se dota de una dimensión espacial y temporal, la plataforma global adopta una escala hiperlocal (aquí y ahora) (Radcliffe, 2012), los tiempos y propósitos de la figuración digital se materializan en espacios virtuales y geográficos concretos todavía por explorar. En representaciones intencionalmente parciales del espacio social sobre el cual se despliega la plataforma: la ciudad. 


\begin{tabular}{|c|c|c|c|c|c|}
\hline & $\begin{array}{l}\text { Comunicación } \\
\text { directa (cara a } \\
\text { cara) }\end{array}$ & $\begin{array}{l}\text { Comunicación } \\
\text { recíproca a } \\
\text { través de } \\
\text { medios } \\
\text { (teléfono) }\end{array}$ & $\begin{array}{l}\text { Comunicación } \\
\text { producida por } \\
\text { los medios } \\
\text { (Web 1.0) }\end{array}$ & $\begin{array}{l}\text { Comunicación } \\
\text { mediatizada y } \\
\text { virtualizada } \\
\text { (Plataformas) }\end{array}$ & $\begin{array}{l}\text { Servicios } \\
\text { geolocalizados } \\
\text { (LBS) }\end{array}$ \\
\hline $\begin{array}{l}\text { Constitución } \\
\text { espaciotemporal }\end{array}$ & $\begin{array}{l}\text { Co-presencia en } \\
\text { espacio y tiempo }\end{array}$ & $\begin{array}{l}\text { Separación de } \\
\text { contextos } \\
\text { espaciales (no } \\
\text { temporales) }\end{array}$ & $\begin{array}{l}\text { Separación total } \\
\text { de contextos }\end{array}$ & $\begin{array}{l}\text { Separación total } \\
\text { de contextos }\end{array}$ & $\begin{array}{l}\text { Representación } \\
\text { parcial del } \\
\text { contexto }\end{array}$ \\
\hline $\begin{array}{l}\text { Rango de } \\
\text { significados } \\
\text { simbólicos }\end{array}$ & Indeterminado & $\begin{array}{l}\text { Limitación del } \\
\text { medio }\end{array}$ & $\begin{array}{l}\text { Limitación y } \\
\text { estandarización } \\
\text { del medio }\end{array}$ & $\begin{array}{l}\text { Limitación } \\
\text { relativa y } \\
\text { estandarización } \\
\text { del medio }\end{array}$ & $\begin{array}{l}\text { Limitación } \\
\text { relativa y } \\
\text { estandarización } \\
\text { del medio }\end{array}$ \\
\hline $\begin{array}{l}\text { Orientación de } \\
\text { la acción }\end{array}$ & $\begin{array}{l}\text { Orientado al } \\
\text { interlocutor/es }\end{array}$ & $\begin{array}{l}\text { Orientado a un } \\
\text { interlocutor }\end{array}$ & $\begin{array}{l}\text { Orientado a } \\
\text { cualquier usuario } \\
\text { de Internet }\end{array}$ & $\begin{array}{l}\text { Orientada a un } \\
\text { propósito }\end{array}$ & $\begin{array}{l}\text { Orientada a un } \\
\text { propósito }\end{array}$ \\
\hline $\begin{array}{l}\text { Modo de } \\
\text { comunicación }\end{array}$ & Diálogo & Diálogo & Monólogo & $\begin{array}{l}\text { Interlógica } \\
\text { (participantes y } \\
\text { consultas a } \\
\text { servidores) }\end{array}$ & $\begin{array}{l}\text { Interlógica } \\
\text { (participantes y } \\
\text { consultas a } \\
\text { servidores) }\end{array}$ \\
\hline $\begin{array}{l}\text { Forma de } \\
\text { conectividad }\end{array}$ & Local & Translocal & $\begin{array}{l}\text { Translocal y } \\
\text { abierta }\end{array}$ & $\begin{array}{l}\text { Translocal } \\
\text { semiabierta }\end{array}$ & $\begin{array}{l}\text { Hiperlocal } \\
\text { semiabierta }\end{array}$ \\
\hline
\end{tabular}

Tabla 1. Tipos de comunicación según el medio - Elaboración propia en base a (Hepp y Hasebrink, 2014)

Pero antes de entrar en el marco teórico de la ciudad mediatizada, conviene aclarar las características del espacio social interno de una plataforma digital como ente autónomo de su contexto físico. Ese mediaspace (Couldry y McCarthy, 2004a) o metaespacio (Humphreys, 2012) "como un concepto dialéctico que captura los múltiples niveles por los que las operaciones de los medios contribuyen a la rearticulación del espacio y la sociedad" (Couldry y Hepp, 2016, p. 81).

\subsubsection{Los medios y el espacio social}

Lefebvre presentó el concepto de espacio social es aquel fruto e impulsor de las relaciones sociales. Lo presenta como un ente dialéctico; como producto y productor que soporta las relaciones económicas y sociales, ya que en este se materializa la organización del trabajo, el transporte y flujos de materia y energía en el que convergen las dimensiones interrelacionadas: su representación, percepción y experimentación (espacio concebido, espacio percibido y espacio vivido) (Lefebvre, 1975). Sin caer en el 'networkismo' (Jessop, Brenner y Jones, 2008; Brenner, 2019) originario de las teorías absolutas de la red sobre el espacio a escala global que aseveran que sin la red la vida social sería inconcebible (Castells, 1996b), no se puede negar que el espacio haya adquirido una nueva dialéctica en los procesos de mediatización social.

La incorporación de lo social a las plataformas de internet ha posibilitado establecer comunicaciones remotas recíprocas y continuas entre un rango de lugares y temporalidades casi total ${ }^{17}$, y constituir una forma básica de encontrar y conocer personas

\footnotetext{
${ }^{17}$ Deben tenerse en cuenta que las brechas digitales todavía existen tanto entre grupos de edad como niveles de desarrollo económico de las distintas partes del mundo. Aunque estas brechas se están reduciendo. (Graham, 2015)
} 
(Zhao, 2006; Hepp y Hasebrink, 2014), y por tanto una nueva herramienta de construcción del espacio social 'desde abajo' (Goodchild, 2007). Un espacio híbrido de recintos físicos y redes físicas y digitales que gracias a las plataformas se dotan de una componente, si no pública, común a los participantes de las plataformas (Mitchell, 2003; Lange, 2019).

Asumiendo la dualidad del propósito y la autopoiesis de los usuarios y las plataformas, los efectos de las tecnologías de la información sobre el espacio social no son universalizables. Aun a pesar de existir una literatura extensiva acerca de cómo las telecomunicaciones transforman la estructura espacial de las ciudades (Dadashpoor y Yousefi, 2018; Yousefi y Dadashpoor, 2019), sería un error conceptual de base pensar que el efecto de las TIC sobre la reconfiguración del espacio es unívoco.

Que el espacio social se haya mediatizado (Jansson, 2013), no implica que se haya digitalizado en su totalidad. Lo segundo implicaría que, mantenido sus condiciones topológicas físicas que le dotaron de una lógica social (Hillier y Hanson, 1984), el espacio físico contaría con una réplica digital accesible por una red global de comunicaciones celulares equiprobables y omnipresentes. Lo cual no deja de ser ciencia ficción en la actualidad (Graham, 2015). El espacio social físico ha mantenido sus recintos, ahora embebidos en un espacio celular mediatizado en el que emergen nuevos regímenes socioespaciales de dependencia (Couldry y McCarthy, 2004b; Schwanen y Kwan, 2008; Adams y Jansson, 2012)

La idea de retroalimentación física y digital del espacio - o del espacio y de los mediosse ha abordado por distintos autores cuyas observaciones de su funcionamiento oscilan entre las corrientes antes expuestas que confluyen en la idea de figuración: la autorregulación de un ente híbrido humano/objeto/máquina-red (Latour, 2005) frente al propósito e torno al que articular la capitalización, control y poder que posibiliten la 'producción y reproducción del espacio comunicativo digital' (Foucault, 1975; Thrift y French, 2002; Jansson, 2013).

Las implicaciones de la mediatización del espacio social van más allá de la 'presencia remota' en una red ubicua y carente de propósito. Las nuevas figuraciones digitales constituyen nuevos procesos de diferenciación de los espacios embebidos en las redes comunicativas emergentes (Graham y Marvin, 2001). Cuya programación tiene implícitos los propósitos bajo los cuales se recodificarán las relaciones sociales en el espacio (Schwanen y Kwan, 2008; Kitchin y Dodge, 2011; Kitchin, 2014a; Couldry y Hepp, 2016).

Al igual que el espacio y tiempo sociales se han mediatizado (Couldry y Hepp, 2016), la mediatización ha alcanzado también a la propia información, por lo que la propia producción y acumulación de información también se hará en el marco de las economías del propósito. Dado que la cantidad de información digital producida y almacenada es inaprehensible por medios humanos, se adapta a las particularidades de los medios digitales para extraer valor y conocimiento 'humanizado' de esta. 
La propia digestión de la información por la base de datos cuenta con una estructuración previa. Implica una clasificación de tipos de datos y una estructura previa. Asimismo, el universo de datos digitalizados implica mecanismos de reclasificación y categorización de modo tal que aquello no categorizable deja de ser aprehensible a través de los medios digitales, y aquello erróneamente clasificado inducirá un error en su aprehensión ${ }^{18}$. Esto confluye en una categorización y priorización selectiva; favoreciendo la visibilidad de algunos lugares frente a otros, y con ello de determinados intercambios sociales (Graham y Zook, 2013). En suma, la representación del espacio físico y los comportamientos sociales derivados responderán al propósito de la figuración a la que pertenezcan (Gillespie, 2010, 2014).

Dado que las ciudades son el espacio social donde las plataformas de servicios geolocalizados buscan su despliegue inicial, sus espacios se encuentran insertos en figuraciones contrapuestas que acompasan numerosos cambios de significación, propósito, uso y condiciones de accesibilidad.

\subsection{Alteraciones digitales de la información en el sistema urbano. Los LBS y las plataformas}

Desde antes de la democratización de los smartphones existió un interés por conocer la información contextual del usuario de un dispositivo informático portátil. El paradigma de la computación ubicua expuesto por Mark Weiser en su texto "El ordenador del siglo XXI" (1995) afirmaba que "las tecnologías más profundas son aquellas que desaparecen integrándose en el tejido de la vida cotidiana hasta hacerse inseparables”. Para lo cual, no sólo era necesario disminuir el tamaño de los componentes internos de las computadoras - proceso natural de la evolución de la electrónica según la ley de Moore (1998) ${ }^{19}$ - sino también de dotarlas de la capacidad de no imponer sus códigos operativos propios sobre la vida humana ni el mundo real, es decir, "crear una nueva forma de pensar sobre los ordenadores en el mundo que tenga en cuenta el entorno natural del ser humano [...] en lugar de imponer una 'realidad virtual' donde la única posibilidad de operar con el entorno sea un ordenador [... de modo que] la gente utilice los ordenadores de forma inconsciente para acometer sus tareas cotidianas" (ibid. 1995, pp. 1-2, 8). Para esto, era necesario que el ordenador tuviera la capacidad de comunicar la información que procesa con relación al entorno físico del usuario, para lo que se requerían dos funcionalidades básicas: la

\footnotetext{
${ }^{18}$ Los casos de hackeo de representaciones digitales son ejemplos de este fenómeno. Resulta llamativo el caso de Simon Weckert (2020), quien cargó una carretilla con 99 teléfonos utilizando Google Maps. La plataforma, en base a la velocidad de desplazamiento y al recuento de terminales, determinó que se trataba de un atasco de tráfico, desalentando que otros vehículos en circulación siguieran la ruta por la que transitaba el artista.

${ }^{19}$ La ley de Moore; quien fue el cofundador del fabricante de procesadores Intel, establece que cada año se duplica el número de transistores en un circuito electrónico. Ello implica un crecimiento exponencial de la capacidad de computación, o bien una disminución exponencial del tamaño de los circuitos manteniendo la misma capacidad de computación.
} 
geolocalización y las telecomunicaciones inalámbricas — que no poseían los ordenadores de hace 30 años.

Hasta finales de la década de los 90, las aplicaciones de la computación ubicua resultaban anecdóticas, pues todavía no se había incorporado la capacidad de geolocalización en los dispositivos ni la conexión ubicua a Internet. Sin embargo, dentro del campo de la computación ubicua ya habían aparecido las primeras aplicaciones de lo que se denominaron "servicios adaptados al contexto" o "servicios contextuales" (del inglés "context-aware services"). Estos servicios comprendían la localización de trabajadores dentro de edificios de oficinas para remitir llamadas telefónicas a su ubicación exacta (Want etal., 1992), o guías turísticas (Abowd etal., 1997; Sumi etal., 1998; Cheverst etal., 2000).

\subsubsection{Los LBS como sistema-entorno de la ciudad. Marco tecnológico}

En ese momento surgieron definiciones dentro de la disciplina de la informática sobre las 'entidades' y sus 'atributos', dentro del 'contexto'. Las entidades pueden ser lugares, personas y cosas, como mínimo, poseen atributos de cuatro tipos: identidad, ubicación, estado $o$ actividad (como las propiedades intrínsecas de la entidad), y tiempo entendido como una marca temporal atribuida a cada observación en el sistema. Así pues, el contexto se define como "cualquier información que no requiera de comunicación explícita (como gestos, vínculos sociales, tiempos y lugares) que puedan utilizarse para caracterizar la situación de entidades (personas, lugares u objetos) relevantes para la interacción entre un usuario y una aplicación, incluyendo a los mismos usuario y aplicación” (Salber, Dey y Abowd, 1999; Dey y Abowd, 2000, p. 1).

Sin embargo, hasta el año 2000 no se superaron las limitaciones técnicas de conectividad y ubicación geográfica que Weiser observó como las dos barreras clave para el desarrollo de la computación ubicua. A partir de aquel año, durante la administración Clinton en los EEUU, se democratizaron dos tecnologías fundamentales para el desarrollo de los servicios contextuales, el GPS ${ }^{20}$ (geolocalización) (Spiekermann, 2004) y el GPRS ${ }^{21}$ (conectividad).

En ese momento, y en paralelo a los servicios contextuales surgió el concepto de 'servicios basados en la geolocalización', o brevemente 'servicios basados en la geolocalización'. Sus definiciones se solapan con la de servicios contextuales, pero varían en función de la

\footnotetext{
${ }^{20}$ Dado que el GPS se inventó con fines militares en 1983 por el ejército estadounidense, su precisión estaba limitada intencionadamente por motivos de seguridad nacional. El 2 de mayo del año 2000, la administración Clinton deshabilitó las limitaciones de precisión de los sistemas GPS para la población civil (Zumberge y Gendt, 2001; Huang etal., 2018)

${ }^{21}$ GPRS (del inglés General Packet Radio Service o Servicio General de Paquetes por Radio) consistía en dotar a los dispositivos móviles de conexiones a internet con el protocolo TCP/IP para que pudieran transmitir información digital además de la conexión GSM para la transmisión de llamadas de voz y mensajes de texto. Aunque su desarrollo inicial data de los años 80 , su comercialización se produciría en el año 2000 .
} 
movilidad del usuario con respecto de su entorno y viceversa (Gratsias etal., 2006; Jiang y Yao, 2006), así como de la interactividad que proporcionan a la hora de generar valor a través de la información.

Algunos autores definen los LBS como son aplicaciones informáticas conectadas a internet que permiten consultar información digital sobre el entorno de sus usuarios al contar con la geolocalización del objeto remoto (Gray, 2004; Raper etal., 2007; Huang etal., 2018). De manera más genérica, otros autores los definen como "servicios de la información dependientes de datos geográficos destinados a usuarios de redes móviles" (Shiode etal., 2002), o "la entrega de datos y servicios de la información donde el contenido de los mismos está adaptado a la ubicación y el contexto del usuario" (Brimicombe y Li, 2009).

Conviene subrayar las diferencias entre estas definiciones y los 'servicios de localización' (del inglés "LoCation Services" (LCS)), o los 'servicios informativos' con respecto de los 'servicios funcionales' (Virrantaus etal., 2001) como aquellos que únicamente permiten la consulta de datos del contexto -típicamente los servicios de mapas de primera generación, en los que la única entidad en movimiento es el propio usuario. Un LBS puede considerarse un capacitador, ya que añade valor a la información geográfica proporcionada por un LCS posibilitando determinadas interacciones con terceras partes (Spiekermann, 2004; Pontikakos, Glezakos y Tsiligiridis, 2005; Wang, Min y Yi, 2008; Xu etal., 2009; Abbas, Michael y Michael, 2014; Cheung, 2014; Ryschka, Murawski y Bick, 2016) -por ejemplo, reservar una mesa en un restaurante cercano a través de una aplicación móvil (LBS) en lugar de utilizar Google Maps para consultar el teléfono del restaurante (LCS) y realizar la reserva por medios convencionales. Por ello, se espera que los LBS ofrezcan un nivel más de utilidad con respecto a los LCS, lo cual incide en un mejor encaje socio-tecnológico (Junglas y Watson, 2008).

Teniendo en cuenta las definiciones presentadas, y dado que la información geográfica es necesariamente contextual, una definición operativa para el conjunto de servicios geolocalizados es "aquellos servicios digitales diseñados para implementarse en entornos de computación ubicua que operan en base a la información contextual de su conjunto de usuarios de modo tal que se genere un valor añadido a la información del contexto". Esta definición refleja la vocación de integración de la informática en todo ámbito social cotidiano a través de la miniaturización y la conectividad inalámbrica a internet, y la complejidad implícita en la idea de contexto: todos los lugares, personas y objetos representables digitalmente, y cuya representación digital al menos contenga su identidad, situación geográfica y temporal, amén de las propiedades intrínsecas de la entidad en función del propósito del servicio.

\subsubsection{Arquitectura del sistema}

Para diferenciar un LBS de otros tipos de aplicación móvil es conveniente analizarlo por las tecnologías que convergen en él. Estas son las comunicaciones TCP/IP (internet), la geolocalización, los servicios móviles, y los Sistemas de Información Geográfica y bases 
de datos espaciales (GIS por sus siglas en inglés), que permitieron el desarrollo de bases de datos espaciales, servicios de localización, y el GIS online adaptado a dispositivos móviles; tecnologías ampliamente implementadas a la fecha [VÉASE Figura 13] (Pontikakos, Glezakos y Tsiligiridis, 2005; Steininger, Neun y Edwardes, 2006; Brimicombe y Li, 2009).

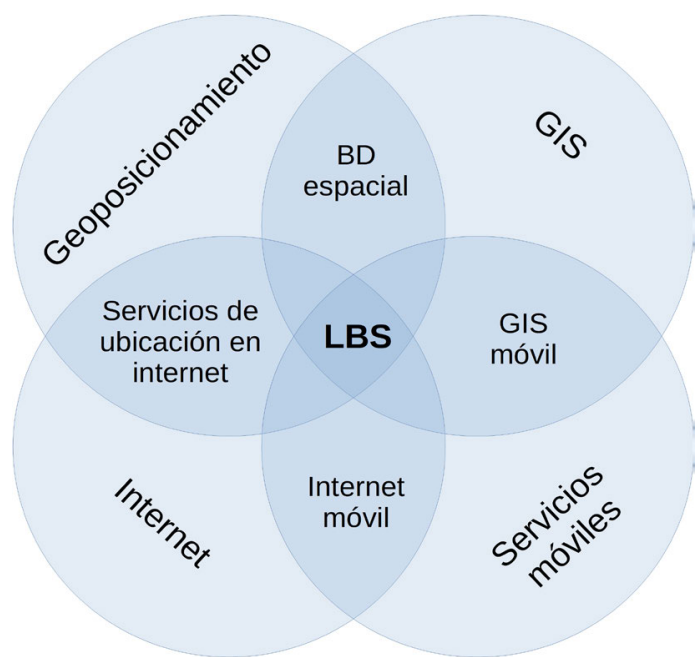

Figura 13. Convergencia tecnológica en los LBS - Fuente: (Brimicombe, 2002; Pontikakos, Glezakos y Tsiligiridis, 2005; Brimicombe y Li, 2009)

La arquitectura de los sistemas informáticos para acoger la enorme cantidad de información generada en un LBS - teniendo en cuenta su variabilidad geográfica, y temporal, y de formatos- es muy diversa. Por caer fuera del campo de interés de esta tesis, y porque inciden sobre una sola tipología de servicio para los usuarios finales, en esta revisión no se van a tener en cuenta las distintas arquitecturas de sistemas informáticos que puedan utilizar los LBS - se aporta un resumen en el [ANEXo II].

En resumidas cuentas, la arquitectura de un LBS tiende a basarse en un sistema de clienteservidor. La parte cliente (generalmente los usuarios finales), utiliza una aplicación de programación generalmente sencilla para crear y consultar información geográfica almacenada en un servidor remoto, que almacena los datos y define los protocolos de acceso a los mismos, tanto por parte de los usuarios, como por parte de sistemas externos al servicio, que pueden hacer uso de la información que existe en la base de datos para desarrollar nuevos servicios en base a ésta -como se desarrollará en el apartado [2.4.2.2 LA PLAZA, LA RED, Y EL ECOSISTEMA].

En definitiva, un LBS conforma un sistema complejo, generalmente abierto, integrado por una masa de usuarios que interactúan en un entorno común de datos digitales almacenados de forma remota, cuyo valor depende de que los usuarios vean en este sistema una utilidad. Por ser abierto, el servidor puede ser accedido por terceras partes ajenas al servicio, acrecentando su valor desde el entorno del sistema, bien proporcionando información para su funcionamiento, o bien aportando recursos económicos para utilizar su información. 
Pero al igual que el sistema tiene inputs, produce outputs en los sistemas urbanos en los que se insertan, acumulando información de los mismos -dónde se encuentra la población y parte de las actividades que se producen en el sistema urbano, observadas desde dentro- y teniendo la capacidad de transformar el significado de esta información según el propósito de cada servicio ${ }^{22}$ - una vivienda en AirBnB se convierte en una hospedería, en Wallapop en un mercadillo de segunda mano, en Facebook en una sede social de una empresa, etc...

\begin{tabular}{ll} 
Necesidades de investigación & Maduración \\
\hline Urgentes (2007): & \\
\hline Posicionamiento en interiores y fusión con otros sensores además del GPS & En curso \\
Privacidad & En curso \\
Redes sociales & Maduro \\
Gestión de contenidos geoespaciales & Maduro \\
Desarrollo de arquitecturas y plataformas & Maduro \\
Sistemas de búsqueda & Maduro \\
Desarrollo interfaces diferentes al mapa & Maduro \\
Modelos productivos y de negocio & Maduro \\
Diseño de modelos de interacción & Maduro \\
Modelos de navegación de vehículos & Maduro \\
Soporte institucional a la investigación y aplicaciones & En curso \\
Próximos (2007)/ Actuales (2018) & \\
\hline LBS basados en la web semántica & \\
'Arranque en frío' (falta de comunidad de usuarios inicial) & Temprano \\
Métodos de filtrado de información relevante & En curso \\
Soporte de orientación & En curso \\
Estándares de calidad & En curso \\
Veracidad de la información & Temprano \\
Comercio móvil & En curso \\
Creación de mapas personalizados & En curso \\
Perfilación de usuarios & Maduro \\
Sensibilidad a contextos mayores (socioeconómicos, medioambientales...) & Maduro \\
Modelos de negocio de los LBS & Temprano \\
Extracción de lugares naturales en base a los datos de los usuarios & En curso \\
Largo plazo (2007) /Próximos (2018) & En curso \\
Teorías geográficas para los LBS y la movilidad & \\
El espacio social de los LBS & Temprano \\
La crítica a los LBS (economía, privacidad, medio ambiente...) & En curso \\
\hline
\end{tabular}

Tabla 2. Necesidades de investigación según (Raper et al., 2007), (Grifoni, D’Ulizia y Ferri, 2018) y (Huang et al., 2018) y estado de maduración de la cuestión - Elaboración propia

En suma, la literatura sostiene la hipótesis de que los servicios geolocalizados forman ya parte de la realidad cotidiana y se han integrado en las ciudades en todo el mundo. Cada LBS forma parte de un ecosistema social de escala global; quiere decir que forma parte del entorno tecnológico del sistema urbano, y por tanto su integración armónica en este dependerá, por un lado, de crear una disrupción positiva en la que se aporte valor a sus

\footnotetext{
${ }^{22}$ Para más información sobre los tipos de servicios basados en la geolocalización, ver Anexo I Taxonomía de los LBS
} 
integrantes, y por otra, de controlar las disrupciones o interacciones negativas con el sistema social en el cual se introduce.

Como se verá a continuación, su estado de madurez tecnológica (Raper etal., 2007) [VÉASE TABLA 2], ha relegado lógicamente a un segundo plano el estudio de los mismos como una estrategia productiva -conocida como 'plataforma digital'(Gawer, 2014).

\subsubsection{La economía de las plataformas. Marco socioeconómico}

Teniendo en cuenta el papel de intermediario que juegan los servidores remotos, gestionados por compañías digitales en la arquitectura de los LBS -almacenando los datos proporcionados por los clientes, incorporando datos de fuentes externas, y liberando al hardware del cliente de las pesadas tareas de procesamiento de modelos complejos de información contextual en sus consultas-, el modelo productivo en el que pueden inscribirse este tipo de servicios es la plataforma digital.

En el contexto de esta investigación, una plataforma digital se define como un árbitro ${ }^{23}$ tecnológico que media entre dos o más grupos de participantes diferentes ${ }^{24}$ con intereses complementarios, facilitando que, a través de ella, se realice una actividad económica (Eisenmann, 2006; Eisenmann, Parker y Van Alstyne, 2006; Dhar y Sundararajan, 2007; Srnicek, 2017; Karhu, Pajulahti y Syd, 2018). Esta definición diferencia las plataformas digitales de otras organizaciones destinadas a la provisión de servicios remotos a través de cadenas de distribución y de valor verticales - en las que el productor persigue atraer el máximo número de consumidores para maximizar su beneficio, así como colectivos sociales, redes físicas de distribución, o distribuidores tradicionales (Benkler, 2006; Eisenmann, 2006; De Reuver, Sørensen y Basole, 2018). También excluye las denominadas plataformas industriales en las que distintos fabricantes participan para la fabricación de un producto (Cusumano y Gawer, 2002; Gawer, 2014). Sin embargo, conviene estudiarlas como antecedentes de las plataformas digitales que soportan la cadena de valor de los LBS como servicios que interrelacionan a los participantes de una actividad determinada (Evans y Schmalensee, 2016).

\subsubsection{De la plataforma industrial a la plataforma digital}

La separación de los agentes económicos con respecto de los medios de producción que garantiza la máxima reducción de costes para mantener la competitividad en un mercado global, se ha apoyado en la sofisticación tecnológica para optimizar las transacciones de la cadena de valor de un producto o servicio (Srnicek, 2017). La red, se convertiría en la

\footnotetext{
${ }^{23}$ Se ha seleccionado el término árbitro intencionadamente, para eliminar del vocabulario la concepción de que una plataforma digital es un intermediario. Su arquitectura está planificada, las interacciones que posibilita, aunque autorreguladas en su nivel más básico, están catalizadas por los roles asignados por la compañía que gestiona la plataforma.

${ }^{24}$ Desde la perspectiva del propietario de la plataforma (y la infraestructura informática que la soporta), todos los participantes en ésta son clientes. Sin embargo, en el interior de la plataforma convergen un mínimo de dos grupos: productores y consumidores (Kornberger, Pflueger y Mouritsen, 2017)
} 
tecnología garante de un "capitalismo sin fricciones" aclamado por Bill Gates, que aceleraría y optimizaría los procesos de financiación, innovación y producción de conocimiento y bienes, y por supuesto los intercambios comerciales repletos de intermediarios que encarecían el coste de los bienes de consumo. La "Carta Magna para la Era del Conocimiento", demandaba acceso universal a un ciberespacio integrado por información mercantilizada sobre el que renovar 'el sueño americano' para el siglo XXI (Dyson etal., 1994; Schröter, 2016).

En una economía globalizada post-industrial capitalista, el procesamiento de la información se ha convertido en una actividad estratégica para la productividad y la competitividad. Mas allá de una transformación de los productos, la información a través de los procesos comunicativos digitales permite la difusión de conocimiento necesaria para la optimización del rendimiento de los sistemas productivos. La revolución del producto industrial de la primera mitad del siglo XX se sucedió con la 'revolución de la información' en la que las TIC, una vez se hicieron más asequibles, favorecieron nuevos procesos de innovación y producción abierta, nuevos canales logísticos globales y nuevas estrategias de comercialización (Castells,

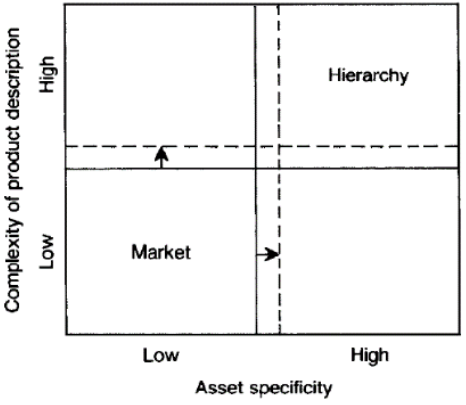

FIGURE 1. Product Attributes Affect Forms of Organization Fiqura 14. Jerarquías y mercados seqún los atributos del producto. - Fuente: (Malone Yates y Benjamin, 1987) 1996b; Keen, 2015; Alfonso Sánchez, 2016).

Esta emergencia del capitalismo mediado por las TIC se sostiene en la literatura académica sobre las nuevas estrategias de desarrollo y producción de productos de la década de los 70 del siglo XX. En ella se estudiaban las plataformas industriales como estrategias de organización óptimas para el desarrollo de productos en entornos productivos de grandes intercambios de información. Las plataformas trataban de descentralizar la producción creando alianzas comerciales entre compañías que se especializarían en el desarrollo de componentes aislados de un producto base.

Si la producción y comercialización de un bien o servicio resultaba complejo y/o estaba ligada a un espacio, tiempo, o conocimiento determinados, o bien a su vez entraña complejidad en su descripción su modelo productivo tendería a materializarse a través de jerarquías rígidas representadas por firmas, las cuales Chandler (1977), identificaba como hegemónicas en el transcurso de la economía del siglo XX. Sin embargo, Malone, Yates y Benjamin (1987) desafiaron esta observación de la hegemonía de la firma en el modo de producción industrial del siglo XX apoyándose en la hipótesis de que el progreso digital favorecería las comunicaciones entre agentes y que por tanto un número de actividades productivas crecientes podrían organizarse como los mercados [VÉASE FIGURA 14] -es decir, externalizando al máximo la producción y socializando sus riesgos (Greenfield, 2015). De este modo, los elevados costes de organización e innovación dentro de una firma jerárquica para la fabricación de productos complejos se minimizarían -economía del propósito frente a la economía de la escala (Chandler, 1977; Panzar y Willig, 1986; Malone, Yates y Benjamin, 1987; Nickolas, 2019) 
Teniendo ello en cuenta, una plataforma industrial se refiere a un conjunto de recursos (componentes, procesos, conocimiento, personas y relaciones) comunes a la producción de un conjunto de productos, cuyas interacciones se han planificado intencionadamente hacia un propósito, de modo que se optimicen los costes de producción e innovación que supondría el desarrollo de tal producto bajo la estructura jerárquica de una firma (Robertson y Ulrich, 1998; Muffatto y Roveda, 2002; Gawer, 2014). Una plataforma se compone por tanto de un producto base, que satisface las necesidades de un grupo de clientes abierto a su personalización y posterior comercialización por terceros. Por ello, la estrategia de plataformas se consideran basadas en el mercado dado que invitan a la interacción múltiple de productores y consumidores (Kornberger, Pflueger y Mouritsen, 2017).

La industria de las TIC de consumo es un claro ejemplo de este tipo de organización. Los bienes, tanto tangibles como intangibles que produce requieren de entornos relativamente flexibles de innovación, y sistemas de producción distribuida que integren componentes diseñados y producidos por fabricantes diversos en cada producto. La estrategia de la plataforma ha permeado profundamente esta industria de maneras más que diversas, que abarcan entre otros campos el comercio de bienes de consumo, al desarrollo de software, al acceso a servicios de computación -ahora distribuidos a través de 'la nube'-, y por supuesto al acceso a recursos físicos en el espacio a través de servicios geolocalizados.

Si las plataformas industriales podían describirse como alianzas temporales entre agentes para la producción de un bien tangible bajo una jerarquía de diseño coordinadora de la acción o arquitectura del producto (Clark, 1985; Ulrich, 1995), las plataformas digitales son entornos ligados a la industria de las TIC -que integran hardware y software-que modulan las interacciones posibles en una actividad no necesariamente ligada a la producción de bienes tangibles (Tiwana, Konsynski y Bush, 2010; Ghazawneh y Henfridsson, 2015; Kenney y Zysman, 2016; De Reuver, Sørensen y Basole, 2018) sino a su comercialización, reutilización, y optimización o aprovechamiento de su capacidad de carga (Gansky, 2010; Yoo, Henfridsson y Lyytinen, 2010).

La misma diversidad funcional de los servicios geolocalizados se pone de manifiesto en la literatura sobre plataformas digitales (Schor, 2014; Kenney y Zysman, 2016; WEF y PWC, 2017) siendo también inoperativo clasificarlas por su sector de aplicación (Owyang, Tran y Silva, 2013; WEF y PWC, 2017) por la rápida transformación del sector, es más conveniente atender al tipo de relaciones productivas que favorecen. Dejando al margen las plataformas industriales de la "industria 4.0" y las de desarrollo de software/hardware (Srnicek, 2017) la taxonomía de las plataformas que soportan los LBS [VÉASE ANEXO I] pueden reducirse a tres categorías en función de las relaciones entre los proveedores de contenidos o servicios que favorecen [VÉASE TABLA 3].

Los cuatro tipos de plataforma digital ponen de manifiesto su vocación de mercantilizar la entrega de servicios que previamente se encontraban altamente jerarquizados. Las 
definiciones estudiadas hasta ahora proceden del campo de la organización industrial y se han mostrado útiles para para comprender, tanto la complejidad material y organizativa implícita en los LBS como la versatilidad de su organización que no favorece la comprensión formal de una estructura productiva tan abstracta (De Reuver, Sørensen y Basole, 2018) que sin embargo se está imponiendo como hegemónica (Karhu, Pajulahti y Syd, 2018; Schenker, 2019) debido a las peculiaridades de una arquitectura que propicia su crecimiento acelerado.

\begin{tabular}{|c|c|c|c|}
\hline Tipo de plataforma & Descripción & $\begin{array}{l}\text { Vínculos } \\
\text { productivos }\end{array}$ & Ejemplos \\
\hline Publicitaria & $\begin{array}{l}\text { Evalúan las interacciones de sus usuarios para } \\
\text { distribuir publicidad hacia audiencias segmentadas. }\end{array}$ & PCe-PD & $\begin{array}{l}\text { Google, Facebook, } \\
\text { Redes Sociales... }\end{array}$ \\
\hline $\begin{array}{l}\text { Alquiler de recursos } \\
\text { propios }\end{array}$ & $\begin{array}{l}\text { Alquileres de recursos propios que posee la } \\
\text { plataforma a usuarios finales. }\end{array}$ & PD-PCi & $\begin{array}{l}\text { Lime, Car2Go, } \\
\text { AWS... }\end{array}$ \\
\hline $\begin{array}{l}\text { De servicios externos / } \\
\text { mínimas }^{25}\end{array}$ & $\begin{array}{l}\text { Proporcionan servicios de compraventa y alquiler } \\
\text { de bienes y servicios personales no poseídos por la } \\
\text { plataforma }\end{array}$ & $\begin{array}{l}\text { PCi- PCi } \\
\text { (comisión de } \\
\text { servicio a PD) }\end{array}$ & AirBnB, Uber... \\
\hline Híbridas & $\begin{array}{l}\text { Dedicadas a la venta de productos propios y de } \\
\text { terceros articulando los procesos logísticos }\end{array}$ & PCi-PD-PCe & Amazon \\
\hline
\end{tabular}

\subsubsection{La plaza, la red, y el ecosistema}

Un aspecto que se repite en la literatura económica sobre las plataformas digitales es su descripción como mercados a dos o más bandas. El papel de la plataforma en esta corriente pone de manifiesto que la plataforma constituye un espacio relacional sin el cual no serían posibles los intercambios que favorecen —o serían mucho más costosos- (Evans, 2003; Rochet y Tirole, 2003; Evans y Schmalensee, 2016).

Dentro de esta corriente, a menudo se traza la analogía - a todas luces aventurada- de las plataformas digitales y la plaza medieval de mercado, dado que productores y consumidores se reunían en este espacio para realizar intercambios sin intermediarios que dificultaran o encarecieran el comercio. La plaza constituía un entorno de intercambios productivos simbióticos: cuantos más vendedores reuniera la plaza, más compradores acudirían a ella, y viceversa - lo cual incrementa el valor de uso de la plaza como infraestructura comercial.

Pero las plazas, dada su materialidad y relativa inmutabilidad a lo largo del tiempo no cuentan con las características advertidas por la bibliografía economicista de las plataformas digitales (Gawer, 2014) que evidencian el carácter sistémico de las plataformas y los LBS como parte del entorno tecnológico del sistema urbano - entorno

\footnotetext{
${ }^{25}$ Esto es una traducción del término en inglés 'lean platforms'(Srnicek, 2017), se refiere a aquellas plataformas que poseen el mínimo de activos posibles para posibilitar su funcionamiento.
} 
número 2 según (Ruiz-Sánchez, 2001b): la interacción directa y satisfactoria entre participantes, los efectos de red, la autorreferencialidad y la modularidad.

\section{COMUNICACION DIRECTA, INTERACCIÓN PRODUCITVA -EL PROPÓSITO}

La primera de estas características no quiere decir que fuera de la plataforma las partes implicadas no tengan acceso a una comunicación directa, sino que a través de esa plataforma incrementan sus posibilidades de que se produzca de manera satisfactoria. La tecnología informática adaptada al contexto evalúa las circunstancias de los participantes para favorecer las relaciones más productivas -en base a la ubicación geográfica, las preferencias de los usuarios, las descripciones de los productos, etc...

La plataforma no solo actúa como un 'emparejador' sino como una infraestructura evaluativa (Kornberger, Pflueger y Mouritsen, 2017), pues las partes pueden evaluarse mutuamente para garantizar para garantizar el funcionamiento adecuado de la plataforma. Ambos factores contribuyen a la economía del propósito antes apuntada - p. ej. para encontrar un taxi en una calle residencial de un único carril, lo más efectivo es que utilice una aplicación que llame al taxista evitando acudir a una calle más transitada, la acumulación de valoraciones negativas del pasajero o el taxista contribuye a la expulsión de la plataforma.

Esta es la primera diferencia entre la plaza y la plataforma digital. A diferencia de las plazas, una plataforma tiene un propósito único, y a pesar de su versatilidad, resulta complicado reprogramar el propósito originario para el que una plataforma se ha concebido.

\section{EFECTOS DE RED - LAS INTERACCIONES SINÉRGICAS}

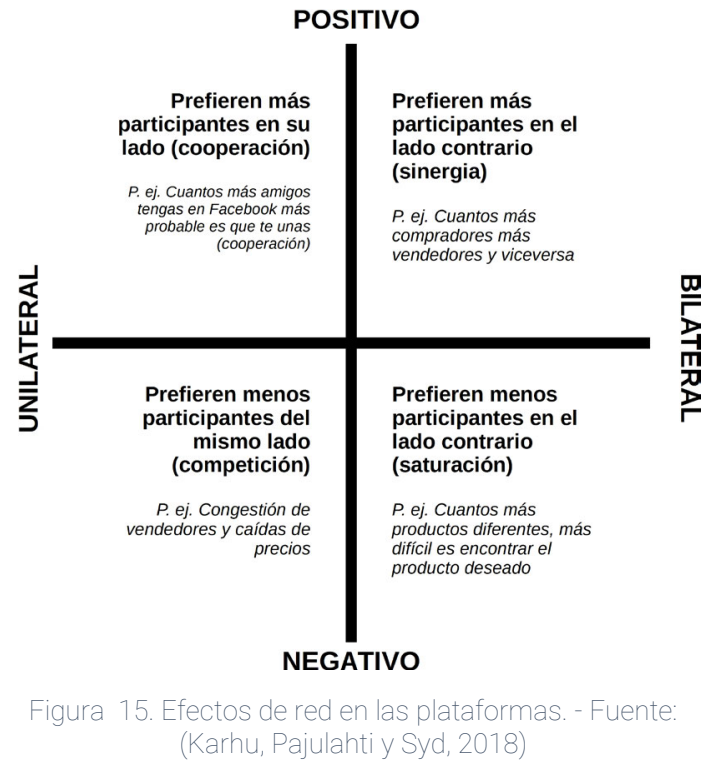
de su número de usuarios (Metcalfe, 2013).

Igualmente, para que una plataforma funcione tiene que poseer una escala tal que ambas partes se atraigan, y de la mutua atracción entre participantes surge el escalamiento de la plataforma. Esta retroalimentación basada en las codependencias se conoce como efectos de 吕 red.

A diferencia de la plaza medieval; cuya capacidad de escalamiento estaba limitada por su forma relativamente estable a lo largo de la historia- las plataformas digitales se sirven de la inaparente capacidad del ciberespacio. Si la miniaturización de la tecnología ilustrada en la ley de Moore hizo posible la aparición de una informática cada vez más pequeña y ubicua, las plataformas manifiestan la ley de Metcalfe; que determina que el valor de una red es una función exponencial —en el mejor de los casos- 
No obstante, esta no es una verdad absoluta. Si bien los efectos de red son importantes y su capacidad de crecer no se ha igualado en la historia previa a internet, no todos los efectos de red contribuyen al crecimiento de una plataforma. Pueden darse casos de efectos de red negativos fruto de la competencia o la saturación. Por tanto, las plataformas que favorecen su crecimiento son aquellas que favorecen los efectos de red positivos [VÉASE FigURA 15] (Armstrong, 2006; Evans, Hagiu y Schmalensee, 2008; Karhu, Pajulahti y Syd, 2018).

\section{AUTORREFERENCIALIDAD - AUTOPOIESIS}

La autorreferencialidad (Yoo, Henfridsson y Lyytinen, 2010) de una plataforma es la propiedad emergente que hace que su valor sea superior a la suma de sus partes. Las contribuciones e interacciones contribuyen a fortalecer el valor de uso de la plataforma como un ente independiente. Por ejemplo, Google Maps como servicio online de mapas (propósito) atrae usuarios que buscan lugares, por lo que los comerciantes prefieren anunciarse para encontrar usuarios (efecto de red), y el conjunto de usuarios desplazándose hacia lugares publicados construye un modelo global de tráfico cuyo valor excede el propósito originario de la plataforma. Esta es una característica fundamental para comprender la última de las características identitarias que explican el escalamiento de las plataformas: los recursos de borde.

\section{$\underline{\text { RECURSOS VINCULADOS-SISTEMA ABIERTO }}$}

Si una plataforma se construye de manera autorreferencial su propuesta de valor es superior a su propósito inicial. Por ello, puede servir a terceras partes para que construyan servicios en torno a las funcionalidades de la plataforma. Para ello, la plataforma necesita determinados elementos de apertura para compartir información con terceras partes; es decir, de servir como proveedor de contenido externo para otros. Estas aperturas, denominadas recursos de borde (Ghazawneh y Henfridsson, 2013; Karhu, Pajulahti y Syd, 2018) suelen ofrecerse en forma de APIs ${ }^{26}$, afianza la dependencia de otras aplicaciones hacia la plataforma, y por tanto afianza la hegemonía de determinada plataforma dentro del 'ecosistema' económico y social de las TIC.

La solidez de este modelo de negocio basado en estas características ${ }^{27}$ atrajo cantidades masivas de capital financiero que aceleró su desarrollo a nivel global, y acrecentó el abanico de campos de aplicación de la confusamente conocida como 'economía colaborativa'.

\subsubsection{Economía ¿colaborativa?}

De un modo muy diferenciado del de una empresa al uso o una firma industrial se ha visto cómo el modelo de negocio de las plataformas se basa en (1) el aprovechamiento de las

\footnotetext{
${ }^{26}$ Las siglas API proceden del inglés "Application Programming Interface” o Interfaz de Programación de Aplicaciones, y consisten en conjuntos de reglas y especificaciones que las aplicaciones pueden seguir para comunicarse entre ellas.

${ }^{27}$ Dada la similitud que tienen con el modelo de plataforma publicitaria de Google AdSense, la revista Wired acuñó el término Googlenomics (Levy, 2009).
} 
TIC para comunicar participantes de un intercambio, (2) la institucionalización ${ }^{28}$ de la confianza entre las partes comunicadas a través de mecanismos de valoración, (3) maximizar la capacidad productiva de valor de un recurso humano (plataformas publicitarias), propio (plataformas de alquiler de recursos propios), de terceros (plataformas mínimas), o todos en su conjunto (mixtas) (Gansky, 2010; Tanz, 2014; Couldry y Hepp, 2016; Sundararajan, 2016; Kornberger, Pflueger y Mouritsen, 2017; WEF y PWC, 2017; De Reuver, Sørensen y Basole, 2018). Por ello, "la ventaja competitiva $-\mathrm{y}$ responsabilidad - de una plataforma es el arbitraje de las prácticas de sus participantes [...] su operador tiene un control sin precedentes sobre la organización del trabajo y la distribución de beneficios, a pesar de retratarse como meros intermediarios [...] hasta el punto de encontrarnos en una reorganización de nuestra economía en la que los dueños de las plataformas parecen estar ganando un poder más formidable incluso que aquel de los dueños de las fábricas en la temprana revolución industrial" (Kenney y Zysman, 2016, p. 62; Schenker, 2019).

Cabe reseñar la evolución del concepto de 'economía colaborativa' y su transformación en el denominado 'capitalismo de las plataformas', para comprender el interés del capital financiero en este modelo productivo, introducir las controversias y oportunidades introducidas por las plataformas digitales — de las cuales muchas basan su operativa en la información geográfica a través de LBS - y abrir el camino hacia su análisis social y urbano.

El modelo sociotécnico de una plataforma digital busca la producción de valor basada en las relaciones sociales coordinando los propósitos y hábitos de consumo de sus usuarios productores y consumidores a través de una estrategia innovadora de gestión de la información para emparejar particulares que busquen compartir un recurso maximizar su ciclo de vida (Benkler, 2004; Bauwens, 2005; Botsman y Rogers, 2010; Gansky, 2010; Sundararajan, 2016) o valor de retorno (Dhar y Sundararajan, 2007; Slee, 2017; Srnicek, 2017).

Bajo la premisa de que el consumismo favorece la infrautilización de los bienes en propiedad (Benkler, 2004; Gansky, 2010; Sundararajan, 2016; WEF y PWC, 2017), en numerosas ocasiones las plataformas digitales se han servido de la metáfora del intermediario para justificar su valor social. Sin embargo, se ha visto que las plataformas se articulan mediante mecanismos de control de las transacciones que se lleven a cabo entre sus usuarios diseñados bajo un propósito específico. Por tanto, se puede programar hacia un consumo colaborativo, o hacia la creación de nuevos servicios que extraigan valor resignificando bienes de terceros - favoreciendo su cambio de uso - ¿es un apartamento en AirBnB una vivienda, o un alojamiento turístico?, ¿es un vehículo con conductor un taxi?, ¿una tienda de barrio en Amazon Hub un comercio de proximidad, o un operador logístico de última milla?...

\footnotetext{
${ }^{28}$ La institucionalización en la sociedad consiste en la validación de los roles atribuidos a una entidad mediante la aceptación de su operativa (Couldry y Hepp, 2016)
} 
Debido al rol intrínseco como árbitro que tiene cada plataforma digital, y los costes que tiene su infraestructura, y que su popularización en la última década se ha producido no tanto por aquellas plataformas sin ánimo de lucro, sino a la fuerte inversión de capital financiero en empresas que han contribuido a consolidar la expansión de este modelo de organización de determinadas actividades humanas. La crisis financiera tras la quiebra de Lehman Brothers en 2008 (Gruszka, 2017; Srnicek, 2017); produjo un consecuente desplome del crédito al consumo, adopción de medidas de austeridad por parte de los gobiernos, conversión de deuda privada en pública, bajada de tipos de interés, y con todo ello una fuerte caída en la rentabilidad de los activos financieros. Asimismo, los discursos sobre el consumo colaborativo ganaron popularidad (Botsman y Rogers, 2010) en un contexto de austeridad en el que parte de la población requería de nuevas fuentes de ingresos. Ante el éxito de los gigantes tecnológicos apuntalado en la plataforma digital y los factores que favorecen su rápido escalamiento global- como modo de organización, el capital-riesgo incrementó sus inversiones en 'startups' tecnológicas [VÉASE FIGURA 16] que pretendían aplicar el mismo modo de organización en actividades lucrativas todavía por digitalizar (Schor, 2014; Wallenstein y Shelat, 2017; WEF y PWC, 2017). Estas nuevas empresas, sirviéndose de la retórica de la economía colaborativa (comprar, reaprovechar, proporcionar oportunidades de trabajo a los más afectados por la crisis...) perseguían la obtención de financiación rápida bajo la idea de convertirse en «el Uber para esto» o «el AirBnB para aquello», dos plataformas basadas en la geolocalización cuyos objetivos eran 'eliminar las fricciones' (Evans y Schmalensee, 2016; Schröter, 2016; Slee, 2017) en el taxi y el alojamiento turístico (Srnicek, 2017).

Ello explica las controversias en torno a la idea originaria de economía colaborativa y cómo se ha transformado a lo largo de estos últimos años. el concepto se originó desde una visión centrada en los aspectos positivos de este tipo de aplicaciones informáticas, remarcando que posibilitaban una 'economía colaborativa' ("sharing economy" o “collaborative economy”) (Benkler, 2004; Heinrichs, 2013; John, 2013; Owyang, Tran y Silva, 2013), 'economía de pares' ("peer economy”) (Bauwens, 2005; Chase, 2015), 'economía híbrida'29 (Lessig, 2008), o más neutralmente 'la red' ("the mesh") (Gansky, 2010). A medida en que se profundizó en sus aspectos técnicos y se ahondó en la autorreferencialidad y los efectos de red generados por los sistemas informáticos, se popularizaron las visiones sobre una 'economía de las masas' ("gig economy" o "crowd-based capitalism") (Friedman, 2014; Sundararajan, 2016) y una 'economía bajo demanda' ("ondemand economy") (van Doorn, 2017) o 'economía de las plataformas' ("platform economy") (Kenney y Zysman, 2016; Karhu, Pajulahti y Syd, 2018). Sin embargo, los más críticos hacia el desarrollo de este sistema sociotécnico, al observar sus impactos negativos -entre otros, precarización de las profesiones liberales y trabajos no cualificados, gentrificación, y problemas de privacidad (Standing, 2013; OECD, 2016) - y observando las dinámicas

\footnotetext{
${ }^{29}$ Una economía híbrida está definida por Lessig con relación a la economía colaborativa como las posibilidades que gana una entidad comercial de generar valor a través de la economía colaborativa, o bien una 'economía colaborativa' que adquiere una entidad comercial para soportar sus intereses colaborativos.
} 
de acumulación de capital en manos de empresas tecnológicas basadas en el modelo de plataforma, la denominaron 'capitalismo de las plataformas' ("platform capitalism") (Srnicek, 2017).

FUNDING GROWTH HAS TAKEN OFF SINCE 2013

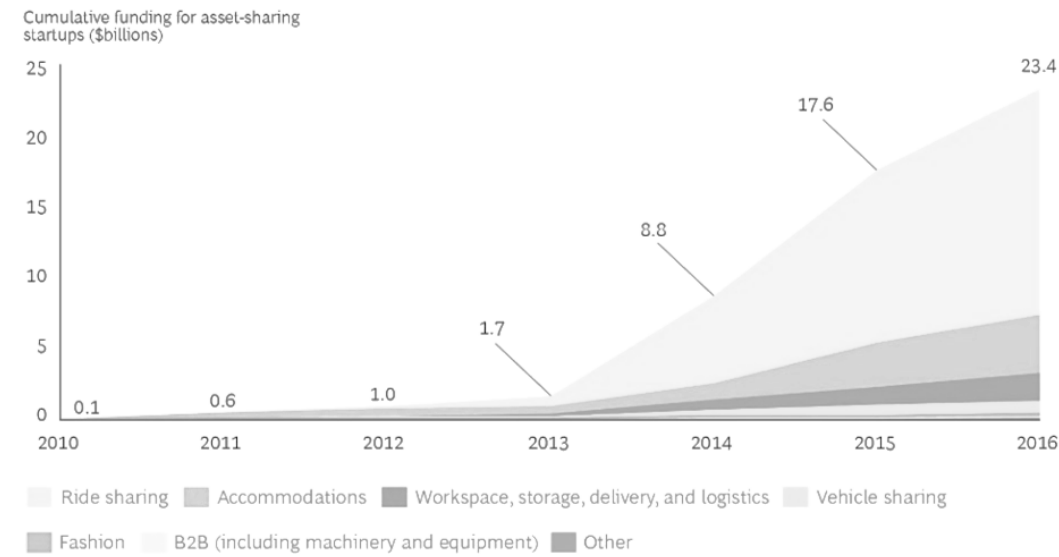

INVESTMENTS ARE DIVERSIFYING ${ }^{1}$

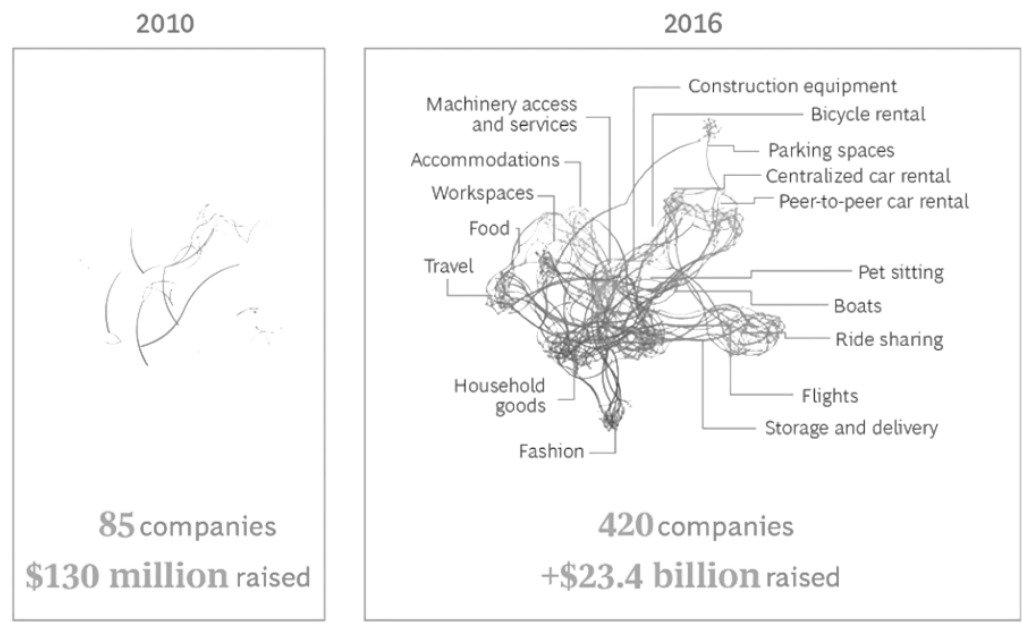

Sources: Quid; BCG Center for Innovation Analytics; BCG analysis.

Note: Quid analyzed venture financing for 476 sharing-economy companies, which it placed into 17 clusters according to similar products, technologies, and customers. The calegories in the diagram on the night are more granular than those in the graph on the left. Thus, Wor the aces, stoge and dess rental centralized car rental, and bicycle rentat on the right are part of the vehiclesharing cluster on the left.

Figura 16. Inversiones en plataformas digitales a lo largo del tiempo - Fuente: (Wallenstein y Shelat, 2017)

Además de la economía del propósito, también se ha observado que en esta etapa de crecimiento basado en inversión de capital, las plataformas han mostrado una predilección por la ciudad (Hecht y Stephens, 2014). La aglomeración urbana (Mumford, 1966; Jacobs, 1970; Glaeser, 2011) permite acceder a grandes cantidades de población y recursos optimizando las operaciones logísticas requeridas para que la diversidad de plataformas que se solapan en el espacio urbano capten una densidad de usuarios potenciales suficiente. Ello incide en que la economía de las plataformas es un fenómeno netamente urbano (Sundararajan, 2013, 2016; Davidson y Infranca, 2015; Tachet etal., 2017b), cuyos mecanismos, entre los que destaca el despliegue de LBS producen un 
espacio de interferencias y fricciones entre la información acumulada en el sistema urbano y sus canales de transmisión con los canales emergentes desde el entorno tecnológico del sistema.

\subsection{Fricciones entre el sistema urbano y su entorno tecnológico}

El comportamiento sistémico de la ciudad y los LBS como sistemas abiertos cognitivos doblemente complejos - donde las partes que interactúan entre sí son también sistemas complejos que perciben una información de su entorno y actúan en función de ella induciendo transformaciones constantes del estado del sistema urbano- motiva la premisa de la que parte esta tesis, de que un LBS constituye un mapa cognitivo del espacio urbano generado en un sistema autorregulado capaz de gestionar información del sistema urbano contribuida por sus usuarios ${ }^{30}$ cuyo propósito difiere en complejidad con el del sistema urbano en la medida que la información y el acceso a la misma se programa bajo los propósitos de cada plataforma digital.

Aunque en lo relativo a los LBS, el artículo los presente como un sustituto de las encuestas de movilidad para evaluar y calibrar los resultados obtenidos por el Space Syntax (Hillier, 1996; Lamiquiz Daudén, 2011) -lo cual es a todas luces aventurado dados los sesgos que posee este tipo de fuente-, sí identifica que los LBS podrían influir en los procesos de cognición espacial urbana. Este reconocimiento lo realiza en base a las ya crecientes estadísticas de adopción de smartphones (recuérdese que el artículo data de 2005, y el smartphone y los LBS se popularizaron a partir de 2007) y de casos; tanto especulativos como por aquel entonces implementados, de estos servicios. Estos ejemplos incluyen servicios de recomendación de lugares (restaurantes, museos, refugios de emergencia...); "líneas de chat para el encuentro de personas con perfiles similares en el espacio mediante serendipia aumentada tecnológicamente" - es decir, servicios de citas-; o de un modo más genérico, "tapices digitales que adjuntan diferentes tipos de información a espacios físicos (Ratti, 2005, p. 91). La existencia de estos servicios supone la apertura de un canal inmaterial de información entre un espacio y su observador, un cambio de su mapa cognitivo del espacio, y por tanto un potencial cambio de comportamientos. El subsistema informacional digital que constituye un LBS, podría cambiar el comportamiento social en la ciudad.

Recurriendo a Hägerstrand, Raubal, Miller y Bridwell (2004) advirtieron que los LBS podrían influir en las decisiones y comportamientos de los individuos con respecto a la movilidad en el espacio y en el tiempo ya que evidencian un abanico de acciones posibles en el espacio superior a las adquiribles sensorial o socialmente, y reduciendo la duración del proceso de toma de decisiones sobre dónde y cómo ir. Analizando la actividad de usuarios individuales en Twitter; Lee, Wakamiya y Sumiya (2015) establecieron una

\footnotetext{
${ }^{30}$ Se propone utilizar el término de información geográfica colaborativa (del inglés VGI o "Volunteered Geographic Information") en referencia a aquellos datos geográficos en las plataformas digitales aportados por sus participantes para que éstas funcionen.
} 
correlación entre la distancia social a través de redes sociales y cómo esta distancia social determina patrones de movilidad urbana. En otras palabras, cómo un determinado desplazamiento puede venir más influenciado por la existencia de un mapa cognitivo digital del espacio urbano que sitúa varios espacios urbanos fuertemente relacionados, más que por las condiciones materiales del espacio.

Asimismo, y recurriendo a entrevistas y análisis de historiales individuales, Constantiou, Lehrer y Hess (2014) concluyen que en contextos de uso específicos, los LBS cambian el comportamiento de los individuos en acceder a información relacionada con el lugar. De la población investigada, los usuarios mostraban una tendencia a descubrir información sobre lugares a través de estos servicios. En un $60 \%$ de los casos, preferían este canal de información frente a cualquier otro no tanto por su fiabilidad percibida -especialmente baja en los usuarios noveles de smartphones-, sino por su disponibilidad, facilidad de uso, y por considerar los LBS como la alternativa más fácil y rápida para obtener información urbana. En lo que respecta a la cognición del espacio urbano, los autores alcanzaron dos conclusiones relevantes a la luz de los datos (ibid. 2014, p. 524):

1. "Cuando los usuarios de teléfonos móviles experimentan que los LBS les proporcionan un valor añadido con respecto a cualquier otra opción disponible, los servicios son propensos a adquirir un nuevo status quo de substitución del servicio prexistente".

2. "En un entorno dinámico, los usuarios móviles están dispuestos a pagar por un LBS cuando satisface necesidades no cubiertas y posibilita la formalización de una nueva rutina o adquisición de información”

Aunque estas investigaciones sean puntuales y todavía incipientes, debido a la relativamente baja fiabilidad de algunas fuentes de datos (Ratti, 2005) o a la intangibilidad del canal de comunicación (Graham, 1997), refuerzan la hipótesis de la desmaterialización cognitiva del espacio urbano físico y ponen en valor empíricamente a los LBS como subsistemas urbanos virtuales y espaciales de organización de intercambios y de nuevos comportamientos sociales en el espacio.

Se sostiene que a pesar de la aparente aleatoriedad de la información acumulada en el LBS - usuarios que requieren o demandan un servicio accediendo o informando de su ubicación geográfica-, el mapa del servicio tiene una estructura urbana -en la medida que la información procede del sistema urbano, que como se ha visto alberga una información en sus estados materiales y energéticos-, que se organizan según las características del sistema informático donde la información urbana se acumula y hace accesible- emergiendo un sistema organizador de intercambios de materia-energíainformación imbricado en la ciudad como parte de su entorno tecnológico.

En base a este mapa cognitivo externo, los ciudadanos pueden organizar parte de su actividad cotidiana de modo tal que (1) aportan datos a la plataforma, retroalimentándola y favoreciendo su crecimiento orgánico, y (2) introducen nueva información en el sistema urbano favoreciendo cambios observables que por tanto alimentan posibles 
transformaciones sinérgicas de esta. Así pues, estos cambios, percibidos como externos al sistema por determinados agentes agentes, inducen nuevos procesos cognitivos sobre el sistema urbano 'desde arriba', y motivan esfuerzos por parte del planeamiento urbano de readaptar el planeamiento urbanístico como un mapa cognitivo más de la ciudad.

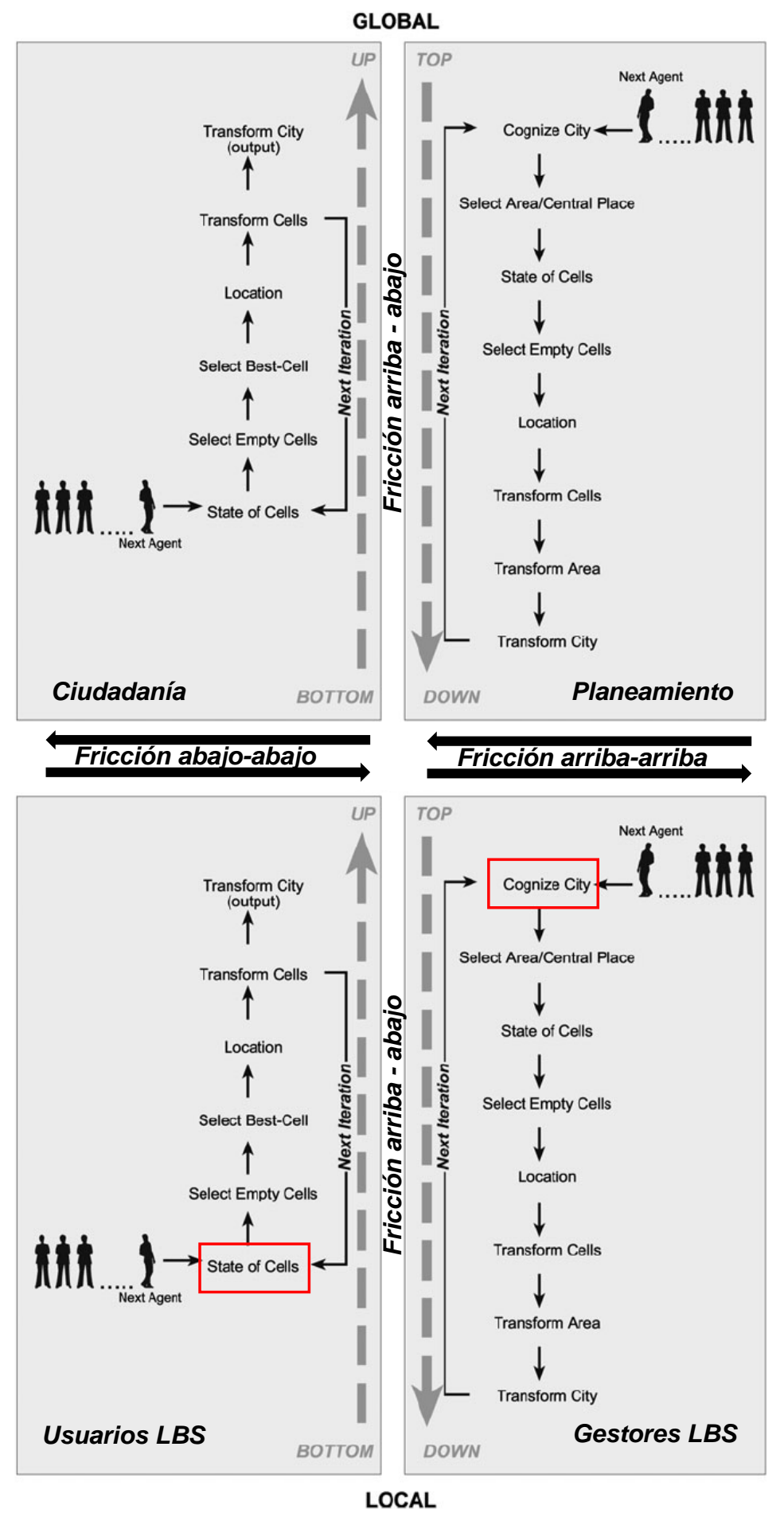

Figura 17. Sistemas urbanos (arriba) e informáticos (abajo) cognitivos (derecha) y no cognitivos (izquierda). Nota: El mapa cognitivo urbano de un LBS todavía está poco explorado porque no se han presentado tanto el estado de las 'células' pertenecientes al servicio (información colaborativa) como los protocolos de filtrado de la información propios de las plataformas de información geolocalizada Fuente: Adaptado de (Portugali, 2011a) 
Esta fricción entre espacios sociales, ya presentada por Lefebvre (1975) en la tríada de espacios concebido, percibido y vivido se ha complejizado con la democratización de los servicios geolocalizados resuena con esta teoría de la complejidad, la cognición y la ciudad. En primer lugar, existe una fricción entre espacios concebidos, como aquellos mapas cognitivos 'desde arriba' que son creados en base a la observación intencionada e ideológica del sistema urbano en su conjunto. Los creadores de un servicio geolocalizado tienen una idea de aquello representable, aprehensible y monetizable de la ciudad como recurso extractivo, lo cual puede entrar en conflicto con los objetivos de planeamiento fijados por el abanico de documentos de planeamiento que tratan de proporcionar al sistema urbano un orden [VÉASE FIGURA 17].

Además, pueden existir fricciones de segundo orden 'de abajo a arriba entre los espacios percibidos -en los que se desarrollan las prácticas espaciales ligadas al uso canónico del espacio- y los espacios vividos en los que se generan simbologías derivadas del uso de esos espacios. En determinadas ocasiones, un servicio geolocalizado puede plantear un cierto cambio de uso del espacio que durará un tiempo determinado - de vivienda a apartamento turístico, de calle secundaria a parada instantánea de VTC, de local comercial a punto de entrega de paqueterías... Y la consecución continuada de esos pequeños cambios de uso puede cambiar la 'imagen' del barrio o esas simbologías derivadas de la experiencia cotidiana - la vida cotidiana de los habitantes frente a la de los turistas en un barrio 'turistificado'.

Este conjunto de fricciones arriba-abajo, arriba-arriba, y abajo-abajo que pueden desplegar los LBS en el espacio social urbano incide en la dificultad de conceptualizar el espacio social de las telecomunicaciones urbanas, y hacerlo aprehensible para los planificadores urbanos -incluso en un momento en que el paradigma de la 'smart city' ha tomado más impulso que nunca. Si los planificadores ya se enfrentaban a la 'paradoja de la predicción' de los sistemas urbanos - basada en (1) la no-linealidad de estos sistemas implica que no se pueden determinar relaciones causa-efecto entre variables aisladas; (2) los cambios son generalmente impredecibles en el largo plazo salvo que sean catastróficos; y (3) todo observador, interno o externo al sistema, con sus acciones y predicciones elabora nuevos mapas cognitivos del sistema que transforman los existentes (Portugali, 2006, p. 23).

Sin embargo, dentro de esta incertidumbre existen escenarios de probabilidad y 'previsibilidad' dada la estabilidad en la organización física de la ciudad a lo largo del tiempo. Al igual que el mapa del espacio físico existente se utilizó y utiliza como herramienta para planificar las ciudades, la representación de los espacios urbanos virtuales en contraste con los físicos, los decalajes entre las accesibilidades física y digital a la información contenida en el espacio urbano, la repetición de entidades y comunicaciones de los usuarios que describen algunos patrones estructurales del espacio urbano mediatizado, y la aplicación de normas desde el planeamiento urbanístico para rearticular las fricciones generadas, podría ilustrar las características de los sistemas urbanos actuales profundamente mediatizados. 


\subsection{Síntesis teórica}

Dada la necesidad de incorporar el pensamiento sistémico para comprender el papel de las TIC como parte del entorno del sistema urbano; un sistema cuya forma determina los canales de comunicación entre espacios por los que se articulan los flujos de materia y energía sobre los que se acumula y comunica la información del sistema (Margalef, 1980) -en las ciudades, los usos del suelo ligados a la estructura de la propiedad-, cuya evolución produce una diversificación de los mismos y sus volúmenes edificados que hacen posible su adaptación a las necesidades de la población -y sus capacidades cognitivas para la percepción y actuación en base a la información percibida del sistemay circunstancias del entorno (Alexander, 1964; Ruiz-Sánchez, 2001b; Aquilué Junyent, 2017), se asume que los LBS son una tecnología al servicio de la mediatización de la información del sistema, que se rearticulará en un nuevo espacio perceptivo para reorganizar tales intercambios. La alteración de dicha información puede alterar la información existente del sistema, es decir, producir alteraciones de los usos del suelo, y con ello alterar el abanico de funciones accesibles que determinan el estado, y la complejidad urbana.

Como base conceptual, se asume la paradoja cognitiva del observador-planificador que queda ejemplificada en el 'problema del huevo y la gallina': no se puede establecer si una ciudad moldea el espacio de un servicio geolocalizado, o un servicio geolocalizado moldea el espacio urbano, sino que ambos son sistemas comunicativos en constante interacción, los cambios en un sistema se conceptualizan como cambios de entorno en el otro y viceversa. En cambio, se plantea que la interacción entre la ciudad y los LBS puede producir sinergias y antisinergias, afectando a la diversidad funcional accesible del sistema.

Por el hecho de ser sistemas comunicativos en constante interacción, comprender las componentes funcionales de cada sistema permitirá elaborar una descripción de su estado de equilibrio actual. Estas componentes funcionales se han agrupado en cuatro categorías: espacios y redes como aspectos formales, y patrones y normas como desafíos estructurales.

Los aspectos formales definen la apariencia del sistema asumiendo su generatividad autorregulación. Es decir, la acumulación de elementos y acciones llevadas a cabo por agentes en el espacio que actúan en red. Asumiremos que, en su nivel más básico, una ciudad es un conjunto de espacios habitables interconectados por medio de redes físicas que articulan intercambios de materia y energía mediante la información. Asimismo, en los LBS existirán representaciones intencionadas cuya forma espacial más sencilla será un par de coordenadas geográficas de los espacios físicos representados en un espacio celular virtual. Igualmente, la información será accesible a través de redes celulares. En este nivel existirán dos fricciones.

La primera fricción se dará entre los espacios/lugares tangibles y la información digital colaborativa que los representan, surgiendo una primera pregunta a verificar en esta tesis 
acerca del sesgo de las plataformas digitales a la hora de producirse una digitalización más intensiva de determinados lugares urbanos frente a otros, y con ellos sus funciones $\underline{\text { asociadas, }}$ poniendo en cuestión si un LBS constituye un 'gemelo digital' (Batty, 2018) de la ciudad. Aunque este marco teórico indique que no pueda serlo, todavía no se han explorado suficientemente estos espacios informacionales en su dimensión geográfica; una de las carencias perennes en la investigación actual sobre LBS (Raper etal., 2007; Huang etal., 2018).

En segundo lugar, existirá una fricción entre las redes de comunicación físicas y digitales. Desde el nivel más elemental, las primeras tendrán una estructura organizativa más o menos compleja que oscilará entre la semitrama ${ }^{31}$ y el árbol (Alexander, 1964). Sin embargo, la topología elemental de las comunicaciones móviles es su celularidad ${ }^{32}$ (Lee, 1965). Sin embargo, esa información se ha dotado de una componente espacial, por tanto las comunicaciones e interconexiones sociales describirán dos topologías cuyas jerarquías pueden o no coincidir. Por ello, el segundo aspecto formal de la interacción entre el sistema urbano y sus LBS el modo en que las redes comunicativas urbanas físicas y virtuales presentan decalajes jerárquicos.

Además de los aspectos formales, la tesis estudia lo que pueden denominarse 'desafíos estructurales'; es decir, aquellas fricciones observables de los sistemas en interacción. Si la información en un LBS se resignifica en función de su propósito - “el medio es el mensaje"-, se produce una alteración de usos del suelo que afecta a la complejidad urbana en la medida que altera la diversidad de estados accesibles del sistema en el momento de acción del servicio digital.

En última instancia, quedan por analizar las fricciones en el nivel más alto del sistema: las normas. Estas normas son aquellas manifestaciones que rigen las interacciones legítimas en un sistema social. Este nivel de fricción se da entre dos modos de gobernanza de cada sistema. Mientras que los sistemas urbanos son objeto de aplicación del planeamiento urbanístico como acción política, y este planeamiento legitima "qué puede suceder, dónde, y cómo se va a comunicar con el resto de usos”, una plataforma también establece mecanismos de gobernanza definiendo las interacciones posibles entre sus partes, su nivel de apertura hacia el exterior, y las interfaces donde esas interacciones podrán tener lugar. Este nivel cabe estudiarse desde dos perspectivas, la primera es la perspectiva reactiva la ciudad contra el LBS - analizando las normas aprobadas por las administraciones para el control de la economía de las plataformas. También, si fuera el caso, las maneras por las que la administración ha desplegado un LBS propio para el análisis de la información urbana y el despliegue de servicios adaptado a dichos flujos de información en tiempo real.

\footnotetext{
${ }^{31}$ Una semitrama es una topología de red que describe los vínculos entre elementos del sistema como igualmente posibles en un espacio continuo.

${ }^{32}$ Una topología celular en la telefonía móvil describe un espacio de células vecinas interconectadas (todos con todos) en el que todas las comunicaciones son posibles y equiprobables.
} 


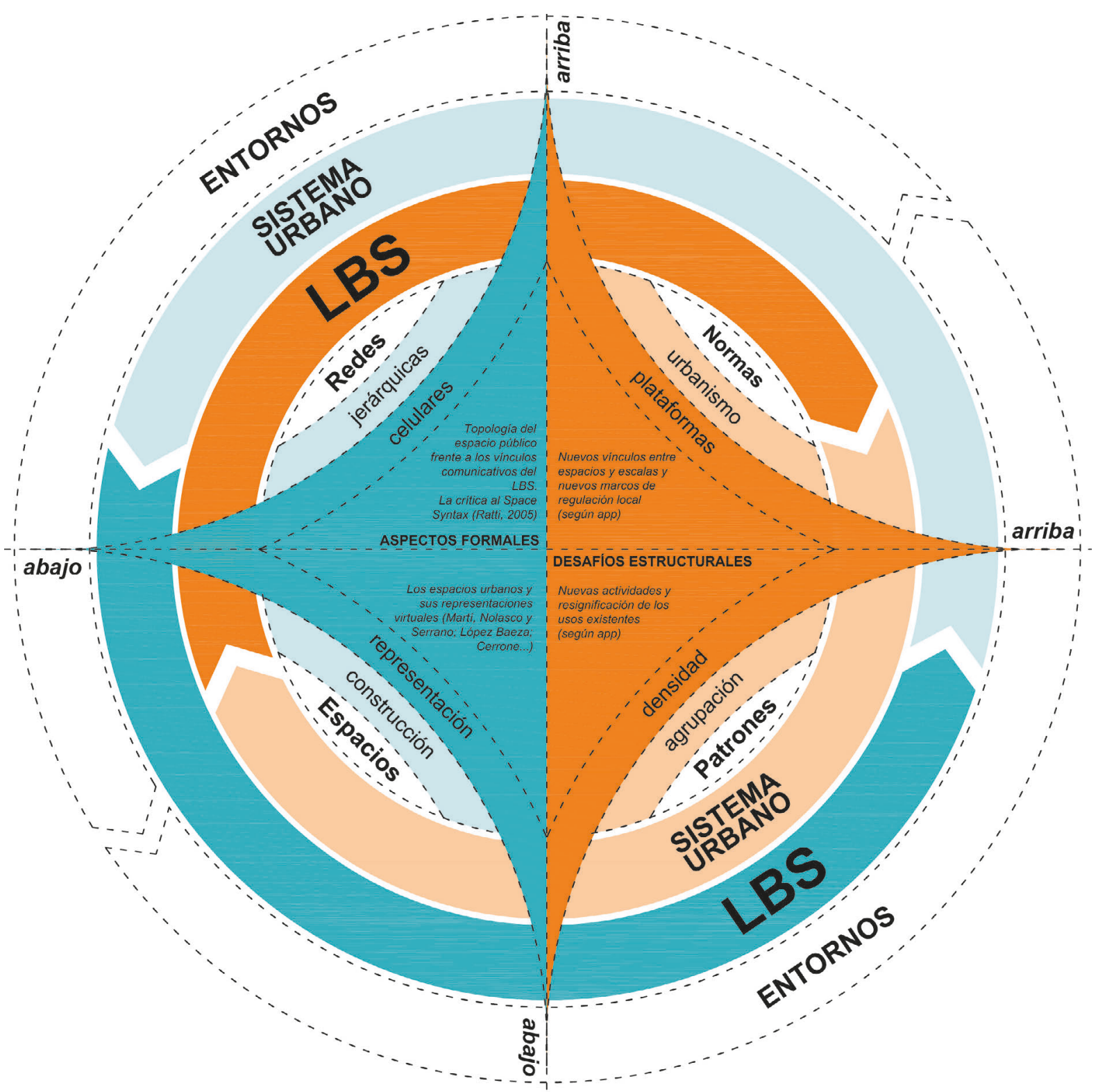

Figura 18. Ciclos transformadores de los LBS y el espacio urbano. Elaboración propia

Esta perspectiva de integración de sistemas complejos a nivel teórico se ha considerado necesaria para comprender ciertas limitaciones que se han producido a nivel empírico, tanto en el campo de estudio de la ciudad y las plataformas digitales, como en el desarrollo de herramientas para analizar la complejidad del sistema resultante [VÉASE FIGURA 18] 


\section{capítulo 3 \\ Describir la ciudad o transformar el sistema}

«La estructura de los datos probablemente sugeriría nuevas interpretaciones de la 'lógica social del espacio'»

(Ratti, 2005)

\section{Resumen del capítulo}

La mayoría de aproximaciones desde los estudios urbanos a las plataformas digitales se centran en los aspectos descriptivos del "big-data"; utilizando las plataformas como una fuente de información de lo que ocurre en la ciudad más que como un motor de transformación.

La capacidad de las plataformas de acumular información geolocalizada parece dotarlas de una cierta inteligencia colectiva, proporcionando a los urbanistas una fuente de información granular sobre los lugares urbanos que sería imposible reproducir -por complejidad, tiempo y coste- siguiendo técnicas de recogida de datos convencionales. Sin embargo, numerosos estudios cuestionan la veracidad de estas fuentes de información urbana. Si "el medio es el mensaje" (McLuhan, 1964), la información acumulada cumple con un propósito específico - generalmente ajeno a la planificación-, que puede sesgar la representación digital de la ciudad, haciendo que. los lugares más rentables serán aquellos más intensamente digitalizados. 
Ante esta crítica, y basándose en la no-neutralidad de los LBS, la 'corriente transformativa' plantea caminos por los que la digitalización reorganiza la actividad social; extrayendo valor del abanico denso y variado de actividades y tipos de lugares existentes en las ciudades complejas.

\section{Chapter's summary}

Most of the empirical "big-data" approaches to LBS in the domain of Urban Studies stay in the descriptive, rather than transformative use of LBS of urban life.

On one hand, the platform's capability of crowdsourcing volunteered geographic information makes LBS become a source of urban data characterized by collective intelligence, as they can provide third parties with substantial amounts of subjective granular data of the city lived by the people. This reduces the costs of generating publicly available institutional surveys, maps and databases commonly used for planning, being able to track the locations and preferences of significant population samples.

On the other hand, many scholars have questioned the validity of social platforms as an alternate source of information for planning. According to the media theory, if "media is the message" (McLuhan, 1964), the collected information meets a specific purpose that modulates its content, emitters and receivers, introducing sociodemographic and geographic biases. The most profitable places and users for platforms may thus be the ones most intensively digitalized. As a result, LBS may just be a part of the media that drives everyday activity in a non-neutral way. As such, besides reflecting existing activity, they create data-driven feedback loops that must be accounted for understanding the present city.

Considering the arguments against the neutrality of LBS, the transformative approach focuses on the ways trough which digitalization reorganizes social activity in space. To this respect, digital platforms are already implemented technologies enabled to benefit from coordinating the dense and varied range of places and activities that complex cities have. 


\subsection{Dos corrientes complementarias}

El propósito de este capítulo es presentar el marco empírico que trata la incorporación de los servicios digitales geolocalizados en los Estudios Urbanos. Dada su reciente incorporación, se trata de un campo en crecimiento, con una literatura muy fragmentada que se debate, a muy grandes rasgos, entre dos corrientes aquí identificadas como 'la corriente descriptiva' y 'la corriente transformativa'.

La primera de ellas es la más popular, dado que las plataformas que en inicio mostraron un mayor crecimiento en número de usuarios fueron las redes sociales. Buena parte de la academia se centró en el análisis de los datos masivos en estas redes aportados voluntariamente por sus usuarios de manera consciente o inconsciente (Craglia, Ostermann y Spinsanti, 2012) ${ }^{33}$. El hecho de que los datos contengan información geográfica permite vincular cada contribución a un ámbito espacial determinado para así poder describir sus características intrínsecas - como la ubicación, uso, inserción en la trama urbana...- y extrínsecas - como la afluencia en el tiempo, valoraciones, elementos socialmente considerados como representativos...- (Martí, García-Mayor y SerranoEstrada, 2019). Esta corriente sostiene que el análisis de estas fuentes es un recurso imprescindible para los planificadores urbanos, quienes a través de este tipo de aplicaciones puede acceder a una información más completa del sistema urbano, la cual incluye aquellos aspectos de la ciudad percibidos por sus habitantes y manifestados públicamente en las redes, así como patrones de conducta colectivos que emergen de la masa de datos estudiados.

Por otra parte, la corriente transformativa plantea los LBS como sistemas capaces de modificar determinados comportamientos de sus usuarios gracias a determinadas aplicaciones. La adopción masiva de éstas puede modificar determinados hábitos colectivos y así alterar determinados aspectos funcionales del sistema urbano.

Esta corriente puede dividirse en dos vertientes; una propositiva y otra crítica. La primera se caracteriza por la propuesta de aplicaciones digitales que reestructuren servicios a los que el individuo podría acceder ocasionalmente. Por ejemplo, sistemas de movilidad compartida, recomendaciones personalizadas de lugares, economías circulares, etc... De estos proyectos se espera que su escalamiento produzca nuevos patrones de uso competitivos con servicios prexistentes en sus respectivos campos de acción -movilidad, logística, alojamiento, comercio... Esta es la corriente más relacionada con los paradigmas de una 'smart city' en la que la tecnología juega un papel principal en el planteamiento de soluciones innovadoras. Por el contrario, del escalamiento de determinados servicios denominados 'inteligentes', y la emergencia de nuevos patrones de conducta, y con ello transformaciones del espacio urbano, pueden surgir nuevas problemáticas, fundamentando la vertiente crítica a los LBS como transformadores de la ciudad. En ella

\footnotetext{
${ }^{33}$ Es posible que esta aportación no sea consciente -en caso de que un usuario no lea los términos y condiciones de cada servicio. Se utiliza la noción de voluntariedad para enlazar la investigación sobre las líneas de investigación sobre la denominada 'información colaborativa' o 'información contributiva' (del inglés 'Volunteered Geographic Information' o VGI).
} 
proliferan los debates sobre la uberización del tejido comercial en el comercio electrónico, la transmisión de ITS $^{34}$ y compraventa de sustancias ilegales a través de plataformas de citas, o la gentrificación del tejido residencial a través de plataformas de alquiler vacacional.

Esta división empírica se hace más palpable en la cantidad de conocimiento producido en una y otra vertiente. Mientras que en la primera abundan las investigaciones sobre el espacio urbano descrito por las plataformas digitales, la segunda cuenta con literatura de carácter netamente teórico en su parte propositiva, y creciente en su parte crítica ante la influencia del capitalismo de las plataformas (Srnicek, 2017) en la economía urbana.

Además, esta división hace patente la paradoja cognitiva presentada en el marco teórico y muestra una cierta división en la manera de comprender el planeamiento urbano. Puede afirmarse que la corriente descriptiva busca completar el mapa cognitivo de la ciudad a través de la información contribuida 'de abajo a arriba', y así adecuar los mecanismos tradicionales de los que se ha servido la planificación urbanística 'espacial', mientras que la 'transformativa' busca comprender el nuevo mapa cognitivo que suponen las plataformas digitales y trabajar en la fricción entre la ciudad preexistente y el sistema comunicativo digital emergente. Se empieza por tanto a evidenciar un urbanismo de lugares frente a un urbanismo de redes adaptativas a las circunstancias del contexto socioespacial urbano.

A pesar de la división, estas corrientes no son incompatibles sino complementarias. Siempre y cuando se comprendan las relaciones entre el espacio urbano físico y el digital, cómo se articulan, y qué sinergias aparecen entre estos. Para lo cual, la teoría de la complejidad cognitiva en entornos artificiales (Portugali, 2006) adaptada en el capítulo anterior puede resultar una aproximación válida para estructurar el marco empírico. Partiendo de las cuatro componentes fundamentales básicas del sistema urbano espacios/lugares, patrones, redes, y normas-, se observa que el conocimiento acumulado en ambas vertientes refleja fragmentos del problema, así como herramientas metodológicas para enfrentarlo.

De este modo, la primera parte del marco empírico presenta los objetivos y herramientas pertenecientes a la corriente descriptiva. Aunque estos objetivos y métodos son enormemente diversos, pueden estructurarse en la búsqueda de complementar fuentes institucionales de información geográfica mediante la descarga masiva de datos en las plataformas mediante acceso a APIs o "scrapping". En un segundo nivel de complejidad, esta corriente persigue conocer los aspectos perceptivos de la ciudad a través del análisis semántico de la información desestructurada o semiestructurada presente en las plataformas digitales. Con esta información, y combinando fuentes oficiales y contributivas, se pueden identificar comunidades de interés en la planificación urbanística en un sentido amplio -no sólo comunidades de usuarios sino también agrupamientos de lugares que describen características análogas como afluencia de

${ }^{34}$ Infecciones de Transmisión sexual 
público en el tiempo, sentimientos o valores perceptivos. Para lo cual, se sirve de técnicas de agrupamiento dada la granularidad de los datos en las plataformas.

Como se verá, la gran cantidad de contribuciones en esta línea ha motivado la acumulación de críticas y defensas con respecto al uso de estas fuentes. Si bien puede concluirse que cada vez más, son fuentes imprescindibles para conocer la ciudad y complementarias al análisis urbano convencional (Martí, Serrano-Estrada y NolascoCirugeda, 2019).

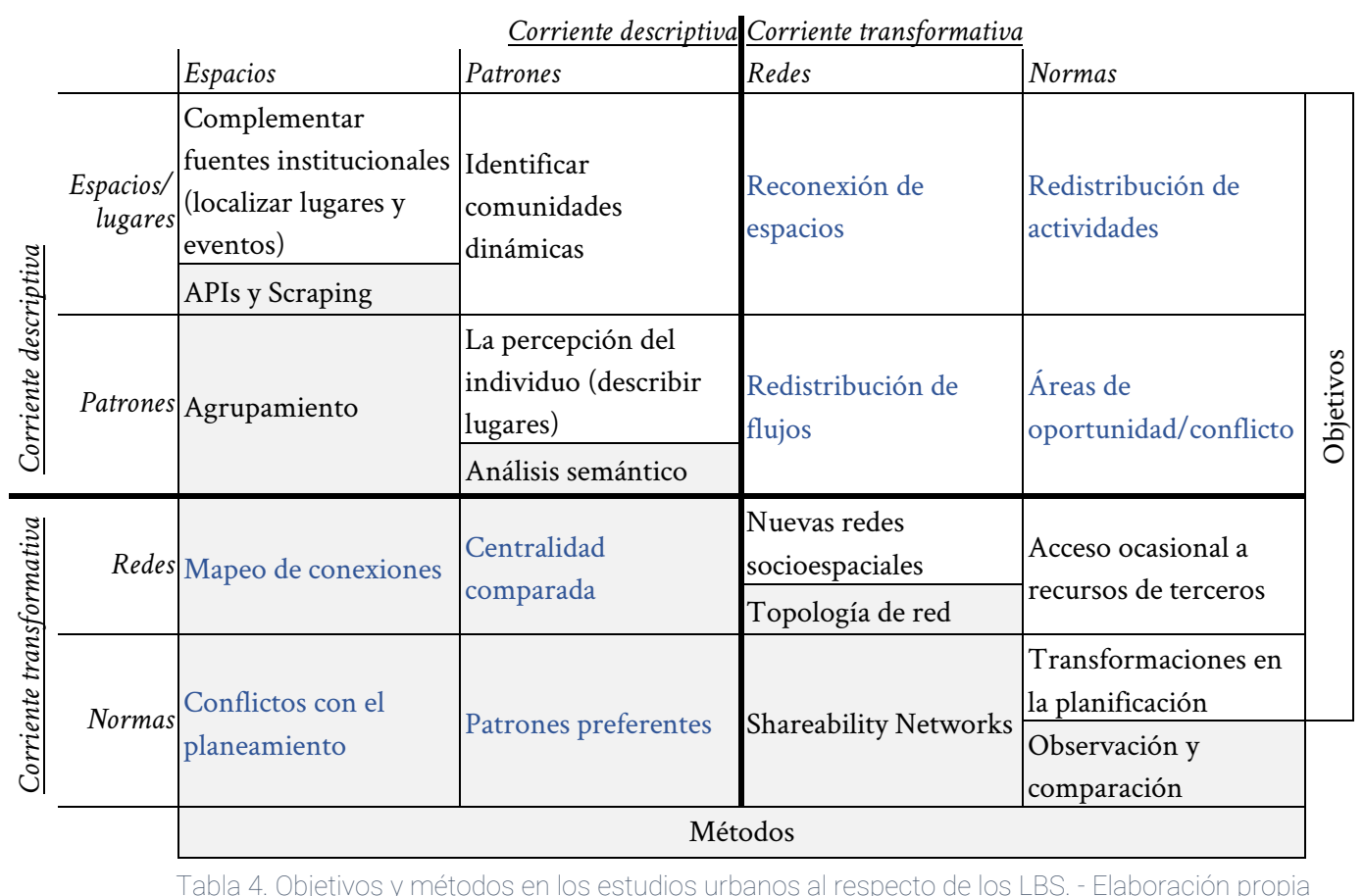

La segunda corriente persigue la descripción de las nuevas redes socioespaciales que articulan la actividad en las plataformas, y con ello su cadena de valor. Aunque existan técnicas para realizar estas descripciones los estudios basados en datos empíricos en esta corriente son todavía incipientes. Si la topología de red ya se ha incorporado al análisis del espacio social urbano 'tangible' (Hillier y Hanson, 1984), también podría utilizarse para el análisis de ese espacio digital 'intangible'. Aunque las transformaciones en el planeamiento urbanístico sean todavía incipientes, han comenzado a producirse estudios comparativos de los mismos. Asimismo, estas ideas de despliegue de nuevas redes de distribución de servicios urbanos compartidos planificados bajo los propósitos del consumo de recursos de terceros se han empezado a explorar a través de la teoría de 'redes de acceso compartido'(Tachet etal., 2017a) ${ }^{35}$ [VÉASE TABLA 4].

Para concluir este marco, se presentarán las fricciones entre sistema urbano que emergen de esta división entre la planificación de espacios y redes físico-digitales presentadas.

\footnotetext{
${ }^{35}$ Se ha traducido literalmente del inglés 'shareability networks', que indica el potencial de que un recurso sea compartido siempre y cuando dos o más individuos compartan un propósito similar en un marco temporal determinado.
} 


\subsection{Describir la ciudad}

Como se ha introducido, la mayor parte de la literatura sobre los LBS en los estudios urbanos se centra en la descripción de la ciudad y su funcionamiento. La aparición de este tipo de servicios digitales permite acceder a la información aportada por sus usuarios y hace posible un análisis del espacio urbano 'de abajo a arriba'. Cada usuario de un servicio accesible a través de un smartphone es capaz de aportar información a la base de datos de un servicio, convirtiéndose en cierto modo en un 'sensor' de aquello que acontece en su entorno (Goodchild, 2007). Las plataformas digitales consolidan así un microcosmos de aportaciones puntuales que son de utilidad en los estudios urbanos (Arribas-Bel, 2014; Martí, Serrano-Estrada y Nolasco-Cirugeda, 2019).

Cada contribución cuenta con dos tipos de datos, estructurados y no estructurados. Los primeros son aquellos cuyo formato responde a reglas estrictas, como por ejemplo las coordenadas geográficas, las valoraciones por puntuación, marcas temporales, o categorías. En general, estos datos estructurados hacen posible la funcionalidad básica de una plataforma, dado que su entropía es menor, son más fáciles de procesar por los algoritmos de búsqueda y representación de la información. Los datos no estructurados son aquellos que muestran una mayor variabilidad en sus contenidos, como las descripciones, opiniones, vídeos e imágenes que añaden contenido complementario a los datos estructurados.

Esta primera distinción resulta fundamental para comprender la cantidad de información relevante sobre la ciudad que puede extraerse de ellas. El análisis de la información estructurada garantiza la consistencia de la fuente de datos y su correspondencia con un espacio-tiempo determinado. La información desestructurada contiene percepciones individualizadas de los ciudadanos que utilizan una plataforma.

De forma integrada, una plataforma digital utilizada por una cantidad representativa de usuarios, alberga un mapa colectivo de la ciudad con información granular (Cranshaw etal., 2012; Arribas-Bel, 2014; Martí, Serrano-Estrada y Nolasco-Cirugeda, 2019), objetiva y subjetiva (O'Reilly, 2005; Goodchild, 2007, 2013; Haklay, 2010; Cranshaw etal., 2012; Graham y Zook, 2013; Arribas-Bel, 2014; Hu etal., 2015; Campagna, 2016; Romanillos etal., 2018; Martí, Serrano-Estrada y Nolasco-Cirugeda, 2019) acumulada y mantenida a lo largo del tiempo por la comunidad de usuarios de la plataforma (ArribasBel, 2014; Kitchin, 2014b; Hu etal., 2015; Huang y Wong, 2015; Martí, Serrano-Estrada y Nolasco-Cirugeda, 2019). Además, la globalidad que le dan Internet y las arquitecturas informáticas para la provisión de servicios contextuales permite, en caso de que la plataforma se utilice en varias ciudades, establecer estudios comparados cuya escala antes estaba limitada a la disponibilidad de datos procedentes de fuentes institucionales homologables (Cranshaw etal., 2012; Arribas-Bel, 2014; Bejar etal., 2016; Bоy у Uitermark, 2016; Martí, Serrano-Estrada y Nolasco-Cirugeda, 2019)

Teniendo estas oportunidades, han aparecido numerosos estudios cuyo valor fundamental es complementar fuentes de información institucionales favoreciendo 
enfoques holísticos capaces de integrar las perspectivas y comportamientos de los ciudadanos de una manera más directa en la planificación urbana (Batty, 2013) sin el coste institucional que supondría acceder a esta información mediante la elaboración de encuestas 'ad-hoc' (Martí, Serrano-Estrada y Nolasco-Cirugeda, 2019).

En este contexto, Granell y Ostermann (2016) distinguen tres aproximaciones empíricas a la información geolocalizada de carácter contributivo. En primer lugar, las aproximaciones orientadas al desarrollo de aplicaciones específicas ("application-centric") centradas en prestar un servicio concreto. En segundo lugar, un campo de estudio centrado en los datos ("data-centric") orientado a la extracción, preservación, y contextualización de datos masivos de plataformas digitales existentes y su procesamiento para obtener nueva información sobre la ciudad. Esta aproximación pone en valor fundamentalmente los datos estructurados. Por último, identifican una tercera aproximación centrada en los usuarios ("human-centric"), estudiando los comportamientos humanos en la ciudad: su percepción, socialización y acción. Estas segunda y tercera categorías son de especial interés en esta descripción de los espacios urbanos, sus características subjetivas, y sus patrones de actividad social.

\subsubsection{Localizar y describir lugares}

La omnipresencia de las TIC en la vida cotidiana tras la popularización del smartphone; convirtiendo a la población mundial en consumidora y creadora de información geolocalizada (Butler, 2006; Goodchild, 2007; Ratti y Claudel, 2016) podría permitir complementar la información geográfica de carácter institucional; cuya información está condicionada por un propósito específico ${ }^{36}$, cuya frecuencia de actualización está limitada a la periodicidad con la que se publican, y cuya descripción y valoración está limitada a categorías estables y criterios de valoración estandarizados que no captan la diversidad de valores del lugar por parte de aquellos usuarios que lo ocupan (Arribas-Bel, 2014).

Si la geolocalización se utiliza para estructurar el contenido de determinadas plataformas; entre las que destacan las redes sociales y los servicios de búsqueda y recomendación de lugares, las plataformas contienen un mapa de la ciudad cuyo valor radica en la 'ingeligencia colectiva' (Surowiecki, 2005). La acumulación de conocimiento desagregado acerca del espacio urbano se espera que produzca un mapa colectivo representativo de la ciudad vivida por sus habitantes (Haklay, 2010).

Por una parte, los estudios en esta categoría utilizan los puntos de interés de plataformas de búsqueda y recomendación de lugares como 'Google Maps o Places' (De Vries etal., 2013; Bentley, Cramer y Müller, 2015; Monnot etal., 2016), Foursquare (Silva et al., 2014; López-Baeza, Cerrone y Männigo, 2017; Martí, Serrano-Estrada y Nolasco-Cirugeda, 2017), Facebook Places (Cheng etal., 2011; Wilken, 2014), o TripAdvisor (Čerba etal., 2016; Chen etal., 2017). Estas aplicaciones tienen en común la función de encontrar

\footnotetext{
${ }^{36}$ Por ejemplo, la finalidad de un catastro, o un censo de actividades comerciales no es el cartografiado topográfico sino el registro de bienes para la recolección de impuestos. Por ello, carecerán de un registro de hitos urbanos o redes de transporte.
} 
lugares cercanos a la ubicación del usuario y en su caso aportar valoraciones, y fotografías en torno a las cuales las aplicaciones pueden localizar los lugares urbanos más adecuados a las búsquedas que otros usuarios realicen.

La información de estas fuentes no solo incluye lugares comerciales sino también puntos de interés general como paradas de transporte público, y elementos representativos de la ciudad; hasta el punto de crear un atlas detallado de ésta con información masiva, diversa y numerosa. En última instancia, cualquier persona o cosa puede contar con una o varias representaciones digitales con información parcialmente estructurada.

Por ello, la complementariedad más básica es la cantidad y diversidad de contenido que puede haber en una plataforma de mapeado búsqueda $\mathrm{y}$ representación de lugares. Por ello, estas se han utilizado para geocodificar información; es decir, localizar ubicaciones por su nombre (Ratcliffe, 2004; Goldberg, Wilson y Knoblock, 2007; Zandbergen, 2008).

Las bases de datos colaborativas sobre lugares suelen incluir, como datos estructurados básicos a) las coordenadas espaciales y/o la dirección postal completa, b) el nombre del lugar, su c) categoría de uso y posibles subcategorías, además de d) valoraciones y variables indicativas de la afluencia o popularidad del lugar representado.

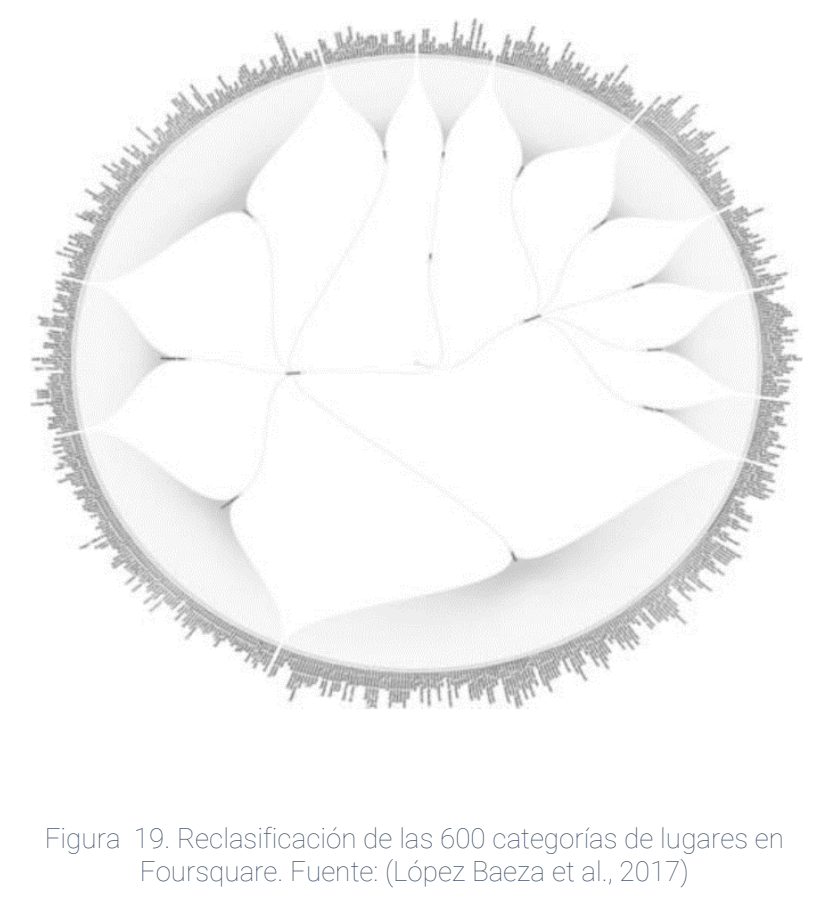

Dentro de esta categorización [VÉASE FIgURA 19] reside la utilidad de estas fuentes para el mapeo de las actividades urbanas. clasificables dentro de las múltiples taxonomías dentro de la enorme diversidad de categorías y subcategorías de lugares que un LBS puede albergar (Gehl y Svarre, 2013; Cerrone, Lehtovuori y Pau, 2015; López-Baeza, Cerrone y Männigo, 2017).

Por ello, una segunda familia de estudios descriptivos de la ciudad es la identificación de usos del suelo vinculados a la actividad representada De esta identificación de actividades emergen usos potenciales del suelo. Lo cual resulta particularmente relevante en aquellas ciudades que no tienen publicados censos de actividades comerciales, o la información catastral disponible es demasiado genérica para realizar estudios detallados. Con ello, se han realizado estudios de la complejidad urbana a través del binomio uso/actividad (Nolasco-Cirugeda y García Mayor, 2014; Quercia y Saez, 2014; Agryzkov etal., 2015; Bentley, Cramer y Müller, 2015; Cerrone, Lehtovuori y Pau, 2015; Jiang etal., 2015; López-Baeza, Cerrone y Männigo, 2017). 
En tercer lugar, y basados en la premisa de que las redes sociales y las plataformas de búsqueda de lugares constituyen el plano de encuentro entre el plano físico y virtual de la vida social; y que por tanto la red social es un indicador del "pulso" de los lugares urbanos, una enorme cantidad de estudios infieren la afluencia de público hacia éstos a través de las plataformas, y con ello conocer su demanda o popularidad y con ello ubicar lugares de interés (Van Canneyt etal., 2012), áreas de oportunidad (Cerrone, Lehtovuori y Pau, 2015; Martí, García-Mayor y Serrano-Estrada, 2019), o espacios que incitan a ser utilizados por el público (Cheng etal., 2011; Quercia, Aiello, etal., 2015). Esta inferencia puede establecerse por recuento de publicaciones geoetiquetadas - como fotografías en Flickr y Panoramio (Chen y Roy, 2009; Hamstead etal., 2018; Salas-Olmedo etal., 2018) o Instagram (Xia etal., 2014; Cerrone, Lehtovuori y Pau, 2015), 'tweets' (Silva etal., 2014; Lansley y Longley, 2016; Hamstead etal., 2018), check-ins en Foursquare (Cheng etal., 2011; Hong, 2015; Martí, Serrano-Estrada y Nolasco-Cirugeda, 2017; Salas-Olmedo etal., 2018), por acumulación de valoraciones (Chen, 2016).

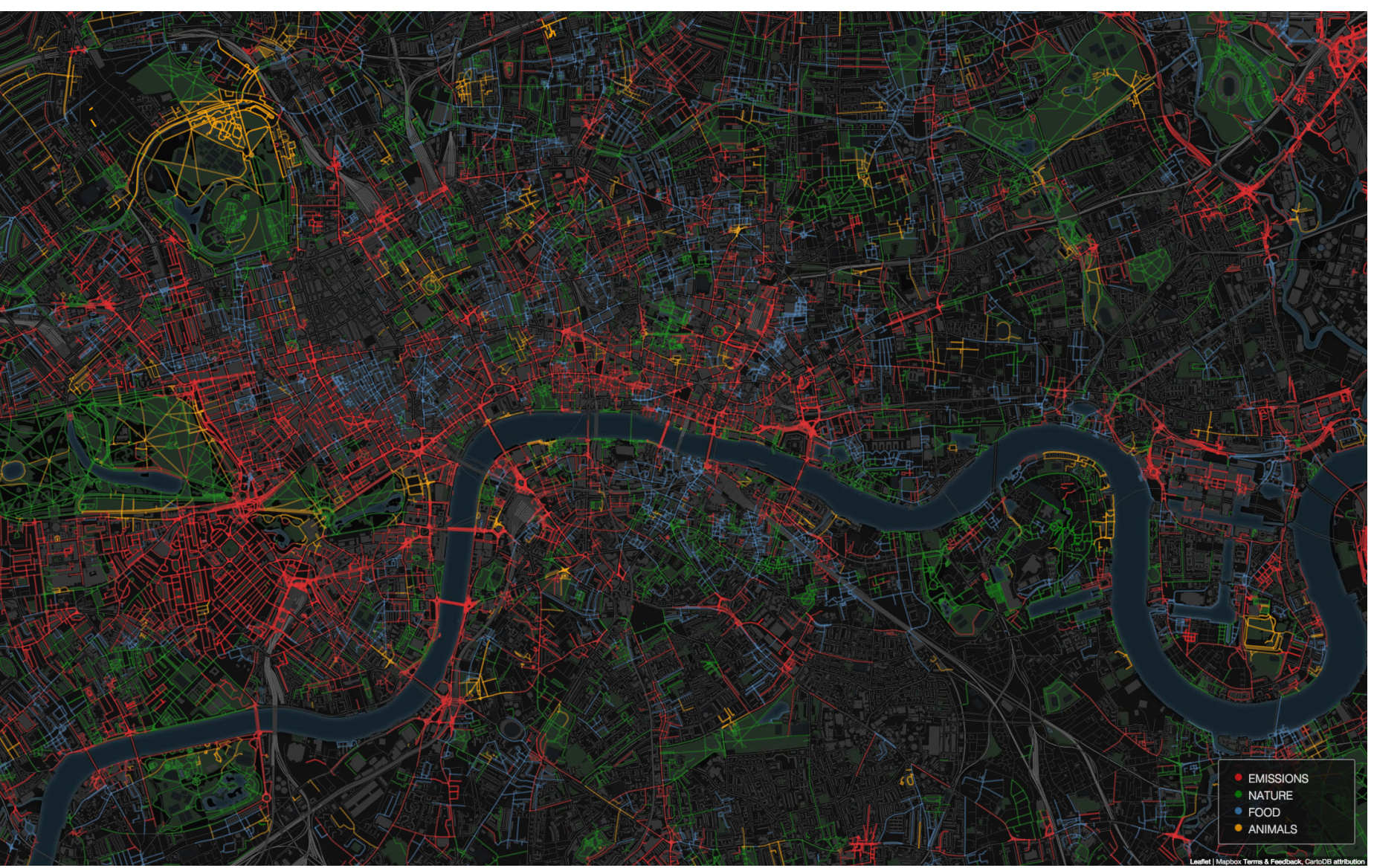

Figura 20. Mapa olfativo de Londres. Fuente: (Quercia, Schifanella, et al., 2015)

Aparte de los estudios derivados de las características objetivas de los lugares, otros persiguen identificar sus características subjetivas analizando la información no estructurada de cada publicación para elaborar mapas perceptivos urbanos. Son populares las investigaciones de Daniele Quercia y otros $(2015 ; 2015)$ en las que se identifican los las calles de encuentro social, con olores característicos, o con sentimientos de felicidad manifestados en redes sociales [VÉASE FIGURA 20]. También la asociación de emociones positivas o negativas en lugares a través de sus hashtags asociados (Cerrone, Lehtovuori 
y Pau, 2015), u otras sensaciones como la percepción de ruido utilizando herramientas de análisis semántico de texto no estructurado basadas en inteligencia artificial sobre redes sociales y plataformas de información turística (Gasco, Asensio y De Arcas, 2017; Gascó etal., 2019). También se han realizado análisis perceptivos basados en imágenes para identificar elementos representativos del paisaje urbano (Hochman y Manovich, 2013; Dunkel, 2015), o el análisis de imágenes basado en inteligencia artificial para inferir índices de cobertura vegetal en las ciudades ${ }^{37}$ (Seiferling etal., 2017).

Como evidencian estos cuatro tipos de estudio, las fuentes participativas de información geográfica se han utilizado para elaborar descripciones del espacio urbano desde su percepción individual produciendo acumulaciones de conocimiento accesibles de manera colectiva, y como tales, accesibles por los planificadores urbanos. Sin embargo, la corriente descriptiva no se limita a la localización y descripción colectiva de lugares, sino que también plantea vías para el estudio de dinámicas urbanas de agrupación y comportamiento colectivo.

\subsubsection{Comunidades y dinámicas}

Si las investigaciones en la línea anterior estaban más centradas en un espacio urbano integrado por lugares monitorizados por sus usuarios, una segunda derivada en los estudios urbanos basados en plataformas digitales es la monitorización de usuarios. En su conjunto, el uso de fuentes convencionales de información geográfica urbana, combinados con las descripciones de los lugares urbanos y su popularidad, en combinación con las descripciones de los hábitos individuales de los ciudadanos que quedan reflejados en determinadas plataformas sociales, permite elaborar una descripción espaciotemporal todavía más detallada del sistema urbano.

Llegados a este punto, la elección del término 'sistema' no es banal. La ciudad es un sistema comunicativo dinámico cuyas unidades básicas son las parcelas, sus usos asociados, y sus redes de comunicación internas y externas, y las actividades humanas que en ella se desarrollan (Ruiz-Sánchez, 2001b). Por agregación, las plataformas digitales permiten rastrear esas actividades individuales al interior del sistema urbano, y con ello inferir el comportamiento de la masa.

En esta línea, han proliferado estudios tratando de geolocalizar a la población en contraste con los censos oficiales (Steiger etal., 2015), comunidades sociales basadas en el idioma, raza y otras características sociodemográficas (Fischer, 2011; Wall y Kirdnark, 2012; Graham y Zook, 2013; Graham, Hale y Gaffney, 2014; Luo etal., 2016), temas de conversación (Lansley y Longley, 2016) o ideologías (Himelboim, McCreery y Smith, 2013; Smith etal., 2014). Consecuentemente, la detección de comunidades urbanas puede contribuir en la evaluación de la segregación de éstas (Shelton, Poorthuis y Zook, 2015; Xu etal., 2019).

\footnotetext{
${ }^{37}$ Los resultados del proyecto Treepedia pueden consultarse en: http://senseable.mit.edu/treepedia
} 
Otra parte del análisis de datos agregados de individuos ha permitido la detección de patrones de desplazamiento generales en la ciudad en el tiempo (Noulas etal., 2012; Lee, Wakamiya y Sumiya, 2013; García-Palomares etal., 2018). Incluso, conociendo las características de los usuarios, pueden conocerse algunos hábitos de movilidad de determinadas comunidades urbanas; como por ejemplo residentes y turistas (Girardin etal,, 2008; Fischer, 2010; Salas-Olmedo etal., 2018) [VÉASE FIGURA 21], o comunidades representadas por la finalidad de la aplicación; como por ejemplo los deportistas (Vanky, 2017; Romanillos etal., 2018).

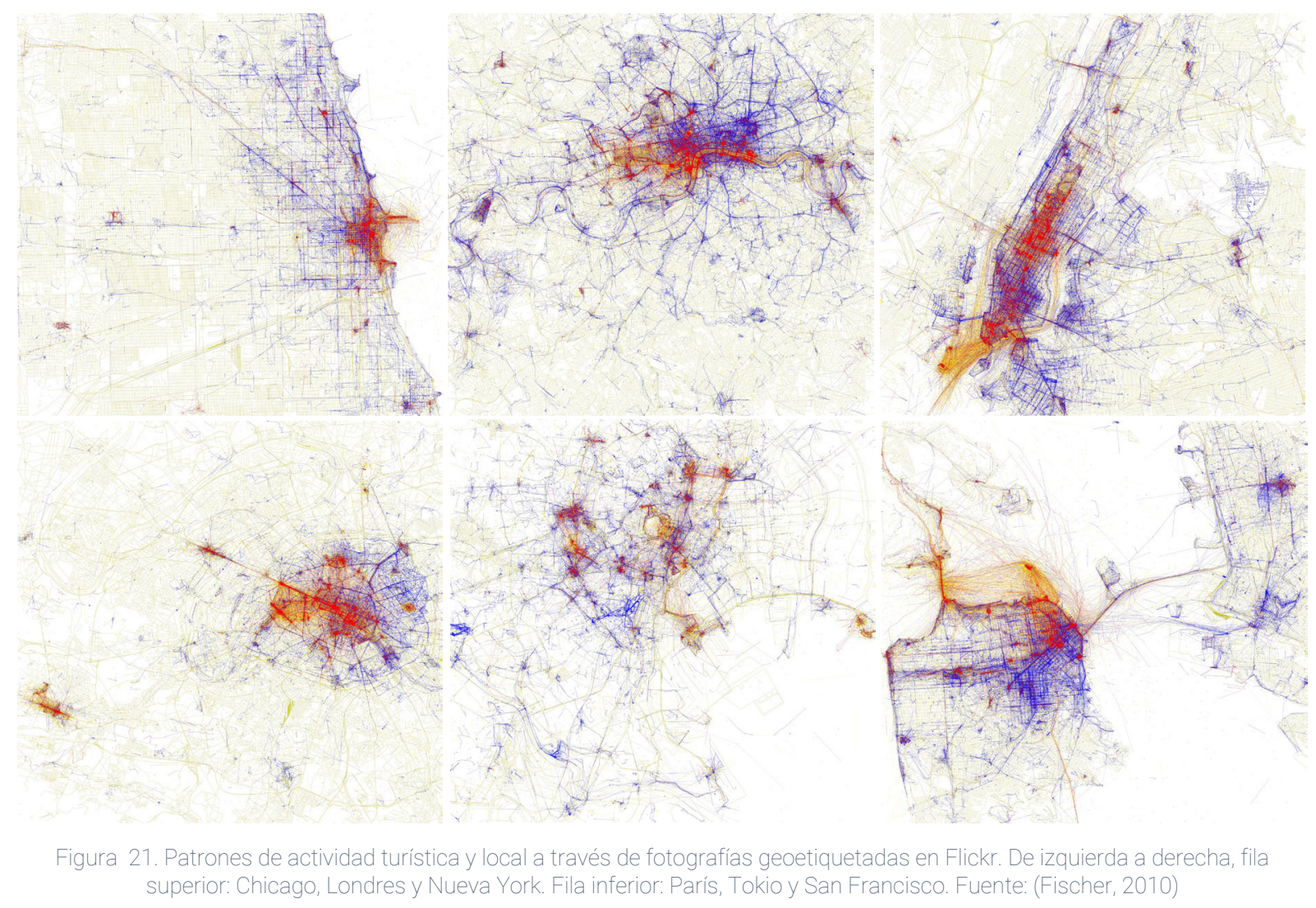

En esta línea, los LBS constituyen fuentes de datos útiles para detectar tanto polos de actividad cotidiana Oas (Jaeger etal., 2007; White etal., 2009; Granell y Ostermann, 2016) o eventos (Hochman y Manovich, 2013; Cordeiro y Gama, 2016).

Necesariamente, esta revisión bibliográfica es incompleta dada la gran cantidad de investigaciones que todavía se llevan a cabo con el fin último de realizar descripciones detalladas del sistema urbano en el tiempo. En esta variedad, caben destacarse los métodos más relevantes utilizados para la incorporación de los LBS en los estudios urbanos, entre los que se encuentran en primer lugar el acceso a APIs y 'scrapping' para la obtención de datos, y análisis de agrupamiento. Estas metodologías se presentan en el [ANEXO III] de esta tesis. 


\subsubsection{La crítica a la corriente descriptiva}

No cabe duda de que la descripción de la ciudad a través de LBS constituye una especialidad en relativo auge dentro de los estudios urbanos. La ubicuidad de este tipo de servicios, su uso por una parte de la sociedad cada vez mayor; su cobertura global y protocolos de acceso estandarizados facilitan la elaboración de estudios comparativos entre diferentes ciudades; la dimensión temporal en la creación y actualización de los datos permiten elaborar estudios dinámicos; y la granularidad de los datos basada en las observaciones individuales de los usuarios permite extraer con facilidad de características subjetivas de la ciudad percibidas por una población de usuarios numerosa en comparación con las técnicas de análisis convencionales. Todo ello en un coste de recolección menor a la elaboración de estudios ad-hoc para recopilar la misma cantidad de información (Folch, Spielman y Manduca, 2018; Martí, Serrano-Estrada y NolascoCirugeda, 2019). Una literatura académica que crece a pasos agigantados, rica en objetivos, métodos y representaciones hasta ahora inéditas de los sistemas urbanos así lo evidencia.

Sin embargo, la popularidad de este método descriptivo también ha hecho crecer en número las críticas a este tipo de fuentes; llegando a ponerse en cuestión la veracidad de las representaciones de la ciudad realizables por estos medios. Al margen de las cuestiones que conciernen a la privacidad de los usuarios que ven rastreadas sus publicaciones con fines (Acquisti y Gross, 2009; Lindamood etal., 2009; Boyd y Crawford, 2012; de Montjoye etal., 2013; Graham y Shelton, 2013; Arribas-Bel, 2014; Kitchin, 2014b; Dunkel, 2015); la crítica plantea una cuestión crucial que atañe a esta tesis: ¿ofrecen los LBS una representación veraz de la ciudad?

Boyd y Crawford (2012, p. 663) advierten del peligro de la 'mitificación' del big-data como "la creencia extendida de que los grandes volúmenes de datos ofrecen una forma elevada de inteligencia y conocimiento antes inalcanzable; dotada de un aura de verdad, objetividad y precisión". Frente a esto, subrayan la preocupación de que se tengan en cuenta las propiedades y límites de cada conjunto de datos con independencia de su tamaño para evitar observar patrones donde no los hay. A este respecto, se han identificado numerosos sesgos y desafíos que, si bien no invalidan estas fuentes de datos para describir los sistemas urbanos, plantean cuestiones sobre la naturaleza de los LBS. Si la fuente está sesgada 'per se', debe adecuarse la metodología a tal efecto.

Un primer grupo de limitaciones de utilizar plataformas de información geolocalizada son aquellas de carácter técnico. Dada la imprecisión ocasional del GPS (Raper etal., 2007), algunas plataformas pueden ofrecer sistemas de estandarización por lugares y/o direcciones postales exactas mientras que otras no. Esto evidencia una falta de estándares de calidad de la información geográfica accesible; no existiendo métodos unificados para garantizar que la ubicación reportada de algunos datos sea la real (Raper etal., 2007; Goodchild, 2013; Spyrou, 2016; Huang etal., 2018). Además, cada API impone limitaciones sobre la cantidad de información descargable en cada consulta -de número de resultados, fecha de consulta, o número de consultas en un periodo de tiempo. Esto 
impide acceder a la totalidad de la información almacenada en la base de datos de un LBS. Asimismo, los criterios por los que una plataforma ordena y selecciona la información descargable pueden no estar previamente especificados (Joseph, Landwehr y Carley, 2014); lo cual dificulta calibrar los sesgos de la fuente (Boyd y Crawford, 2012; Tufekci, 2013). Como se ha explicado en profundidad en el capítulo anterior, las plataformas digitales cumplen con un propósito de monetización de la información; lo cual hace que la fracción observable de la fuente de datos responda a los intereses de cada plataforma. La relevancia de una publicación puede variar con los criterios propios de cada plataforma, los cuales no deben pasar inadvertidos. Por ello, y aunque esta circunstancia también se dé en fuentes institucionales, no se debería atribuir el valor de la 'neutralidad' a los LBS, por muy desregulada que parezca la aportación de datos a estas fuentes. Por último, salvo que la información descargada se ponga a disposición del público -lo cual podría incurrir en infracciones de copyright - la investigación no sería reproducible por terceras partes, y por ello se dificulta su verificabilidad (González-Bailón etal., 2014; Granell y Ostermann, 2016; Martí, Serrano-Estrada y Nolasco-Cirugeda, 2019).

Además de las limitaciones técnicas, se unen las sociodemográficas. El primer sesgo es la representatividad de la muestra analizable. El uso de LBS tiende a limitarse a usuarios de con conexión a internet ${ }^{38}$ (Arribas-Bel, 2014; Graham, 2015); brecha que aun existiendo, es cada vez menor. A pesar del estrechamiento de dicha brecha, existen otro tipo de barreras que convergen en una adopción desigual de una plataforma digital; lo cual supondría que, a pesar del enorme tamaño de las muestras de datos desagregados descargables de una plataforma digital, el resultado manifieste los sesgos implícitos en esta adopción desigual (Folch, Spielman y Manduca, 2018). Entre otros, estos sesgos incluyen la usabilidad de la interfaz o el distinto uso de una plataforma hecho por una ciudadanía diversa demográfica y socialmente (Nielsen, 2006; Elwood, 2008; Elwood, Goodchild y Sui, 2012; Tufekci, 2013; Sloan y Morgan, 2015; Yuan, Wei y Lu, 2018). Generalmente, las plataformas digitales, incluyendo las basadas en la geolocalización se utilizan por grupos sociales acotados (Sloan y Morgan, 2015). Por ello, algunas fuentes podrían resultar inutilizables para un análisis urbano cuyo propósito sea crear descripciones generales de la ciudad (Bennet, 2015; Cerrone, Lehtovuori y Pau, 2015). Además, en la medida que estos sesgos sociales varían con el lugar, se ponen de manifiesto barreras digitales interculturales en caso que se estén realizando estudios comparados (Graham, 2015), los cuales pueden ser multiescalares - entre lugares, barrios, ciudades, países, o cualesquiera que sean las unidades espaciales de análisis (Shelton, Poorthuis y Zook, 2015). Es prácticamente imposible garantizar que la muestra sea representativa, o igualmente representativa en la totalidad de una ciudad (Bao, Zheng y Mokbel, 2012; González-Bailón etal., 2014; Huang y Wong, 2015; Granell y Ostermann, 2016), ya que habrá lugares que estarán más representados que otros, como resultado de los sesgos

\footnotetext{
${ }^{38}$ Aunque la mayoría de autores consideran el smartphone como un equipo esencial para acceder a LBS, en la práctica muchos de ellos también cuentan con interfaz web accesible desde un ordenador de sobremesa con una conexión no inalámbrica; dado que procesan la geolocalización de los usuarios por medio de la dirección postal.
} 
comportamentales de los usuarios de cada servicio digital, además de los sesgos del propósito de cada plataforma.

Además de los técnicos y demográficos (qué público utiliza cada aplicación), existen otros sesgos de carácter comportamental, respectivos al uso que determinados usuarios hacen de las plataformas digitales. Algunos autores sostienen que en los servicios geolocalizados se tiende a sobrerrepresentar la excepcionalidad e infrarrepresentar la cotidianeidad (Boyd y Crawford, 2012; Bentley, Cramer y Müller, 2015). Los usuarios pueden tender a realizar más publicaciones ligadas al ocio - como visitas a eventos, locales de hostelería y lugares con valores culturales- que aquellas relativas a sus lugares de trabajo y residencia. También existen tendencias sociales a reportar las experiencias excepcionalmente buenas o malas, y por tanto infrarrepresentar aquellas neutrales (Marwick y Boyd, 2011); y sesgos de adquisición, es decir informar sobre eventos cuya participación ha requerido de una inversión económica como transacciones comerciales (Hu, Pavlou y Zhang, 2017). Además, los usuarios pueden crear información falsa que a pesar de adecuarse al propósito de la aplicación donde se ha creado, podría añadir ruido en un análisis urbano. Es el caso de crear publicaciones con carácter humorístico en redes sociales etiquetado en lugares que no se corresponden bien con las coordenadas; o bien con la descripción del lugar representado (Cramer, Rost y Holmquist, 2011; Rost etal., 2013). Por último, y quizás de los sesgos más relevantes se presenta la reflexividad de determinadas plataformas digitales. Si su función es informar a los usuarios, éstos podrían modificar su comportamiento en base a la información a la que acceden. En la medida en que un usuario toma una decisión informada en base a un LBS, y ese servicio se utiliza como fuente de información en una investigación urbanística, la fuente podría no estar reflejando comportamientos 'normales' sino alterados (Hochman y Manovich, 2013; Tufekci,

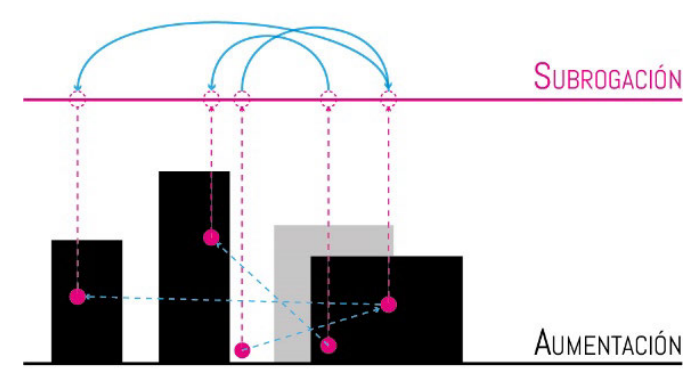
2013).

Ante estas limitaciones, parece imposible la subrogación [VÉASE FIGURA 22] de las metodologías de investigación social tradicionales a utilizar las plataformas digitales como una fuente representativa de una realidad tan compleja como la ciudad. Si bien es cierto que la adopción masiva de plataformas ha incrementado la cantidad de información sobre la actividad social, y en consecuencia ha ampliado la capacidad de los investigadores de estudiar temas, sujetos, poblaciones y técnicas de análisis (Edwards etal., 2013). Por ello, los LBS como fuentes de información urbana aumentan las dimensiones observables de los mismos con respecto a las fuentes de información institucionales (ibid. 2013). Lo cual no hace sino subrayar su complementariedad (Cranshaw etal., 2010, 2012; Edwards etal., 2013; Tufekci, 2013; Massa y Campagna, 2016; Martí, Serrano-Estrada y NolascoCirugeda, 2019). El espacio tangible, y la comprensión de sus dimensiones espaciales y sociales hace posible contextualizar la información accesible a través de LBS. Por ello se sostiene que 'lo que sucede' en el espacio urbano es una combinación de lo observable, 
tanto por métodos tradicionales como por las nuevas fuentes de información en su contexto específico (Deng y Newsam, 2017; Folch, Spielman y Manduca, 2018).

Aun teniendo potencial de evidenciar procesos urbanos de manera relativamente sencilla, sería naif atribuir neutralidad y una fiabilidad total a los datos accesibles en los LBS para describir muchos de los aspectos urbanos que han quedado descritos hasta aquí. Estos datos se han recolectado con el propósito específico de cada aplicación; que en muy contadas ocasiones es el de informar a las administraciones y a los urbanistas sobre el funcionamiento de un sistema urbano. Se trata de información recopilada y filtrada (Couldry y Hepp, 2016) constituyendo un entorno socioespacial mediatizado específico (Couldry y McCarthy, 2004a) que cumple con un propósito. Incluso si este propósito es mapear una ciudad -como sucede por ejemplo en Google Maps-, la priorización de cierta información sobre otra está supeditada a los propósitos de monetización de dicha aplicación.

Debido a esto, una parte de la literatura se centra en la reorientación (Edwards etal., 2013, p. 254) social que resulta de esta mediatización de la información geográfica urbana. En ella, los LBS no se contemplan como una fuente para la descripción de la ciudad, sino como un motor de transformación social y urbana. Esta corriente analiza las jerarquías sociales emergentes de las redes de telecomunicaciones, y los comportamientos individuales y colectivos en estos nuevos entornos digitales; que actúan como facilitadores o inhibidores de intercambios, puentes entre comunidades, catalizadores de acciones y sentimientos (ibid. 2013). Para estudiar estos fenómenos, tiende a recurrir a la ciencia de redes y a la descripción de las transformaciones normativas y económicas derivadas de la adopción masiva de determinadas plataformas. Es decir, contempla los LBS no como 'sensores' - de lo que acontece en un dominio urbano-, sino como 'actuadores'-basados en esa información contextual- en un espacio urbano digitalmente integrado (Ratti y Claudel, 2016). 


\subsection{Transformar el sistema}

Aunque los servicios geolocalizados proporcionen información útil para el análisis urbano; ampliando los métodos posibles para afrontar cuestiones perennes en los estudios urbanos - representación, movilidad y actividad cotidiana y eventual, percepción del entorno, y complejidad urbana entre otras-, su rol en los estudios urbanos no se limita a describir el funcionamiento de las ciudades, sino que se ha estimado su capacidad de transformar la ciudad.

Los sesgos anteriores ponen de manifiesto que no son un reflejo de la ciudad, y en numerosas ocasiones deben calibrarse los sesgos de estas fuentes con otras fuentes y técnicas tradicionales. Pero también muestran que los LBS constituyen un espacio digital 1) regulado por las compañías que poseen los datos aportados por sus usuarios, limitando el acceso a terceros partes por razones técnicas y económicas; 2) en el que en ocasiones, los protocolos de filtrado y ordenado de los resultados no se especifican -quedando a criterio del observador la evaluación de los sesgos y limitaciones técnicas que pudiera tener la fuente de datos-; 3) al que la población accede de manera desigual en función de sus circunstancias socioespaciales y las de su entorno; 4) donde los individuos pueden manifestar comportamientos alterados debido a la naturaleza de cada aplicación que en última instancia alteran el estado del sistema digital que les ha informado.

Esta alteración del comportamiento individual se apoya en las decisiones 'racionales'39 tomadas en base a la información digital que aumenta los datos del entorno perceptibles por un individuo. Si bien ya es difícilmente predecible el comportamiento individual en un espacio urbano, mucho más difícil de predecir es su comportamiento en ese mismo espacio mediatizado. Sin embargo, al igual que la configuración espacial y normativa de una ciudad condiciona las opciones individuales de interacción social (Hillier y Hanson, 1984), la configuración de un LBS añade nuevas condiciones, posibilidades y limitaciones a las interacciones sociales en el espacio urbano.

Esto tiene lugar en los espacios relacionales y normativos urbanos; como apuntan algunas investigaciones recientes. Por una parte, los LBS generan un nuevo abanico de comunicaciones posibles para un individuo con otros ubicados en los lugares que un algoritmo de filtrado de información prioriza - por sus características, o por proximidad entre usuarios. Estas conexiones potenciales se pueden representar y analizar utilizando la topología de red; de manera análoga a estudios del espacio tangible. Por otra parte, los LBS pueden superponer dinámicas urbanas que transformen la planificación de la ciudad, desde los usos del suelo hasta la distribución de servicios de transporte y logística.

\footnotetext{
${ }^{39}$ La teoría de la acción racional parte de la premisa de que un individuo ante un abanico de comportamientos seguirá aquel que maximice su beneficio frente al coste. Este beneficio puede no ser económico sino también de satisfacción de otros valores individuales. Asimismo, la idea de racionalidad no es universal sino subjetiva.
} 


\subsubsection{Reconexiones informacionales}

La topología de red puede mostrarse eficaz a la hora de evaluar la accesibilidad a distintos lugares urbanos. Es una rama de las matemáticas que estudia las interconexiones entre los elementos de un sistema y las características estructurales que de estas conexiones se deriva. Alexander (1964) ya analizó la importancia de la complejidad de la red de interacciones entre las actividades en una ciudad para garantizar su durabilidad histórica y capacidad de adaptación a las circunstancias del entorno urbano. Esta visión entre complejidad topológica y resiliencia ha sido validada desde numerosas disciplinas ajenas al urbanismo, desde las que se han estudiado las dinámicas evolutivas de las 'redes complejas libres de escala' (Albert y Barabasi, 2002; Gao, Barzell y Barabasi, 2016). En el [ANEXO IV - APUNTES SOBRE TOPOLOGÍA DE REDES], se ha realizado un resumen sobre conceptos relevantes de la ciencia de redes que han sido relevantes en el urbanismo, abarcando los tipos de redes (semitramas, mallas, árboles, estrellas...), su resiliencia, y variables analíticas como la centralidad.

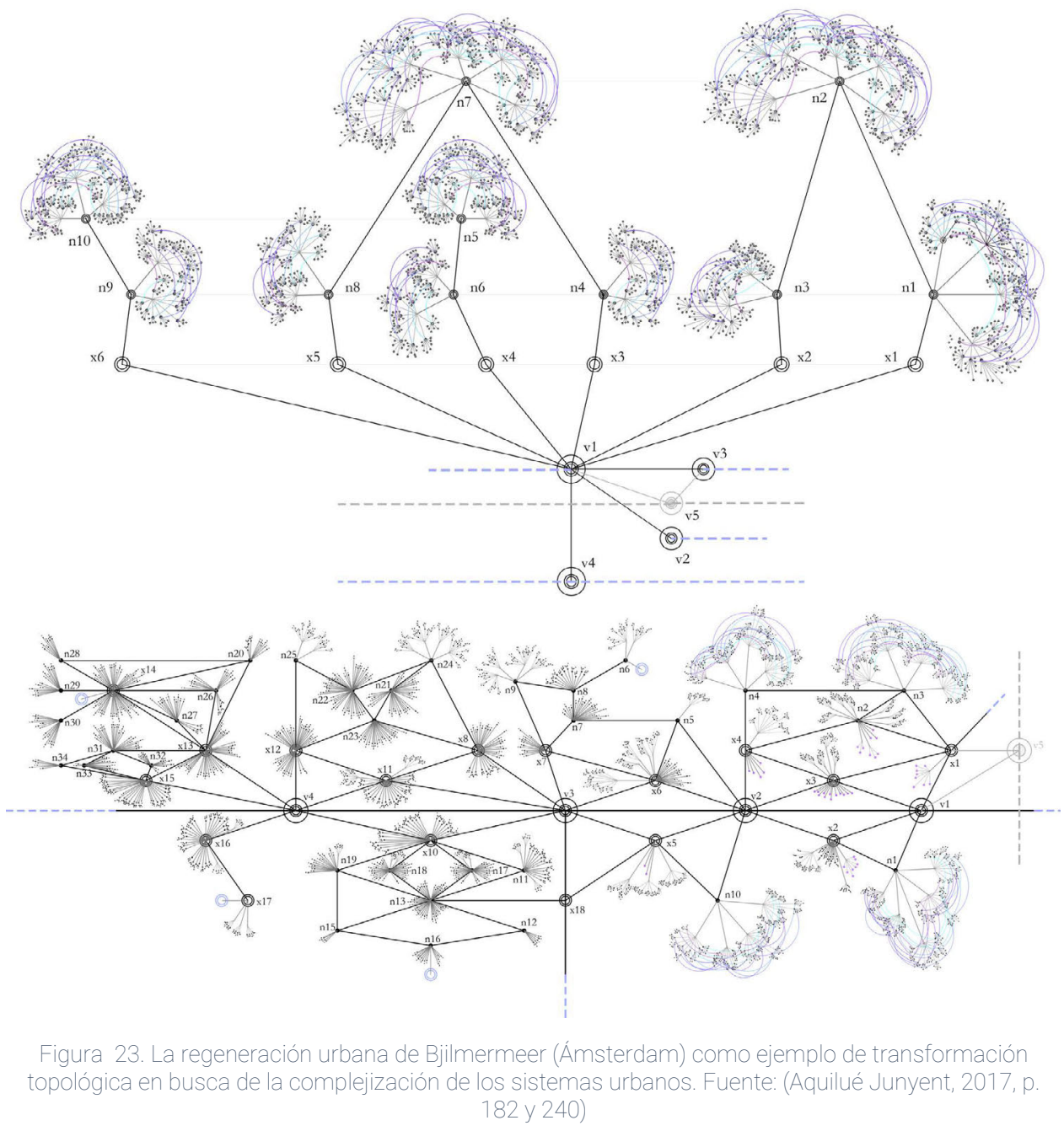

En relación con procesos de cambio urbano desde una perspectiva de sistemas resilientes; la tesis de Aquilué Junyent (2017) "El urbanismo de la seguridad frente a la complejidad urbana", donde se evalúan desde la topología de red las transformaciones de Bjilmermeer (Ámsterdam) [VÉASE FIgURA 23], Dobrinja (Sarajevo) y Beirut. Sea mediante el grafo primario 
o el dual, este tipo de trabajos evalúan las topologías urbanas desde una dimensión netamente material; basándose en la disposición de las infraestructuras de movilidad tangibles para evaluar los intercambios posibles y más probables en los sistemas urbanos. En línea con la accesibilidad introduciendo una componente informacional y normativa en línea con Webber, mi Trabajo de Fin de Máster "Conexidad y evolución, una aproximación topológica a la idea de resiliencia" (Lorente-Riverola, 2015a) se presta una especial interés a los proyectos en el territorio como piezas de información que pueden legitimar o deslegitimar el uso de las infraestructuras que conforman los sistemas urbanoterritoriales.

Sin embargo, el cambio en los sistemas urbanos también se puede entretejer desde el plano geográfico intangible que construyen unas telecomunicaciones que ahora han adquirido la capacidad de mediatizar el dominio de los lugares urbanos. Internet es prácticamente ubicuo en las ciudades del norte global a través de las redes móviles 3,4 y próximamente $5 \mathrm{G}$, y la informática se ha miniaturizado hasta el punto de convertirse prácticamente en un apéndice del cuerpo humano. En este contexto, se están dando reestructuraciones de determinadas redes urbanas a través de las TIC (Mitchell, 1999, 2003; Ratti, 2005; Ratti y Claudel, 2016). Aunque la analogía del ciudadano-cíborg de William Mitchell $(1999,2003)$ se antoje ciertamente utópica, los smartphones y con ellos los LBS han posibilitado que los ciudadanos formen parte de redes geográficas digitales en todo momento y lugar -incluso si no se hace uso de estos servicios ${ }^{40}$.

A nivel global, el Senseable City Lab del MIT; dirigido por Carlo Ratti, Fabio Duarte y Paolo Santi, es uno de los grupos de investigación que más investigaciones ha realizado sobre la topología de las redes digitales en la ciudad. Sus estudios abarcan desde el análisis territorial y urbano a través de redes telefónicas, hasta la utilización de LBS para la rearticulación estratégica de servicios urbanos.

Los primeros estudios se basan en las llamadas telefónicas para establecer vínculos entre lugares urbanos localizables a través de la centralita telefónica de origen a la centralita de destino. Con esta base, pueden estudiarse las relaciones sociales en el espacio, tanto a nivel urbano, evidenciando la segregación de comunidades urbanas y territoriales que, en ocasiones, cuestionan las divisiones administrativas existentes en favor de las que evidencia la modularidad de red (Ratti etal., 2010; Xu etal., 2019). Sin embargo, la finalidad de estas investigaciones no es resaltar los cambios que posibilitan las redes comunicativas en las ciudades sino representar un estado actual del sistema en el presente.

Estas reestructuraciones tienen un carácter fundamentalmente cognitivo, y sin embargo sus efectos se extienden al espacio urbano más tangible. Sin embargo, se han evaluado desde una óptica más teórica que empírica, existiendo escasos estudios topológicos de las redes de intercambio que pueden generar los LBS en la ciudad. Al igual que los estudios

\footnotetext{
${ }^{40}$ Por ejemplo, Google utiliza los datos de ubicación de los teléfonos móviles en todo momento, no sólo cuando se utiliza el GPS del dispositivo, sino también para personalizar anuncios, calcular la afluencia a lugares de pública concurrencia presentes en Google Maps entre otros fines (Google, 2016).
} 
urbanos descriptivos, la literatura sobre las transformaciones urbanas a través de servicios geolocalizados es fragmentaria, pero en comparación con los anteriores estudios es muy escasa.

En primer lugar, cabe destacar que las plataformas digitales crean comunidades humanas policéntricas y eventuales cuyas comunicaciones se articulan en torno a intereses compartidos (Hochman y Manovich, 2013; Stefanidis etal., 2013; Hochman, Manovich y Yazdani, 2014; Manovich, 2016). "El código (informático) hace posible que las relaciones entre causas y efectos tangibles tengan lugar en la distancia [...] construyendo una red compleja densa e inescapable de interconexiones en el espacio y tiempo" (Mitchell, 2003, pp. 4-5).

La acumulación de información puede hacer visibles determinados lugares urbanos a terceras personas, desvinculando así la cognición de la red urbana tangible con respecto a su representación digital mediatizada (Maitland, 2010; Couldry y Hepp, 2016) de manera similar al descubrimiento de la ciudad por medio de recomendaciones cara a cara, que se han hecho confiables dada la reputación de las plataformas digitales (Duhan etal., 1997; Kumar y Benbasat, 2006; Tuominen, 2011).

Por ello, un LBS construye un mapa de relaciones entre lugares urbanos variable en el tiempo [VÉASE FIGURA 24] que, por los sesgos propios de cada servicio, cabe debatir si es un mapa real o intencionalmente producido para rearticular la actividad humana hacia los puntos de interés que cada plataforma integra (Silva etal., 2014). A través de estos servicios, la imagen de la ciudad viene determinada por medios y canales intangibles (Alghamdi y Al-Harigi, 2015).
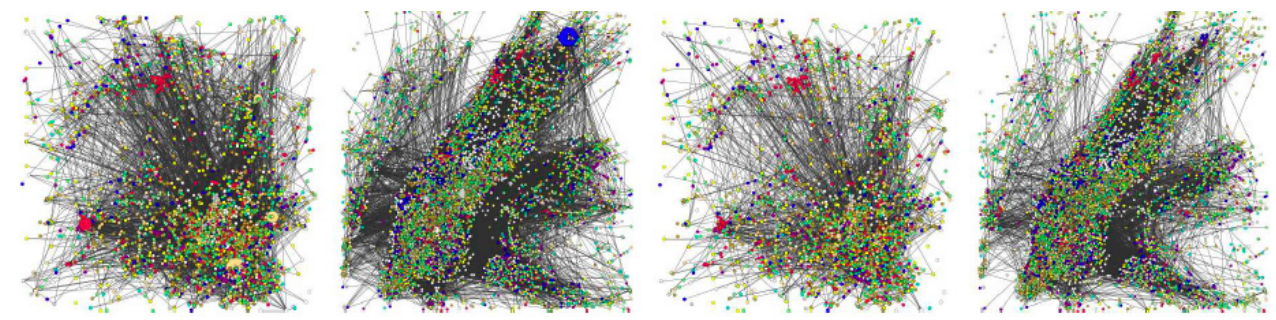

Figura 24. Relaciones de complementariedad entre lugares evidenciados a través de Foursquare. Fuente: (Silva et al., 2014, p. 1.20)

Cada plataforma digital tiene su propia topología basada en las interacciones entre participantes - que tienen un alto grado de autorregulación en busca de generar los efectos de red positivos o sinérgicos que favorecen el escalamiento de las plataformas digitales. Al establecer contactos entre viajeros y viviendas, una selección de lugares urbanos amplía su espacio relacional mediante una red de pares (P2P) de escala global que muestra las características de mundo pequeño e inescalaridad, pero también de enlace preferente hacia aquellos lugares con métricas de reputación (puntuación y número de reservas) relativamente altas [VÉASE FIGURA 25] (Zervas, Proserpio y Byers, 2017; Teubner, 2018). Este comportamiento se repite en plataformas de movilidad privada compartida (Teubner y Flath, 2015). 

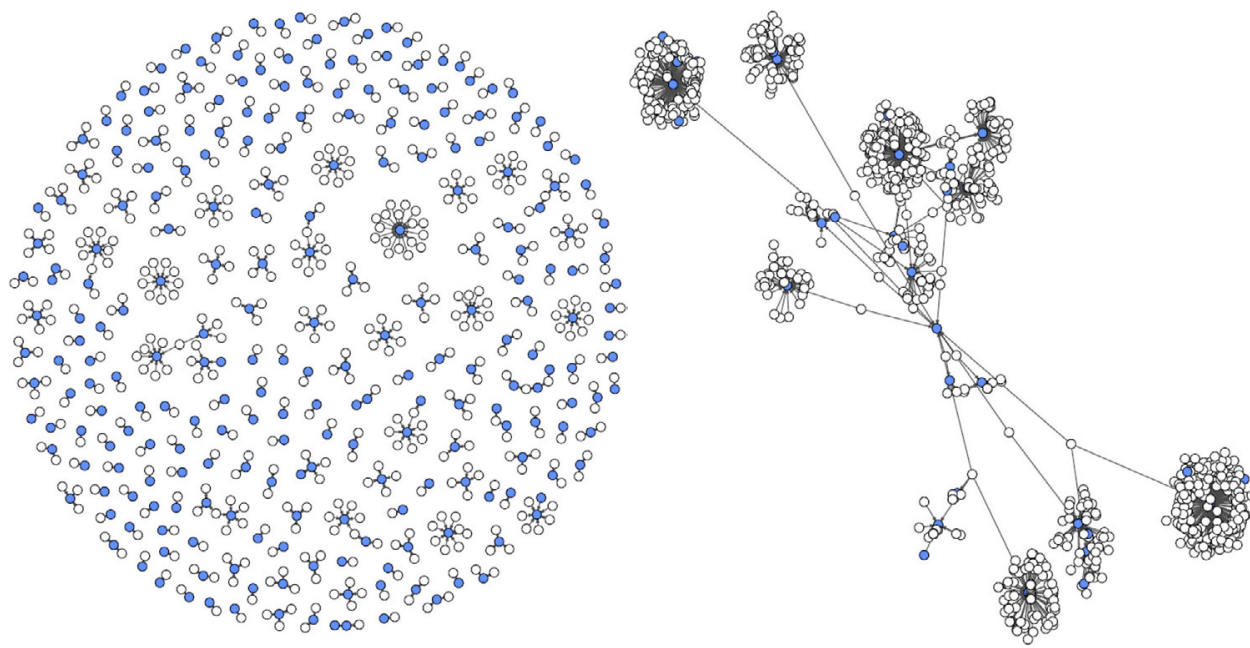

Figura 25. Interacciones entre huéspedes y anfitriones en AirBnB. Selección aleatoria de 500 transacciones (izquierda) y grafo de tres iteraciones desde un nodo semilla (derecha). Fuente: (Teubner 2018)

Si los criterios de enlace preferente dependen de las métricas propias de cada plataforma, cabe plantear la hipótesis de que los LBS están modificando la centralidad cognitiva de los lugares que incorporan. Al igual que se ha realizado por medio de proyectos de regeneración urbana, y situaciones d conflicto (Aquilué Junyent, 2017), podrían constituir un motor de transformación urbana analizable desde el plano comunicativo que construyen.

Quizás el ejemplo más relevante de esta transformación transformación topológica intencionada como herramienta de proyecto a escala urbana se de en torno a la mediatización de los viajes compartidos. Bajo el pretexto de aprovechar la capacidad de uso de determinados recursos geolocalizados -objetivo transversal en la mal denominada 'economía colaborativa'- las comunicaciones posibles entre usuarios y recursos puede ser objeto de proyecto en aras de la optimización.

Tachet y otros (2017b) evaluaron en base a la alta predictibilidad que muestran los patrones de movilidad humana en las ciudades (Song etal., 2010) la posibilidad de que estos viajes se realicen en coches compartidos con un coste temporal menor de 5 minutos a la espera de un vehículo. Apoyados en ese principio, y con el apoyo de LBS de movilidad, la complejidad de los viajes privados, en apariencia aleatorios, es gestionable y optimizable en aras de optimizar el uso de recursos en tiempo real (Vazifeh etal., 2018); lo cual puede extenderse de redes de transporte privado, a alternativas de transporte público de masas (Álvarez, Ortega y Ratti, 2018) [VÉASE FIGURA 26].

Estas transformaciones todavía se estén empezando a explorar desde la ciencia de redes, y prácticamente no existan estudios de los decalajes entre las redes geográficas de actividad urbana y sus numerosas digitalizaciones. Sin embargo, los desafíos que plantean a nivel normativo en la ciudad hacen patente la necesidad de explorar un marco unificado del espacio social de los LBS en el urbanismo. 


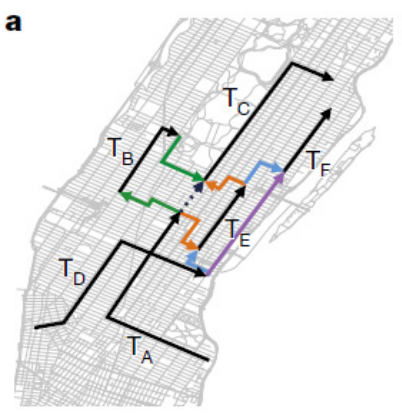

b

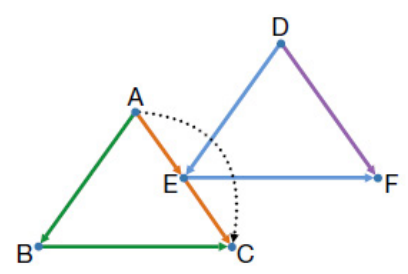

c

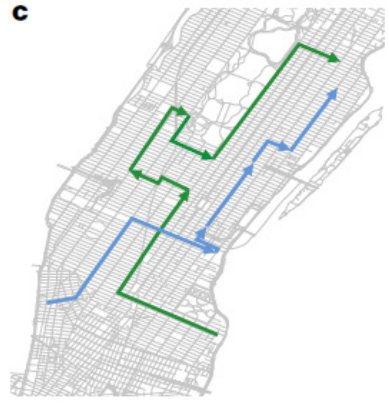

d

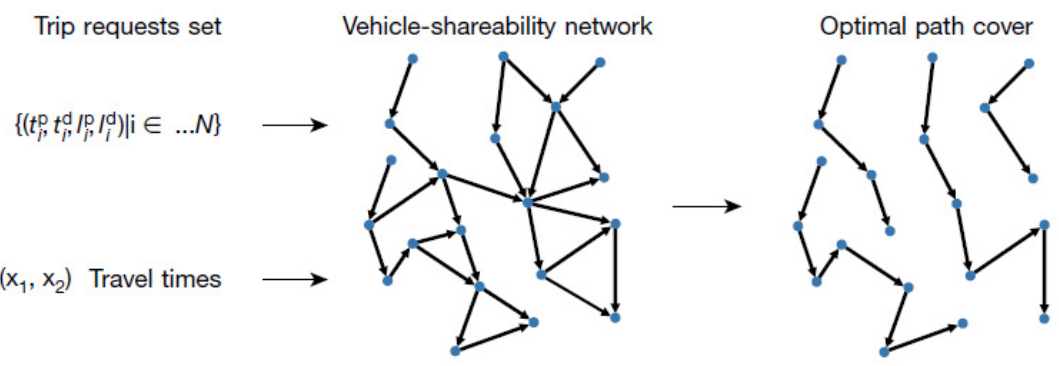

Figura 26. Modelo de compatibilidad de desplazamientos privados basado en LBS. Fuente: (Vazifeh et al., 2018, p. 535)

\subsubsection{Cambios de uso y desafíos organizativos}

Como muestran los apartados anteriores, los LBS constituyen un reflejo de parte de la actividad humana en las ciudades y el potencial de reestructuración de las relaciones que establecen los lugares urbanos con su entorno geográfico local y global. Creando representaciones de lo existente rearticuladas a través de redes autoorganizadas bajo los parámetros que cada plataforma define, se producen "inclusiones y exclusiones aumentadas; visibilidades e invisibilidades que conformarán la manera por la que los lugares se definen, imaginan y experimentan” (Graham y Zook, 2013, p. 77), de modo que "las infraestructuras urbanas se redibujen a través de modelos de asociación basados en la masa social” (Sundararajan, 2016, p. 203).

El último nivel de interacción entre la ciudad y las plataformas digitales son los aspectos normativos y culturales. Con respecto a estos, quizás los LBS hayan supuesto una transformación para las ciudades más palpable. Se parte de la base que un servicio de este tipo legitima una acción con respecto a determinado recurso. Una plataforma de recomendación no sólo constituye un mapa de lugares; además determina los que más probablemente sean de interés a un usuario (Bao, Zheng y Mokbel, 2012) - proceso en el cual el gestor o propietario del lugar puede invertir dinero para aumentar la exposición. Una plataforma de citas legitima utilizar el espacio doméstico privado como lugar de encuentros esporádicos -digitales y físicos; una plataforma de transporte privado incrementa las posibilidades de encontrar un vehículo en lugares ajenos a lógicas precedentes; o una de alquiler vacacional transforma una vivienda hacia un uso hostelero, entre otros muchos ejemplos.

La economía de las plataformas "crea nuevas formas de proveer de servicios convencionales, en general estrictamente regulados, por lo que es esperable que 
aparezcan conflictos regulatorios" (Sundararajan, 2016, p. 137). Sin afán de elaborar una revisión exhaustiva, entre estas externalidades se han observado la propagación de infecciones de transmisión sexual y construcción de mercados de substancias ligadas a las plataformas de citas (Beymer etal., 2014; Winetrobe etal., 2014; Goedel y Duncan, 2016), la competencia con el taxi de las plataformas de transporte de pasajeros, la sobrecarga logística de pequeños comerciantes a través de plataformas de comercio online (Cardenas etal., 2017; Beckers, 2019), o el fenómeno de la gentrificación transnacional de carácter turístico favorecida por el alquiler vacacional de corta duración (Lees, 2015; Cócola-Gant, 2016b, 2016a; Aalbers, 2019).

Para una gran parte de situaciones, la gobernanza urbana institucionalizada no contaba con la emergencia y escalamiento global de estas plataformas, y con ello las numerosas resignificaciones espaciales que producen. Los ejemplos más paradigmáticos son el alquiler vacacional y las VTC; servicios basados en la geolocalización que han alcanzado cierta madurez en su implantación. En España, representadas por las plataformas Uber y Cabify en el caso del transporte, y AirBnB en el de la vivienda vacacional.

La situación en Europa para Uber, como empresa representativa del sector del transporte privado con conductor, - pero que ejemplifica numerosos desafíos que otras plataformas digitales presentan - ha pasado por numerosas batallas legales sobre la regulación del servicio con relación a otros operadores regulados ya establecidos. En primer lugar, por la estabilidad laboral de los conductores, que generalmente operan como trabajadores autónomos bajo una licencia de chófer, más barata que una de taxi. Encarecimiento debido a la fuerte especulación que sufrieron éstas ante la falta de alternativas en el mercado en el que las plataformas de transporte entran disruptivamente. En segundo lugar por las licencias de VTC, que difieren de las de taxi no sólo en precio, sino también en el tipo de servicio prestado - un conductor de VTC únicamente puede recoger pasajeros previa contratación vía app, nunca como una bajada de bandera. Sea como fuere, las plataformas de transporte con conductor han consolidado su operativa y continuado su expansión competitiva en las ciudades (Dudley, Banister y Schwanen, 2017). Fruto de ello, las protestas de taxistas frente al competidor han aumentado (RTVE, 2019), y en Europa se han concretado en la toma de medidas de control del número total de licencias VTC frente a las del taxi (Domínguez Pérez, 2016).

Las plataformas de alquiler vacacional suponen un incremento de la oferta de camas para hospedarse en un destino turístico, entrando en competición con el sector hotelero (Exceltur, 2015; Red2Red Consultores, 2017), pero los impactos disruptivos de estas plataformas han trascendido la mera competencia para suponer desafíos de planificación urbana del uso residencial. Destacan los ejemplos de San Francisco, donde se aprobó la primera regulación en 2014, Amsterdam (2015), o Berlin en 2016. En España, se creó el consorcio "Turisme i Ciutat" en Barcelona para observar los impactos del alquiler vacacional en el mercado inmobiliario. Entre los que destaca un posible incremento de los precios de la vivienda, particularmente aquella en alquiler, ante el mayor potencial de retorno que tiene el alquiler vacacional ante una ocupación turística de la vivienda 
durante un 70\% del año (Pérez etal., 2015; López García, 2017; Red2Red Consultores, 2017). Desde la perspectiva del consumidor, el alquiler vacacional proporciona una experiencia más “auténtica” que un hotel a un precio más asequible (Füller y Michel, 2014; Novy, 2019). Sin embargo, desde la perspectiva de la planificación, el escalamiento de esta solución tecnológica podría estar ligada a problemas denominados de "gentrificación transnacional" (Hackworth y Smith, 2001; Lees, Slater y Wyly, 2008; Aalbers, 2019; Ardura Urquiaga, Lorente-Riverola y Ruiz Sanchez, 2020), que superan en complejidad a la visión tradicional de la gentrificación como el mero reemplazo de la población residente en un barrio por una población de mayor poder adquisitivo (Echaves García, 2017; López García, 2017) encareciendo el coste de la vida.

El posicionamiento de determinadas economías del sur de Europa entre las que se encuentra España, como destino turístico facilita el uso de la vivienda como un recurso para el hospedaje turístico (Janoschka, Sequera y Salinas, 2014; Barron, Kung y Proserpio, 2018), en ocasiones por encima del uso residencial. Se produce un tipo de gentrificación caracterizado por el desplazamiento de la población residente por población extranjera, residente o no, que acude a la ciudad con fines turísticos o laborales. La rentabilidad de acoger en la ciudad este tipo de visitantes puede venir apoyándose en la idea de "rent-gap" (Smith, 1979, 1982) global, que se produce en una propiedad al cambiar su uso (de residencial a hostelero), y su colectivo de usuario, que puede proceder de economías de servicios desarrolladas, y con un fuerte poder adquisitivo, que pueden permitirse pagar una renta mensual superior por el inmueble que la población local, aumentando su valor económico (Cócola-Gant, 2016b, 2016a). Esta red compite con la del mercado de alquiler convencional de larga duración, ya que no sólo podría estar encareciendo los costes de acceso a la vivienda (Wachsmuth y Weisler, 2018), sino que también elimina nodos de la red de otra plataforma - viviendas antes ofrecidas por plataformas especializadas en el alquiler de larga duración frente al alquiler convencional.

Pero el residencial no es el único uso susceptible de transformarse en la economía de las plataformas digitales. Otras aplicaciones como las de distribución logística de comercio electrónico como "Amazon Hub Locker", se sirven de locales comerciales existentes que podrían complementar su actividad con la logística de última milla, reestructurando una red de distribución entre centros logístico de periferia y compradores, y colateralmente transformando potencialmente la afluencia a locales comerciales (Weltevreden, 2008; Carotenuto etal., 2018; Beckers, 2019). Por último, las aplicaciones de citas, o las de movilidad crean una red de accesibilidad informacional a recursos y personas en movimiento en función de su posición geográfica digitalizada (Teubner y Flath, 2015; Vazifeh etal., 2018).

En su conjunto, las alternativas a servicios preestablecidos en forma de servicios geolocalizados tienden a partir de la premisa de que determinados recursos pueden cumplir con una función desarrollada por otros, en la medida que la mano de obra para tales puestas en servicio requiere de un bajo nivel de especialización. En cambio, la red comunicativa por la que se articulan estos servicios está organizada de modo tal que 
genera unas relaciones de mercado, inicialmente arbitradas por los parámetros que cada plataforma fija en ausencia de regulaciones externas. Pero el hecho de que en tales redes la práctica totalidad de comunicaciones sean posibles, no quiere decir que sean equiprobables, precisamente por esos parámetros de arbitraje - véase el concepto de 'datificación' en (Couldry y Hepp, 2016) -, lo cual resulta en una distribución desigual de las centralidades en las redes sosteniendo acumulaciones desiguales de información, y por ello de intercambios probables en determinadas áreas urbanas que, en conjunto han visto aumentar los espacios comunicativos informacionales por las que se hacen accesibles, y que por tanto podrían ser objeto de regulación institucional.

La economía de las plataformas se presta a una regulación que mitigue los 'fallos de mercado'41 que pueden emanar en las plataformas como la competencia con un operador que goza de la ventaja de la 'economía de escala', la asimetría informacional de la que goza el gestor de la plataforma frente al público general, y las externalidades socioeconómicas que produce la apertura de estos nuevos mercados (Rienstra, Bakker y Visser, 2015; Sundararajan, 2016).

Cabría entonces plantear en qué medida las redes de intercambio de información de los LBS constituyen un sistema de aprovechamiento de recursos hipotéticamente infrautilizados, o por el contrario un subsistema urbano competitivo en coste, eficiencia, o desregulación con la organización de actividades precedente. Pero el debate entre el uso especulativo de los recursos frente a las oportunidades de optimización que posibilitan los servicios geolocalizados es secundario para los intereses de esta tesis, puesto que apenas se han estudiado las características estructurales de este tipo de servicios que expliquen cuál es la estructura funcional a escala urbana de los LBS.

Aunque numerosos autores se centran en ilustrar las fricciones o fallos de mercado entre la economía de las plataformas y la economía urbana, la fricción entre estructura funcional urbana y estructura funcional de estos servicios no se ha indagado en profundidad. Atender a las diferencias estructurales entre sistema urbano y subsistemas digitales podría ilustrar las dinámicas de acumulación desigual de información, y por tanto de accesibilidad a los recursos urbanos que acompasa el desarrollo de plataformas digitales de muy diversa índole. Comprender estas dinámicas estructurales podría favorecer el aprovechamiento de las oportunidades que brindan los LBS y contribuir a mitigar los numerosos fallos de mercado que el capitalismo de las plataformas parece favorecer en las ciudades.

\footnotetext{
${ }^{41}$ Un fallo de mercado consiste en una asignación indeseada de recursos que se han puesto en circulación de manera autorregulada al respecto de los objetivos de un colectivo determinado. A grandes rasgos, pueden considerarse una falta de redistribución de los beneficios de un sistema económico (Bator, 1958).
} 


\title{
capítulo 4. \\ Diversidad y accesibilidad
}

METODOLOGIA

\begin{abstract}
Si el marco empírico mostraba una tendencia a realizar estudios comparativos de ciudades a través de una plataforma, esta tesis invierte el método: analizar varias plataformas a través de una ciudad: Madrid
\end{abstract}

\section{Resumen del capítulo}

Como se ha introducido, la complejidad urbana está relacionada con la densidad, diversidad y accesibilidad (Gao, Barzel y Barabási, 2016) de las redes urbanas, sean físicas en la ciudad consolidada o digitales emergentes a través de servicios basados en la geolocalización. Se plantea que la configuración del sistema urbano y la de su entorno digital son interdependientes. La ciudad proporciona la información que recogen los LBS, los cuales la reorganizan pudiendo alterar el funcionamiento de la fuente.

La hipótesis por explorar, dada la naturaleza autorregulada de ambos sistemas, defiende que las zonas urbanas más complejas son aquellas más propensas a la digitalización intensiva, produciéndose una distribución desigual de la información acumulada por los LBS correlativa a la morfología urbana. Dado que esta información se utiliza para rearticular las actividades existentes, el vínculo entre complejidad y digitalización produce un balance desigual de desafíos y oportunidades en la ciudad en forma de alteraciones de la diversidad de estados accesibles que el sistema físicodigital resultante tiene en comparación con su estado anterior. 
El método seguido estudia la morfología urbana y topología de las redes de comunicación de diferentes LBS como paso previo a estudiar la complejidad del sistema urbano en el que se insertan. Se ha elegido Madrid; como ciudad representativa de las capitales sureuropeas que han alcanzado la escala global, aunando morfologías diversas (Lamiquiz Daudén, 2011; López de Lucio et al., 2016). Su estructura pseudo-radial describe un centro de trama orgánica, un ensanche decimonónico ortogonal, y una primera periferia moderna con un desarrollo orgánico en su zona norte (Valdeacederas) coetáneo al ensanche. El río Manzanares y la circunvalación M-30 separan esta ciudad central de una periferia urbano-metropolitana que data de finales del siglo XX. En el terreno digital, Madrid cuenta con buena disponibilidad de datos abiertos institucionales, y se han implementado numerosas plataformas de servicios geolocalizados, pertenecientes a distintas ramas de actividad con alto grado de adopción social. Se han estudiado Facebook places y Foursquare como plataformas de búsqueda y promoción de lugares, HailO/MyTaxi como plataforma de movilidad privada con conductor, Deliveroo y Amazon Hub representando el comercio electrónico B2C (de empresa a consumidor) y Wallapop el C2C (de consumidor a consumidor), Grindr como red geosocial y AirBnB como plataforma líder en el alquiler vacacional.

Utilizando bases de datos espaciales de alto rendimiento (PostgreSQL/PostGIS), se ha creado un modelo geográfico físico-digital de Madrid utilizando que reúne datos abiertos sobre su morfología, redes viarias, e indicadores socioeconómicos y muestras representativas de datos procedentes de las anteriores plataformas. Utilizando algoritmos propios, se ha computado la complejidad del modelo siguiendo un análisis en tres etapas:

1. Análisis morfológico: Análisis geográfico cualitativo y cuantitativo de la huella geográfica de los LBS en Madrid para revelar su estructura formal e identificar las áreas más intensamente digitalizadas, tratando de discernir los lugares urbanos preexistentes de aquellos creados digitalmente. La densidad de datos digitales se ha correlacionado mediante regresión bivariante simple con los indicadores socioeconómicos para comprobar los sesgos sociales del espacio colonizado por las plataformas.

2. Análisis topológico: Utilizando los datos anteriores, y analizando la interfaz de usuario de los LBS, se han estimado sus redes comunicativas en contraste con la trama viaria de Madrid para visualizar la capacidad de los LBS de crear proximidades digitales desligadas de la configuración material de la trama. Este análisis se hace cualitativa y cuantitativamente sirviéndose de indicadores de centralidad de redes.

3. Análisis complejo: Teniendo en cuenta la capacidad de crear nuevos lugares o alterar el uso de los existentes, embebiéndolos en redes comunicativas alternativas, la evaluación de la complejidad se basa en el cálculo de la diversidad de usos accesibles, existentes y digitalmente alterados en Madrid. El cálculo se basa en diferentes índices de diversidad, que incluyen la riqueza de especies, la entropía de Shannon-Wiener (1950), y la diversidad de Margalef (1975). 


\section{Chapter's summary}

As introduced, urban complexity depends on the density, diversity and accessibility (Gao, Barzel and Barabási, 2016) of urban networks - whether physically consolidated or emerging through geolocation-based services in its digital realm. The configuration of the physical and the digital urban landscape are interdependent, as the information collected by LBS originates in the urban material realm, gets reorganized and repurposed by apps that collectively alter the functioning of the city.

Given the self-regulatory nature of both systems, the hypothesis to explore argues that the more complex urban environments are more prone to an intensive digitalization, originating an uneven distribution of LBS-sourced digital information that correlates with urban morphology. Given that such information is used to reorganize existing activities, the linkage between urban complexity and digitalization creates an uneven distribution of challenges an opportunities in the consolidated city in form of alterations of the diversity of accessible states the integrated physical-digital system has compared to its past configuration.

The chosen method studies several LBS urban morphology and topology in Madrid; a city representative both in scale and complexity of Southern-European cities that have scaled up to achieving the global scale integrating different canonical patterns of urbanization (Lamiquiz Daudén, 2011; López de Lucio et al., 2016). It has a pseudo-radial structure with an organic center, an orthogonal expansion planned in the 19th century, and an inner periphery with organic developments at the Northern limit (Valdeacederas), and mid-20th century modern unitary developments. The M-30 ring-road and Manzanares river separate these areas from an outer urban-metropolitan periphery developed during the late 20th century. In the digital arena, this city also has great availability of open institutional data sources, as well as a substantial adoption of LBS by the population. The explored services belong to different areas of economic activity to verify if their spatial structure shows similarities despite their different purposes. The selection includes Facebook Places and Foursquare representing place-search and promotion platforms, Hail-O/MyTaxi representing private mobility, Deliveroo and Amazon Hub representing B2C (business-to-consumer) e-commerce, Wallapop as C2C (consumer-to-consumer) commerce, Grindr as a geosocial network, and AirBnB as the leader of short-term accommodation.

Open and platform-source data have been collected and processed with a local, highperforming, open-source geospatial database (PostgreSQL/PostGIS) fed and queried using Python algorithms, consolidating a hybrid physical-digital model of Madrid used to compute the complexity of the urban system following the next steps that group the results obtainedUsing the constructed digital-physical model of Madrid, the following explorations are proposed:

1. Morphological analysis: Map-based qualitative and quantitative analysis of the spatial footprint of LBS over the city in order to reveal the urban morphology of digital data, and the areas that are being digitalized more intensively, and the 
new places of LBS can insert activity into. The spatial density of digital data has been correlated by simple pairwise regression with sociodemographic environmental indicators to check their potential social biases.

2. Topological analysis: Based on the platform-sourced data collected and LBS interface configuration, the digital communicative networks have been modeled in contrast with Madrid's street network to understand the capacity of digital networks to communicate physically disconnected places. A qualitative analysis based on their cartographic representation added to a quantitative analysis based on network centrality indicators has been carried out.

3. Complex analysis: Once understood the capacity of LBS to put new activities in place, and to create an alternate communicative structure to street networks, the evaluation of complexity focuses on computing the diversity of accessible activities in Madrid taking the already existing and the digitally introduced ones into account. The analysis is based on different quantitative diversity indices, like "species" (land-use) richness, Shannon-Wiener's entropy (1950), and Margalef's (1975) diversity. 


\subsection{Terminología}

Como paso previo a presentar la metodología de esta investigación, se ha considerado oportuno acotar algunos de los términos que aquí se utilizarán, dado que provienen de campos de conocimiento ajenos a los estudios urbanos. Aunque todos estos términos quedan recogidos en los capítulos anteriores, a partir de este punto se utilizarán de manera continuada y sin aclaraciones.

- $\quad$ Plataforma digital: Modelo de organización de la actividad en torno a un agente intermediario -en este caso tecnológico- que legitima y posibilita comunicaciones e intercambios entre los usuarios que participan de ella. Se trata por tanto de un modelo de gobernanza de las relaciones interpersonales en que la tecnología mercantiliza el uso de un conjunto determinado de recursos, generando un espacio, en este caso virtual, de encuentro entre partes interesadas para realizar un intercambio. En esta investigación, se utiliza también para referirse a las empresas tecnológicas que articulan su actividad siguiendo este modelo. Dentro de una plataforma es incorrecto utilizar los términos de cliente y proveedor para identificar a las partes que participan en un intercambio habilitado por ésta. Dado que ambas partes son 'clientes' o usuarios de la plataforma. En su lugar se opta por 'usuarios', de entre los que se distinguen los siguientes roles:

o Usuario contribuyente, activo, u ofertante: Asimilable a un proveedor del servicio, es aquel sujeto activo, propietario o gestor de un recurso, que gestiona la presencia de dicho recurso en la plataforma. Por ejemplo: el propietario de una vivienda que la oferta como alquiler vacacional, un vendedor de productos de segunda mano, un conductor de VTC, o el propietario de un lugar en plataformas de búsqueda de lugares.

o Usuario perceptor, pasivo, o demandante: Es aquel que hace uso de un recurso en una plataforma tras comunicarse con el usuario contribuyente. Con respecto a los ejemplos anteriores: el turista que se hospeda en un alquiler vacacional, el comprador de un producto de segunda mano, el pasajero en un VTC, o el visitante potencial a un lugar buscado en la plataforma de búsqueda de lugares.

- $\quad$ Recurso: En una plataforma digital, el recurso se es el objeto en torno al cual se articula un servicio - una vivienda en alquiler vacacional, un producto de segunda mano, un vehículo...

- Efectos de red: Son las sinergias, o la expectativa de ellas, que favorece una plataforma digital y que facilitan su capacidad de atraer usuarios perceptores y contribuyentes. Un usuario perceptor puede participar en una plataforma ante la expectativa de encontrar una mayor variedad de oferta - gestionados por usuarios activos-, y un usuario activo se ve atraído hacia una plataforma ante la expectativa de encontrar una mayor demanda. Como se ha explicado, los efectos 
de red también pueden ser negativos si no conducen a la atracción de usuarios hacia la plataforma.

- Servicio geolocalizado (LBS): Es una aplicación informática que utiliza la geolocalización de recursos para su funcionamiento, y como tal constituye un canal comunicativo virtual entre sus usuarios. La posibilidad de que se de una comunicación entre usuarios dependerá por tanto de la ubicación geográfica de éstos.

- Aplicación (“frontend"): Se refiere a la interfaz de usuario - construida por una plataforma- por la que un LBS es accesible por parte de sus usuarios.

- API: (del inglés "Application Programming Interface", en español Interfaz de Programación de la Aplicación) es un conjunto de procedimientos definido por una plataforma para acceder a la información que posee por terceras partes. Se compone de un conjunto de consultas posibles a la base de datos gestionada por una plataforma, la cual responde con fragmentos de la información que almacena.

- "Scrapping": Consiste en la observación automatizada y almacenamiento de la información mostrada en una aplicación. Se realiza a través de la propia aplicación sin hacer uso de la API.

- Sistema urbano: El conjunto de elementos que integran una ciudad y las relaciones comunicativas posibles (en términos de existencia de medios materiales), probables (adecuadas en términos de coste-beneficio), y legítimas (permitidas normativa y culturalmente).

- Mediatización: Es la intervención de los medios de comunicación en las relaciones humanas transformándolas; "dando lugar a nuevas formas de acción e interacción que permiten transmitir información o contenidos simbólicos para potenciales receptores que no se encuentran cara a cara" (Thompson, 1995). Se sostiene que los LBS son medios que transforman la percepción del paisaje urbano.

- $\quad$ Paisaje urbano (físico/digital): Alude a la relación perceptiva que se establece entre el sistema urbano como objeto observado y el sujeto observador. Según Cullen (1959), el objeto urbano produce una reacción en el sujeto mediante la visión, la construcción de escenarios, y la construcción de relaciones métricas y simbólicas.

- Mapa cognitivo: Interpretando a Portugali (2006), se trata de la esquematización subjetiva que un agente observador construye sobre de sus entornos urbanos y sus estructuras funcionales. La construcción de este mapa subjetivo determina la acción de los agentes en el sistema (cognitivo) complejo urbano.

- Vínculo/conexión: Representa la posibilidad, probabilidad y legitimidad de que entre dos componentes de un sistema se produzca un intercambio. Si tal intercambio cumple las tres condiciones, existe un vínculo entre dos componentes del sistema. Estos vínculos pueden son materiales e informacionales. 
- Topología/topología de red: Es una representación lógica; analizable mediante técnicas matemáticas, del conjunto de vínculos de un sistema.

- Estructura funcional: La manera por la que las componentes del sistema urbano se organizan y por tanto jerarquizan.

- Grafo primario: Para una red viaria, el grafo primario es el que se construye utilizando los cruces entre viales como nodos, y los tramos de calle como vértices -utilizando la longitud de cada tramo como peso de la arista para incorporar la distancia métrica entre nodos al grafo. Es de utilidad para medir las distancias recorridas entre lugares urbanos, y con ello estimar los costes energéticos de desplazamiento.

- Grafo dual: Análogamente, el grafo dual utiliza cada vial como nodo, y construye sus vértices por intersección. Para elaborarse, se requiere de una estrategia de consolidación de viales por nombre, ángulo de intersección, o ejes visuales (Space Syntax). Si el primario constituye una topología energética de los desplazamientos urbanos, el dual almacena la "información" asociada a cada lugar -sabiendo qué elementos del sistema urbano comunican con qué otros.

- Centralidad: Es la importancia jerárquica de un elemento de una red en su topología. Aunque existen medidas muy diversas de centralidad, en esta tesis se acota el concepto a la centralidad de grado, de cercanía o proximidad ('closeness'), y de intermediación ('betweenness'). La primera mide el número de conexiones de un nodo, la segunda su distancia con respecto al resto de nodos de un sistema, y la tercera la cantidad relativa de recorridos que atraviesan un nodo.

- Enlace preferente: Es una propiedad evolutiva de las redes complejas libres de escala descrita por Barabási y Albert (1999) que determina que en una red compleja, la conexión de nuevos nodos tiende a realizarse hacia aquellos que gozan de mayor centralidad de grado, lo cual a lo largo del tiempo conduce a distribuciones desiguales de grado describiendo una ley de potencias.

- "Python": Es uno de los lenguajes de programación más populares, muy utilizado en el ámbito científico dado que cuenta con conjuntos de funciones ya programadas -en términos informáticos: de alto nivel-, y como tal favorece el aprovechamiento de código externo en un programa propio - lo cual acelera la producción. En esta tesis se utiliza este lenguaje en su versión 3.6 para la programación de algoritmos de descarga y análisis de datos.

- PostgreSQL y PostGIS: El primero es un sistema de bases de datos relacional basadas en tablas-, multiplataforma -compatible con varios sistemas operativos-, de código abierto. Como indica su nombre, las consultas a la base de datos se realizan en el lenguaje de programación SQL, y las respuestas son legibles con una amplia variedad de programas informáticos. PostGIS es una extensión del sistema que incorpora funciones para almacenar y analizar grandes cantidades de objetos geométricos - puntos, líneas y polígonos- haciendo uso de índices espaciales. Se utiliza esta base de datos por su velocidad, estabilidad, e interoperabilidad con múltiples programas informáticos de visualización y procesamiento de datos. 


\subsection{Estructura de la exploración}

Aunque las tesis de carácter exploratorio no suelan tener otra hipótesis que la observación de un fenómeno, es necesario recurrir a una línea discursiva que articule la observación. En este caso, se persigue explorar la relación entre las plataformas de servicios geolocalizados y la ciudad, no desde una óptica descriptiva - utilizar el servicio para representar lo que sucede en la ciudad- sino transformativa; es decir, observando los servicios geolocalizados como herramientas al servicio de plataformas digitales para consolidar en el espacio social urbano, nuevos sistemas comunicativos capaces de alterar la percepción del entorno y de producir intercambios poco probables de no existir tales herramientas. Como tal, constituyen una pieza esencial de la mediatización de un espacio urbano más concebido desde su espacialidad que desde su componente sistémica (Portugali etal., 2012; Batty, 2013).

Como se ha visto en los marcos teórico y empírico, tanto la ciudad como las plataformas digitales que en ella operan pueden conceptualizarse como sistemas comunicativos complejos compuestos por lugares en constante interacción, por lo que esta tesis los liga desde el marco conceptual de la complejidad de sistemas. Esta complejidad se puede definir como la diversidad de estados accesibles del sistema (Wagensberg, 1985; RuizSánchez, 2001b; Aquilué Junyent, 2017); definición que implica dos aspectos, tanto de la ciudad como de los servicios digitales a observar con especial detenimiento: la diversidad y la accesibilidad. Tomada de la teoría de la información, la diversidad puede evaluarse como la cantidad de información no redundante que integra una partición de un sistema (Shannon, Weaver y Vajda, 1950; Nolasco-Cirugeda y García Mayor, 2014; López-Baeza, Cerrone y Männigo, 2017), la cual es empíricamente evaluable a través del índice de diversidad de Shannon-Wiener, basado en la idea de entropía. Sin embargo, por tratarse de un sistema abierto, sus particiones también lo son e interactúan, por lo que la complejidad no puede entenderse como una función evaluable a través de recintos espaciales estancos, sino en absoluta interacción. En consecuencia, la complejidad urbana no puede medirse tan solo como la variación de entropía por unidades espaciales, pues la falta de diversidad funcional en una partición del sistema puede complementarse con otra partición estrechamente relacionada con ésta. La complejidad urbana es por tanto una sinergia entre diversidad y una topología propia de los sistemas complejos que Alexander (Alexander, 1964) ya introdujo, y en las que la ciencia de redes (Barabasi, 2002), y sus aplicaciones recientes al urbanismo (Hillier y Hanson, 1984; Hillier, 1996) han profundizado. A pesar de ello, existen pocas aproximaciones metodológicas que concilien la topología de redes con la diversidad urbana, por lo que esta tesis planteará un método para enfrentar este desafío de evaluar la complejidad urbana utilizando métodos cuantitativos basados en el "big-data".

Es crucial comprender esta idea de complejidad como diversidad de estados accesibles a la hora de entender cómo interactúan la ciudad y los servicios digitales geolocalizados, pues si la complejidad urbana se entiende como una acumulación de funciones diversas en un ámbito de proximidad relacional, la ciudad compleja se caracteriza por la 
acumulación de información diversa, y por tanto no redundante. Si un servicio geolocalizado opera como un subsistema abierto en constante retroalimentación con el sistema urbano, existirán unas dinámicas de enlace entre el espacio urbano tangible y su representación digital comunes a pesar de la aparente aleatoriedad y dinamismo de la información urbana voluntariamente contribuida por los usuarios de las plataformas digitales.

Se ha visto que los espacios que integran un LBS dependen de la voluntad de sus usuarios de informar sobre su existencia para su posible puesta al servicio de los propósitos de cada plataforma. Pero esta acumulación de información no puede, o no debería ser equiprobable en todos los lugares urbanos, pues al no contener la misma variedad de, actividades accesibles, no entrañan la misma cantidad de información para sus usuarios potenciales, por lo que su afluencia y en consecuencia las probabilidades de que un ciudadano notifique la existencia de un lugar en un servicio digital variarían en función de esa cantidad de información que entraña el sistema urbano. Un fragmento complejo de una ciudad entraña una gran diversidad de estados accesibles, por lo que las probabilidades de que este espacio urbano tangible aparezca representado en una u otra plataforma digital incrementa. Por el contrario, un fragmento poco complejo limita en gran medida su vitalidad, número de interacciones potenciales, observadores, y en consecuencia presencia digital. En qué medida esto se produce se encuentra entre los objetivos principales de esta exploración.

Por otra parte, no debe perderse de vista que una plataforma digital responde a una estrategia de acumulación capitalista, basada en favorecer ciertas interacciones productivas frente a otras. En una situación de enlace preferencial entre lugares digitalizados y aquellos ámbitos de mayor complejidad en el sistema urbano, podría producirse un reemplazo de ciertas actividades prexistentes por aquellas orquestadas por una plataforma. Esto, como se desarrollará en este capítulo, podría suceder en dos niveles, tanto en el de las actividades posibles, ligadas a los usos del suelo, como en el plano comunicativo ligado a la topología de la red urbana. Las transformaciones de ambos niveles podrían explicar parte de las fricciones que se producen entre el sistema urbano y sus subsistemas comunicativos digitales emergentes.

Como ilustra Portugali (2006), establecer relaciones causa-efecto en un entorno artificial complejo corre el riesgo de caer en una paradoja cognitiva. ¿Transforma un servicio geolocalizado una parte del sistema urbano, o es el sistema urbano el que determina el campo de acción de dicho LBS? Es una pregunta tan tentadora como incontestable, puesto que ambos son sistemas dinámicos en constante interacción y procesos autorregulatorios basados en los procesos cognitivos de sus usuarios y sus planificadores, por lo que debe evitarse trazar cualquier hipótesis en esta línea. Los debates a nivel empírico que concitan las plataformas digitales en la ciudad; al respecto tanto de sus sesgos como fuente de datos descriptiva, como el balance incierto entre los desafíos y oportunidades que plantean como transformadores de la actividad urbana, hacen necesaria una exploración formal, 
pero también procesual de la interacción de ambos sistemas comunicativos en interacción.

Para desgranar metodológicamente esta doble interacción entre el sistema urbano y sus paisajes digitales se propone una secuencia de observaciones para estructurar esta exploración sobre la mediatización del espacio social urbano, explorando algunas de las múltiples características del 'espacio urbano digitalmente integrado' (Mitchell, 2003; Ratti y Claudel, 2016). Por orden:

a. Análisis morfológico (patrones de acumulación de información sobre la trama urbana): Los servicios digitales basados en la geolocalización tienden a generar 'digitalizaciones selectivas de recursos' en lugares y tiempos determinados, acotadas por los propósitos de las plataformas que los soportan - por generalistas que parezcan. Esto produce una base de datos parcial de lugares de la ciudad; una nube de lugares representados como pares de coordenadas cuya observación está regulada por la empresa gestora de la plataforma digital. A pesar de la aparente aleatoriedad y del dinamismo de estas nubes de lugares interrelacionados, ambos sistemas comunicativos mostrarán 'patrones relativamente estables de acumulación de información e interacciones' distribuidos desigualmente por la trama urbana. Estos podrían guardar una estrecha relación con la complejidad urbana, leída como la acumulación de información no redundante sobre un ámbito accesible del sistema urbano. La ciudad compleja podría acumular una mayor cantidad de información, por lo que será susceptible de una digitalización más intensiva de sus lugares.

2. Análisis topológico (creación de jerarquías comunicativas alternativas a la urbana): Los protocolos de organización de la información ligados a la anterior regulación articulan nuevas probabilidades de interacción con un recurso $-\mathrm{y}$ por tanto entre dos lugares urbanos, el que ocupa el usuario de la plataforma y el que ocupa el recurso digitalizado-, ello genera una topología de red alternativa' a la dada por las redes urbanas tangibles de movilidad y comunicación.

3. Análisis complejo (por acumulación de alteraciones puntuales sobre los $\underline{\text { lugares de prestación del servicio digital, alteración de la diversidad funcional }}$ accesible en la ciudad): En la medida que se produzca una acumulación de información de cierta plataforma sobre una zona de la ciudad, el acceso a los recursos en dicha zona se encontrará más intensamente condicionado por ella. Si dichas plataformas motivan cambios de uso en el espacio urbano, o cambios en la jerarquía comunicativa de dichos espacios, el sistema resultante (ciudad + plataformas) podría mostrar bien un incremento sinérgico de la complejidad del sistema, aumentando la diversidad funcional o accesibilidad informacional de sus lugares, o bien una excesiva acumulación de recursos mediatizados en detrimento de la diversidad funcional y/o de la accesibilidad, pudiendo, en algunos casos, motivar intentos de regulación 'regulación externa' de las plataformas digitales sobre la ciudad. 
Dado que la tesis se centra en el aspecto sistémico de la mediatización del paisaje urbano, la metodología debe contemplar, tanto la organización material del sistema urbano como la de sus múltiples servicios geolocalizados. Si el marco empírico mostraba una tendencia a realizar estudios descriptivos de ciudades utilizando datos procedentes de plataformas, esta tesis plantea una inversión metodológica: analizar varias plataformas sobre una sola ciudad para conocer en mayor profundidad las características comunes de sus múltiples paisajes digitales de actividad. Se ha seleccionado Madrid como caso de estudio no solo por conveniencia para el autor, sino por aunar una gran escala dada por su capitalidad nacional y una gran diversidad tipológica - y por consiguiente grados de complejidad diferentes-, fruto de su evolución histórica.

\subsection{Oportunidad de Madrid}

La tesis utiliza la ciudad de Madrid como ciudad de interés. Se trata de una ciudad que por sus características espaciales y socioeconómicas supone un caso relevante para la comprensión de las dinámicas urbanas inducidas por el auge económico de las plataformas digitales tras la crisis financiera del año 2008. Ello unido al interés y experiencia personal del doctorando, aquí residente, motiva la elección de este caso concreto.

En primer lugar, cabe destacar la gran accesibilidad a datos abiertos sobre el municipio a través de su portal de datos abiertos [DATOS.madRid.es]. Aquí se recopilan y ponen a disposición de la ciudadanía numerosas fuentes de información digital entre las que destaco el padrón histórico municipal con un nivel de desagregación por sección censal, cartografía actualizada y detallada a escala 1:1000 del municipio, y datos sobre la red viaria en formato GIS útiles a la hora de elaborar un modelo de red urbana en el que se basa esta investigación, y que se detallará más adelante en este capítulo. Además, en este portal se publica el Censo de Actividades y Locales comerciales de la ciudad actualizado mensualmente y la cartografía del Plan General de Ordenación Urbana vigente en formato GIS.

Debido a la disponibilidad de datos institucionales desagregados y actualizados, la investigación se limita al término municipal de Madrid; que se considera suficiente para mostrar en su extensión diferentes grados de centralidad, diversidad morfotipológica y social suficiente. No se han tenido en cuenta los municipios cercanos en la corona metropolitana por no disponer de las mismas fuentes de información que la capital publica en el portal antes mencionado.

Se trata de un término municipal de $606 \mathrm{~km}^{2}$. Durante el periodo 2008-2020, la población total, residente en sus 21 distritos y 128 barrios, ha oscilado de 3.255.087 habitantes empadronados en enero de 2008 hasta 3.348.536 habitantes en enero de 2020. Sin tener en cuenta las coronas metropolitanas, se coloca como la tercera capital europea en población por detrás de Londres y Berlín, seguida de Roma y París. 
La estructura formal de esta ciudad refleja los procesos típicos de urbanización propios de los siglos XIX y XX (Terán, 1992), llegando a constituir "un muestrario de los entornos, tejidos y estructuras urbanas producidos en el sur de Europa" (Lamiquiz Daudén, 2011, p. 214). Esta estructura es en apariencia radioconcéntrica limitada al oeste por el Palacio Real y la Casa de Campo. Entre centro y periferia, se extiende el ensanche decimonónico con una trama ortogonal y manzana cerrada definido por el 'Plan Castro' (1859), al tiempo que se consolidaba una trama orgánica al norte del ensanche -en el actual distrito de Tetuán-, y coetáneo a éste, donde las clases populares se instalaban ante la imposibilidad de acceder a un ensanche burgués (López de Lucio, 1999) [VÉASE FIguRA 27].
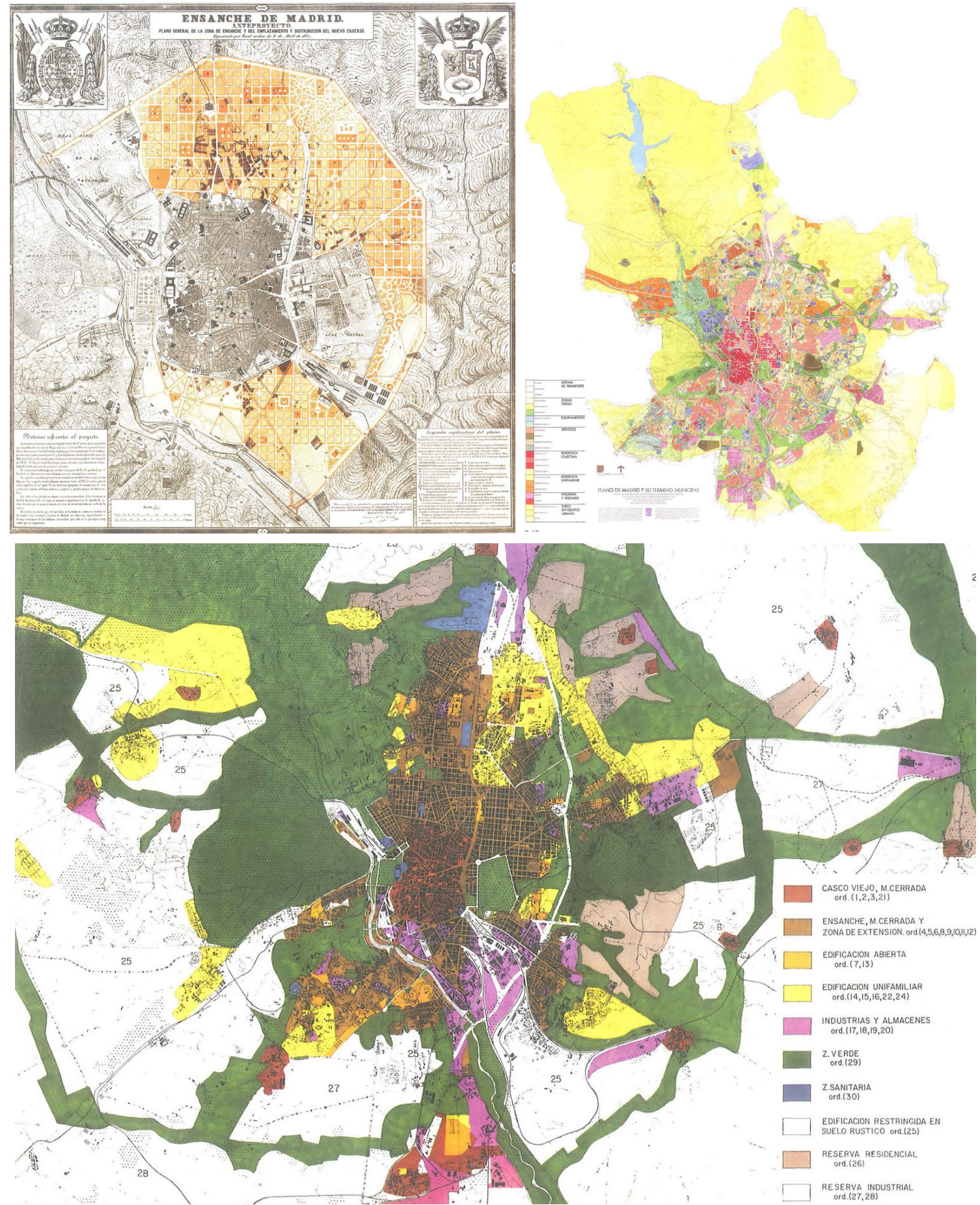

Figura 27. Mapas de Madrid del Plan Castro (1859) (arriba izquierda), de las ordenanzas de 1952 (abajo), y de la aprobación inicial del Plan General de 1985 (arriba derecha). Fuente: (López de Lucio, 1999) 
Desde los años 90 hasta la actualidad (2020), Madrid ha adquirido un rango de ciudad global de segundo rango (Sassen, 1999), consolidando los procesos periféricos de suburbanización ligados a la red viaria arterial (Ruiz-Sanchez, 1999; López de Lucio etal., 2016) y al roceso de acumulación de capital global característico de finales del siglo XX. Ha dejado de ser la ciudad de las administraciones públicas rodeada por un cinturón industrial — todavía muy relevante más allá del límite del término municipal-, para convertirse en una ciudad con un sector servicios que creciendo más de un $90 \%$ durante estos veinte años, ahora da empleo al $83 \%$ de su población. Las actividades industriales en esta ciudad se centran en el apoyo a las industrias próximas y la logística (López de Lucio etal., 2016).

De esta época data el Plan General de Ordenación Urbana (1997) todavía vigente en Madrid. Este plan otorga a la autovía de circunvalación M-40 el papel de delimitar la ciudad central, previendo la ejecución de nuevos desarrollos periféricos de gran escala propios del 'boom' inmobiliario español. Al interior, y especialmente al interior de la M30 de la ciudad, las grandes operaciones realizadas han sido principalmente de reurbanización junto con promociones privadas. Como gran operación, destaca la reforma de la ribera del Manzanares para crear el parque lineal Madrid-Río soterrando la circunvalación M-30 (véase López de Lucio et al., 2016 para una cronología completa de las actuaciones urbanísticas en Madrid entre 1900 y 2010).

La estructura radial de Madrid se reforzó dada la centralidad de esta ciudad en la red nacional de carreteras. En sentido horario y desde el norte, el primer eje principal de la ciudad es el formado por el Po del Prado, Po de Recoletos y de la Castellana, atraviesa el núcleo desde la estación de tren de Atocha hacia el Norte, entroncando con la autovía de Burgos (A-1). Desde la Estación de Atocha, arranca al sur un tridente formado por la avenidas de la Albufera - que entronca con la A-3 hacia Valencia-, el Po de las Delicias, que entronca con la A-4 dirección Andalucía, y el Po de Santa María de la Cabeza hacia Toledo. El límite sur de la Casa de Campo está delimitado por el Po de Extremadura y la A-5. En dirección este-oeste, la autovía de La Coruna (A-6) conecta con la ciudad en el intercambiador de Moncloa, iniciando la Calle Princesa y la Gran Vía, que desemboca en la Calle Alcalá, y continúa al este entroncando con la Avenida de América y la autovía a Zaragoza y Barcelona (A-2).

Además de estas radiales, durante el crecimiento histórico de la ciudad se han consolidado distintas tramas que definen anillos de circulación en torno al centro urbano y el ensanche, así como la circunvalación M-30 que intuitivamente define una divisoria entre las primeras periferias urbanas de mediados del siglo XX y una periferia urbanometropolitana todavía en desarrollo.

Atendiendo a los criterios de morfología urbana y trazado de los grandes ejes viarios y circunvalaciones, se han delimitado cinco grandes ámbitos urbanos [VÉASE MAPA 1].

1. Centro: Corresponde a la delimitación administrativa del distrito con el mismo nombre, incluyendo las manzanas aledañas al parque del Retiro al oeste (calle de 
Alfonso XII), conformadas previa planificación del ensanche decimonónico. Este ámbito queda delimitado por el eje Génova - Sagasta - Carranza - Alberto Aguilera al norte; la calle de Alfonso XII, las rondas de Toledo y Valencia al sur, y el Palacio Real junto a la calle Princesa al oeste.

2. Ensanche: Corresponde a la delimitación del Plan Castro. Su área queda delimitada por el río Manzanares al sur y al oeste, pues el plan no planificaba la ocupación de su margen opuesta. Al este queda limitado por la calle Doctor Esquerdo y Joaquín Costa; y al norte por la calle Raimundo Fernández de Villaverde en la que se encuentra la glorieta de Cuatro Caminos. Abarca los distritos de Chamberí, Salamanca, Retiro, Arganzuela, y la parte al suroeste del distrito de Chamartín abarcada por el plan de ensanche.

3. Valdeacederas: Por su crecimiento anterior y coetáneo al ensanche y trama orgánica en manzana cerrada adaptada a la topografía, se ha disgregado este ámbito de otras periferias de la ciudad y su demarcación prácticamente se ajusta al distrito de Tetuán. Se encuentra delimitado al sur por la calle Raimundo Fernández de Villaverde, al este por la calle Bravo Murillo al norte de Cuatro Caminos; y al oeste por el actual Parque de Rodríguez Sahagún. Se prolonga al norte hasta la Avenida de Asturias y la Plaza de Castilla.

4. Primeras periferias: En la margen izquierda del Manzanares, abarcan el ámbito interior de la circunvalación M-30, y comprende el distrito Chamartín. En la margen derecha, abarca los barrios periféricos desarrollados a partir de los años 50 en el ámbito delimitado por las avenidas de los Poblados y Andalucía hasta encontrarse con la M-30.

5. Periferia urbano-metropolitana: Abarca las zonas exteriores a la M-30 pertenecientes al término municipal; algunas de ellas todavía sin consolidar aunque planificadas. Se ha optado por esta denominación por responder a una tipología de edificación periférica y su posicionamiento entre el núcleo consolidado de la ciudad y su corona metropolitana; evidenciando una relativa dependencia de las grandes infraestructuras de movilidad rodada y transporte público (metro y cercanías) para comunicarse con las zonas centrales de Madrid. 

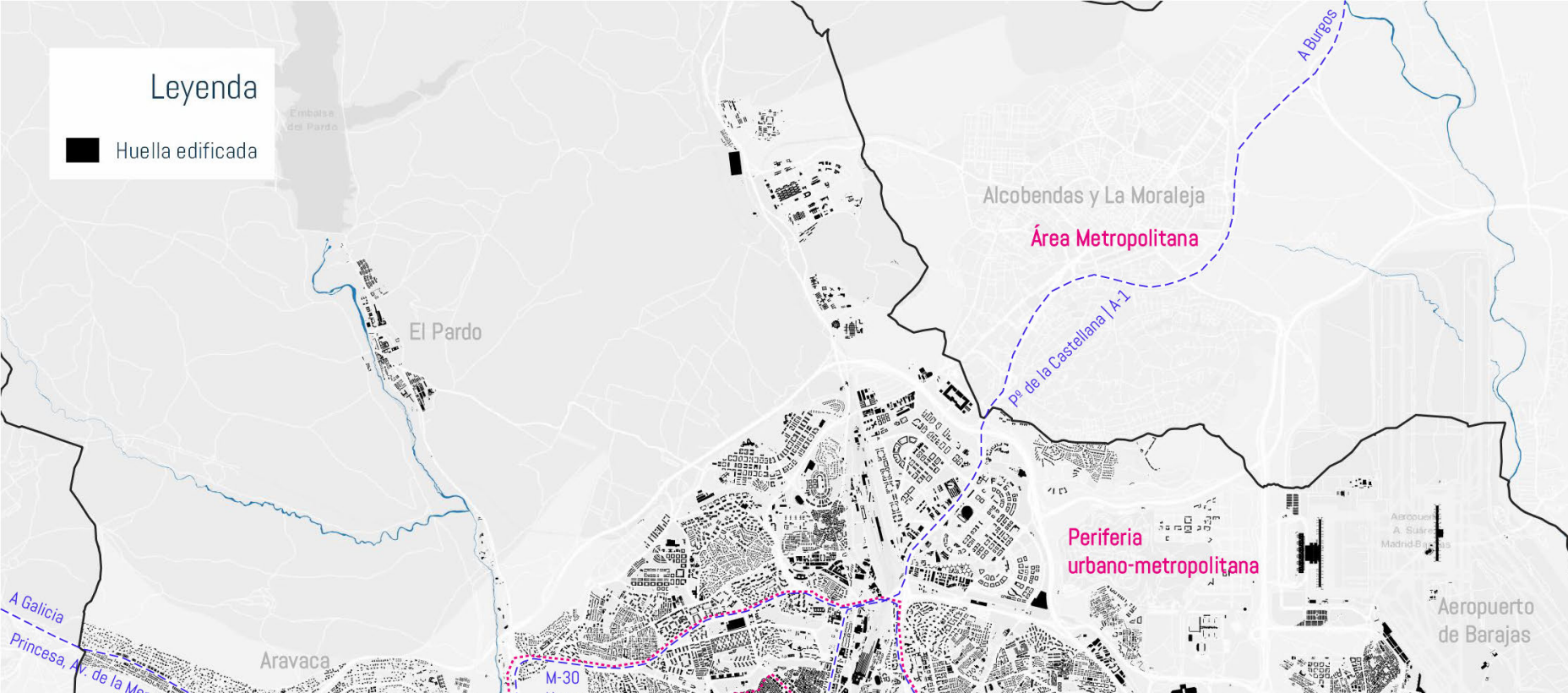

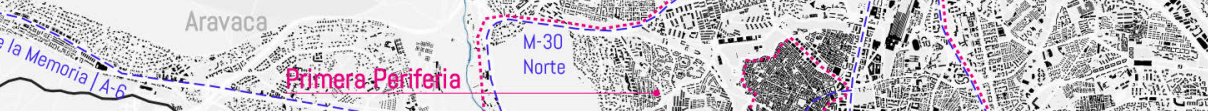

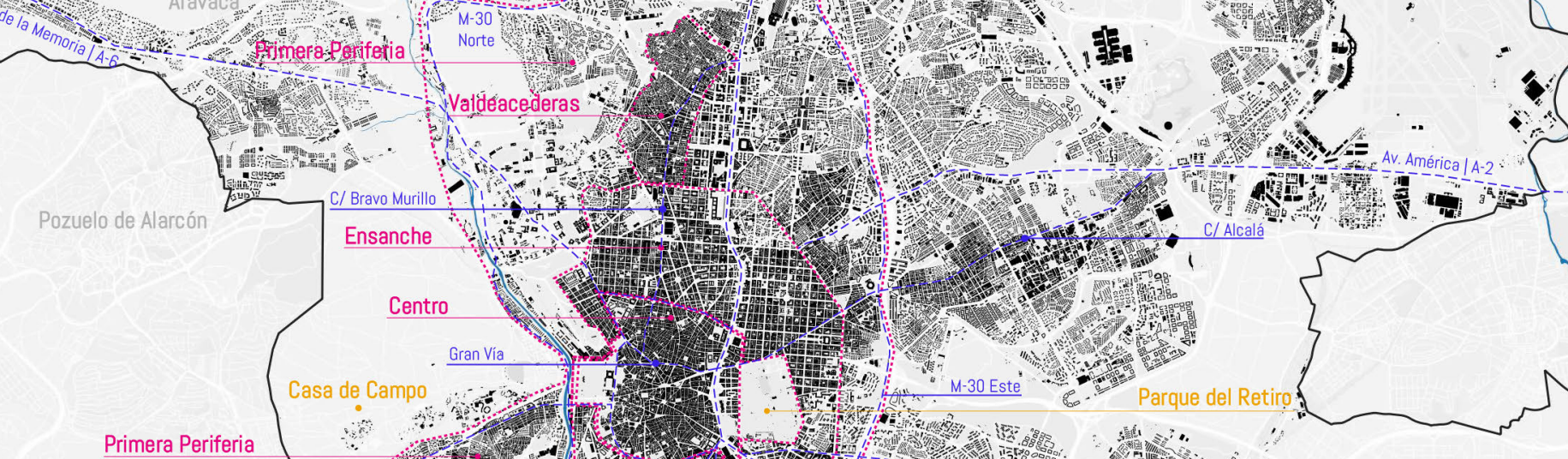

Primera Periferia

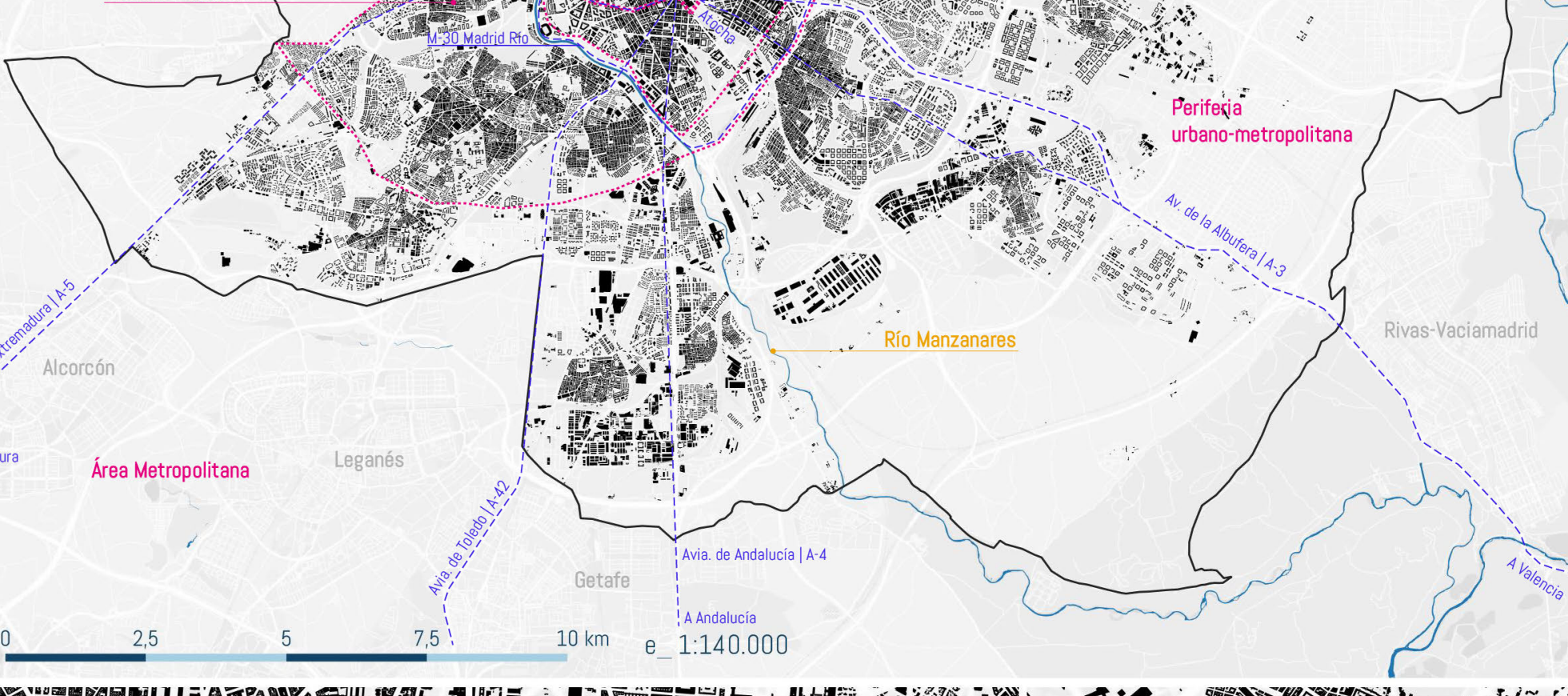

:

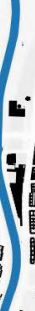

\section{\&} 7 , (
10:

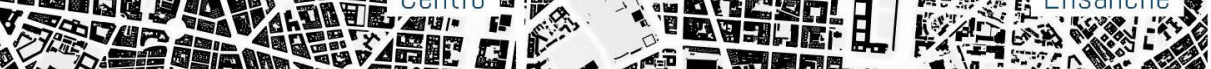
-

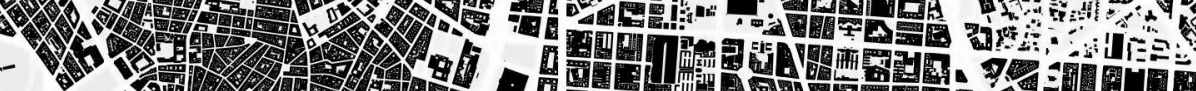
S R - 10 on

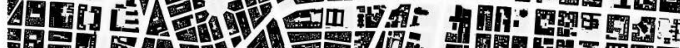

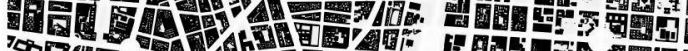

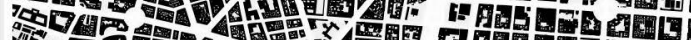
Sy

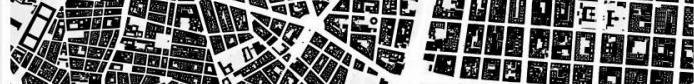
(1) \% 告

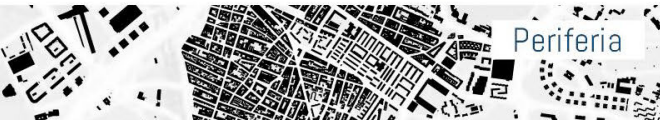

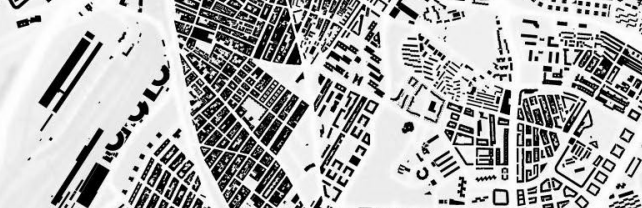

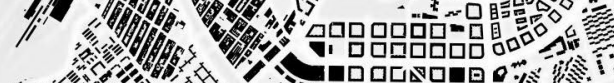

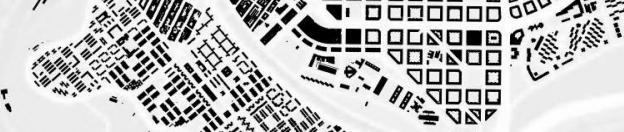
1.d

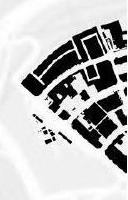


Presentada en líneas generales la estructura urbana de Madrid, corresponde aportar algunas pinceladas sobre su situación socioeconómica. Con respecto a la distribución de la población [VÉASE FIGURA 28], se dan las mayores concentraciones en el distrito Centro (especialmente en los barrios de Chueca y Malasaña al norte del distrito, y Lavapiés al sur) y los distritos periféricos (especialmente Tetuán; Carabanchel; Puente de Vallecas; el entorno de Puerta del Ángel en el distrito Latina), mientras que los distritos del ensanche histórico del Plan Castro cuentan con una densidad de población intermedia.

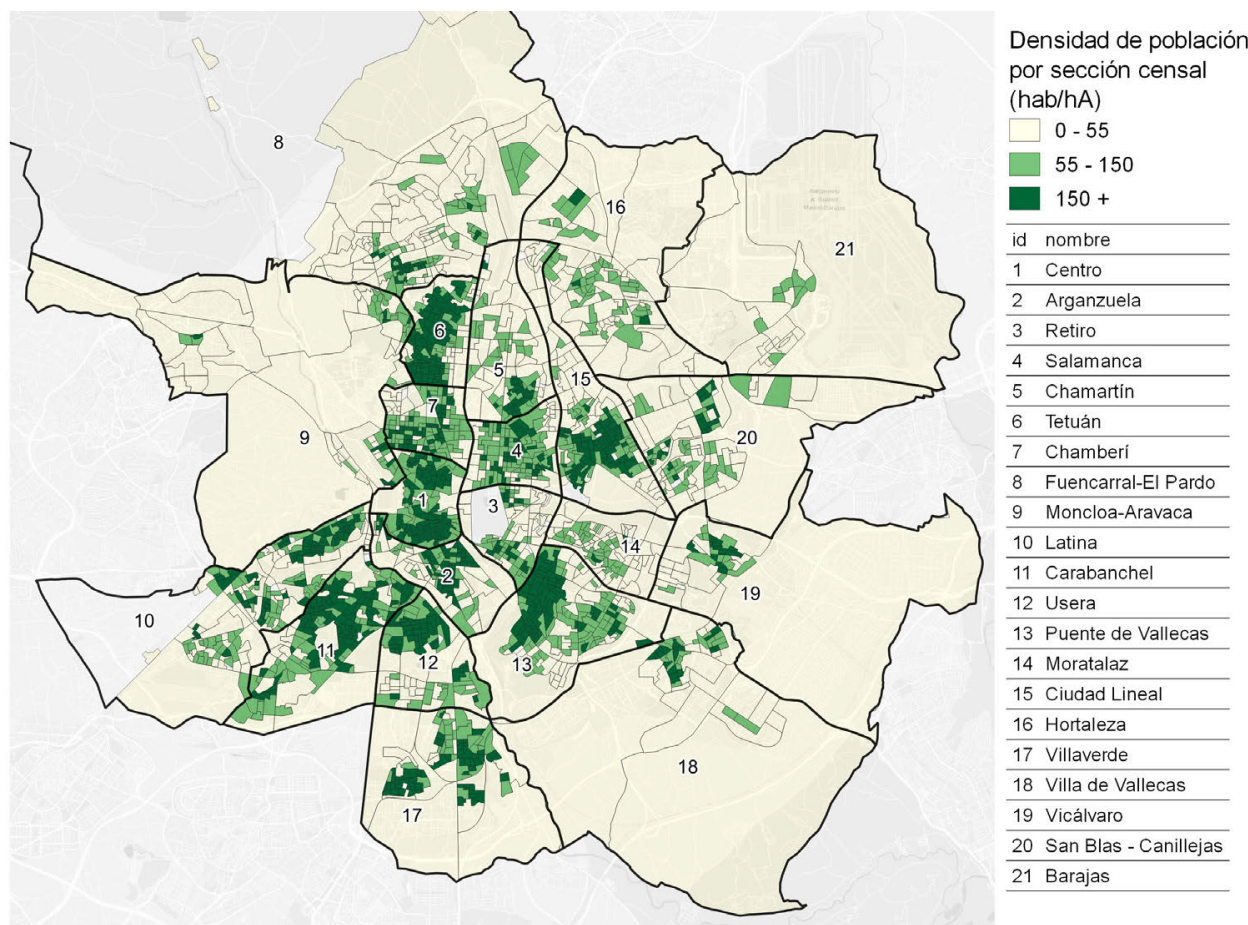

Figura 28. Densidad de población en Madrid (2016) por sección censal sobre división distrital. Elaboración propia. Fuente: Ayuntamiento de Madrid. Padrón Municipal de Habitantes.

Esta distribución poblacional muestra una clara correspondencia con los niveles de renta [VÉASE MAPA 2]. Son estos distritos que muestran una densidad mayor aquellos que tienen las poblaciones de menor poder adquisitivo. Mientras que los distritos de Salamanca, Retiro, y Chamartín al interior de la M-30 albergan las rentas más altas, sucede lo contrario en Centro y Valdeacederas, distritos integrados en el núcleo urbano que tradicionalmente han acogido a las clases populares. Al exterior de esta primera circunvalación, el contraste de rentas se produce entre el norte y el sur de la ciudad.

Aunque los procesos de colmatación de la periferia urbano-metropolitana vieron una fuerte deceleración con la 'crisis del ladrillo', Madrid fue, y sigue siendo un nodo urbano relevante en la economía global. Su atractivo turístico a nivel internacional creció tras la crisis, lo cual contribuyó a acelerar la transformación de un centro urbano otrora en declive, y en la actualidad todavía envuelto (Roch Peña, 2008; García Pérez, 2014) en procesos de elitización (o gentrificación), iniciados con anterioridad acogiendo a las denominadas 'clases creativas' (Sorando y Ardura, 2016) y a visitantes internacionales en la actualidad. Dado el atractivo que supone esta capital, la almendra central ha sido objeto de numerosas operaciones de reforma para favorecer la actividad cultural y turística 
(García Pérez, 2014). Si los mercados inmobiliarios en las periferias se encontraban en declive, los activos en los centros urbanos continuaron manteniendo su exclusividad. Así pues, el centro de Madrid, lejos de frenarse su deriva de encarecimiento y elitización previa al estallido de la burbuja perseveraba en las dinámicas ya iniciadas. Como apuntaba Fernando Roch (2008), la morfología urbana se convierte en un mapa de valor en el que el centro tenderá a mantener su estátus alpha en el mercado inmobiliario. economías con menor poder adquisitivo que la media española, y pérdida de valor de los activos inmobiliarios propios de una economía especialmente afectada por la crisis.

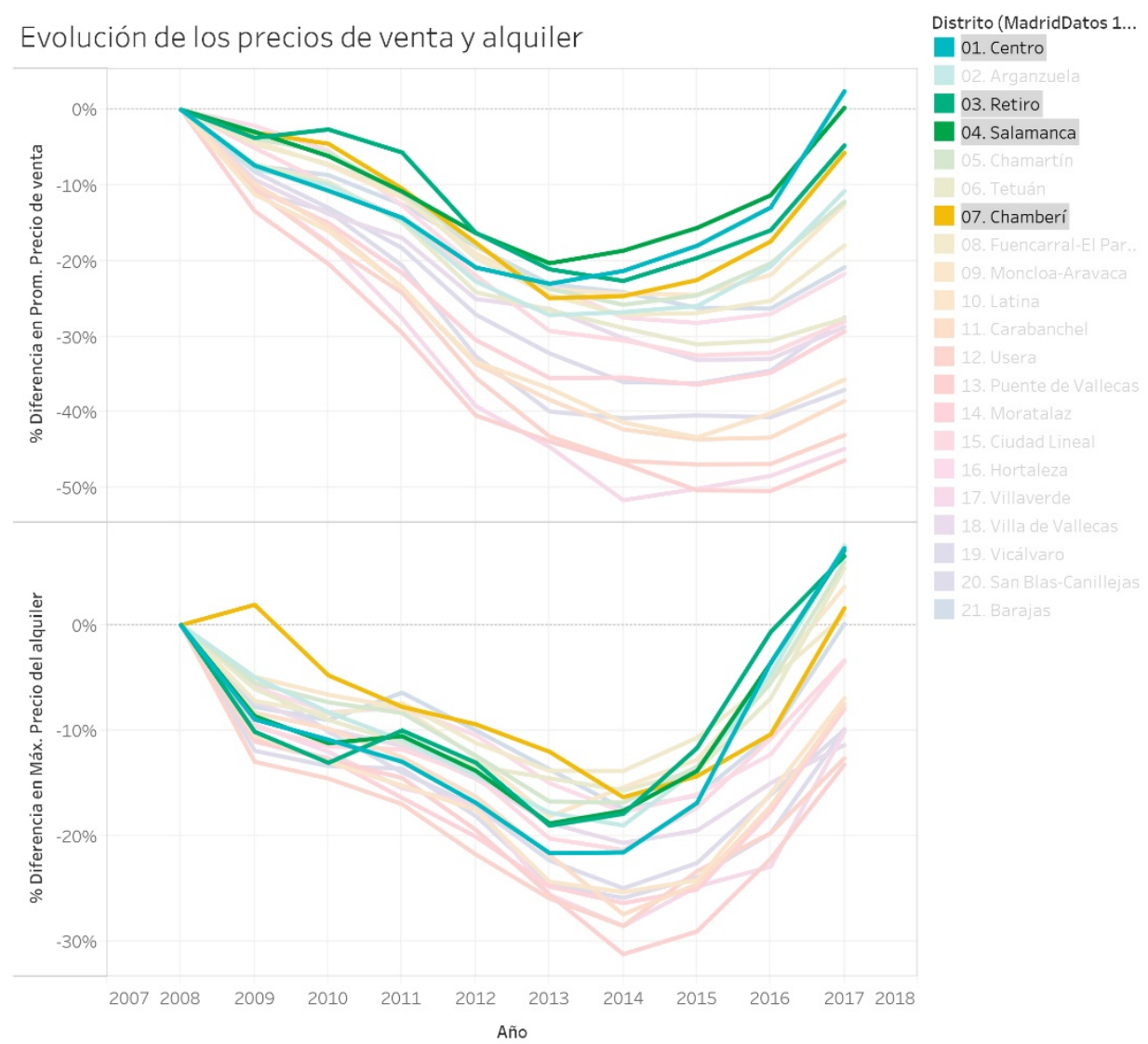

Figura 29. Evolución porcentual de los precios de venta y alquiler de viviendas por distrito de Madrid desde el año 2008. Se observa el encarecimiento de los precios del distrito centro especialmente a partir del año 2013; alcanzando en la actualidad revalorizaciones superiores a los distritos más exclusivos de la ciudad. Elaboración propia. Fuente: Idealista.com

Con estos antecedentes Madrid se perfila como una capital global de estructura sociofuncional diversa fruto de una evolución histórica característica de las ciudades globales en la que el advenimiento de la denominada 'economía de las plataformas digitales' está favoreciendo determinadas transformaciones sistémicas.

Srnicek (2017) advierte como una de las consecuencias de la crisis financiera ha sido el flujo de capital financiero hacia nuevos nichos de actividad entre los que la creación de 'startups' buscando un crecimiento especulativo veloz tratando de replicar el modelo de plataforma tecnológica ha sido abrumador a nivel global. En este sentido, y como se ha explicado, ahora prácticamente cualquier recurso de la ciudad puede contar con una representación digital, ahora puesta en relación a través de un espacio geográfico digital 
mediatizado. Si bien este fenómeno ya se daba con anterioridad al smartphone (Castells, 1996b), la ubicuidad de los dispositivos móviles está incrementando la capilaridad de un 'ciberespacio social' capaz de extenderse del espacio doméstico al espacio público mediante artefactos que, si bien otrora su propósito era facilitar una comunicación espontánea y libre de otro propósito que el transmitir un mensaje, hoy día pueden articular las comunicaciones e intercambios necesarias para cumplir con propósitos económicos específicos.

La estructura de este mapa digital de Madrid se desconoce, si bien los efectos de la mediatización de los recursos en la ciudad comienzan a vislumbrarse. Si antes el distrito centro estaba sometido a procesos de elitización local y revalorización de su tejido inmobiliario [VÉASE FIGURA 29] para satisfacer las necesidades de alojamiento de ciertos colectivos prevalentes, la pertenencia de las viviendas a una nueva red global que legitima su uso turístico transforma su destinatario, induciendo procesos de gentrificación turística transnacional (Cócola-Gant, 2016b).

Tan es así, que tras la llegada de la alcaldesa Manuela Carmena al frente del ayuntamiento, la economía de las plataformas tomó relevancia en el discurso político. La prevalencia del alquiler vacacional de corta duración sobre las modalidades tradicionales de acceso a la vivienda -especialmente en el centro urbano- motivó la elaboración de planes para tratar de mitigar las dinámicas inducidas por el fenómeno con la elaboración de un Plan Especial de Hospedaje en 2019. Este plan prácticamente replica la estructura formal de la ciudad en 4 anillos (centro, ensanche, primera, y por omisión segunda periferia), mientras que en Barcelona, el plan homólogo utiliza una estrategia de zonificación basada en criterios menos formales [VÉASE FIGURA 30]. La existencia de este tipo de planes no hace sino confirmar la toma de conciencia
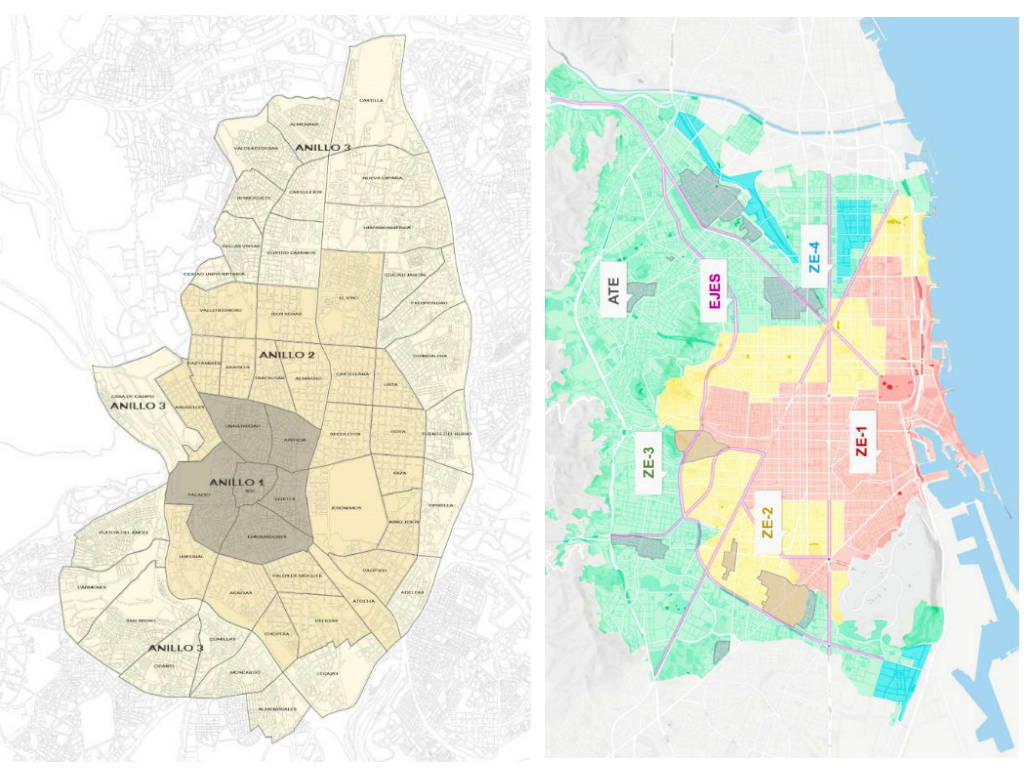

Figura 30. Zonificaciones del Plan Especial de Hospedaje PEH de Madrid (izda.) y e Plan Especial Urbanístico de Alojamientos Turísticos de Barcelona (dcha.). Fuentes: Ayuntamientos de Madrid y Barcelona por parte del planeamiento municipal sobre la economía de las plataformas digitales y sus impactos inducidos sobre la ciudad. Al mismo tiempo, verifica la relevancia del caso de estudio. 


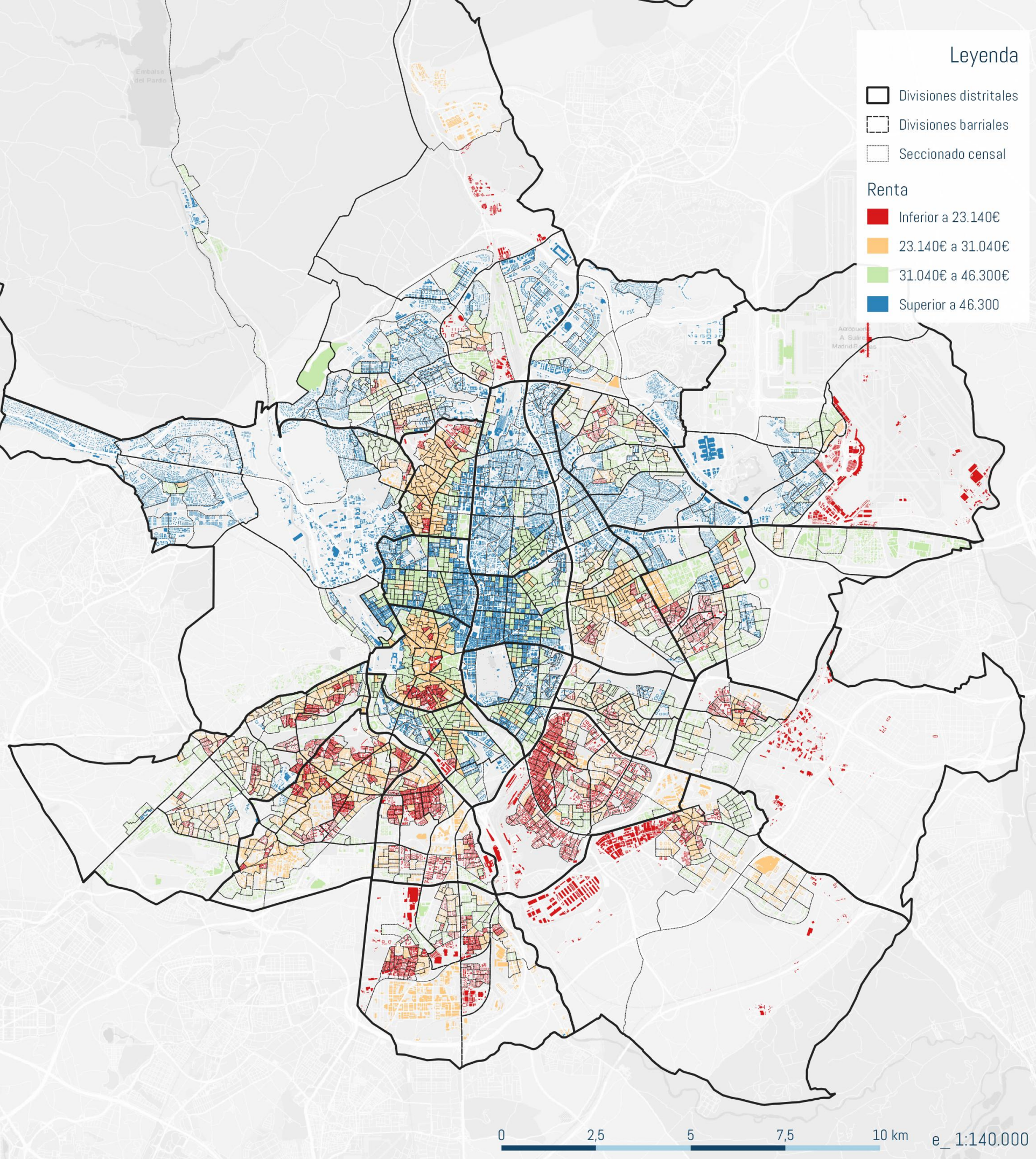

政

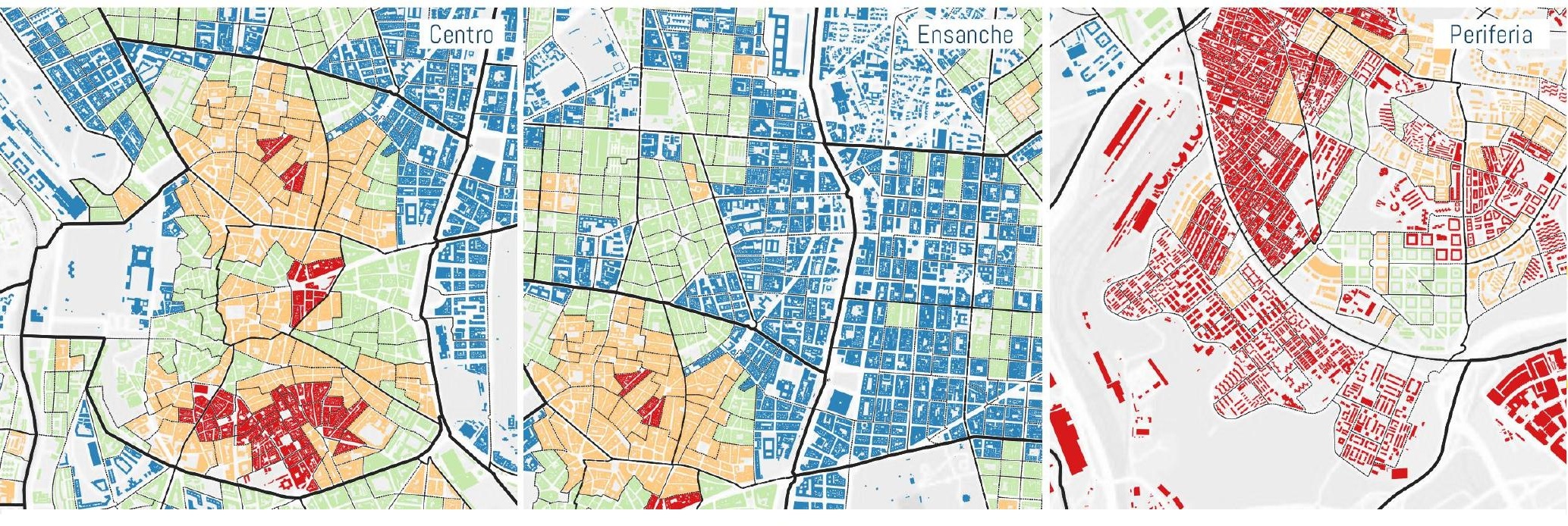


Aunque la gentrificación turística de los centros urbanos sea el caso más palpable de 'plataformización' del espacio urbano, muchos otros recursos en la ciudad están adoptando las lógicas comunicativas de esta modalidad de capitalismo comunicativo del espacio construido. Prácticamente cualquier actividad comercial es descubrible mediante plataformas de búsqueda, pero aquellas con mayor inversión en publicidad reciben más exposición. Otros comercios que por su actividad podrían estar en declive, se acogen a la red logística de última milla de Amazon para ganar exposición (Peinado, 2019). Los coches, motocicletas y patinetes en alquiler salpican las aceras y bandas de aparcamiento. Los restaurantes pueden ocupar un local comercial, pero también pueden ocultarse al público y distribuir a domicilio mediante 'riders' (Gispert, 2019).

Estos son sólo ejemplos de que el sistema urbano madrileño, parece estar sufriendo ciertas desviaciones de su estado de equilibrio orquestadas por el espacio geográfico de actividad de las plataformas digitales. A pesar de no haberse dado transformaciones espaciales significativas en la ciudad tras la crisis inmobiliaria, parte de las redes por las que los espacios urbanos adquieren y sostienen su actividad se han digitalizado. Sin embargo, se desconoce el alcance de esta digitalización, las estructuras comunicativas producidas por estas plataformas digitales, y en definitiva el efecto de un subsistema comunicativo emergente sobre un sistema urbano complejo ya consolidado.

\subsection{Construcción del modelo digital de Madrid para evaluar su complejidad urbana}

Evaluar la estructura sistémica de una ciudad requiere en primer lugar de distinguir nítidamente entre sistema y entorno a la hora de definir las partes que han de integrar un modelo de análisis; hecho que depende de la finalidad del mismo. En este caso, la finalidad es la de comprobar la estructura funcional interna de la ciudad a nivel material, descubriendo las actividades accesibles que tiene y cómo se hacen accesibles para la mayor parte de la población con independencia de sus características sociodemográficas. Esto hace el análisis de la ciudad necesariamente incompleto, como todo análisis empírico basado en datos cuantitativos.

En líneas generales, el sistema analizado está compuesto por todos los bienes inmuebles de la ciudad registrados en Catastro y zonas verdes en el espacio parcelado. Estos bienes se han clasificado por uso y superficie, e interconectado a través de la red viaria por aquellas vías accesibles peatonalmente - excluyendo carreteras y autovías. Esta decisión viene motivada por las siguientes distinciones entre sistema y entorno, que excluyen condicionantes sociales, económicas y técnicas - a excepción de los LBS- que puedan mediar en la accesibilidad a las actividades programadas en la ciudad. 


\subsubsection{Definición de contenidos y entornos 4.4.1.1. Dentro/fuera (Entorno I)}

Recordando la definición de Ruiz (2001b), la primera distinción que debe realizarse es entre la ciudad y su entorno geográfico, es decir, diferenciar entre dentro y fuera. El desarrollo metropolitano de la ciudad hace que esta distinción no resulte fácil de realizar en la medida que los núcleos periféricos al término municipal forman parte del mismo área metropolitana, y por tanto es difícil estimar si son funcionalmente independientes de Madrid, o si por el contrario los municipios de la corona metropolitana pueden considerarse parte del mismo sistema. Otros núcleos urbanos, estando dentro del término municipal se encuentran relativamente inconexos del núcleo urbano central. Es el caso de Aravaca, más cercano a Pozuelo de Alarcón que a Madrid, o El Pardo, extensión al norte del municipio. Del mismo modo, Vallecas, al sureste del núcleo se anexionó a la capital en 1950 durante la administración franquista.

El criterio para diferenciar el límite de Madrid [VÉASE FIgURA 31], responde a un criterio de accesibilidad peatonal, incluyendo dentro de la demarcación todos aquellos ámbitos periféricos que sean accesibles a pie desde viarios urbanizados. Este criterio se debe a que el utilizar un vehículo a motor para acceder a ámbitos lejanos supone utilizar una tecnología cuyo desarrollo y acceso depende del entorno del sistema urbano, y los criterios de uso o no de ésta dependen de condiciones sociales y políticas. En cambio, el acceso peatonal es la única elección modal accesible a la mayoría de la población en cualquier momento y circunstancia (Lamiquiz Daudén, 2011). Teniendo este criterio en cuenta, quedan excluidos del análisis los municipios de Aravaca y El Pardo, dado que su único modo de acceso a Madrid es por carretera o metro ligero.

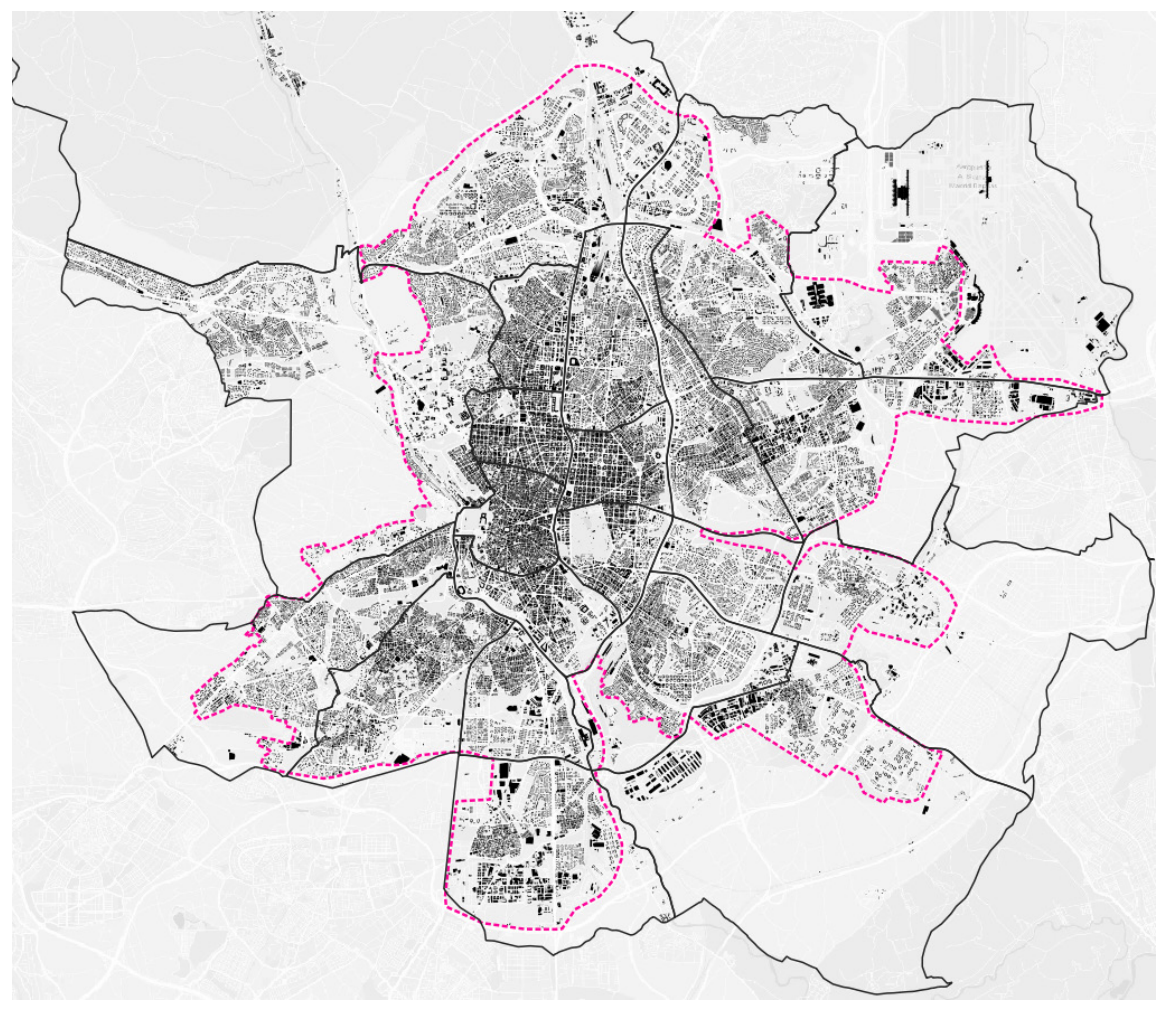

Figura 31. Definición del límite espacial de análisis (magenta). Elaboración propia 


\subsubsection{Externalidades socio-tecnológicas(Entorno II)}

Al igual que se ha optado por limitar la extensión espacial de análisis a las zonas de Madrid accesibles a pie desde el núcleo central, se han excluido del modelo otros sistemas en relación con la ciudad y su funcionamiento que no sean los servicios geolocalizados en sí mismos.

Es cierto que el funcionamiento de los sistemas urbanos depende del comportamiento de los agentes que lo utilizan, que actúan por el principio de la acción racional en base a las posibilidades de intercambio que poseen, y con ello configuran el carácter del lugar. Sin embargo, la infinidad de condicionantes entraña un gran indeterminismo a la hora de modelar los intercambios reales que en la ciudad se producen.

Como se ha visto anteriormente, en la accesibilidad interfiere el uso o no de vehículos a motor, pero también el nivel educativo y de ingresos de los individuos determina el ámbito de actividades de la ciudad a las que accederán con mayor frecuencia. También las condicionantes externas al sistema condicionan su comportamiento, como por ejemplo la economía y el empleo o las decisiones políticas y normativas.

A todo ello se suma el entorno tecnológico del que una parte es objeto de interés de esta tesis y para analizarse empíricamente, debe aislarse de sus condicionantes externas. Los LBS constituyen una parte del ecosistema de desarrollo informático de los teléfonos móviles, parte a su vez de un ecosistema de servidores integrado en un sistema de proveedores de telecomunicaciones, empresas y desarrolladores informáticos.

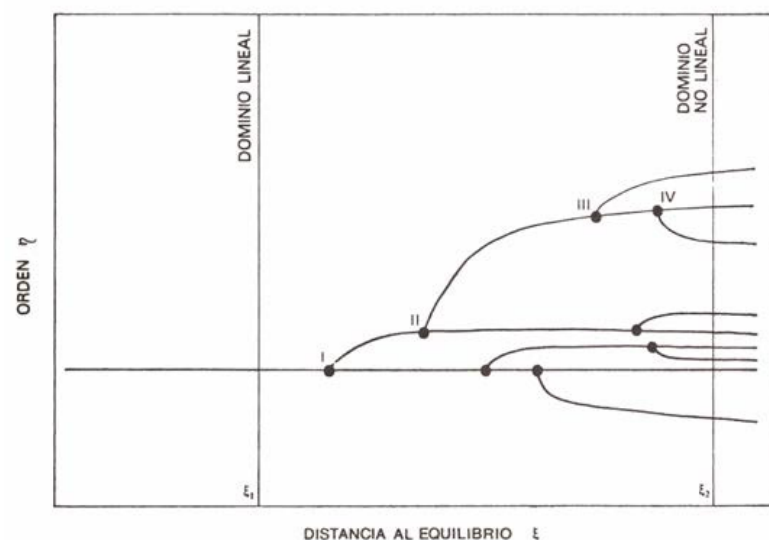

Cualquier cambio en el entorno altera el comportamiento del sistema urbano y a largo Fuente: (Wagensberg, 1985, p. 43) plazo altera su proceso de desarrollo evolutivo al alejarlo de un determinado estado de equilibrio [VÉASE FIGURA 32]. Sin embargo, la estabilidad de la parcelación y la edificación muestra un cierto grado de estabilidad que permite aislarlas de las condiciones del entorno a la hora de caracterizar la estructura interna del sistema urbano.

\subsubsection{Parcelas como subsistemas elementales (Entorno III)}

En un sistema urbano la parcela puede considerarse la unidad de información (RuizSánchez, 2001a). Aquello que sucede en el conjunto de parcelas de la ciudad constituye parte de la descripción del 'estado' del sistema.

Una parcela define una estructura de la propiedad y de la capacidad de acción sobre una unidad de suelo definida por una normativa de planeamiento. Su superficie y forma regula los posibles tipos edificatorios que en ella puedan construirse. Cada parcela tiene en su 
interior una estructura de la propiedad que determina su capacidad de cambio y en la medida que esta estructura de la propiedad es más fragmentaria menor es la probabilidad de que el contenido de las parcelas - tipo edificado- cambie.

Si la estructura de la propiedad, particularmente en sistemas urbanos de propiedad horizontal es poco mutable, el abanico de funciones en el espacio parcelado queda relativamente acotado no tanto por su diversidad de usos en un momento histórico, sino por la diversidad tipológica de la propiedad que, dentro de unos parámetros de accesibilidad a cada recinto del espacio parcelado.

Debe recalcarse que la parcela en sí misma no forma parte del sistema como un elemento sino como parte de sus entornos, dado que la parcela es en sí misma un sistema que en su interior alberga funciones específicas y define sus condiciones de accesibilidad a través de la definición de límites construidos.

Por ello, en la definición de unidades elementales de información en la ciudad se han seleccionado los bienes inmuebles, dado que cuentan con un propietario, una función específica, y unas condiciones acotadas de accesibilidad.

\subsubsection{La red urbana (Entorno IV)}

Se asume que la distancia entre elementos diferenciados del sistema urbano condiciona las probabilidades de interacción entre estos. No se trata de una distancia euclídea, pues el espacio no parcelado posee una topología de red condicionante, no solo de las distancias entre lugares, sino también del mapa cognitivo que cada habitante de la ciudad construye de ella (Hillier y Hanson, 1984; Hillier, 1996; Portugali, 2006). En este sentido, la tecnología juega un papel fundamental a la hora de condicionar estas distancias. Tanto la motorización como la tecnología digital favorecen la creación de 'comunidades sin proximidad' (Webber, 1964; Graham, 1997), si bien, en ausencia de artefactos de mejora de la accesibilidad, la propia forma urbana constituye un marco sobre el que evaluar la accesibilidad a los lugares, la formalización de comunidades de lugares en el espacio, y sobre ellas la evaluación no condicionada de su accesibilidad.

Como se ha mostrado en el capítulo anterior, la topología es una herramienta analítica que permite estudiar, no sólo la jerarquía de las comunicaciones en un sistema, sino también su cuantía y probabilidad. Estas estrategias y las características de las redes resultantes se han expuesto en mayor detalle en el [AnEXo IV]. Mientras que el grafo primario; cuyos vértices son los tramos de calle y los nodos son los cruces, representa la red de distancias geográficas de una ciudad, el grafo dual - en el que los tramos de calle son nodos y los cruces entre ellas vértices- representa la estructura jerárquica de los viales, dado que aquellos más centrales son aquellos que articulan un mayor número de conexiones entre calles, y por tanto gozan de una centralidad mayor. Aunque, el grafo dual representa la estructura cognitiva de la red urbana que evidencia las propiedades de las redes complejas -mundos pequeños, agrupamientos, y enlace preferencial (Albert y Barabási, 2002), el grafo primario permite evaluar las distancias reales entre los lugares 
de la red y a él se vinculan los costes energéticos de desplazamiento sin utilizar criterios subjetivos para su creación. Por ello, para construir el modelo del sistema se ha preferido este modelo frente al dual para evaluar de la manera más objetiva posible la accesibilidad urbana (Porta, Crucitti y Latora, 2006b).

\subsection{Estimación de la complejidad urbana}

En base a las distinciones anteriores puede definirse como el conjunto de bienes inmuebles y sus actividades asociadas, que la red urbana conformada por los espacios no parcelados - de acceso público- hace perceptibles y accesibles sin utilizar medios artificiales - quedando su funcionalidad, accesibilidad equilibrio y distancia al mismo supeditada a los acontecimientos que sucedan en el entorno del sistema (social, económico, tecnológico, cultural, y en última instancia individual).

Como se ha introducido, y adaptada de la definición de complejidad sistémica de Wagensberg (1985), la complejidad urbana puede entenderse como la "diversidad de estados accesibles de la ciudad" (Aquilué Junyent, 2017, p. 132). Esta definición implica dos dimensiones de la ciudad a analizar: la diversidad funcional y la accesibilidad. Ambas dimensiones pueden verse alteradas por la acción de los LBS; dado que pueden modificar tanto el uso como la perceptibilidad de unos lugares urbanos que ahora cuentan con una imagen digital inserta en nuevos espacios relacionales cuyas estructuras topológicas se desconocen.

Debe acotarse la definición de estado del sistema. En la termodinámica, se refiere al conjunto de valores que toman las propiedades de un sistema necesarias para reproducirlo y en las ciencias de la información es una configuración única de un programa o una máquina. En el caso de una ciudad, es en la práctica imposible definir todas esas variables que la pudieran reproducir, pues se trata de un sistema cognitivo, y como tal no sólo depende de su configuración material sino también de su configuración social. Mientras que la primera tiene un nivel de certidumbre mayor, las características individuales de la población son más difíciles de reproducir. Por ello, realizar un modelo determinista de un sistema urbano en todas sus escalas es metodológicamente imposible.

Se opta por comprender el estado de un sistema urbano como el conjunto de interacciones potenciales entre sus espacios habitables, dadas por la configuración espacial de la ciudad, fruto de un proceso evolutivo autorregulatorio, cuyos límites se han coordinado por un planeamiento que asigna a cada propiedad unas condiciones de uso y aprovechamiento, y que a la par modela las condiciones de accesibilidad entre unas y otras propiedades disponiendo una red de espacios públicos. Por ello, la diversidad de estados accesibles se entiende como el abanico de interacciones planificadas que el espacio urbano posibilita.

Habida cuenta del indeterminismo implícito en la definición de complejidad, a partir de este punto se propone el método para poder estimarla. En este caso, y teniendo en cuenta 
los bienes inmuebles como recintos elementales del sistema, si puede estimarse la cantidad máxima hipotética de interacciones diferenciadas que la ciudad posibilita, y que garantizan su capacidad de adaptación a los cambios producidos en su entorno (Alexander, 1964; Portugali, 2000; Ruiz-Sánchez etal., 2014; Gao, Barzel y Barabási, 2016; Aquilué Junyent, 2017).

El desarrollo de la informática permite el análisis cuantitativo de grandes cantidades de datos, como son el total de bienes inmuebles y accesos a los mismos, o las grandes cantidades de información geográfica producidas en las plataformas digitales. Gracias a estos métodos, puede analizarse la ciudad en su conjunto de manera unitaria, sin fragmentar sus espacios; pues están interconectados a su entorno inmediato.

\subsubsection{Accesibilidad en la red urbana}

Tomando en cuenta la estructura de la propiedad y de la red de espacios públicos de Madrid, la complejidad urbana se ha evaluado utilizando un algoritmo informático de elaboración propia, creado en lenguaje Python, que puede consultarse en el [ANEXo VII].

Toda la información acerca de la estructura de la propiedad en Madrid puede consultarse en el Catastro. Como fuente de datos, no sólo proporciona la parcelación, sino que incluye información sobre cómo esta se ha subdividido y las actividades que se dan en cada una de sus subdivisiones - viviendas, locales, y elementos comunes. Por ello, se ha considerado la fuente más fiable para obtener una visión actual del potencial de actividad que ha adquirido Madrid a lo largo del tiempo.

Desde su sitio web [ENLACE], la información de libre acceso para su descarga se divide en información cartográfica, descargable en formato SHP, el estándar para sistemas GIS que contiene la geometría de parcelas y edificaciones. También, el Catastro proporciona información alfanumérica en un formato propio denominado .CAT de texto delimitado no compatible con software GIS por defecto. Un archivo en este formato incluye información para 6 registros que albergan la información detallada sobre las fincas catastrales. De estos, son de interés los denominados registro 14 de unidad constructiva dentro de cada parcela catastral ${ }^{42}$. Dado que la fuente se utiliza por las administraciones públicas para calcular el valor catastral de los bienes inmuebles en la práctica totalidad del territorio nacional español, puede encontrarse en el registro 14 del fichero datos fiables sobre el uso y tipología de los bienes inmuebles ${ }^{43}$.

Para procesar este fichero, se ha seguido la especificación del formato .CAT y se ha creado, un algoritmo Python denominado "MinaCAT" [Véase Anexo V], basado en las librerías de terceros -Sqlalchemy y Pandas; para la conexión a bases de datos y procesamiento de grandes cantidades de datos en la memoria RAM respectivamente-, que lee el archivo procedente de Catastro, y procesa sus distintos registros para convertirlo en un formato

\footnotetext{
${ }^{42}$ La información sobre el formato .CAT puede descargarse desde el siguiente [ENLACE]

${ }^{43}$ Puede encontrarse el detalle de las tipologías catastrales en el documento de preguntas frecuentes sobre el formato [ENLACE].
} 
común de base de datos tabular. Para el municipio de Madrid, esta base de datos alfanumérica tiene una longitud 6.259.380 filas, de las cuales, 3.071.441 corresponden a bienes inmuebles, elementos comunes, y usos asociados. La dimensión de esta fuente de información ha hecho necesario recurrir a métodos ad-hoc de procesamiento y almacenado de la información sin comprometer la estabilidad del sistema informático utilizado.

Los registros pertenecientes a bienes inmuebles, junto al parcelario de Madrid se han almacenado en una base de datos PostgreSQL con su extensión de datos geográficos PostGIS activada. De este modo, se ha vinculado la enorme cantidad de información alfanumérica sobre las propiedades en la ciudad con su cartografía.

La información obtenida sobre los bienes inmuebles se encuentra desagregada alcanzando niveles de detalle distintos, y por lo general menos fiables cuanto mayor es el detalle. Debe tenerse en cuenta que el propósito del Catastro es el gravamen de la propiedad en función de su valor catastral, por lo que la información relativa al uso, superficie y tipología de un bien inmueble suelen ser precisos. Por el contrario, otra información complementaria, como la actividad comercial que en un local se está dando, o la antigüedad específica de un bien inmueble, también presentes en esta fuente de datos podrían ser menos fiables pues están basadas en que la reforma del mismo se haya reflejado en una ponencia de valores, y que no haya sufrido cambios significativos en el transcurso del tiempo.

Para cada parcela catastral, se han tenido en cuenta sus bienes inmuebles excluyendo elementos comunes, y se han tenido en cuenta, en primer lugar los campos de "uso" y "clase" de cada bien, diferenciando las recogidas en la siguiente tabla [TABLA 5]. La clasificación de actividades en los bienes inmuebles según el catastro no cuenta con las zonas verdes en el espacio parcelado, por lo que, aquellas parcelas en suelo urbano designadas en el con esta función, reflejadas en el PGOUM 96 de Madrid con este uso, se han incluido en la clasificación. Igualmente, se observa en la clasificación tipológica del catastro la existencia de inmuebles con un uso categorizado como "Almacen Estacionamiento", generalmente ligado a trasteros y plazas de aparcamiento, al igual que la tipología "Auxiliar deportivo" (vestuarios, salas de depuración...), como tales.

Para modelar la red urbana, se ha utilizado el callejero de la Comunidad de Madrid accesible mediante el sitio web denominado "Nomecalles. Nomenclátor oficial y callejero" [ENLACE], que por sí mismo, constituye el grafo primario de la red de espacios públicos de Madrid. Se ha utilizado por su simplicidad cartográfica y extensión espacial superior al término municipal. Sobre esta fuente se han realizado diversas correcciones para que el grafo represente más adecuadamente las distancias y conexiones posibles en determinados espacios públicos. Se han añadido conexiones transversales en las plazas peatonales y añadido sendas y pasarelas peatonales.Dado que se pretende aislar la elección modal de medios de transporte distintos al peatonal en los desplazamientos, y limitar la forma de la red urbana a la definida por el espacio no parcelado, se han excluido de la red 
las carreteras y la red de metro, pues su conexión con las actividades del espacio parcelado no suele ser directa.

\begin{tabular}{|c|c|c|}
\hline Uso & Clase & $\begin{array}{l}\text { Recuento } \\
\text { (todo Madrid) }\end{array}$ \\
\hline (R) Residencial & Viviendas colectivas de carácter urbano & 1.512 .627 \\
\hline & Viviendas unifamiliares de carácter urbano & 42.210 \\
\hline (I) Industrial & Naves de fabricación y almacenamiento & 11.462 \\
\hline (O) Oficinas & Oficinas en edificio exclusivo & 13.048 \\
\hline & Oficinas en edificio mixto & 21.223 \\
\hline & Banca y seguros & 387 \\
\hline (C) Comercio & Comercios en edificio mixto & 83.696 \\
\hline & Comercios en edificio exclusivo & 1.902 \\
\hline & Mercados y supermercados & 1.924 \\
\hline & Banca y seguros & 2.891 \\
\hline (K) Deportes & Cubiertos & 1.384 \\
\hline & Descubiertos & 13.821 \\
\hline & Espectáculos deportivos & 10 \\
\hline & Auxiliares deportivos $(*)$ & - \\
\hline (T) Espectáculos & Varios & 62 \\
\hline & Bares musicales, Salas de fiestas, Discotecas & 194 \\
\hline & Cines y teatros & 191 \\
\hline (G) Ocio y hostelería & Hostelería con residencia & 7.228 \\
\hline & Hostelería sin residencia & 14.964 \\
\hline & Exposiciones y reuniones & 150 \\
\hline (Y) Sanidad y beneficencia & Sanitarios con camas & 365 \\
\hline & Sanitarios varios & 406 \\
\hline & Benéficos y asistencia & 841 \\
\hline$(E-R)$ Culturales y religiosos & Culturales con residencia & 84 \\
\hline & Culturales sin residencia & 2.448 \\
\hline & Religiosos & 945 \\
\hline (P) Edificios singulares & Histórico-Artístico & 23 \\
\hline & De carácter oficial & 328 \\
\hline & De carácter especial & 62 \\
\hline (A) Almacenamiento (*) & - & - \\
\hline Sin datos & Sin datos & 689 \\
\hline Zonas verdes & General & 829 \\
\hline & Básico & 2.343 \\
\hline & Singular & 374 \\
\hline & Distrital y metropolitano & $\begin{array}{l}6 \\
1.739 .117\end{array}$ \\
\hline
\end{tabular}

El grafo dual que se deriva de esta fuente se ha elaborado por el método de unificación por nombres de vial en lugar del método de visuales del Space Syntax o el método de "continuidad negociada entre cruces" (Porta, Crucitti y Latora, 2006b, 2006a). Esta decisión viene motivada porque se considera que, al menos para el caso de Madrid, la toponimia refleja la unidad espacial de sus calles, pues por norma general, los viales cambian su denominación al alcanzar cruces con viales de jerarquía superior. Se han realizado manualmente algunas correcciones en la unificación de ejes por el nomenclátor, 
particularmente en los bordes de las grandes zonas que definen la estructura urbana de Madrid. Por ejemplo, el eje Alberto Aguilera - Carranza - Sagasta - Génova se ha unificado, mientras que la Calle Bravo Murillo, se ha dividido en sus tramos que atraviesan el ensanche (distrito Chamberí) y Valdeacederas (distrito Tetuán) en la Glorieta de Cuatro Caminos.

Para evitar los denominados 'efectos de borde' propios del análisis de grafos, se ha extendido la zona de alcance de la red $5 \mathrm{~km}$ desde el límite del término municipal de Madrid, capturando así los posibles vínculos entre lugares urbanos con recorridos parcialmente fuera del municipio [VÉASE MAPA 3].

$\mathrm{Al}$ igual que el tamaño de la base de datos de bienes inmuebles de la ciudad dificulta su análisis utilizando software y formatos de almacenamiento GIS tradicionales, el tamaño de la red que configura este sistema es también difícil de analizar utilizando soluciones populares ya integradas en sistemas GIS como el "Network Analyst" de ArcGIS. El conjunto de vínculos entre tramos de calle, parcelas y actividades supone un grafo de 2.024.535 vértices en su modo primario, cuya componente conexa excluye Aravaca y El Pardo por su inaccesibilidad peatonal desde el resto de la red urbana.

Sobre ambos grafos, se han incorporado los accesos a las parcelas cartografiados en el Nomenclátor, de este modo, a cada tramo de vial se le incorporan las parcelas a las que da acceso, y con ello a las actividades en el espacio parcelado que integra en el sistema urbano.

Las subdivisiones de la parcela también se han analizado geométricamente utilizando otros formatos de intercambio de datos complementarios a los 'shapefiles' y archivos.CAT de Catastro. Para ello se han utilizado los archivos KML de planta publicados para cada parcela, los cuales tienen un plano esquemático de los recintos y usos de sus inmuebles. Estos se han procesado de forma automática utilizando un script de elaboración propia detallado en el [ANEXo VI - KML2PG. SOFtwARE DE DESCARGA Y ALMACENAMIENTO DE ARCHIVOS KML DE CATASTRO EN BASES DE DATOS POSTGIS]. Los resultados de este algoritmo pueden verse en el [MAPA 4], donde se ven los contrastes entre una subdivisión de la propiedad más compleja en los distritos centrales que en las actuaciones urbanísticas unitarias características de la periferia madrileña.

De este modo, se construye una topología espacial y funcional representativa de toda la ciudad sobre la que evaluar la diversidad en función de la distancia recorrida como indicador cuantitativo de la complejidad urbana. 


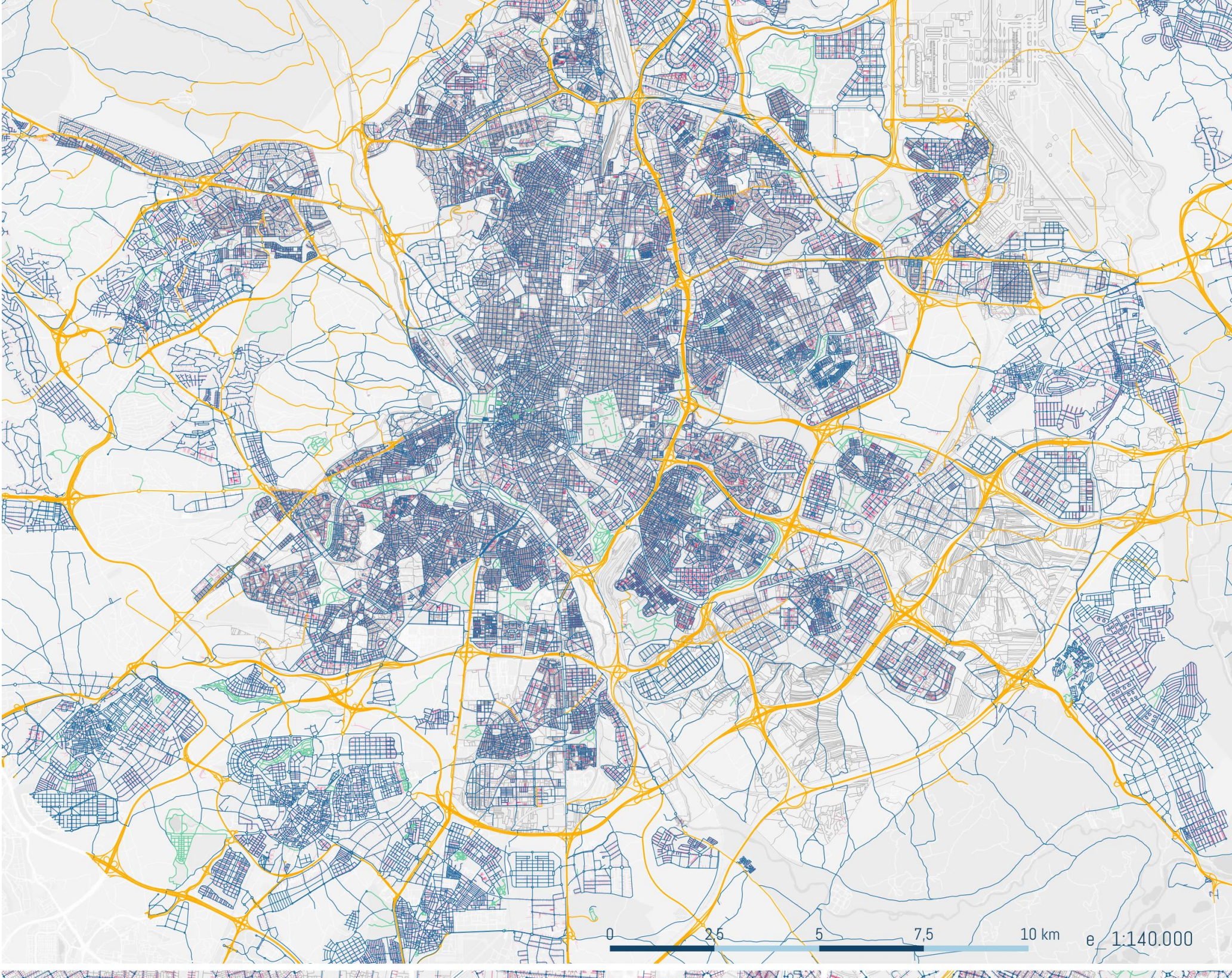
Calles (grafo primario)

solo trafico rodado Camino peatonal

- Calle tráfico genera Parcelas |

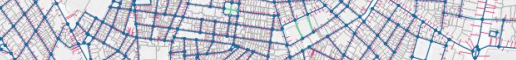

(1) $\rightarrow$ I

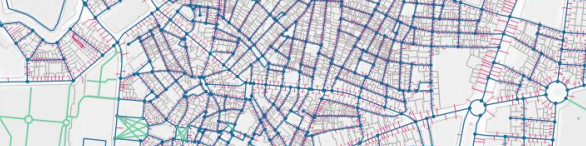

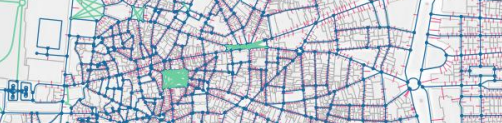
$=\quad-x^{2}$ 7. 5 -

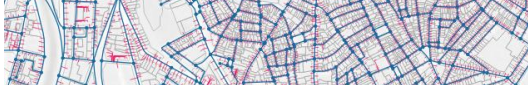

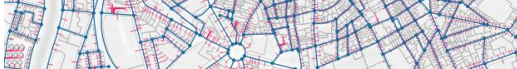
(2)

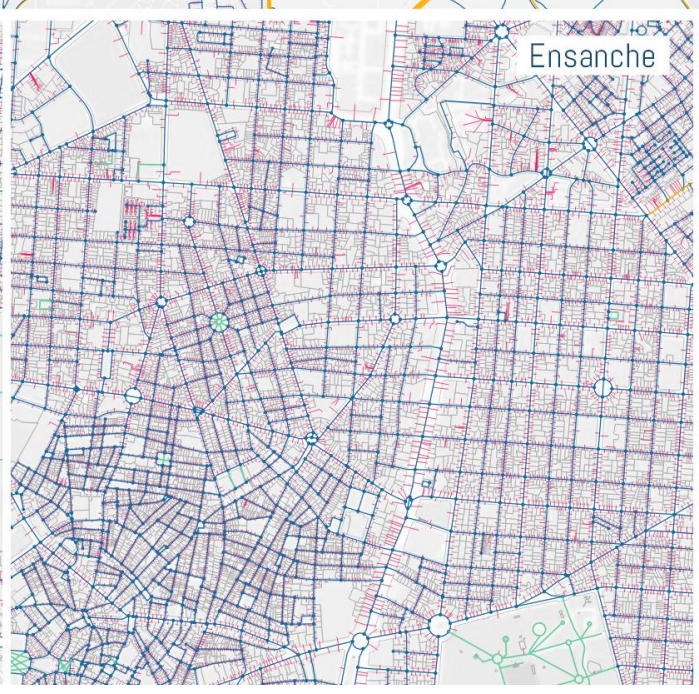

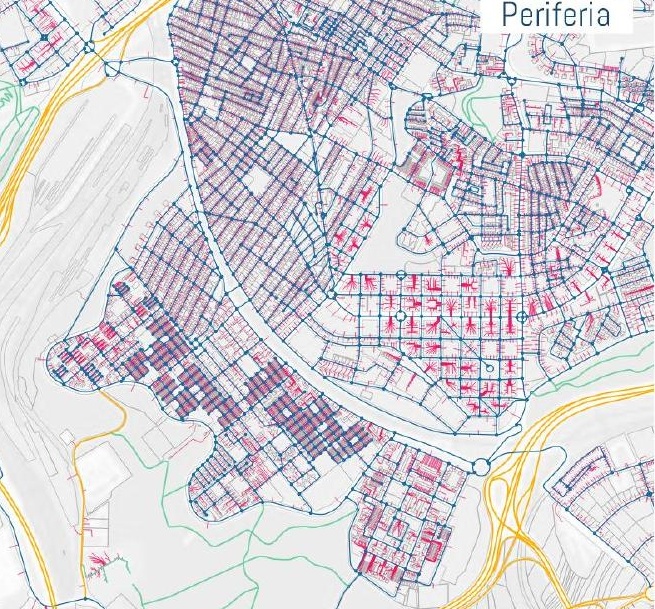




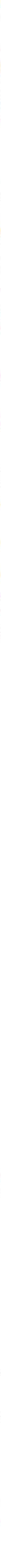




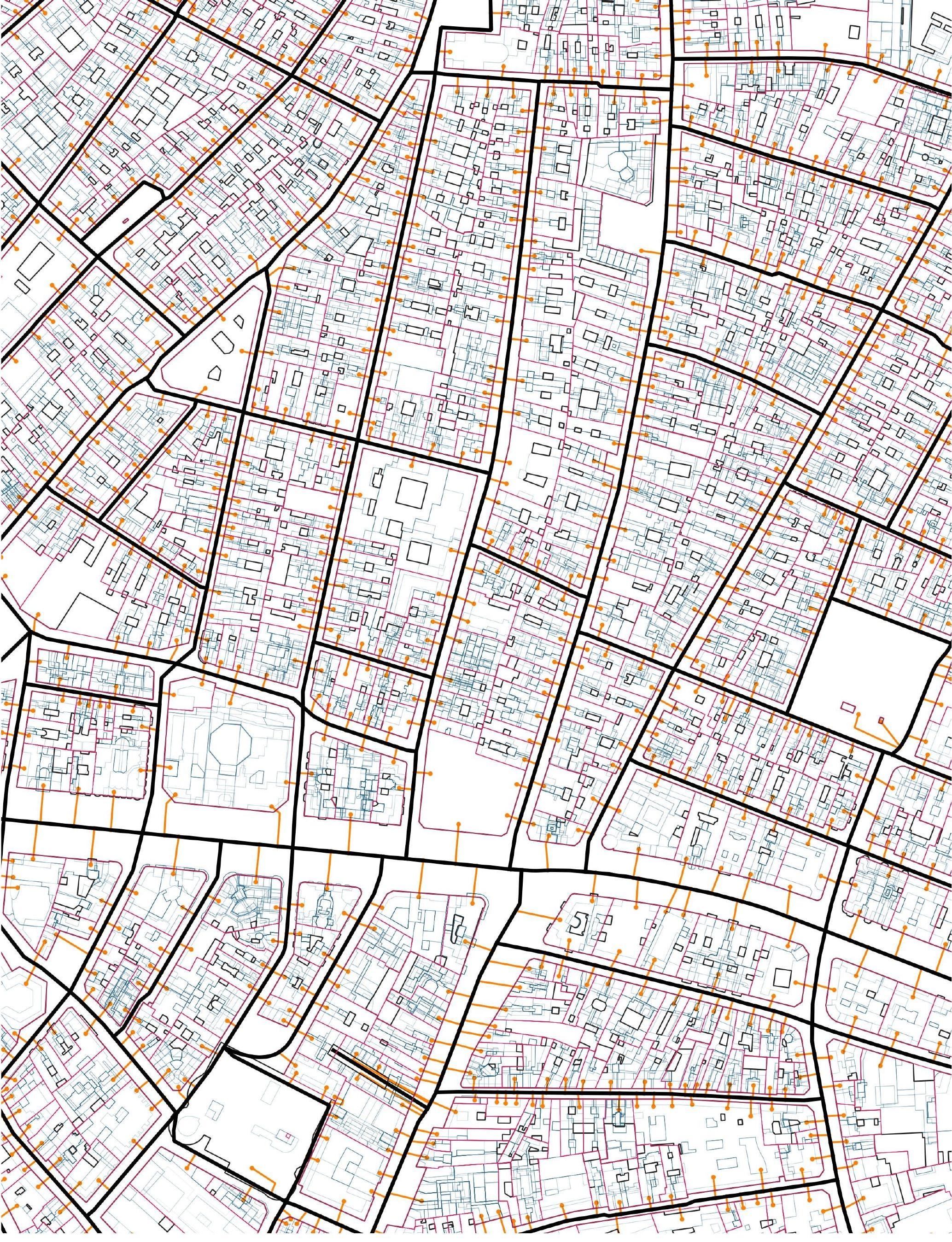




\subsubsection{Los índices de diversidad}

Bajo la premisa de que todos los espacios en la ciudad son accesibles, numerosos estudios utilizan retículas espaciales para calcular la variedad de usos en cada una de sus celdas utilizando índices de diversidad. Otros estudios, analizan la accesibilidad en la red viaria atendiendo a sus propiedades topológicas, atribuyendo a una red menos jerárquica (similar al árbol) y más se parezca a la "semitrama” de Alexander, mayor será la integración de sus espacios y por tanto, mayores serán las posibilidades de interacción entre los ciudadanos. Tiende por tanto a producirse una cierta dicotomía entre los estudios que hablan de complejidad urbana desde la diversidad de usos o desde la accesibilidad o la topología de la red urbana.

Metodológicamente, se pone de relieve la necesidad de complementar ambas posiciones. Por muy accesibles entre sí que sean los lugares de la trama urbana, si sus funciones son similares -información redundante- no se puede producir una observación de diferencias y por tanto es poco probable que se establezca cualquier acto comunicativo por parte de los usuarios de dichos espacios. Análogamente, por muy diversos que sean dos espacios, si no son accesibles entre sí la probabilidad de que se produzca una comunicación entre ambos es limitada.

Desde la perspectiva de la diversidad funcional, existen diversos índices para medir la diversidad en un conjunto de especies, muchos procedentes de la teoría de la información y de la ecología. El primero, y más simple de estos índices es la riqueza ecosistémica, que mide el número de especies diferentes en un ecosistema. Aunque intuitivamente este índice sea un indicador de diversidad, no contempla la abundancia de cada especie, por lo que un sistema podría tener muchas especies diferentes, pero recuentos muy desiguales de las mismas, hecho contrario a la idea de complejidad.

Para tratar de acomodar la idea de diversidad y la abundancia, la teoría de la información popularizó el índice de entropía de Shannon [VÉASE Fórmula 2]. Aplicado al urbanismo, calcula la suma de probabilidades parciales de que en un conjunto acotado de usos del suelo se seleccione cada cual -introduciendo un término logarítmico para normalizar las distribuciones de probabilidad. El índice parte de la premisa de que la mayor diversidad de actividades y tipologías corresponde a una mayor incertidumbre en elegir de manera aleatoria una específica, al igual que en un mensaje, el mayor número de caracteres diferentes implica una mayor cantidad de información.

$$
H^{\prime}=-\sum_{i=1}^{S} p_{i} \log p_{i}
$$

Fórmula 2. Entropía de Shannon-Wiener (H): Siendo pi la proporción de objetos de la categoría de interés sobre el número de objetos de una muestra, cuantifica la incertidumbre en la predicción en la categoría i sobre un total de S categorías, de un objeto perteneciente a la muestra.

Podría afirmarse que cuanto mayor sea la cantidad de información que una distribución de actividades y tipologías en una zona urbana tiene, más probabilidades de interacción facilita. Por ello, el desorden puede ser un indicador de complejidad. Como afirma Fariña 